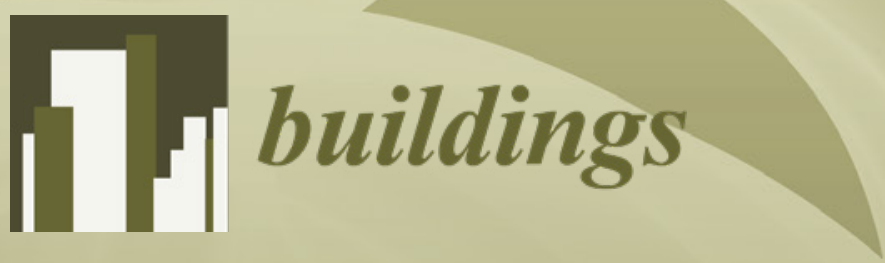

Environmental

Impact Assessment

of Buildings

Edited by

Wahidul Biswas

Printed Edition of the Special Issue Published in Buildings 


\section{Environmental Impact Assessment of Buildings}





\section{Environmental Impact Assessment of Buildings}

Special Issue Editor

Wahidul Biswas

MDPI • Basel • Beijing • Wuhan • Barcelona • Belgrade

MDPI 
Special Issue Editor

Wahidul Biswas

Sustainable Engineering Group,

Curtin University

Australia

Editorial Office

MDPI

St. Alban-Anlage 66

4052 Basel, Switzerland

This is a reprint of articles from the Special Issue published online in the open access journal Buildings (ISSN 2075-5309) from 2018 to 2019 (available at: https://www.mdpi.com/journal/buildings/ special_issues/Environmental_Impact_Assessment).

For citation purposes, cite each article independently as indicated on the article page online and as indicated below:

LastName, A.A.; LastName, B.B.; LastName, C.C. Article Title. Journal Name Year, Article Number, Page Range.

ISBN 978-3-03928-243-2 (Pbk)

ISBN 978-3-03928-244-9 (PDF)

(C) 2020 by the authors. Articles in this book are Open Access and distributed under the Creative Commons Attribution (CC BY) license, which allows users to download, copy and build upon published articles, as long as the author and publisher are properly credited, which ensures maximum dissemination and a wider impact of our publications.

The book as a whole is distributed by MDPI under the terms and conditions of the Creative Commons license CC BY-NC-ND. 


\section{Contents}

About the Special Issue Editor $\ldots \ldots \ldots \ldots \ldots \ldots \ldots \ldots \ldots \ldots \ldots$

Preface to "Environmental Impact Assessment of Buildings" . . . . . . . . . . ix

Faiz Shaikh

Mechanical and Durability Properties of Green Star Concretes

Reprinted from: Buildings 2018, 8, 111, doi:10.3390/buildings8080111 . . . . . . . . . . . 1

Amer Hakki, Lu Yang, Fazhou Wang, Ammar Elhoweris, Yousef Alhorr and Donald E. Macphee

Photocatalytic Functionalized Aggregate: Enhanced Concrete Performance in

Environmental Remediation

Reprinted from: Buildings 2019, 9, 28, doi:10.3390/buildings9020028 . . . . . . . . . . . . . 13

Jeeyoung Park, Dirk Hengevoss and Stephen Wittkopf

Industrial Data-Based Life Cycle Assessment of Architecturally Integrated Glass-Glass

Photovoltaics

Reprinted from: Buildings 2019, 9, 8, doi:10.3390/buildings 9010008 . . . . . . . . . . . 23

Upendra Rajapaksha

Heat Stress Pattern in Conditioned Office Buildings with Shallow Plan Forms in Metropolitan Colombo

Reprinted from: Buildings 2019, 9, 35, doi:10.3390/buildings9020035 . . . . . . . . . . . 42

Camille Pajot, Benoit Delinchant, Yves Maréchal and Damien Frésier

Impact of Heat Pump Flexibility in a French Residential Eco-District

Reprinted from: Buildings 2018, 8, 145, doi:10.3390/buildings8100145 . . . . . . . . . . . 63

Stephen Y. C. Yim, S. Thomas Ng, M. U. Hossain and James M. W. Wong

Comprehensive Evaluation of Carbon Emissions for the Development of High-Rise

Residential Building

Reprinted from: Buildings 2018, 8, 147, doi:10.3390/buildings8110147 . . . . . . . . . . . 77

Shahana Y. Janjua, Prabir K. Sarker and Wahidul K. Biswas

Impact of Service Life on the Environmental Performance of Buildings

Reprinted from: Buildings 2019, 9, 9, doi:10.3390/buildings9010009 . . . . . . . . . . . . 96

Umair Hasan, Andrew Whyte and Hamad Al Jassmi

Life-Cycle Asset Management in Residential Developments Building on Transport System

Critical Attributes via a Data-Mining Algorithm

Reprinted from: Buildings 2019, 9, 1, doi:10.3390/buildings9010001 



\section{About the Special Issue Editor}

Wahidul Biswas is Associate Professor at the Sustainable Energy Group, Curtin University, Western Australia. Wahidul trained as a Mechanical Engineer, researching the performance of diesel engines using biogas fuel. He has a master's in Environmental Technology from Imperial College, London, and a PhD in Sustainable Futures from the University of Technology, Sydney. A/Prof Biswas teaches and coordinates postgraduate units on Life Cycle Management, Eco-Efficiency Strategies, Industrial Ecology, Environmental Systems, and Sustainable Energy as well as a core undergraduate Engineering unit, Engineering for Sustainable Development. He has so far carried out extensive life cycle assessment, industrial symbiosis, and sustainability-related research projects for the Australian agricultural, alternative fuels, building and construction, manufacturing, livestock, mining, gas and water sectors in collaboration with the Department of Climate Change, the Grains Research and Development Commission, Department of Agriculture and Food, University of Western Australia, Department of Primary Industries, Meat and Livestock Australia, Worley Parsons, Water Corporation, Alcoa World Alumina, Enterprise Connect, Recom Engineering, Cedar Woods, Earth Care, Department of State Development, Kwinana Industrial Council, Cockburn Cement and Waste Authority. A/Prof Biswas expanded his LCA research overseas as he completed the LCA of water treatment process and developed environmental product declaration (EPD) of building materials for Gulf Organization of Research and Development (GORD), Qatar. He is the recipient of USD545K competitive grant provided by Qatar National Research Fund to carry out a project entitled "Techno-economic and environmental assessment of future water supply options for Qatar's water supply". 



\section{Preface to "Environmental Impact Assessment of Buildings"}

Buildings are the key components of society as a complex system. According to UNEP (2016), the energy consumption in buildings and for building construction represents more than $30 \%$ of global final energy consumption and contributes to nearly $25 \%$ of greenhouse gases (GHG) emissions worldwide. There are other indirect environmental consequences associated with an increased demand for construction materials in the building sector, including land use changes, loss of biodiversity, resource scarcity, ozone depletion potential, human toxicity, acidification, and eutrophication. The designers, builders, developers, and engineers are thus required to adopt an environmentally responsible approach to their design solutions and specification choices of construction materials. Some of the ways to reduce these environmental impacts involve considering the use of byproducts, recycled materials, and clean energy sources in building design. The material choice, building orientation, climatic conditions, building management systems, construction systems (e.g., wood frame, thermal insulating brick, sandwich wall, and concrete block with a peripheral insulation), and construction practices are key areas to consider for enhancing durability and building efficiency. Life cycle assessment has potentially been considered as an environmental management tool to estimate the environmental impacts of the resources applied in the building envelope, floor slabs, and interior walls for green building design as well as to estimate the amount of environmental impact that can potentially be mitigated through innovative engineering practices, designs, and solutions. This Special Issue comprises eight chapters that cover the aforementioned strategies for addressing environmental impacts of the fastest-growing building sector.

Wahidul Biswas

Special Issue Editor 



\title{
Article \\ Mechanical and Durability Properties of Green Star Concretes
}

\author{
Faiz Shaikh (iD \\ School of Civil and Mechanical Engineering, Curtin University, Perth, WA 6120, Australia; \\ s.ahmed@curtin.edu.au
}

Received: 8 June 2018; Accepted: 16 August 2018; Published: 17 August 2018

check for updates

\begin{abstract}
This paper presents mechanical and durability properties of green star concretes. Four series of concretes are considered. The first series is control concrete containing $100 \%$ ordinary Portland cement, $100 \%$ natural aggregates and fresh water. The other three series of concretes are green star concretes according to Green Building Council Australia (GBCA), which contain blast furnace slag, recycled coarse aggregates and concrete wash water. In all above concretes compressive strength, indirect tensile strength, elastic modulus, water absorption, sorptivity and chloride permeability are measured at 7 and 28 days. Results show that mechanical properties of green star concretes are lower than the control concrete at both ages with significant improvement at 28 days. Similar results are also observed in water absorption, sorptivity and chloride permeability where all measured durability properties are lower in green star concretes compared to control concrete except the higher water absorption in some green star concretes.
\end{abstract}

Keywords: green star concrete; slag; recycled aggregate; wash water; sustainability

\section{Introduction}

Concrete is the most widely used construction materials in the world. Ordinary Portland cement (OPC) and aggregates are the important ingredients for concrete, where the former when mixed with water forms matrix which bind the aggregates and the latter contributes to the volume of the concrete. Ordinary concrete is not environmental friendly due to energy intensive manufacturing of OPC. It is reported that manufacturing of OPC contributes between 5 and $7 \%$ of global $\mathrm{CO}_{2}$ emission and about one ton of $\mathrm{CO}_{2}$ is released to produce the equal amount of OPC [1-3]. On the other hand, the aggregates which are sourced from various natural sources (e.g., river beds, rocks, sand dunes, etc.) also affects the natural eco-system. As a result, significant efforts are being directed to reduce the amount of OPC and natural aggregates in concrete to reduce the adverse impact on the environment. Significant research are also conducted to reduce the carbon footprint of concrete by partially replacing OPC and natural aggregates using various supplementary cementitious materials (SCMs) and recycled aggregates, respectively [4-9]. Among various SCMs fly ash, slag and silica fume, which are industrial by-products, are most widely used in concrete as partial replacement OPC. Recycled aggregates are sourced from crushed demolished concrete structures and are used as partial replacement of natural aggregates in concrete. A very good level of understanding exists on various properties of concretes containing SCMs and recycled aggregates either individually or combined through significant amount of research [10-16].

On the other hand, huge amount of tap water is used for washing activities in ready mix concrete plants. It is reported that about 500-1500 litres of tap water is used to wash one concrete mixer truck in the ready mix concrete plant [17]. Therefore, huge amount of clean water is being used in the concrete mixing plants. The reusing of this wash water in concrete mixing is the most sustainable way of reducing the use of clean tap water in concrete mixing facilities. Generally, the wash water 
from concrete mixing plants contains mostly cementitious fines and few chemicals from the use of superplasticizers, which are not different from the ingredients of concrete [17]. In a number of studies the effect of wash water and recycled water on the properties of concretes are studied and all are on concrete containing natural aggregates and OPC as the main binder [17-19].

Energy efficiency of buildings is another important requirement for asset owners, builders as well as the building regulators in many countries. Generally, the reduction of heating and cooling energy of buildings are the main objective in the design of energy efficient building. In one estimate it is found that built environment is world's single largest contributor of greenhouse gas and consumes about a third of water and generates $40 \%$ of wastes (Green Building Council Australia (GBCA)). To promote the environmental efficiency of buildings "green star" rating is introduced in many countries including in Australia, which is an internationally-recognized sustainability rating system for buildings. Among various green star points, up to three points are allocated for concrete. According to green building council of Australia [20] up to "two green star" points can be awarded to the concrete containing $40 \%$ SCMs as partial replacement of OPC, while up to "three green star" points can be awarded to concrete containing $40 \%$ SCMs as partial replacement of OPC, $40 \%$ recycled materials as partial replacement of natural aggregates and $50 \%$ reclaimed water as partial replacement of tap/drinking water. The above incentive encourages the promotion of environmentally friendly concrete in the construction of buildings.

Significant research has been devoted to study the properties of concrete containing partial replacement of OPC using various SCMs of various quantities and partial replacement of natural aggregates using various amounts of recycled concrete aggregates separately as well as their combined used. No study so far reported the properties of green star concretes where industrial by-products, recycled materials and reclaimed wash water are used together. This research presents the first study of this kind where mechanical and durability properties of green star concretes are studied and compared with control concrete containing $100 \%$ OPC, natural aggregates and fresh water.

\section{Materials and Methods}

In this study four series of mixes were considered. The first series was control concrete consisting of $100 \%$ OPC, $100 \%$ natural aggregates and $100 \%$ tap water. The second series was "two green star concrete" contained $40 \%$ slag (a by-product of steel industry) as partial replacement of OPC, while the rest of the materials were similar to the first series. The third series was similar to the second series except where $40 \%$ natural coarse aggregate (NCA) was replaced by recycled coarse aggregates (RCA) that were sourced from construction and demolition wastes. The fourth series was "three green star concrete" which was similar to the third series except where $50 \%$ fresh water was replaced by reclaimed wash water collected from the concrete laboratory. The fourth series was between two and three green star concrete and was considered to study the effect of $50 \%$ reclaimed wash water on the properties of three green star concrete. The mix proportions of all concretes are shown in Table 1 . The percentage replacements of NCA by RCA and OPC by slag were on the basis of weight. The water/binder ratio was kept constant at 0.45 in all mixes. In all three types of green star concretes as well as control concrete mechanical properties in terms of compressive strength, elastic modulus and indirect tensile strength and durability properties in terms of sorptivity, water absorption and chloride permeability were measured at 7 and 28 days.

\subsection{Materials}

Ordinary Portland cement (OPC) was used in all concrete mixes. The blast furnace slag used in this study was obtained from a local supplier. The properties and chemical compositions of OPC and slag are shown in Table 2. The recycled coarse aggregate was obtained from a local construction and demolition (C\&D) waste recycling plant in Perth, Western Australia. Figure 1 shows the analysis of $5 \mathrm{~kg}$ sample of the C\&D waste used as RCA in this study. The percentages are based on mass. It can be seen that approximately $69 \%$ are from concrete and the rest consisted of limestone, masonry, 
etc. Table 3 shows the properties of recycled and natural aggregates. Sieve analysis of RCA is also conducted and about $23 \%$ were $20 \mathrm{~mm}$ size and $75 \%$ were $10 \mathrm{~mm}$ size. The natural coarse aggregates (NCA) used in this study were mixture of $10 \mathrm{~mm}$ and $20 \mathrm{~mm}$ sizes coarse aggregates at a ratio of 1:2. The NCA and RCA used in this study were in saturated and surface dry condition before used in the mixing. Chemical analysis of tap water and reclaimed wash water in concrete laboratory is shown in Table 4. It can be seen that the $\mathrm{pH}$ level of wash water is higher than that of tap water, while the turbidity of the wash water is much higher than the recommended limit for drinking water (5 NTU (Nephelometric Turbidity Unit)) by World health organization [21]. The higher turbidity in wash water can be attributed to various cementitious materials, superplasticizers and alkali chemicals used in the laboratory for the production of concrete and other cementitious materials.

Table 1. Mix proportion of concretes.

\begin{tabular}{lccccccc}
\hline & \multicolumn{7}{c}{ Mix Proportions in Kg/m } \\
\cline { 2 - 7 } \multicolumn{1}{c}{ Series } & OPC & Slag & $\begin{array}{c}\text { Fine } \\
\text { Aggregate }\end{array}$ & $\begin{array}{c}\text { Natural Coarse } \\
\text { Aggregate }\end{array}$ & $\begin{array}{c}\text { Recycled Coarse } \\
\text { Aggregate }\end{array}$ & $\begin{array}{c}\text { Tap } \\
\text { Water }\end{array}$ & $\begin{array}{c}\text { Wash } \\
\text { Water }\end{array}$ \\
\hline Mix 1 (Control) & 413 & - & 512 & 1254 & - & 190 & - \\
Mix 2 (2 Green star) & 248 & 165 & 512 & 1254 & - & 190 & - \\
Mix 3 & 248 & 165 & 512 & 752 & 502 & 190 & - \\
Mix 4 (3 Green star) & 248 & 165 & 512 & 752 & 502 & 95 \\
\hline
\end{tabular}

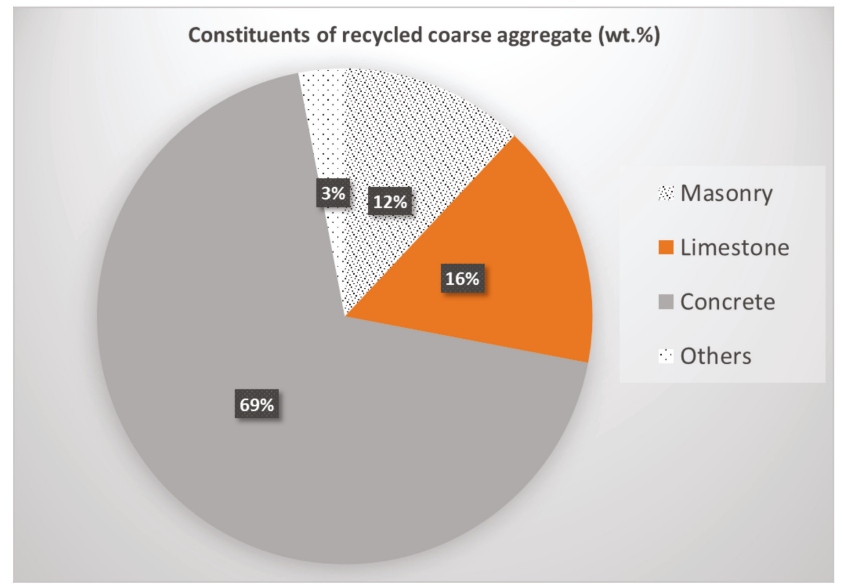

Figure 1. Analysis of construction and demolition wastes used as recycled coarse aggregates in this study.

Table 2. Chemical and physical properties of Ordinary Portland cement (OPC) and slag.

\begin{tabular}{ccc}
\hline Chemical Analysis & OPC (wt \%) & Slag (wt \%) \\
\hline $\mathrm{SiO}_{2}$ & 21.1 & 32.45 \\
$\mathrm{Al}_{2} \mathrm{O}_{3}$ & 5.24 & 13.56 \\
$\mathrm{Fe}_{2} \mathrm{O}_{3}$ & 3.1 & 0.82 \\
$\mathrm{CaO}$ & 64.39 & 41.22 \\
$\mathrm{MgO}$ & 1.1 & 5.1 \\
$\mathrm{~K}_{2} \mathrm{O}$ & 0.57 & 0.35 \\
$\mathrm{Na}_{2} \mathrm{O}$ & 0.23 & 0.27 \\
$\mathrm{SO}_{3}$ & 2.52 & 3.2 \\
$\mathrm{LOI}$ & 1.22 & 1.11 \\
Specific gravity & 3.17 & 3.00 \\
\hline
\end{tabular}


Table 3. Properties of natural coarse aggregate (NCA) and recycled coarse aggregate (RCA).

\begin{tabular}{cccc}
\hline Properties & NCA & RCA & NFA \\
\hline Un-compacted bulk density $\left(\mathrm{kg} / \mathrm{m}^{3}\right)$ & 1547 & 1301 & 1498 \\
Water absorption $(\%)$ & 1.6 & 7.1 & 1.16 \\
\hline
\end{tabular}

Table 4. Chemical analysis of tap water and wash water.

\begin{tabular}{ccc}
\hline Chemical Properties & Tap Water & Wash Water \\
\hline $\mathrm{pH}$ value & 8.95 & 12.26 \\
Chloride content (mg/L) & 60 & 61 \\
Turbidity (NTU) & - & 41 \\
\hline
\end{tabular}

\subsection{Methods}

The compressive strength, indirect tensile strength, elastic modulus, water absorption, water sorptivity and chloride ion permeability were measured at 7 and 28 days for all mixes. At least three specimens were cast and tested in each series for each property measured in this study. All specimens were water cured until the day before the test date. The compressive strength and elastic modulus tests were carried out on $100 \varnothing \times 200 \mathrm{~mm}$ cylinders and the indirect tensile strength was determined on $150 \varnothing \times 300 \mathrm{~mm}$ cylinders. The water absorption, water sorptivity and chloride ion permeability tests were conducted on $100 \varnothing \times 50 \mathrm{~mm}$ thick specimens, which were made by cutting the standard $100 \varnothing$ $\times 200 \mathrm{~mm}$ cylinders. The compressive strength, indirect tensile strength and elastic modulus were measured according to the Australian standards AS1012.9 [22], AS1012.10 [23] and AS1012.17 [24], respectively. The concrete cylinders for the compressive strength and modulus of elasticity were sulphur capped to ensure a smooth surface. A MCC $83000 \mathrm{kN}$ capacity machine was used to test the compressive strength and indirect tensile strength of all concrete samples. In the determination of modulus of elasticity a DMG/Rubicon $2500 \mathrm{kN}$ Universal Testing Machine was used to apply a constant load rate up to $40 \%$ of the ultimate load of respective concrete mix, while two linear variable differential transducers (LVDT) were used as shown in Figure 2 to measure the axial deformation of the cylinder. The slope of the recorded stress vs strain curve yielded the elastic modulus of the concrete.

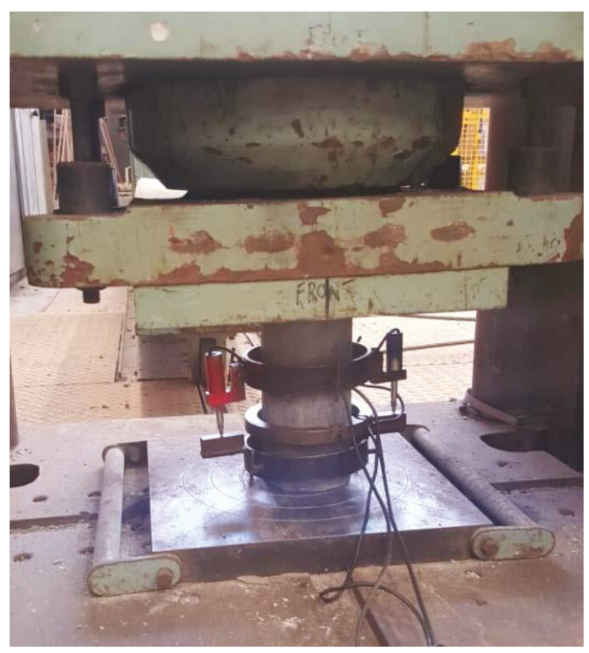

Figure 2. Test setup to measure the elastic modulus of concrete cylinder. 
The rate of water absorption (sorptivity) of concrete samples was measured according to ASTM C1585 [25]. The principle of the method is that a specimen had one surface in free contact with water (no more than $5 \mathrm{~mm}$ above the base of the specimen) while the other sides were sealed. This test determined the rate of absorption of water by hydraulic cement concrete by measuring the increase in the mass of a specimen resulting from absorption of water as a function of time. In this study the mass of the concrete specimen was measured regularly to determine the initial absorption from 1 min to the first 6 hours. The absorption $I$ was the change in mass divided by the product of the cross-sectional area of the test specimen and the density of water. The initial rate of water absorption value $\left(\mathrm{mm} / \mathrm{sec}^{1 / 2}\right)$ was calculated as the slope of the line that is the best fit to $I$ plotted against the square root of time $\left(\sec ^{1 / 2}\right)$. The chloride ion penetration resistance of concrete, popularly called the rapid chloride permeability test (RCPT), was conducted according to ASTM C1202 [26], details of which can be found in the standard. Water absorption of all concretes were measured according to the Australian standard AS1012.21 [27].

\section{Results and Discussion}

The workability of green star concretes in terms of measured slump values are shown in Figure 3 and is bench marked with respect to control concrete. It can be seen that the slump value of two green star concrete is higher than that of control concrete and can be attributed to the use of $40 \%$ slag as partial replacement of OPC. The relatively lower specific gravity of slag than that of cement increases the paste volume in concrete containing $40 \%$ slag, which cause the improvement in workability. The slump of mix 2 is decreased from $175 \mathrm{~mm}$ to $160 \mathrm{~mm}$ when $40 \%$ RCA is used as partial replacement of NCA in mix 3. This reduction can be attributed to the presence of $40 \%$ RCA whose water absorption is higher than NCA and contain more $10 \mathrm{~mm}$ size aggregates than the NCA. The workability is slightly affected in three green star concrete ( $\operatorname{mix} 4$ ) due to addition of $50 \%$ reclaimed wash water as partial replacement of tap water. High turbidity and $\mathrm{pH}$ of wash water are attributed to this slight reduction in workability. Nevertheless the workability of all green star concretes is better than the control concrete.

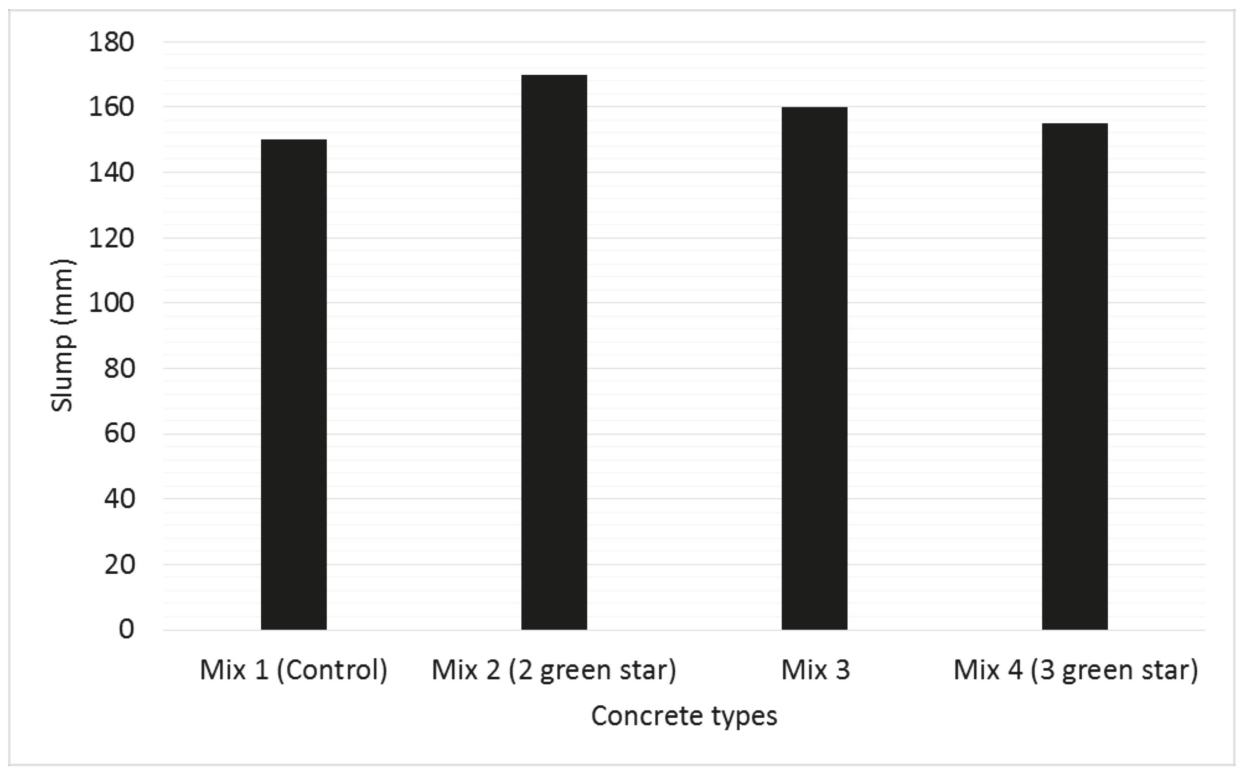

Figure 3. Measured slump values of green star concretes and control concrete. 
The measured compressive strength of all concretes at 7 and 28 days are shown in Figure 4 . It can be seen that the compressive strength of green star concretes is lower than the control concrete at both ages especially at 7 days. The partial replacement of OPC by $40 \%$ slag in two green star concrete exhibited about $31 \%$ and $12 \%$ reduction, respectively at 7 and 28 days compared to control concrete. The slow pozzalonic reaction of slag is the reason for higher compressive strength loss at 7 days in this concrete than at 28 days. However, when $40 \%$ RCA is used as partial replacement of NCA in mix 3 a slight reduction in both 7 and 28 days compressive strength is observed compared to mix 2 . A slight reduction in both 7 and 28 days compressive strength is also observed in three green star concrete (Mix 4) when $50 \%$ wash water is used as partial replacement of tap water compared to Mix 3. The presence of weak interfacial transition zone between old mortar of RCA with new matrix and the higher turbidity of wash water could be the reason of the observed slight reduction in compressive strength in mixes 3 and 4 than mix 2 . Nevertheless the three green star concrete containing $40 \%$ less OPC, $40 \%$ less NCA and 50\% less fresh water exhibited a 28 days compressive strength of $38 \mathrm{MPa}$, which is $18 \%$ lower than the control concrete but still adequate enough for structural application. Similar reduction trend in indirect tensile strength and elastic modulus is also observed in all green star concretes compared to control concrete. It can be seen in Figures 5 and 6 that the reduction of indirect tensile strength of all green star concretes is slightly lower than that of compressive strength at both ages, however, in the case of elastic modulus the reduction was higher than the compressive strength. It is also interesting to observe that indirect tensile strength and elastic modulus of three green star concrete at both ages are similar and slightly higher, respectively than those of mix 3 concrete.

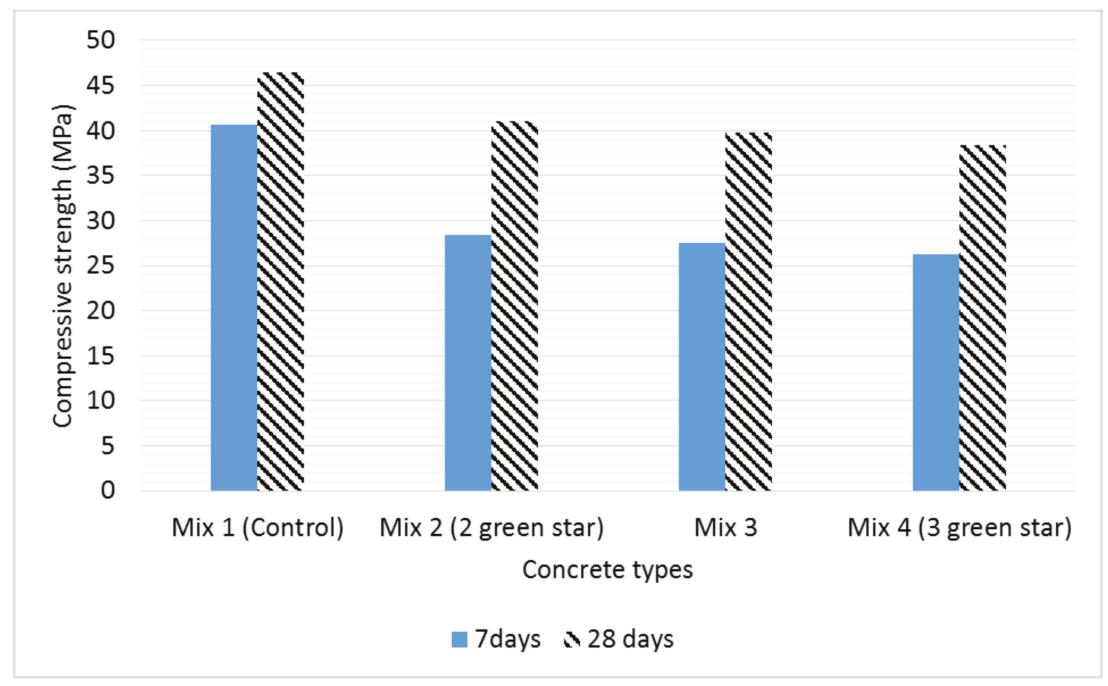

Figure 4. Measured compressive strength of green star concretes and control concrete. 


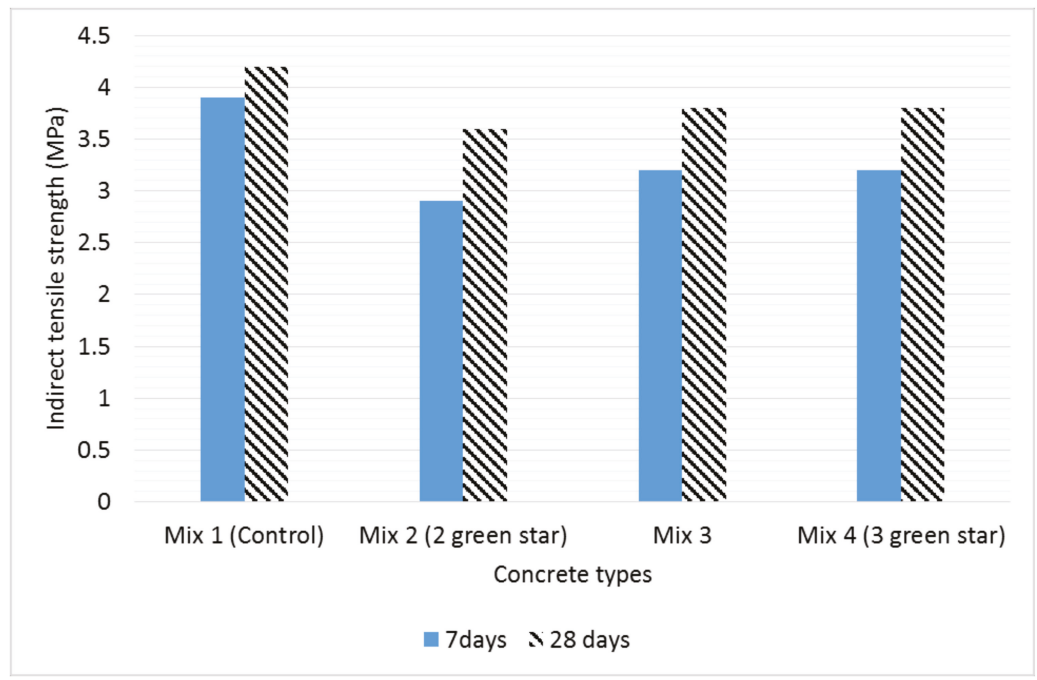

Figure 5. Measured indirect tensile strength of green star concretes and control concrete.

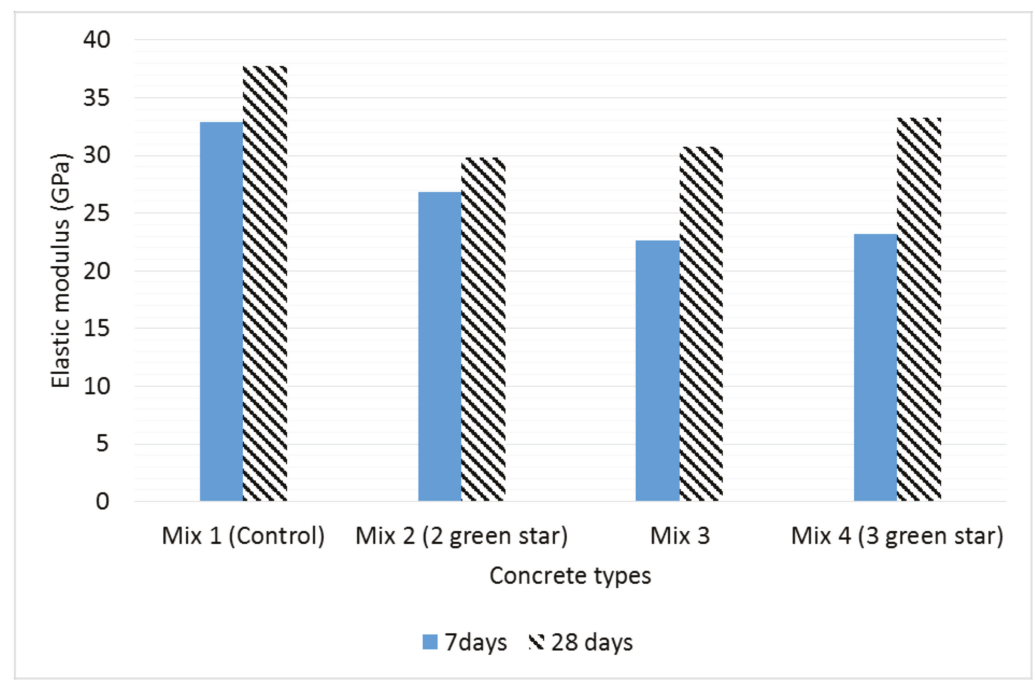

Figure 6. Measured elastic modulus of green star concretes and control concrete.

The measured durability properties of green star concretes are shown in Figures 7-10. Figure 7 shows the water absorption of green star concretes. No changes in water absorption of two green star concrete compared to control concrete after 7 days of wet curing can be seen, however, about $15 \%$ reduction is observed after 28 days curing. This can be attributed to the pozzolaanic reaction of $\mathrm{SiO}_{2}$ and $\mathrm{Al}_{2} \mathrm{O}_{3}$ of slag with $\mathrm{Ca}(\mathrm{OH})_{2}$ of hydration reaction which densified the matrix through formation of additional hydration products and pore filling by the slag particles. The three green star concrete and mix 3 , as expected, showed much higher water absorption than control and two green star concretes due to the presence of $40 \%$ RCA, whose water absorption capacity is much higher than NCA as shown in Table 3. The effect of wash water however is not affected the water absorption of three green star 
concrete than of mix 3 concrete. Unlike water absorption, the rate of water absorption of all green star concretes is lower than that of control concrete at both ages. Among green star concretes, the two green star concrete containing $40 \%$ slag as partial replacement of OPC exhibited the lowest rate of water absorption at both ages and is believed to be due to the pore refinement of its matrix due to additional hydration product formed through pozzolanic reaction and pore filling. After 28 days of curing this rate further reduced. A summary of water sorptivity, which is the slope of the rate of water absorption lines in Figure 8, is shown in Figure 9. It can be seen that the sorptivity of mix 3 and mix 4 concretes is very similar, where no adverse effect of wash water on sorptivity is observed in three green star concrete. Similar result is also observed in chloride ion penetration in green star concretes in RCPT test. It can be seen in Figure 10 that the chloride permeability in two green star concrete is significantly reduced by $62 \%$ after 28 days of wet curing. This can be contributed by the pore refinement of matrix in two green star concrete due to pozzolanic reaction of slag and pore filling. However, after 7 days of curing the reduction in chloride permeability is much lower than that at 28 days due to slow pozzolanic reaction of slag. The addition of $40 \%$ RCA in mix 3 concrete, however, increased the chloride permeability possibly due to higher porosity of RCA than NCA and the presence of more interfacial transition zone with matrix and RCA than with matrix and NCA. Interestingly, the three green star concrete shows lower chloride permeability than the other two green concrete mixes, which is not observed in water absorption and sorptivity tests, where a slight increase in water absorption and sorptivity is observed in three green star concrete than mix 3 . While all three measured durability properties are affected by the pores in the concrete, the water absorption and sorptivity are mostly depend on overall porosity of the concrete as the specimens in those tests are kept in water or in contact with water for long time. However, in RCPT test $\mathrm{Cl}^{-}$is forced to pass from one side of the concrete specimen to other side. Therefore, the observed lower chloride ion penetration in three green star concrete than other two green star concretes indicate that the pores in that concrete are not interconnected rather disperse.

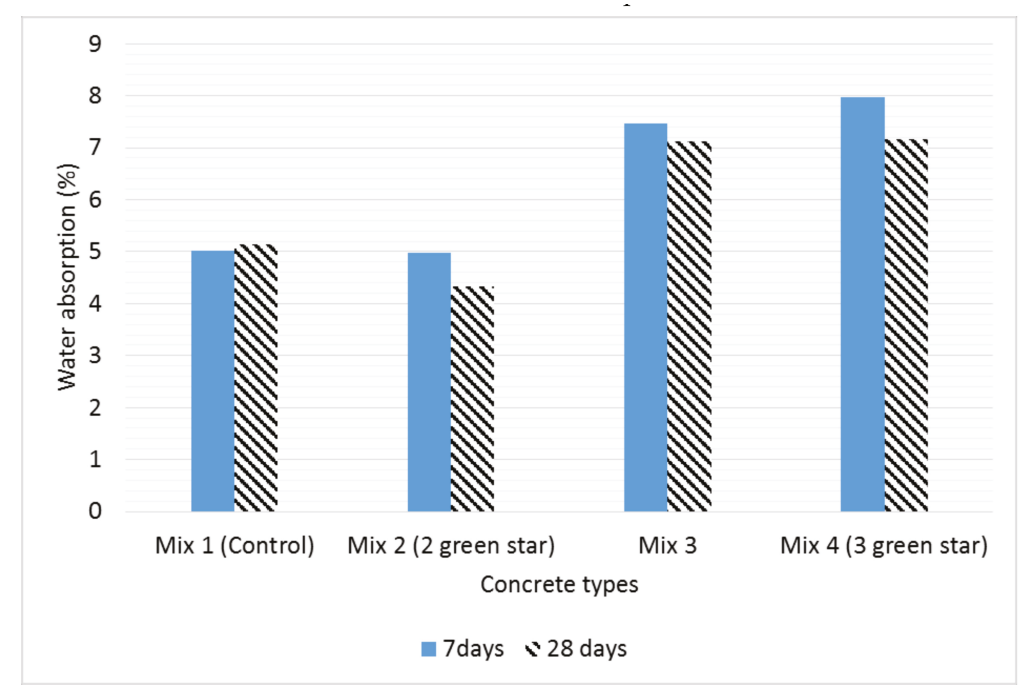

Figure 7. Measured water absorption of green star concretes and control concrete. 


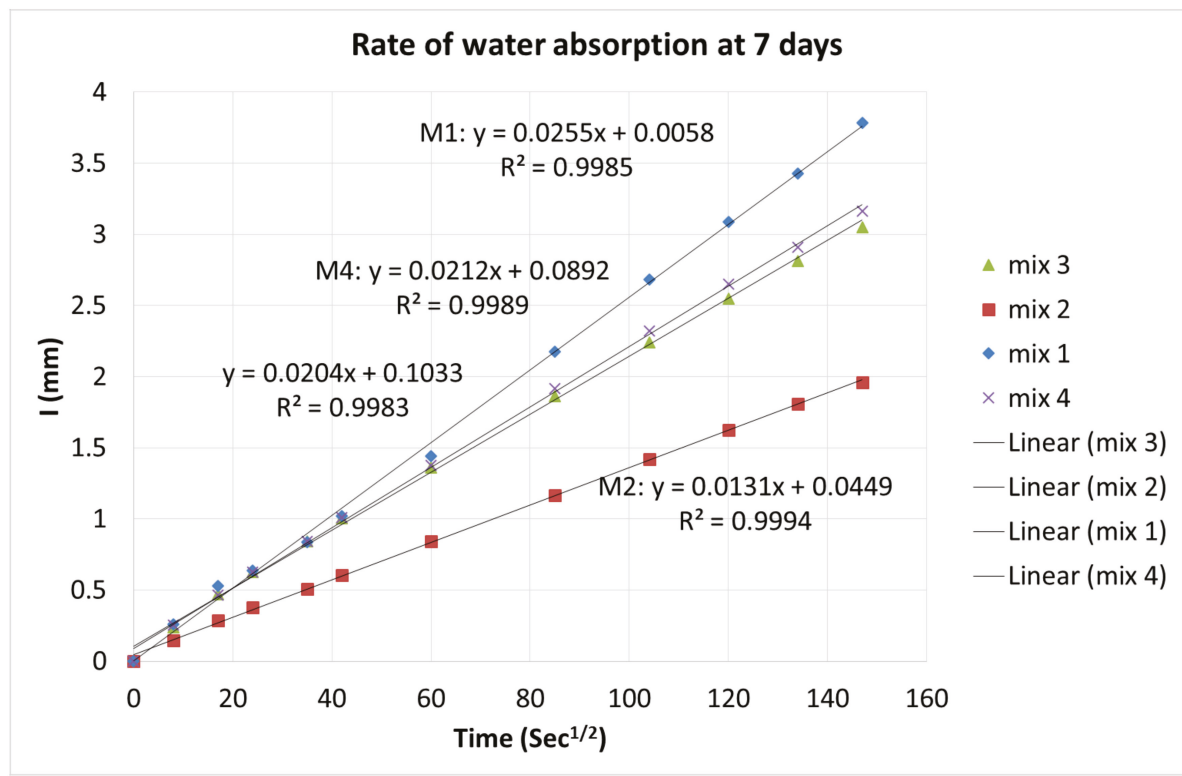

(a)

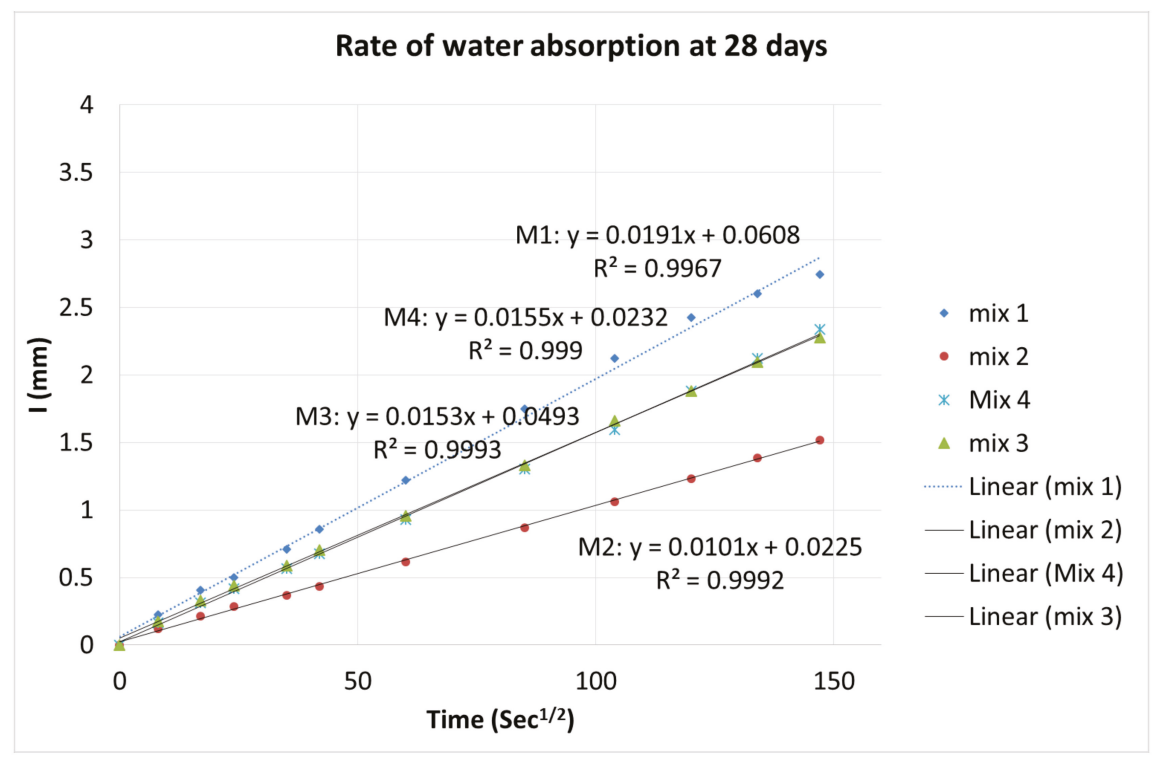

(b)

Figure 8. Rate of water absorption of green star concretes and control concrete at (a) 7 days and (b) 28 days. 


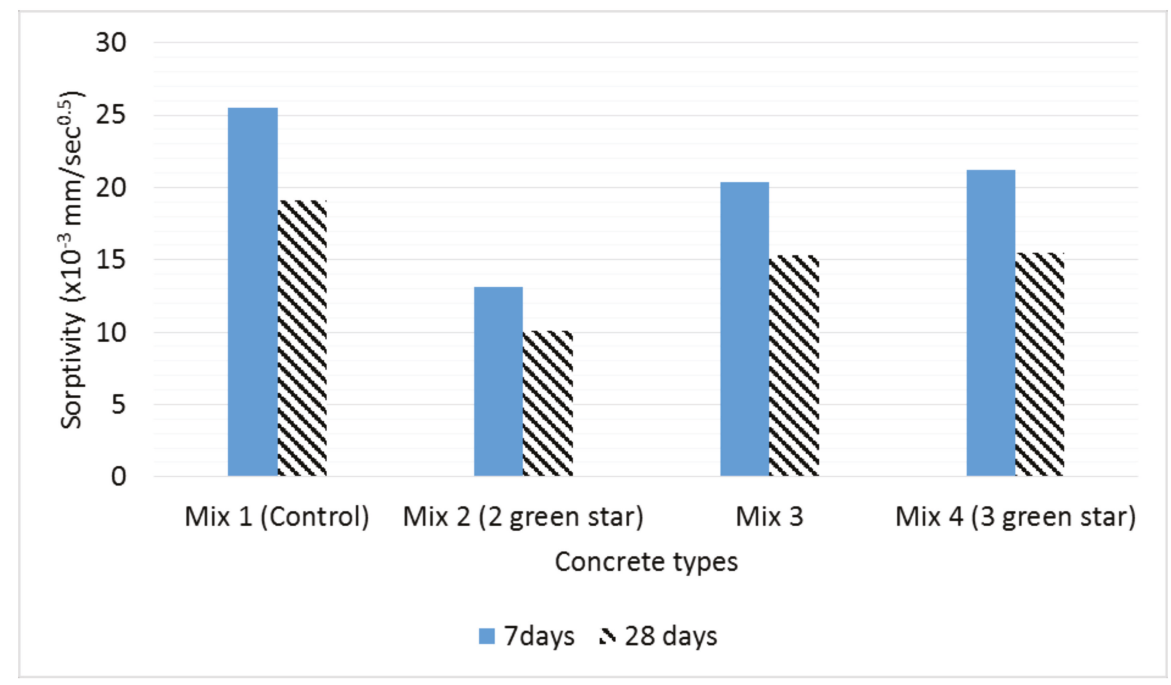

Figure 9. Summary of sorptivity of green star concretes and control concrete.

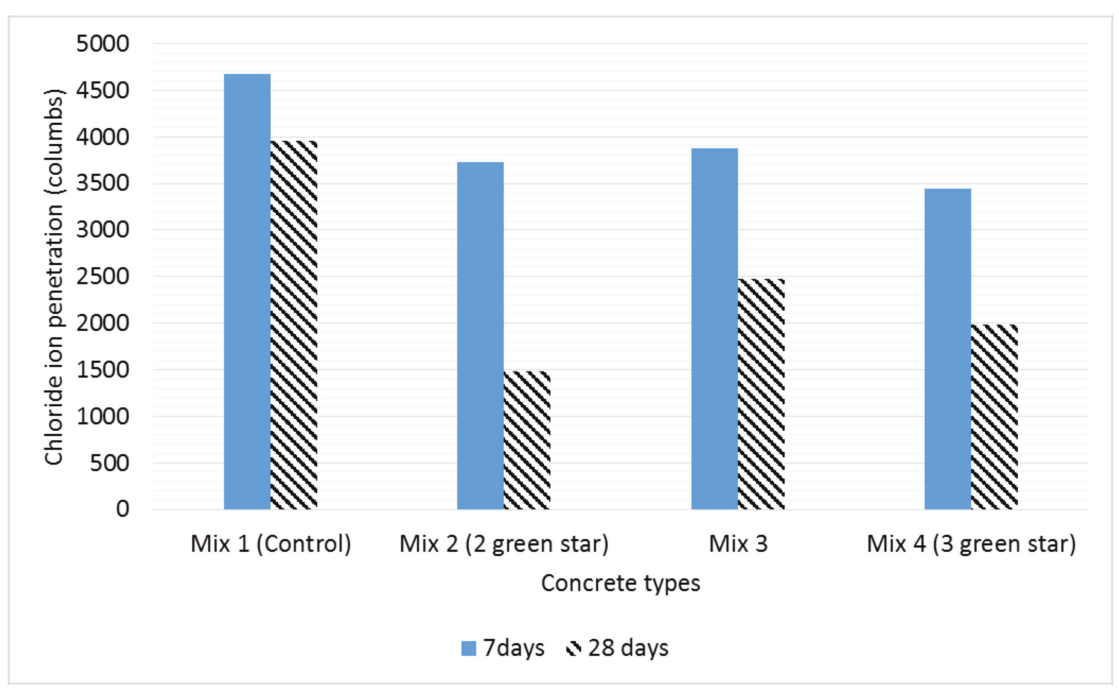

Figure 10. Measured chloride ion prenetration of green star concretes and control concrete.

\section{Conclusions}

This study evaluated mechanical and durability properties of green star concretes according to the definition of green building council Australia and bench marked with control concrete. Within limited studies the following conclusions can be drawn:

- Green star concretes exhibited reduction in compressive strength, indirect tensile strength and elastic modulus at both 7 and 28 days compared to control concrete. However, the reduction at 7 days of green star concrete is much higher than at 28 days. Formation of additional hydration products and particle packing due to pozzolianic reaction and small particle size of slag are 
contributed to the increase in above mechanical properties at 28 days. Three green star concrete exhibited about $18 \%, 10 \%$ and $12 \%$ reduction in compressive strength, indirect tensile strength and elastic modulus, respectively at 28 days compared to control concrete while containing $40 \%$ less OPC, $40 \%$ less NCA and $50 \%$ less fresh water.

- The two green star concrete containing $40 \%$ slag exhibited lower water absorption, sorptivity and chloride permeability than control concrete at both ages, while three green star concrete containing $40 \%$ slag, $40 \%$ RCA and $50 \%$ concrete wash water exhibited better durability properties at both ages except the water absorption which is about $25 \%$ higher than two green star concrete at 28 days. The presence of $40 \%$ RCA, whose water absorption capacity is much higher than the $\mathrm{NCA}$, is the reason for such increase in water absorption.

- Both two and three green star concretes exhibited 28 days compressive strength of about $40 \mathrm{MPa}$ and much lower chloride permeability than control concrete. Therefore, these green concretes can be used in structural application with good resistance against reinforcement corrosion.

While only slag and concrete wash water are used to partially replace the OPC and tap water, respectively in the green star concretes in this study, other SCMs. E.g., fly ash, silica fume, combination of fly ash/slag/silica fume and recycled water from other sources can be used in green star concretes and studied their properties to establish their use.

Funding: This research received no external funding.

Acknowledgments: Author acknowledge to two final year project students Brett Milman and Miss Aije for their assistance in casting and testing of all concrete specimens in this study.

Conflicts of Interest: The authors declare no conflicts of interest.

\section{References}

1. Moretti, L.; Caro, S. Critical analysis of the life cycle assessment of the Italian cement industry. J. Cleaner Prod. 2017, 152, 198-210. [CrossRef]

2. Limbachiya, M.; Bostanci, S.C.; Kew, H. Suitability of BS EN197 CEM II and CEM V cement for production of low carbon concrete. Constr. Build. Mater. 2014, 71, 397-405. [CrossRef]

3. Malhotra, V.M. Sustainable development and concrete technology. Concr. Int. 2002, 24, 1-22.

4. Malhotra, V.M.; Mehta, P.K. High-Performance, High-Volume Fly Ash Concrete: Materials, Mixture Proportioning, Properties, Construction Practice, and Case Histories; HVFA High-Performance-Inc.: Ottawa, ON, Canada, 2002.

5. Siddique, R. Performance characteristics of high-volume class F fly ash concrete. Cem. Concr. Res. 2004, 34, 487-493. [CrossRef]

6. Kou, S.C.; Poon, C.S.; Chan, D. Influence of fly ash as a cement addition on the hardened properties of recycled aggregate concrete. Mater. Struct. 2007, 41, 1191-1201. [CrossRef]

7. Shaikh, F.U.A.; Supit, S.W.M. Compressive strength and durability properties of high volume fly ash concretes containing ultrafine fly ash. Constr. Build. Mater. 2015, 82, 192-205. [CrossRef]

8. Berndt, M.L. Properties of sustainable concrete containing fly ash, slag and recycled concrete aggregate. Constr. Build Mater. 2009, 23, 2606-2613. [CrossRef]

9. Corinaldesi, V.; Moriconi, G. Influence of mineral additions on the performance of $100 \%$ recycled aggregate concrete. Constr. Build. Mater. 2009, 23, 2869-2876. [CrossRef]

10. Poon, C.S.; Shui, Z.H.; Lam, L. Effect of microstructure of ITZ on compressive strength of concrete prepared with recycled aggregates. Constr. Build. Mater. 2004, 18, 461-468. [CrossRef]

11. Sagoe-Crentsil, K.K.; Brown, T.; Taylor, A.H. Performance of concrete made with commercially produced coarse recycled concrete aggregate. Cement Concr. Res. 2001, 31, 707-712. [CrossRef]

12. Ahmed, S.F.U. Properties of concrete containing construction and demolition wastes and fly ash. J. Mater. Civ. Eng. 2013, 25, 1864-1870. [CrossRef]

13. Ahmed, S.F.U. Properties of concrete containing recycled fine aggregate and fly ash. J. Solid Waste Technol. Manage. 2014, 40, 70-78. [CrossRef]

14. Shaikh, F.U.A.; Odoh, H.; Than, A.B. Effect of nano silica on properties of concrete containing recycled coarse aggregates. Constr. Mater. 2014, 168, 68-76. [CrossRef] 
15. Shaikh, F.U.A. Effect of ultrafine fly ash on properties of concretes containing construction and demolition wastes as coarse aggregates. Struct. Concr. 2016, 17, 116-122. [CrossRef]

16. Zhang, W.; Ingham, J.M. Using recycled concrete aggregates in New Zealand ready-mix concrete production. J. Mater. Civ. Eng. 2010, 22, 443-450. [CrossRef]

17. Kadir, A.A.; Shahidan, S.; Yee, L.H.; Hassan, M.I.H.; Abdullah, M.A. The effect on slurry water as a fresh water replacement in concrete properties. IOP Conf. Ser. Mater. Sci. Eng. 2016, 133, 012041. [CrossRef]

18. Al-jabri, K.S.; Al-saidy, A.H.; Taha, R.; Al-kemyani, A.J. Effect of using waste water on the properties of high strength concrete. Procedia Eng. 2011, 14, 370-376. [CrossRef]

19. Lobo, C.; Mullings, G.M. Recycled water in ready mixed concrete operations. Concr. Focus 2003, 2, 1-10.

20. Revised Green Star Concrete Credit, Green Building Council Australia. Available online: https://www. gbca.org.au/green-star/materials-category/revised-green-star-concrete-credit/34008.htm (accessed on 30 October 2017)

21. Water Research Centre National Secondary Drinking Water Standards. Available online: https://www. water-research.net/index.php/standards/secondary-standards (accessed on 9 July 2018).

22. AS 1012.9. Determination of Compressive Strength of Concrete; Australia Standards: Sydney, Australia, 2010.

23. AS 1012.10. Determination of Indirect Tensile Strength of Concrete; Australia Standards: Sydney, Australia, 2010.

24. AS 1012.17. Determination of Elastic Modulus of Concrete; Australia Standards: Sydney, Australia, 2010.

25. ASTM C1585-13. Standard Test Method for Measurement of Rate of Absorption of Water by Hydraulic Cement Concretes; ASTM International: West Conshohocken, PA, USA, 2013.

26. ASTM C1202. Standard Test Method for Electrical Indication of Concrete's Ability to Resist Chloride ion Penetration; American Society for Testing and Materials: Philadelphia, PA, USA, 2012.

27. AS 1012.21. Determination of Water Absorption and Apparent Volume of Permeable Voids in Hardened Concrete; Australia Standards: Sydney, Australia, 1999.

(C) 2018 by the author. Licensee MDPI, Basel, Switzerland. This article is an open access article distributed under the terms and conditions of the Creative Commons Attribution (CC BY) license (http:/ / creativecommons.org/licenses/by/4.0/). 
Article

\title{
Photocatalytic Functionalized Aggregate: Enhanced Concrete Performance in Environmental Remediation
}

\author{
Amer Hakki ${ }^{1,2}$, , Lu Yang ${ }^{1,3}$, Fazhou Wang ${ }^{3}$, Ammar Elhoweris ${ }^{2}$, Yousef Alhorr ${ }^{2}$ and \\ Donald E. Macphee ${ }^{1, *}$
}

1 Department of Chemistry, University of Aberdeen, Meston Building, Meston Walk, Aberdeen AB24 3UE, UK; yanglu@whut.edu.cn

2 Gulf Organisation of Research and Development, Qatar Science and Technology Park, Doha 210162, Qatar; a.elhoweris@gord.qa (A.E.); alhorr@gord.qa (Y.A.)

3 State Key Laboratory of Silicate Materials for Architectures, Wuhan University of Technology, 122\# Luoshi Road, Wuhan 430070, China; fzhwang@whut.edu.cn

* Correspondence: a.hakki@gord.qa (A.H.); d.e.macphee@abdn.ac.uk (D.E.M.); Tel.: +974-44215006 (A.H.); +44-(0)1224-272941 (D.E.M.)

Received: 2 December 2018; Accepted: 4 January 2019; Published: 22 January 2019

\begin{abstract}
Engineering of effective photocatalytically active structures is of great importance as it introduces a solution for some existing air pollution problems. This can be practically achieved through the bonding of particulate photocatalysts to the surface of construction materials, such as aggregates, with a suitable stable binding agent. However, the accessibility of the photocatalytically active materials to both the air pollutants and sunlight is an essential issue which must be carefully considered when engineering such structures. Herein, different amounts of commercial $\mathrm{TiO}_{2}$ were supported on the surface of quartz sand, as an example of aggregates, with a layer of silica gel acting as a binder between the photocatalyst and the support. The thus prepared photocatalytically active aggregates were then supported on the surface of mortars to measure their performance for NOx removal. The obtained materials were characterized by electron microscopy (SEM and TEM), Fourier Transform Infrared Spectroscopy (FTIR), X-ray Diffraction (XRD), and UV-vis Absorption Spectroscopy. Very good coverage of the support's surface with the photocatalyst was successfully achieved as the electron microscopic images showed. FTIR spectroscopy confirmed the chemical bonding, i.e., interfacial Ti-O-Si bonds, between the photocatalyst and the silica layer. The photocatalytic activities of the obtained composites were tested for photocatalytic removal of nitrogen oxides, according to the ISO standard method (ISO 22197-1). The obtained aggregate-exposed mortars have shown up to ca. four times higher photocatalytic performance towards NO removal compared to the sample in which the photocatalyst is mixed with cement, however, the nitrate selectivity can be affected by Ti-O-Si bonding.
\end{abstract}

Keywords: environmental remediation; air pollution; photocatalytic construction materials; nitric oxides; functionalized aggregate

\section{Introduction}

Air pollution is a serious problem which directly affects everyone who lives in populated cities around the world [1]. Incontrovertibly, fossil fuel combustion for energy production and in the transportation sector, together with metallurgical industries, i.e., cementitious and construction industries, are the major sources of most anthropogenically produced pollutants [2]. Common air pollutants that pose risks to human health include nitrogen oxides (NOx; mainly $\mathrm{NO}$ and $\mathrm{NO}_{2}$ ), carbon monoxide $(\mathrm{CO})$, sulfur oxides $(\mathrm{SOx})$, ozone $\left(\mathrm{O}_{3}\right)$, volatile organic compounds (VOCs), and 
particulate matter (PM) [3]. Among them, NOx gases have attracted a lot of concern since they cause or worsen serious health hazards for humans, including diseases such as emphysema and bronchitis, and aggravate existing heart disorders. Moreover, NOx gases are responsible for acid rains and smog and contribute to greenhouse warming [4].

Under solar irradiation, some photocatalysts such as $\mathrm{TiO}_{2}$ have the potential to reduce ambient concentrations of NOx from areas in which the concentrations of these pollutants exceed national exposure level guidelines [5]. The light-induced oxidation reactions occur on the surface of irradiated $\mathrm{TiO}_{2}$ in the presence of molecular oxygen and convert the toxic $\mathrm{NO}$ gas into nitrate through subsequent oxidation steps, with the intermediate formation of nitrogen dioxide: $\mathrm{NO} \rightarrow \mathrm{NO}_{2} \rightarrow \mathrm{NO}_{3}{ }^{-}$[6-9]. The thus formed nitrate $\left(\mathrm{NO}_{3}{ }^{-}\right)$on the $\mathrm{TiO}_{2}$ surface can be rinsed and the catalyst can be recovered for further photocatalytic cycles.

Because of their high surface area and their direct contact with urban atmospheres, construction materials are excellent carriers to which photocatalytic materials can be applied for air purification. Recently, photocatalytically active surfaces have established an important commercial as well as technological position in modern construction technologies [10]. Some trials on the application of $\mathrm{TiO}_{2}$ photocatalysts in several concrete applications have already been conducted. Richard Meier's Dives in Misericordia Church project in Rome [11], the New Road Construction Concepts (NR2C), the Air Quality Innovation Programme (IPL) in the Netherlands, and Photocatalytic Innovative Coverings Applications for Depollution (PICADA) are examples of such trials and projects [5]. These approaches have typically focused on the addition of the photocatalytic materials to the binder phase, where their performance can be strongly influenced by poor dispersibility or occlusion of the added photocatalytic powder [12-14]. Moreover, some reported studies address the impact of photocatalyst additions on the practical characteristics of concrete, e.g., workability and durability [15]. Despite our level of understanding of these mechanisms, there have been few innovative solutions to maintain the cement-free photocatalyst performance level over time.

Therefore, engineering photocatalytically active structures in a way that ensures high performance in air purification is of great importance from both environmental and economical perspectives [16-18]. The approach suggested in this work is supportive of $\mathrm{TiO}_{2}$-based photocatalysts on aggregate materials such that the photocatalyst is positioned above the surface of the concrete. Placement of such aggregates on the surface of the concrete structure during construction ensures that the photocatalyst will have free access to atmospheric pollutants (particularly NOx), rainwater and illuminating radiation, and be free of agglomeration issues. However, although this approach has been previously reported, efficient binding of photocatalytic material to the support surface is still a challenging issue.

\section{Materials and Methods}

\subsection{Synthesis of $\mathrm{TiO}_{2}-\mathrm{SiO}_{2}-\mathrm{Quartz}$ Composites}

Standard quartz sand $(\mathrm{Q})$ was first sieved to obtain a sample with the desired particle size distribution $\left(1-3 \mathrm{~mm}\right.$ ) before it was washed with deionized water several times and dried at $95^{\circ} \mathrm{C}$. A commercial photocatalyst (CristalACTiV ${ }^{\mathrm{TM}}$ PC105, Cristal, Stallingborough, UK) was supported on the obtained Q using a silica-based binder prepared from the precursor tetraethyl orthosilicate (TEOS, Sigma-Aldrich, Schnelldorf, Germany). A TEOS mother solution was prepared by adding the exact amount of TEOS into an ethanol:water: $\mathrm{HCl}$ mixture at a TEOS:ethanol:water: $\mathrm{HCl}$ molar ratio of 1:3:4:4 $\times 10^{-3}$, which was stirred for 10 days at room temperature in a sealed vessel [19]. Then the required volumes of the obtained solution were added to $200 \mathrm{~mL}$ of ethanol, in which the required amounts of $\mathrm{TiO}_{2}$ were suspended, to get $0.5,1,2.5,5$, and $10 \mathrm{wt} \% \mathrm{TiO}_{2}$ :Quartz in the final product. These values were chosen because many reports identified the efficacy of $\mathrm{TiO}_{2}$ photocatalysts conventionally mixed into cementitious materials (with $\mathrm{TiO}_{2}$ loadings from 1 to $10 \mathrm{wt} \%$ as a fraction of the cement content) [20-22]. The molar ratio of $\mathrm{TiO}_{2}$ :TEOS was always kept at 1:1. The suspension was then kept gently stirring at room temperature overnight. It was then added dropwise to $40 \mathrm{~g}$ of $\mathrm{Q}$ 
with continuous stirring at $80{ }^{\circ} \mathrm{C}$ under reduced pressure. The obtained materials were dried at $90{ }^{\circ} \mathrm{C}$ overnight followed by heat treatment at $200{ }^{\circ} \mathrm{C}$ for $4 \mathrm{~h}$. The thus obtained modified $\mathrm{Q}$ samples were then cooled in air, washed with deionized water, dried at $90{ }^{\circ} \mathrm{C}$, and sieved again to collect particles larger than $1 \mathrm{~mm}$ in order to separate modified quartz from loosely or non-connected $\mathrm{TiO}_{2}$-binder. The resulting composite samples are denoted QTx where x represents expected $\mathrm{TiO}_{2}$ content. In order to simplify the characterisation, fine powdered Quartz (particles sizes in the range 20-50 $\mu \mathrm{m}$ obtained by ball milling of commercial quartz (Aldrich) and sieving) was also modified with 10 wt $\% \mathrm{TiO}_{2}$ following a similar procedure; the obtained sample is denoted FQT.

\subsection{Characterization}

X-ray diffraction (XRD) patterns were obtained using a PANalytical diffractometer $\left(X^{\prime}\right.$ Pert $^{3}$ Powder, Malvern Panalytical, UK) equipped with a CuKa1 $1.54 \AA$ X-ray source. FTIR spectra were recorded using a PerkinElmer Spectrum Two equipped with UATR (Single Reflection Diamond, PerkinElmer, Inc, City, State, USA). UV-vis diffuse reflectance spectra of the samples were recorded using a Cary 60 UV-vis spectrophotometer (Agilent Technology, City, State, USA) equipped with a fibre optic coupler. Barium sulphate was used as a reference in the range of 250 to $600 \mathrm{~nm}$. The resulting reflectance spectra were transformed into apparent absorption spectra by using the Kubelka-Munk function $\mathrm{F}(\mathrm{R} \infty)=(1-\mathrm{R} \infty)^{2} / 2 \mathrm{R} \infty$. The amount of $\mathrm{TiO}_{2}$ loaded on the surface of $\mathrm{Q}$ was analyzed by $X$-ray fluorescence spectroscopy (XRF) using Rigaku NexQC. For this purpose, a calibration series of $\mathrm{TiO}_{2}-\mathrm{SiO}_{2}$ was prepared by mixing the required amount of $\mathrm{TiO}_{2}$ (PC105) and $\mathrm{SiO}_{2}$ (ball milled commercial quartz) to get a series from 0.1 to $20 \mathrm{wt} \% \mathrm{TiO}_{2}$. Morphologies of samples were observed using a scanning electron microscope (SEM, Zeiss EVO MA10, Zeiss, City, State, USA) equipped with an energy dispersive X-ray spectrometer (EDS, Oxford INCA) for elemental composition analyses. The transmission electron microscopy (TEM) was performed on a JEOL-JEM-2000EX microscope operated with an accelerating voltage of $200 \mathrm{kV}$; images were captured with a Gatan Erlangshen ES500W camera.

\subsection{Photocatalytic Performance Test}

The removal of nitrogen oxides (NOx), as examples of air pollutants, using the obtained quartz sand modified with the photocatalyst was tested to check their efficiency in purification of the polluted air [23]. Figure 1 illustrates the air-purification test set-up which was established for this purpose. The set-up consists of the following (see Figure 1): gas suppliers; i.e., synthetic air and NO in nitrogen (BOC, Guildford, UK), gas flow controllers (Bronkhorst, Newmarket Suffolk, UK) (1), a humidity supplier unit (2), a photocatalytic reactor according to ISO standard design (ISO 22197-1) (3), a UV(A) irradiation source (4), and a NOx analyzer (5). The gas supplies were NO (100 ppm) in $\mathrm{N}_{2}$ and synthetic air (BOC, UK). The required concentration (1000 ppbv), flow rates $\left(5 \times 10^{-5} \mathrm{~m}^{3} \cdot \mathrm{s}^{-1}\right)$, and humidity (ca. 40\%, confirmed by a Rotronic hygropalm) were achieved by controlling the flow of each gas by the gas flow controllers (1). The photoreactor was constructed from PMMA (Poly(methyl methacrylate)), covered with borosilicate glass, and was positioned below the output from an SS0.5 kW, $500 \mathrm{~W}$ fully reflective solar simulator equipped with a 1.5 AM filter (Sciencetech, London, Ontario, Canada). The irradiation was adjusted to ensure that the test sample (6) received a light intensity of $10 \mathrm{Wm}^{-2}$ at $\lambda<420 \mathrm{~nm}$. The light intensity was measured using a broadband thermopile detector (Gentec-EO-XLP12-3S-H2-D0) located exactly where the test sample should be placed. A Thermo Scientific Model 42i-HL High Level NO-NO $2-\mathrm{NOx}$ Analyzer (Air Monitors Ltd., Gloucestershire, UK) was used to monitor the concentrations of $\mathrm{NO}, \mathrm{NO}_{2}$, and total $\mathrm{NOx}$ in the outlet gas flow. Aggregate exposed mortars were prepared by supporting $10 \mathrm{~g}$ of bare or $\mathrm{TiO}_{2}$-modified quartz sand on the top of mortars (with top surface area of $64 \mathrm{~cm}^{2}$ and thickness of $15 \mathrm{~mm}$ ) in order to examine their efficiencies in NOx removal. For comparison, a reference sample was prepared according to the conventional mixing method (CMM) in which $\mathrm{TiO}_{2}$ was first mixed with cement at a $10 \mathrm{wt} \%$ ratio. Once prepared, 
a $2 \mathrm{~mm}$ thick layer of the mortar mixture was applied to the top of the pre-made mortar similar to those used to prepare the aggregate exposed mortars.

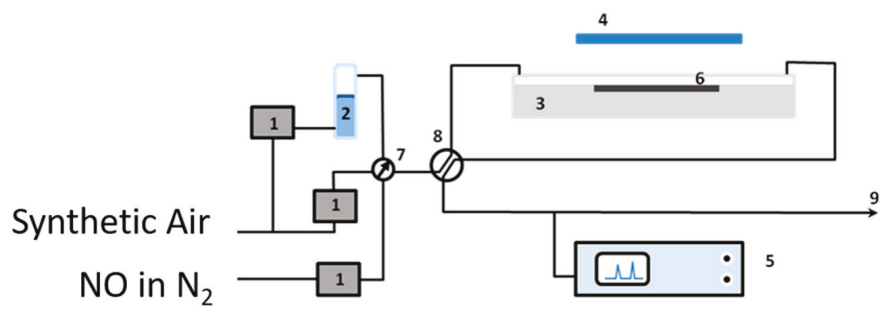

Figure 1. The photocatalytic testing apparatus: (1) mass flow controllers, (2) humidity supplier, (3) photocatalytic reactor, (4) UV(A) irradiation source, (5) NOx analyzer, (6) test sample, (7) and (8) valves, and (9) gas stream outlet.

\section{Results and Discussion}

XRD patterns of uncoated quartz sand (Q) and the prepared $\mathrm{TiO}_{2}-\mathrm{SiO}_{2}-$ Quartz composite (FQT) are shown in Figure 2. The appearance of a clear XRD pattern for anatase $\mathrm{TiO}_{2}$ in FQT sample confirms the successful support of $\mathrm{TiO}_{2}$ on the quartz in FQT.

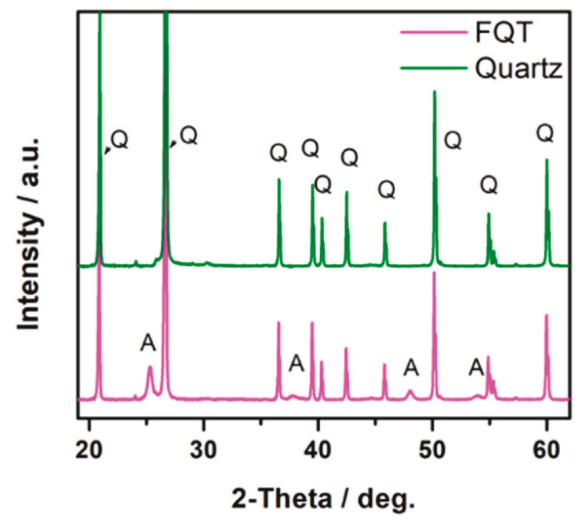

Figure 2. XRD patterns of bare quartz and $\mathrm{TiO}_{2}-\mathrm{SiO}_{2}-$ Quartz composite (FQT), $\mathrm{Q}$ and A refer to quartz and anatase patterns, respectively.

Evidence for the formation of a chemical bond between the $\mathrm{TiO}_{2}$ and $\mathrm{SiO}_{2}$ binding layers can clearly be observed from the FTIR spectrum in the range between $900-960 \mathrm{~cm}^{-1}$ (Figure 3), the absorption being assigned to the stretching vibrational mode of the Ti-O-Si bond. No similar absorption peak due to this mode was observed for $\mathrm{SiO}_{2}$ in the bare $\mathrm{Q}$ sample. 


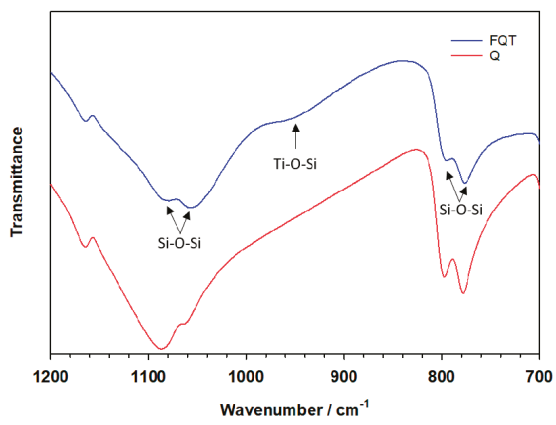

Figure 3. FTIR spectra of bare quartz $(\mathrm{Q})$ and the $\mathrm{TiO}_{2}-\mathrm{SiO}_{2}-$ Quartz composite (FQT).

Figure 4 shows the diffuse reflectance UV-vis absorption spectra of free $\mathrm{TiO}_{2}$ and FQT composite samples. Considering $\mathrm{TiO}_{2}$ as an indirect semiconductor, the modified Kubelka-Munk function $[\mathrm{F}(\mathrm{R} \infty) \mathrm{h} v]^{1 / 2}$ was plotted as a function of the incident photon energy which allowed the determination of the photocatalyst's band gap. The spectra are additional evidence for the presence of $\mathrm{TiO}_{2}$ in the FQT sample and show that the loading of $\mathrm{TiO}_{2}$, via the herein employed method, on the surface of quartz through a $\mathrm{SiO}_{2}$ binding layer has negligible effect on its band gap.

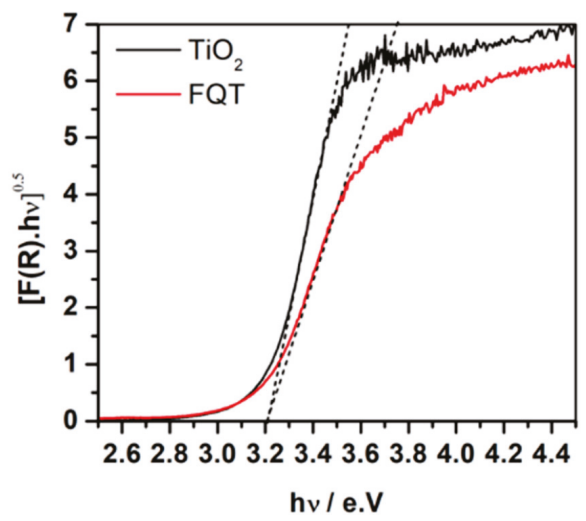

Figure 4. UV-vis absorption spectra presented as the modified Kubelka-Munk function of free $\mathrm{TiO}_{2}$ and $\mathrm{TiO}_{2}-\mathrm{SiO}_{2}-$ Quartz composite (FQT).

The amounts of $\mathrm{TiO}_{2}$ loaded on the surface of $\mathrm{Q}$, as recorded by XRF analyses, are summarized in Table 1. As can be seen from this table, the actual amount of $\mathrm{TiO}_{2}$ loaded is lower than the calculated values for all the prepared samples, meaning that some loss of $\mathrm{TiO}_{2}$ occurred during the preparation procedure. However, the lower the loaded amount the lower the $\mathrm{TiO}_{2}$ loss. This indicates a limitation of the modifying layer thickness over which all the extra added amount of $\mathrm{TiO}_{2}$-binder is lost.

Table 1. Calculated and analyzed loaded amount of $\mathrm{TiO}_{2}$ on quartz via silica gel binder.

\begin{tabular}{cccc}
\hline \multirow{2}{*}{ Sample ID } & \multicolumn{2}{c}{$\left.\mathrm{TiO}_{\mathbf{2}} \mathbf{( w t} \%\right)$} & \multirow{2}{*}{$\mathrm{TiO}_{\mathbf{2}}$ Loss (\%) } \\
\cline { 2 - 3 } & Calculated & Analyzed & \\
\hline QT0.5 & 0.5 & 0.35 & 30 \\
QT1 & 1.0 & 0.63 & 37 \\
QT2.5 & 2.4 & 0.72 & 70 \\
QT5 & 4.7 & 2.9 & 38 \\
QT10 & 9.1 & 2.67 & 71 \\
\hline
\end{tabular}


The level of coverage of the support $(\mathrm{Q})$ with $\mathrm{TiO}_{2}$ was examined using the SEM-EDS technique. Figure 5 compares the SEM-EDS of bare quartz coated with a silicate layer derived from TEOS in which commercial $\mathrm{TiO}_{2}$ (PC105) is dispersed. The effectiveness of a silicate-based layer on quartz (FQT) for the efficient support of $\mathrm{TiO}_{2}$ can be clearly seen from these SEM images. Very good coverage of $\mathrm{TiO}_{2}$ over the sample is achieved as a result of coating a silicate-based film over the quartz substrate.
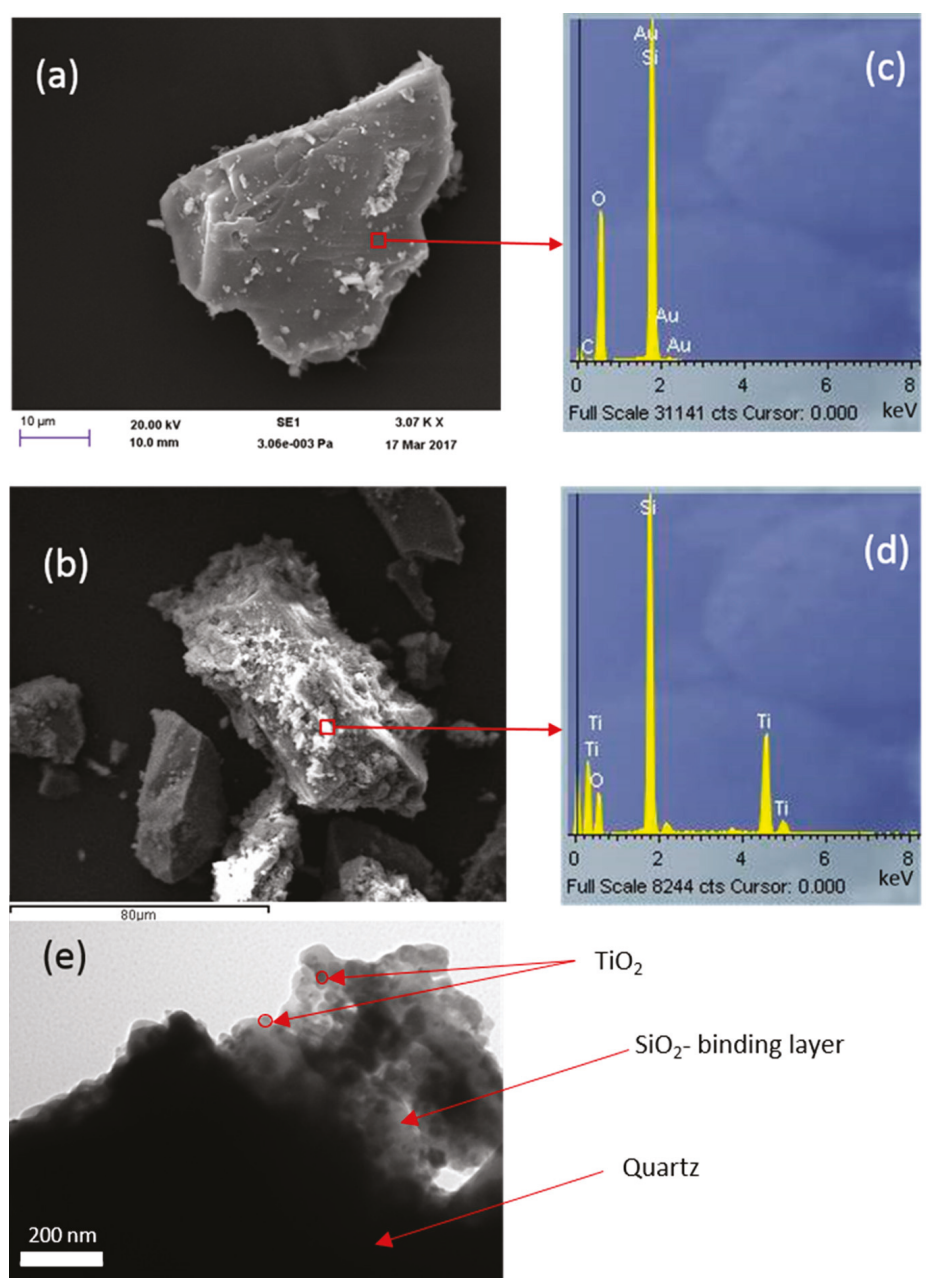

Figure 5. SEM images for (a) uncoated quartz and (b) $\mathrm{TiO}_{2}$ (commercial PC105) immobilized on quartz via a $\mathrm{SiO}_{2}$ binder formed from tetraethyl orthosilicate (TEOS). EDS of these samples are presented in (c,d), and the TEM image for the same samples in (e).

Although a few areas might be clear of silicate coating, Figure 5 shows that the silicate layer has generally been immobilized nicely on the grains. Consequently, in this case, $\mathrm{TiO}_{2}$, associated with the silicate-based gel phase, is also similarly distributed and is not bonded directly to the quartz surface. This is consistent with the TEM image in Figure 5e. Comparing the EDS analyses (Figure 5c,d) indicates the spreading of $\mathrm{TiO}_{2}$ with the silicate layer.

In order to examine the effectiveness of the obtained modified quartz sand samples for the removal of nitrogen oxides from polluted air, aggregate exposed mortars (with top surface areas of 
$64 \mathrm{~cm}^{2}$ ) were prepared, on top of which $10 \mathrm{~g}$ of bare or $\mathrm{TiO}_{2}$-modified quartz sand were supported. An image of the obtained mortars is presented in Figure 6 which shows a clear change in the color of the quartz sand to a whiter one by increasing the amounts of loaded $\mathrm{TiO}_{2}$.

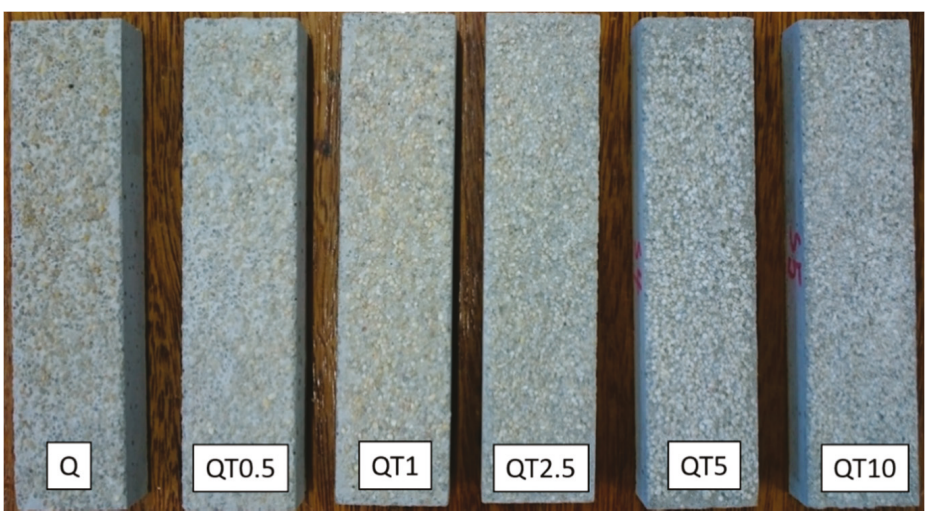

Figure 6. Images of the prepared aggregate exposed mortars. On the top of each sample, $10 \mathrm{~g}$ of bare (Q) or $\mathrm{TiO}_{2}$-modified quartz sand (QTx) were supported.

Figure 7 shows an example of the changes in the concentrations of nitrogen oxides, i.e., NO, $\mathrm{NOx}$, and $\mathrm{NO}_{2}$, in the gas stream flows over the QT10 sample in the dark and under irradiation. The concentration of NO is constant at ca. $1000 \mathrm{ppb}$ as long as the light is off. When the light is switched on, the initial $\mathrm{NO}$ concentration drops with a simultaneous increase in $\mathrm{NO}_{2}$ concentration, as $\mathrm{NO}_{2}$ is one of the NO oxidation products. Consequently, the concentration of NOx, which reflects the total oxidation of $\mathrm{NO}$ to $\mathrm{HNO}_{3}$, is reduced during the illumination time.

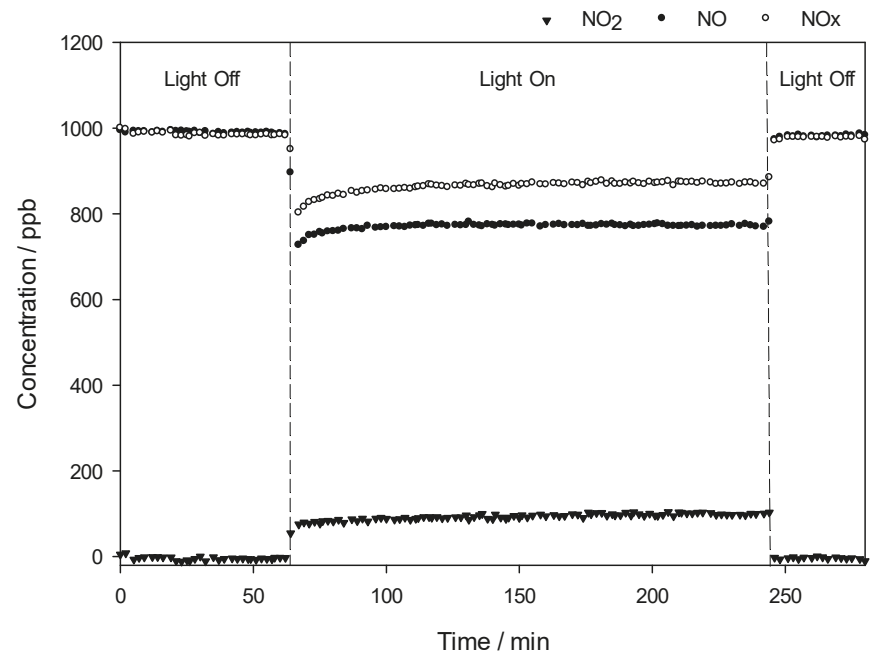

Figure 7. Changes in the concentrations of nitrogen oxides, i.e., $\mathrm{NO}, \mathrm{NO}_{2}$, and $\mathrm{NOx}$, as a function of time in the presence of the QT10 sample.

The activities of the obtained samples for De-NOx remediation were determined by measuring the photonic efficiencies $(\xi)$, which is defined as the ratio of the reaction rate (NO and NOx removal as well as $\mathrm{NO}_{2}$ formation) and the incident photon flux [24]. Equation (1) was used to calculate $\xi$ [25], where 
$\dot{V}$ is the volumetric flow rate, $\mathrm{c}_{\mathrm{d}}$ the concentration of each of the nitrogen oxide gases recorded under dark conditions, $\mathrm{c}_{\mathrm{i}}$ the concentration of the same gases recorded under illumination, $\mathrm{p}$ the pressure, $\mathrm{N}_{\mathrm{A}}$ the Avogadro constant, $\mathrm{h}$ the Plank constant, $\mathrm{c}$ the speed of light, I the incident irradiation intensity, $\lambda$ the employed wavelength assuming monochromatic light $(365 \mathrm{~nm})$, A the irradiated area, $R$ the gas constant, and T the absolute temperature. The obtained results are illustrated in Figure 8a. The results of nitrate selectivity, which was calculated according to Equation (2) employing the obtained $\xi$ NO and $\xi \mathrm{NO}_{2}$, both measured on the same sample, are shown in Figure $8 \mathrm{~b}$.

$$
\begin{gathered}
\xi=\frac{\dot{\mathrm{V}}\left(\mathrm{c}_{\mathrm{d}}-\mathrm{c}_{\mathrm{i}}\right) \mathrm{pN}_{\mathrm{A}} \mathrm{hc}}{\mathrm{I} \lambda \mathrm{ART}} \\
\mathrm{S}=\frac{\xi_{\mathrm{NOx}}}{\xi_{\mathrm{NO}}}
\end{gathered}
$$
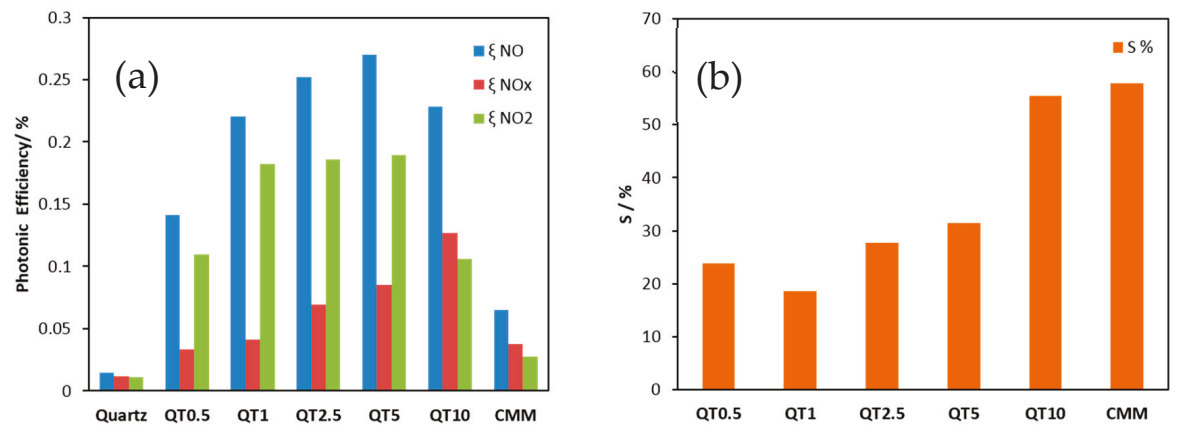

Figure 8. Photonic efficiencies of the aggregate exposed mortars prepared from bare quartz or $\mathrm{TiO}_{2}$-modified quartz for $\mathrm{NO}$ and NOx removal and for $\mathrm{NO}_{2}$ formation (a), and nitrate selectivity recorded for the same samples $(\mathbf{b})$.

As can be seen from Figure 8a, the De-NOx performance $(0.14-0.23 \% \xi \mathrm{NO})$ is clearly enhanced by supporting the photocatalyst on quartz sand when compared to its performance $(0.06 \% \xi \mathrm{NO})$ when mixed with cement $(\mathrm{CMM})$. This means that supporting $\mathrm{TiO}_{2}$ on the quartz surface via a silica gel binder ensures a much higher effective surface area which is translated into higher photocatalytic efficiency. It is worth noting that the herein recorded photonic efficiency for $\mathrm{NO}$ oxidation measured for $\mathrm{TiO}_{2}$ supported on quartz (the QT5 sample for example) is about $58 \%$ of that reported in literature for the highly active bare anatase $\mathrm{TiO}_{2}$ (Hombikat UV100) [25]. Bearing in mind that QT5 had only 2.9\% of the $\mathrm{TiO}_{2}$ loaded, a significantly efficient utilization of the valuable photocatalyst is consequently achieved by supported systems. It is also worth mentioning that although the De-NOx performance improves by increasing the amount of photocatalyst loaded from QT1 to QT5, QT1 might be preferred from an economical viewpoint as this sample showed a $\xi$ NO of more than $80 \%$ of that measured for QT5 although QT1 had ca. five times less $\mathrm{TiO}_{2}$ compared to QT5. On the other hand, nitrate selectivity (Figure $8 \mathrm{~b}$ ) was also enhanced by increasing the amount of photocatalyst loaded but did not exceed that of CMM. The high selectivity is surely a valuable opportunity and improved by a higher loading amount. This observation can be explained by the fact that the porous silica gel coating presents a support for $\mathrm{TiO}_{2}$ both as $\mathrm{TiO}_{2}$ bonded to the silica gel pore walls (which usually negatively affects the selectivity) but also as $\mathrm{TiO}_{2}$ trapped in the pores. This non-bonded $\mathrm{TiO}_{2}$ offers increased activity and selectivity. Factors which control nitrate selectivity appear to be complex. Relevant variables include $\mathrm{TiO}_{2}$ polymorphism, defect state, availability of water, etc., but the role of substrate binding must also be considered. 


\section{Conclusions}

$\mathrm{TiO}_{2}$ has been successfully loaded on the surface of aggregate, with quartz used as an example, utilizing a silicate-based binder. Aggregate exposed mortars with these photocatalytically active aggregates on the surface have shown an excellent performance at the photocatalytic removal of NO from polluted air. The herein developed aggregate exposed mortars have shown up to ca. four times higher efficiency for NO removal compared with the sample prepared according to the conventional mixing method (CMM). Thus, the herein prepared supported $\mathrm{TiO}_{2}$ aggregates offer much greater utilization efficiency for the valuable photocatalyst and thus correspond to a considerably lower cost of use in photocatalytic concrete.

Author Contributions: Conceptualization, A.H. and D.E.M.; methodology, A.H. and L.Y.; validation, A.H., L.Y. and D.E.M.; formal analysis, A.H.; investigation, A.H.; resources, D.E.M. and F.W.; data curation, A.H.; writing — original draft preparation, A.H.; writing—review and editing, D.E.M., A.E. and Y.A.; visualization, A.H., D.E.M. and A.E.; supervision, D.E.M. and F.W.; project administration, D.E.M.; funding acquisition, D.E.M. and F.W.

Funding: This research was funded by the UK Engineering and Physical Sciences Research Council (Grant Ref: EP/M003299/1) and the Natural Science Foundation of China (No. 51461135005) International Joint Research Project (EPSRC-NSFC). The APC was funded by (GORD).

Acknowledgments: The authors gratefully acknowledge funding from the UK Engineering and Physical Sciences Research Council (Grant Ref: EP/M003299/1) and the Natural Science Foundation of China (No. 51461135005) International Joint Research Project (EPSRC-NSFC). L. Zheng and M. R. Jones from the Division of Civil Engineering, University of Dundee, Dundee, UK are gratefully acknowledged for the preparation of the mortars.

Conflicts of Interest: The authors declare no conflict of interest.

\section{References}

1. West, J.J.; Cohen, A.; Dentener, F.; Brunekreef, B.; Zhu, T.; Armstrong, B.; Bell, M.L.; Brauer, M.; Carmichael, G.; Costa, D.L.; et al. What We Breathe Impacts Our Health: Improving Understanding of the Link between Air Pollution and Health. Environ. Sci. Technol. 2016, 50, 4895-4904. [CrossRef] [PubMed]

2. Walton, H.; Dajnak, D.; Beevers, S.; Williams, M.; Watkiss, P.; Hunt, A. Understanding the Health Impacts of Air Pollution in London. King's College London, 15 July 2015.

3. WHO. Ambient (Outdoor) Air Quality and Health; WHO: Geneva, Switzerland, 2014.

4. Abdul-Wahab, S.A.; Chin Fah En, S.; Elkamel, A.; Ahmadi, L.; Yetilmezsoy, K. A review of standards and guidelines set by international bodies for the parameters of indoor air quality. Atmos. Pollut. Res. 2015, 6, 751-757. [CrossRef]

5. Serpone, N. Heterogeneous Photocatalysis and Prospects of $\mathrm{TiO}_{2}$-Based Photocatalytic DeNOxing the Atmospheric Environment. Catalysts 2018, 8, 553. [CrossRef]

6. Engel, A.; Große, J.; Dillert, R.; Bahnemann, D.W. The Influence of Irradiance and Humidity on the Photocatalytic Conversion of Nitrogen(II) Oxide. J. Adv. Oxid. Technol. 2015. [CrossRef]

7. Devahasdin, S.; Fan, C.; Li, K.; Chen, D.H. TiO 2 photocatalytic oxidation of nitric oxide: Transient behavior and reaction kinetics. J. Photochem. Photobiol. A Chem. 2003, 156, 161-170. [CrossRef]

8. Maggos, T.; Bartzis, J.G.; Liakou, M.; Gobin, C. Photocatalytic degradation of NOx gases using $\mathrm{TiO}_{2}$-containing paint: A real scale study. J. Hazard. Mater. 2007, 146, 668-673. [CrossRef] [PubMed]

9. Hüsken, G.; Hunger, M.; Brouwers, H.J.H. Experimental study of photocatalytic concrete products for air purification. Build. Environ. 2009, 44, 2463-2474. [CrossRef]

10. Ballari, M.M.; Brouwers, H.J.H. Full scale demonstration of air-purifying pavement. J. Hazard. Mater. 2013, 254-255, 406-414. [CrossRef] [PubMed]

11. Cassar, L. Photocatalysis of cementitious materials: Clean buildings and clean air. MRS Bull. 2004. [CrossRef]

12. Folli, A.; Pochard, I.; Nonat, A.; Jakobsen, U.H.; Shepherd, A.M.; Macphee, D.E. Engineering photocatalytic Cements: Understanding $\mathrm{TiO}_{2}$ surface chemistry to control and modulate photocatalytic performances. J. Am. Ceram. Soc. 2010, 939, 3360-3369. [CrossRef]

13. MacPhee, D.E.; Folli, A. Photocatalytic concretes-The interface between photocatalysis and cement chemistry. Cem. Concr. Res. 2016, 85, 48-54. [CrossRef] 
14. Folli, A.; Pade, C.; Hansen, T.B.; De Marco, T.; MacPhee, D.E. $\mathrm{TiO}_{2}$ photocatalysis in cementitious systems: Insights into self-cleaning and depollution chemistry. Cem. Concr. Res. 2012, 42, 539-548. [CrossRef]

15. Zhang, R.; Cheng, X.; Hou, P.; Ye, Z. Influences of nano- $-\mathrm{TiO}_{2}$ on the properties of cement-based materials: Hydration and drying shrinkage. Constr. Build. Mater. 2015, 81, 35-41. [CrossRef]

16. Yang, L.; Wang, F.; Hakki, A.; Macphee, D.E.; Liu, P.; Hu, S. The influence of zeolites fly ash bead $/ \mathrm{TiO}_{2}$ composite material surface morphologies on their adsorption and photocatalytic performance. Appl. Surf. Sci. 2017, 392, 687-696. [CrossRef]

17. Hakki, A.; Yang, L.; Wang, F; Macphee, D.E. The Effect of Interfacial Chemical Bonding in $\mathrm{TiO}_{2}$ Composites on Their Photocatalytic NOx Abatement Performance. J. Vis. Exp. 2017, 4. [CrossRef]

18. Yang, L.; Hakki, A.; Wang, F.; Macphee, D.E. Different Roles of Water in Photocatalytic DeNOx Mechanisms on $\mathrm{TiO}_{2}$ : Basis for Engineering Nitrate Selectivity? ACS Appl. Mater. Interfaces 2017, 9, 17034-17041. [CrossRef]

19. Fateh, R.; Dillert, R.; Bahnemann, D. Preparation and characterization of transparent hydrophilic photocatalytic $\mathrm{TiO}_{2} / \mathrm{SiO}_{2}$ thin films on polycarbonate. Langmuir 2013, 29, 3730-3739. [CrossRef]

20. Hanus, M.J.; Harris, A.T. Nanotechnology innovations for the construction industry. Prog. Mater. Sci. 2013, 58, 1056-1102. [CrossRef]

21. Lucas, S.S.; Ferreira, V.M.; De Aguiar, J.L.B. Incorporation of titanium dioxide nanoparticles in mortars-Influence of microstructure in the hardened state properties and photocatalytic activity. Cem. Concr. Res. 2013, 43, 112-120. [CrossRef]

22. Ballari, M.M.; Hunger, M.; Hüsken, G.; Brouwers, H.J.H. NOx photocatalytic degradation employing concrete pavement containing titanium dioxide. Appl. Catal. B Environ. 2010, 95, 245-254. [CrossRef]

23. ISO. ISO 22197-1: Fine Ceramics (Advanced Ceramics, Advanced Technical Ceramics)—Test Method for air-purification Performance of Semiconducting Photocatalytic Materials_Part 1: Removal of Nitric Oxide; ISO: Geneva, Switzerland, 2007.

24. Kisch, H.; Bahnemann, D. Best Practice in Photocatalysis: Comparing Rates or Apparent Quantum Yields? J. Phys. Chem. Lett. 2015, 6, 1907-1910. [CrossRef] [PubMed]

25. Freitag, J.; Domínguez, A.; Niehaus, T.A.; Hülsewig, A.; Dillert, R.; Frauenheim, T.; Bahnemann, D.W. Nitrogen(II) oxide charge transfer complexes on $\mathrm{TiO}_{2}$ : A new source for visible-light activity. J. Phys. Chem. C 2015, 119, 4488-4501. [CrossRef] 
Article

\title{
Industrial Data-Based Life Cycle Assessment of Architecturally Integrated Glass-Glass Photovoltaics
}

\author{
Jeeyoung Park ${ }^{1,+(\mathbb{D})}$, Dirk Hengevoss ${ }^{2,+}$ and Stephen Wittkopf ${ }^{1, *(B)}$ \\ 1 School of Engineering and Architecture, Lucerne University of Applied Sciences and Arts, \\ Technikumstrasse 21, CH-6048 Horw, Switzerland; jeeyoung.park@hslu.ch \\ 2 Institute for Ecopreneurship, School for Life Sciences, University of Applied Sciences Northwestern \\ Switzerland, Hofackerstrasse 30, 4132 Muttenz, Switzerland; dirk.hengevoss@fhnw.ch \\ * Correspondence: stephen.wittkopf@hslu.ch; Tel.: +41-41-349-3625 \\ + These authors contributed equally to this work.
}

Received: 20 November 2018; Accepted: 24 December 2018; Published: 29 December 2018

check for updates

\begin{abstract}
Worldwide, an increasing number of new buildings have photovoltaics (PV) integrated in the building envelope. In Switzerland, the use of coloured PV façades has become popular due to improved visual acceptance. At the same time, life cycle assessment of buildings becomes increasingly important. While a life cycle inventory for conventional glass-film PV laminates is available, this is not the case for glass-glass laminates, and in particular, coloured front glasses. Only conventional glass-film PV laminates are considered in databases, some of which are partly outdated. Our paper addresses this disparity, by presenting life cycle inventory data gathered from industries producing coloured front glass by digital ceramic printing and manufacturing glass-glass PV laminates. In addition, we applied this data to a hypothetical façade made of multi-coloured glass-glass laminates and its electricity generation in terms of Swiss eco-points, global warming potential, and cumulative energy demand as impact indicators. The results of the latter show that the effect of the digital ceramic printing is negligible (increase of $0.1 \%$ ), but the additional glass ( $4 \%$ increase) and reduction of electricity yield (20\%) are significant in eco-points. The energy pay-back time for a multi-coloured PV façade is 8.1 years, which decreases by $35 \%$ to 5.3 years when replacing the glass rain cladding in an existing façade, leaving 25 years for surplus electricity generation.
\end{abstract}

Keywords: coloured glass; life cycle assessment; building integrated photovoltaic; rain cladding; LCA; LCI; BIPV

\section{Introduction}

\subsection{Building Integrated Photovoltaics}

Photovoltaics (PV) offer great opportunities in densely populated regions such as Switzerland, particularly when installed on the surfaces of buildings. This is primarily due to their ability to generate electricity without noise emissions, and deployment in a large range of sizes and forms. Ground mounted photovoltaics are impractical due to the scarcity and consequently high cost of land in Switzerland. However, the Swiss energy strategy 2050 aims to increase the national electricity supply from PVs from about $2 \%$ in 2016 [1] up to $20 \%$ by 2050 . Global warming (climate change) is a critical issue drawing wordwide attention, and Switzerland should reduce green house gas emission by $20 \%$ in comparison to their 1990 level by 2020 according to Swiss law (the $\mathrm{CO}_{2}$ Act). In addition, nuclear power, which is $\mathrm{CO}_{2}$-free and generates about $40 \%$ of Swiss electricity, will phase out [2].

Building integrated photovoltaics (BIPV) contribute to achieving this goal by fully utilising building surfaces, such as the roof or façade, to maximise electricity generation. This goal is difficult 
to achieve with monochromatic BIPV, as they compromise the architectural aesthetic of the building, leading to low visual acceptance on behalf of the architect or the building's owner. Various types of technologies for aesthetically appealing PV systems in buildings have recently been developed, such as thin films or special foils [3]. Such systems are referred to as architecturally integrated. However, the conservative nature of the construction sector, as well as vague or even conflicting building regulations regarding façade elements have thus far delayed the application of these technologies [4].

Multi-coloured glass-glass (MCGG) and crystalline silicon cell (c-Si) PV laminates are an approach to overcome some of these aforementioned issues and achieve aesthetically pleasing, yet technically and economically viable building integrated PV systems, by utilising market-proven technologies which also retain high market potential in the future. This solution combines translucent digital ceramic print technology [5-7] with existing mainstream technologies, notably crystalline silicon cells and glass-glass sheets (see Figure 1).

123456

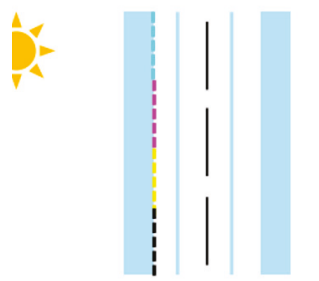

1. Glass

2. Color prints

3. EVA foil

4. Crystalline silicon cells

5. EVA foil

6. Glass

Figure 1. Layers comprising a multi-coloured glass-glass photovoltaic laminate. A translucent multi-coloured motif (layer 2) is printed on the inner surface of the front glass sheet [3].

C-Si is the mainstream technology in commercial PV markets accounting for $94 \%$ of the market share, while thin film accounts for $6 \%$ [8]. Despite the emergence of many new technologies, the former is most likely to remain dominant for next decade, driving substantial market growth by ongoing cost reduction and improvement in efficiency [9].

The most common configuration of PV laminates for grid connected systems comprises 60 cells, which are typically arranged as a 6 by 10 matrix, occupying an area of approximately $1.00 \times 1.615 \mathrm{~m}^{2}$. The cells are wired in series, thus metallic tab wires attached to a front side of a cell are connected to the backside of a neighbouring cell. This interconnecting wiring technology is subject to ongoing improvements in cell efficiency, with a triple busbar arrangement currently dominating the market [10]. Deployed without a frame, this system is referred to as a photovoltaic laminate, while an additional surrounding frame designates it as a photovoltaic panel. A junction box and two ca. $1 \mathrm{~m}$ cables are attached to the laminate or the panel for connection to adjacent units.

Interconnected cells are brittle and easily corroded by moisture. To protect against impact and moisture from hail and rain in outdoor environments, the solar cell strings are encapsulated by two sheets of polymer foils (e.g., Ethylene-vinyl acetate, or EVA), which are in turn encapsulated by two sheets of glass. Finally, these layers are laminated under heat and pressure in a vacuum to form a PV laminate. For a non-BIPV solution, a Tedlar ${ }^{\circledR}$ polymer film is also commonly used instead of a glass back-sheet. However, a BIPV laminate should resist fire hazards and wind loads to comply with architectural regulations on a building façade. Glass sheets are a typical solution to achieve this, as glass is a commonly used façade component under the established building codes. Moreover, even for a non-BIPV solution, glass back-sheets are increasingly popular as they prevent moisture intrusion.

MCGG PV laminates can readily replace façade panels in a rainscreen wall. A rainscreen wall system [11] prevents penetration of rainwater into a building wall and is widely used since the 1970s (see Figure 2). It consists of a rainscreen cladding, ventilated and drained air cavity, and an air barrier system from the outermost layer of a building. Common materials for rainscreen cladding include 
fibre cement, metal, and timber, which are selected based on various criteria. Glass is frequently chosen when an aesthetically pleasing façade finish is preferred. The multi-coloured glass-glass PV laminates have the potential to satisfy this aesthetic criterion and be accepted as rainscreen cladding, making them economically and environmentally beneficial as the existing rainscreen mounting system can accommodate the PV (see Figure 2b).

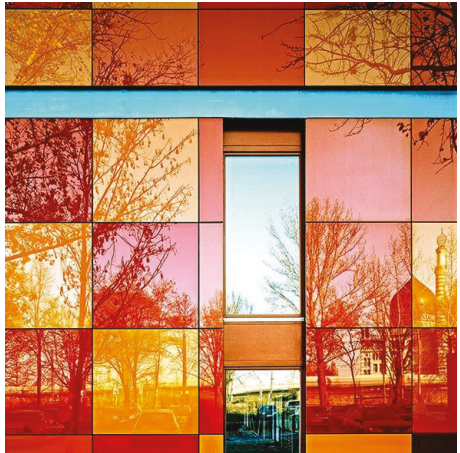

(a)

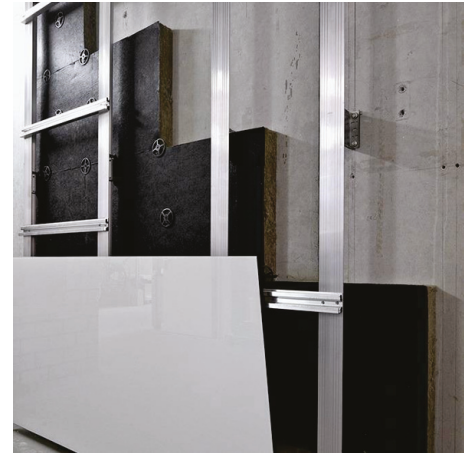

(b)

Figure 2. Rainscreen wall system: Glass cladding installed on the outside of a building (a) and a rainscreen cladding sub-construction $(\mathbf{b})[12]$.

\subsection{Life Cycle Assessment}

Environmental Life cycle Assessment (LCA) is a methodology to assess all the environmental impacts of a product or a service during the whole life cycle from the raw material extraction to final disposal [13]. Alternative products have different eco-profiles over their lifetime; one product's environmental impact contributes mainly to its production phase, while another's dominates during its use or operating phase. A classical example are disposable diapers, which create 90 times more solid waste than reusable cloth diapers. The latter, however, produce tenfold water pollution due to detergents etc., and consume triple the energy [14]. LCA does not provide a simple answer, but it enables rational judgements with trade offs. For this reason, LCA is becoming an increasingly important and popular tool in policy and industry [13].

The International Organisation for Standardisation (ISO) standardised an LCA methodological framework and terminology (ISO 14040:2006) [15] and provided general guidelines and requirements (ISO 14044:2006) [16]. According to ISO, the LCA procedure consists of the following steps:

1. Goal and scope: Definition of the System boundary \& functional unit.

2. Life Cycle Inventory (LCI): Elaboration of a mass balance for a process with all inputs and outputs.

3. Life Cycle Impact Assessment (LCIA): Assessment of environmental consequences of the LCI such as climate change, natural resource depletion, ozone depletion, ecotoxicity etc. with specific indicators. A sensitivity analysis considers the individual effects of the choices made, i.e., flows and indicators.

4. Interpretation: Identification of processes and flows with main environmental impact and recommendation of measures for improvement.

BIPV affects the heating and cooling load in buildings, as it generates heat as well as electricity and replaces building elements which may have a different thermal resistance [17]. The current reviews covering the state-of-the-art of LCA on BIPV assess the influence of BIPV on the energy performance of buildings $[18,19]$. Adaptive BIPV deployed on windows provides shading and admits daylight, while also reducing the energy consumption for lighting, heating, and cooling [20]. These energy reduction factors can be considered in two ways: 
1. Place the factors into a system boundary. For example, Jayathissa [20] estimated the energy load (heating, cooling, and lighting energy) in an office with windows fitted with dynamic BIPV, static shading, and no shading at all. The study compares the environmental impact of the German grid electricity to that generated by different BIPV technologies (thin film and crystalline), and the resulting reduction in energy loads. These results are further discussed in the context of this study in Section 3.5.

2. Alternatively, these factors can be excluded from a system boundary along with building materials serving a similar purpose, (e.g., when replaced by BIPV in a façade). For example, Ng [21] estimated the lifetime performance of semi-transparent BIPV glazing when it replaces double glazing windows, which similarly impacts building energy performance.

In this study, the latter approach was adopted by replacing the rainscreen cladding in a façade with BIPV. This better caters to the focus on electricity generation within the scope of the study, the purpose of which is explained in the following section.

\subsection{Purpose of the Study}

Glass is a commonly used material in both photovoltaic and building industries, and its proportional weight in a glass-glass PV laminate is over $90 \%$. Moreover, glass-glass c-Si PV laminates are the de facto standard for a building integrated solution. However, its environmental impact assessment (LCA) is not available, thus the resulting approximated environmental impact based on life cycle inventory databases may not reflect reality.

To realistically assess the environmental impact of the entire life cycle of a MCGG c-Si PV laminate, this study presents up-to-date data on c-Si production gathered from literature, as well as material and energy flow data from a solar glass and PV laminate supplier. Moreover, a façade case study considers a realistic BIPV use case, in which the PV laminate replaces the rainscreen cladding.

Unlike ground mounted photovoltaics, building integrated photovoltaic systems need to satisfy multiple goals, i.e., aesthetic appeal, fail-safe installation and operation, and electricity generation with lower environmental impact than that of the existing Swiss low-voltage grid. As a consequence, multiple parties contribute towards achieving these goals, including the glass and photovoltaic manufacturer, architect, building owner, planner, and installer. These goals need to be achieved collectively as each party has only a limited scope of influence, thus the relevant information must be consolidated. However, existing PV life cycle inventory data and assessment results are aggregated and averaged, thus individual data relevant to the building context cannot be often identified.

The purpose of this study is therefore to provide life cycle perspectives of BIPV in general, and glass-glass crystalline silicon cell photovoltaics in particular, by presenting life cycle inventory data and the assessment results in an itemised and organised manner, such that they are relevant and comprehensible to the involved parties. Furthermore, the influence of façade components on the environmental impact of BIPV are analysed, as well as the additional benefits of BIPV for a building. In the long term, these results support the parties in making future decisions in their respective areas of influence.

The rest of the paper is organised as follows: In Section 2, we elaborate our LCA methodology of a PV façade, and the impact indicators used; Section 3 presents results obtained from the LCA of the façade components, and the electricity generated in terms of energy pay-back time; in Section 4, we draw our conclusions. A glossary of abbreviated terminology used in this paper can be found in Table 1. 
Table 1. Abbreviations and terminology used in this paper.

\begin{tabular}{cc}
\hline Term & Definition \\
\hline AC & Alternate current \\
BIPV & Building integrated photovoltaics \\
BOS & Balance of system \\
CED & Cumulative energy demand \\
c-Si & Crystalline silicon cell \\
EPBT & Energy pay-back time \\
EVA & Ethylene-vinyl acetate \\
GWP & Global warming potential \\
ISO & International Organization for Standardisation \\
IPCC & Intergovernmental Panel of Climate Change \\
LCA & Life cycle assessment \\
LCI & Life cycle inventory \\
MCGG & Multi coloured glass-glass \\
m-Si & Multi crystalline silicon cell \\
PV & Photovoltaics \\
s-Si & Single crystalline silicon cell \\
\hline
\end{tabular}

\section{Methodology}

The following section specifies the PV laminate and façade installation used in this study. In accordance with the sequence of the four LCA phases in Section 1.2, the goal and scope definition, inventory analysis, and impact indicators used in this study are presented. The impact assessment and interpretations is presented as results in Section 3.

\subsection{PV Laminate Specifications for Life Cycle Assessment}

Table 2 lists detailed specifications of a PV laminate used in this study, which is representative of one of the most common configurations in the market. The basic configuration of a laminate consists of multi-crystalline silicone (m-Si) cells and a multi-coloured front glass sheet. Common variants on the market replace the multi-coloured front glass sheet with a clear glass sheet, and m-Si by s-Si.

Table 2. Typical specifications of a photovoltaic laminate considered in this study.

\begin{tabular}{ccc}
\hline Parameter & Basic Configuration & Variants \\
\hline Dimension of PV laminate & $1.00 \mathrm{~m} \times 1.615 \mathrm{~m}$ & \\
Weight of PV laminate & $35.47 \mathrm{~kg}$ & \\
Glass thickness & $4 \mathrm{~mm} \times 2=8 \mathrm{~mm}$ & \\
Glass weight & $16.15 \mathrm{~kg} \times 2=32.3 \mathrm{~kg}$ & clear glass \\
Glass type & multi-coloured $(80 \%$ performance $)$ & 60 s-Si cells $(250 \mathrm{Wp})$ \\
Type of cells & $60 \mathrm{~m}$-Si cells $(220 \mathrm{Wp})$ & \\
Thickness of cell & $0.2 \mathrm{~mm}$ & 36 active(smart) wirings [10] \\
\hline
\end{tabular}

To consider the entire life cycle of a photovoltaic laminate, the study considers a hypothetical façade installation consisting of 140 laminates (see Table 3 ). The system capacity using the m-Si clear glass PV laminates $(250 \mathrm{Wp})$ is $30.8 \mathrm{kWp}$. When using multi-coloured glass sheets, electricity production decreases by $20 \%$, reducing the capacity to $24.6 \mathrm{kWp}$. The system with clear glass s-Si $\mathrm{PV}$ laminates has $35 \mathrm{kWp}$ capacity. The annual electricity yield expressed in $\mathrm{kWh} / \mathrm{kWp}$ for each orientation is measured in Dübendorf, Switzerland, after the inverter and before being fed into the grid; this takes into account losses due to AC conversion, while transmission losses in the grid are disregarded. The calculation of electricity production assumes a projected PV lifetime of 30 years. To consider various degradation modes such as discolouration and corrosion [22], the annual yield is linearly derated by $0.69 \%$ as recommended by IEA PVPS [23]. 
Table 3. Façade installation considered in this study as use case for photovoltaic (PV) laminates.

\begin{tabular}{|c|c|c|}
\hline Parameter & Basic Configuration & Variants \\
\hline PV type & $\begin{array}{l}\text { m-Si ( } 15 \% \text { efficiency) } \\
\text { multi-coloured }\end{array}$ & s-Si (17\% efficiency) \\
\hline $\begin{array}{l}\text { Laminate capacity } \\
\text { (System capacity) }\end{array}$ & $176 \mathrm{Wp}(24.6 \mathrm{kWp})$ & $\begin{array}{l}\text { m-Si clear glass: } 220 \mathrm{Wp}(30.8 \mathrm{kWP}) \\
\mathrm{s}-\mathrm{Si} \text { clear glass } 250 \mathrm{Wp}(35 \mathrm{kWp}) \\
\text { s-Si coloured glass } 200 \mathrm{Wp}(28 \mathrm{kWP})\end{array}$ \\
\hline Number of laminates & 140 & \\
\hline Laminates used over lifetime & $\begin{array}{l}144.23 \text { ( } 1 \% \text { rejected in construction } \\
\text { of façade, } 2 \% \text { replaced due to early } \\
\text { end of life) }\end{array}$ & \\
\hline Façade dimension & $21 \mathrm{~m} \times 12 \mathrm{~m}=252 \mathrm{~m}^{2}$ & \\
\hline Projected lifetime & 30 years & \\
\hline $\begin{array}{l}\text { Annual yield } / \mathrm{kWp} \text { installed } \\
\text { before degradation according } \\
\text { to façade orientation }\end{array}$ & $\begin{array}{l}\text { Facing south: } 700 \mathrm{kWh} / \mathrm{kWp} \\
\text { Facing east/west: } 530 \mathrm{kWh} / \mathrm{kWp} \\
\text { Facing north: } 200 \mathrm{kWh} / \mathrm{kWp}\end{array}$ & \\
\hline Degradation of PV & $\begin{array}{l}0.69 \% \text { per year from the first year, } \\
\text { total } 20 \% \text { for } 30 \text { years }\end{array}$ & \\
\hline $\begin{array}{l}\text { Lifetime yield according to } \\
\text { façade orientation }\end{array}$ & $\begin{array}{l}\text { Facing south: } 582 \mathrm{MWh} \\
\text { Facing east/west: } 440 \mathrm{MWh} \\
\text { Facing north: } 166 \mathrm{MWh}\end{array}$ & \\
\hline
\end{tabular}

\subsection{Goal and Scope of Life Cycle Assessment}

In accordance with the purpose of the study stated in Section 1.3, the scope of the LCA covers:

- up-to-date crystalline silicon cell production

- clear and multi-coloured glass production by a specific manufacturer

- glass-glass laminate production with various configurations by a specific manufacturer

- a hypothetical but realistic PV façade installation

- electricity generated from the façade facing south, east/west, and north

- and a comparison of the generated electricity to that of the Swiss low voltage electricity grid.

Figure 3 presents functional units of each product along the supply chain of the BIPV system, leading to the generated electricity as final product. The laminate is assessed by applying the "cradle to gate" approach. The system boundary includes the material and energy flows of the upstream processes for the laminate. Nevertheless take back and recycling of a laminate is already included. The electricity is assessed by applying the "cradle to cradle" approach. The system boundary includes all processes for laminate production, including production of the Balance of System (BOS) [24], such as mounting system, cabling, and an inverter. Furthermore, this considers the transportation, installation, cleaning, and maintenance of the PV installation, and its end of life. To obtain the environmental impact per $1 \mathrm{kWh}$ electricity generated using the model in this study, the total environmental impact of the façade (including water and waste water from cleaning) is simply divided by the total electricity generated during its lifetime. 


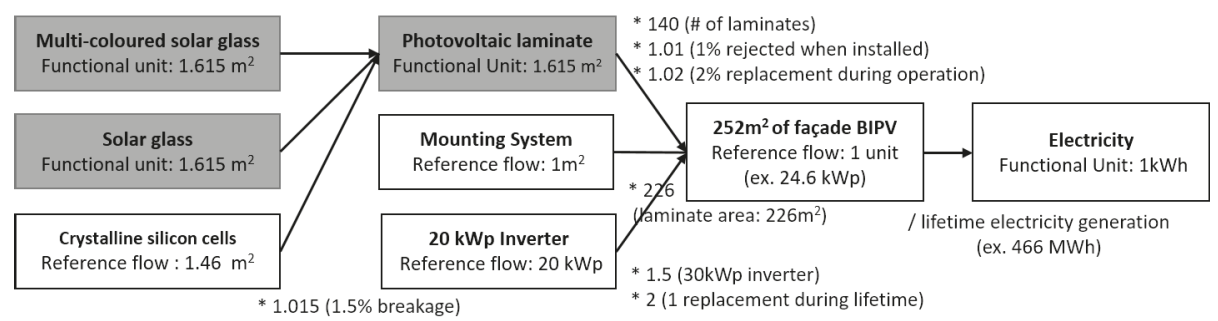

Figure 3. Configuration of an architecturally integrated $24.6 \mathrm{kWp}$ photovoltaic (PV) façade facing south consisting of 140 multi coloured glass-glass (MCGG) laminates generating 466 MWh over 30 years. While a $30 \mathrm{kWp}$ inverter is installed, its data is derived from that of a $20 \mathrm{kWp}$ inverter scaled by a factor of 1.5. Product systems with grey background were specified from industrial data, while those with white background were derived from literature values and estimates.

\subsection{Life Cycle Inventory}

A main challenge in LCA is the collection of data for the Life Cycle Inventory (LCI). This can be mitigated by using the Ecoinvent database [25], which contains basic data on materials, energy, waste, transportation, and other factors. This data is collected from averages of material and energy flows provided by industrial sectors, expert estimates, and literature values. This study uses the APOS [26] data set, which is one of the three sets of data available in Ecoinvent 3.4. The calculations were performed in software mainly using Simapro 6.4, supplemented by MS Excel.

Ecoinvent data is updated frequently, but a literature review has shown that updated LCI data on the requisite photovoltaic components for this study are not yet integrated in the latest Ecoinvent version 3.4. Thus, this study carried out an LCI for system components based on recent literature and current industry data, which are stated in the sections below.

\subsubsection{LCI of Crystalline Silicon Cells}

The LCI for m-Si and s-Si cells in Ecoinvent 3.4 were updated with an LCA of photovoltaics dated 2011 [27] (Part 1: Data Collection, Table 37). A main difference compared to the LCI in Ecoinvent 3.4 is the an increase in electricity consumption for the m-Si wafer process from $4.7 \mathrm{kWh}$ to $20.8 \mathrm{kWh}$. For further differences, see the cited reference.

\subsubsection{LCI of Solar Glass}

Solar glass is made from float glass, i.e., floated on molten tin to obtain a flat and polished surface [28]. The LCI for float glass in Ecoinvent 3.4 was itemised with material flow data from two European float glass manufacturers [29,30].

The energy consumption for the final solar glass production was obtained from the Swiss manufacturer (personal communication P. Schaad, Glas Trösch AG, 25.05.2018). The resulting material and energy flows for the processes to produce $1.615 \mathrm{~m}^{2}$ of clear and multi-coloured solar glass sheets are shown in Figure 4 and Table S1 (supplementary material). The company produces multiple glass types of different sizes, which run through different process steps. Consequently, the production is not optimised for solar glass. This implies higher energy stand-by losses in continuous production flows as well as material losses. Energy flows (electricity and compressed air) are expressed in kWh, while those for the material are expressed in $\mathrm{kg}$. The thickness of an arrow corresponds to the quantity of material flow.

The production of clear solar glass requires four main processes: Cutting the raw material (i.e., float glass) to the desired size; bevelling (grinding the edges); washing off grinding sludge and drying; and finally tempering to increase the strength of the solar glass. Losses and breakages from the raw glass at cutting are about $20 \%$. The cullet is recycled directly in float glass production, which 
reduces the quantity of the primary raw material. Breakages at tempering and quenching of the solar glass are about $5 \%$. To produce $32.30 \mathrm{~kg}$ of two final glass sheets, $43.24 \mathrm{~kg}$ of raw float glass are consumed. Coloured solar glass needs two additional passes before tempering: A second washing and drying step immediately following the first (on the same washing machine), and digital printing with ceramic ink on the clear glass, followed by tempering. The total electricity consumption in production adds up to $19 \mathrm{kWh}$.

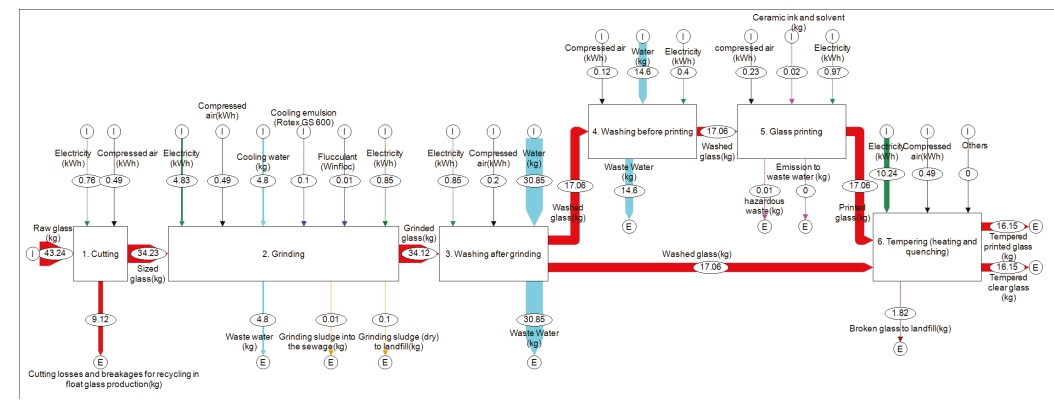

Figure 4. Material $(\mathrm{kg})$ and energy $(\mathrm{kWh})$ flows to produce $1.615 \mathrm{~m}^{2}$ of a multi-coloured and a clear solar glass sheet with $4 \mathrm{~mm}$ thickness at a Swiss glass supplier. Arrowheads labelled $I$ denote import flow, indicating an input material or energy, while those labelled $E$ denote export flow, indicating a product, waste, or loss. The data was derived from the material and energy balance as well as the measured electricity consumption of the production steps and support processes. These were obtained from the Swiss glass manufacturer (courtesy of Glas Trösch AG, 2017).

\subsubsection{LCI of PV Laminate}

The front and back glass are transported from the Swiss glass manufacturer to a PV laminate manufacturer in Germany. The production the glass-glass PV laminate (Figure 5) requires four main processes: Cleaning the glasses in a washing machine (closed water cycle); cutting the EVA foil; brazing crystalline silicon cell strings (by an external supplier) and connecting tap wires; laminating under pressure and heat; cutting EVA leftovers; and final mounting and test. 


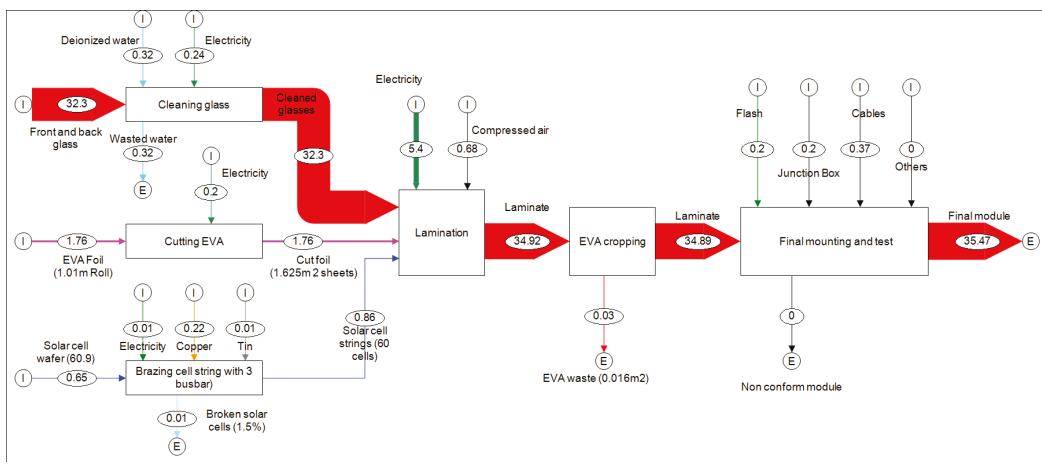

Figure 5. Material $(\mathrm{kg})$ and energy $(\mathrm{kWh})$ flows to produce $1.615 \mathrm{~m}^{2}$ of a multi-coloured glass-glass PV laminate with 60 crystalline silicon cells, a junction box, and connecting cable. Arrowheads labelled $I$ denote and import flow, indicating an input material or energy, while those labelled $E$ denote an export flow, indicating a waste or loss. Data was derived from literature [27] and updated with material balance data and measured electricity consumption of the production steps and supporting processes provided by a German PV module manufacturer (courtesy of GES Gebäude- und Energiesysteme $\mathrm{GmbH}, 2018)$.

The total electricity consumption in production adds up to $6.05 \mathrm{kWh}$. When using crystalline silicone cells with active wires instead of 3 busbars, the total amount of copper in the PV laminate increases from $219 \mathrm{~g}$ to $229 \mathrm{~g}$ by $4 \%$.

\subsubsection{LCI of Further Processes and Components}

The data sources for the LCI of other processes and components considered in the LCA are listed in Table 4.

Table 4. Data sources for the elaboration of the life cycle inventory (LCI) for other processes and components.

\begin{tabular}{ll}
\hline Processes and Components & Remark, Source/Reference \\
\hline $30 \mathrm{kWp}$ inverter & LCA of low power solar inverters (2.5 to 20 kW) [31] \\
\hline Mounting and electric system & Ecoinvent 3.4 [25] \\
\hline Installation & Transportation and electricity for mounting, Ecoinvent 3.4 \\
\hline Cleaning and maintenance & Water consumption and waste water treatment, Ecoinvent 3.4 \\
\hline $\begin{array}{l}\text { Take-back \& recycling of laminate } \\
\text { with one glass sheet }\end{array}$ & $\begin{array}{l}\text { Energy consumption for shredding was adapted to the higher glass } \\
\text { quantity in a glass-glass laminate. It is assumed the quality of the } \\
\text { glass cullet is too low for recycling in float glass production [32]. }\end{array}$ \\
\hline
\end{tabular}

\subsection{Life Cycle Impact Indicators Selected for This Study}

Impact categories and indicators commonly used in LCA of photovoltaic system are presented in [23] (Table 3.2). For this study, the five indicators in Table 5 were selected. 
Table 5. Indicators selected for the life cycle impact assessment (LCIA) in this study.

\begin{tabular}{lll}
\hline Name & Unit & Remark \\
\hline $\begin{array}{l}\text { Global warming potential } \\
\text { (GWP) }\end{array}$ & Grams $\mathrm{CO}_{2}$-equivalents $\left[\mathrm{g} \mathrm{CO}_{2}\right.$ eq] & $\begin{array}{l}\text { Contains Intergovernmental Panel of Climate } \\
\text { Change (IPCC) climate change factors for a } \\
\text { timespan of 100 years [33] }\end{array}$ \\
\hline $\begin{array}{l}\text { Cumulative energy demand } \\
\text { (CED) }\end{array}$ & MJ-equivalents [MJ eq] & $\begin{array}{l}\text { Contains the energy content of renewable and } \\
\text { non-renewable primary energy [23]. In this study, } \\
\text { only non-renewable primary energy is considered. }\end{array}$ \\
\hline Ecological Scarcity 2013 & Eco-points [EP] & $\begin{array}{l}\text { Eco-points reflect both the actual emission situation } \\
\text { and the national or international emission targets } \\
\text { pursued by Switzerland [34]. }\end{array}$ \\
\hline $\begin{array}{l}\text { Energy Payback Time } \\
\text { (EBPT) }\end{array}$ & Years & $\begin{array}{l}\text { Time required to generated enough electricity, so } \\
\text { that Non-renewable CED/kWh becomes the same } \\
\text { as one of the reference electricity [23]. Refers to } \\
\text { the efficiency of the Swiss low voltage electricity } \\
\text { grid at the consumer end (9.43 MJ/kWh acc. to } \\
\text { Ecoinvent 3.4) }\end{array}$ \\
\hline
\end{tabular}

In this study, the LCIA of solar glass, photovoltaic laminate, and façade system mainly use the ecological scarcity as indicator (expressed in eco-points), while the electricity generated by the PV façade is assessed with CED and EPBT, which are commonly used indicators to compare energy generation systems, along with GWP.

\section{Results}

This chapter presents the results of the Life Cycle Impact Assessment (LCIA) according to the sequence of the supply chain described in Figure 3. First, the environmental impact of the production of the front and back glass for a PV laminate is presented in terms of eco-points. Subsequently, the eco-points of the production of PV cells and laminates and of an architecturally integrated PV façade installation are detailed. Finally, the EBPT of the system will be presented along with the eco-points and GWP of $1 \mathrm{kWh}$ of generated electricity at different façade orientations compared to the current impact of the Swiss low voltage electricity grid.

\subsection{Production of Multi-Coloured and Clear Glass}

Figure 6 shows the eco-points of a multi-coloured front glass sheet $\left(1.615 \mathrm{~m}^{2}\right)$ by components and processes, which adds up to a total of $34.2 \mathrm{kPt}$. The eco-point of an unprinted back sheet adds up to $33.2 \mathrm{kPt}$. Consequently, the total eco-points (Figures S1 and S2) for the front and back glass of a PV laminate is $67.4 \mathrm{kPt}$. The eco-points for the clear solar glass $(33.2 \mathrm{kPt}$ ) in this study are $47 \%$ higher than those from Ecoinvent $(22.6 \mathrm{kPt})$. This is because the reference data for float glass used in this study [29] has different input materials from that of Ecoinvent. As mentioned in Section 2.3.2, this is further attributed to the high glass losses and breakages in cutting and tempering. 


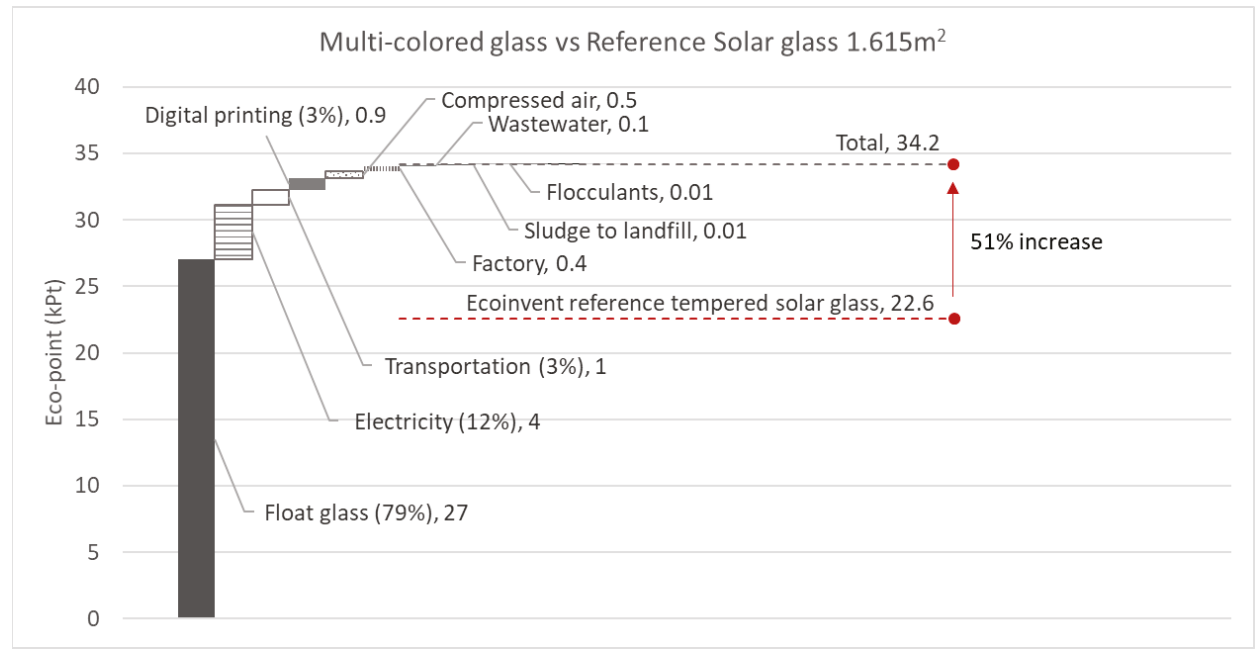

Figure 6. Per-process and component breakdown of eco-points for $1.615 \mathrm{~m}^{2}$ of multi-coloured glass for a PV laminate modelled in this study. The total $(34.2 \mathrm{kPt})$ is $51 \%$ higher than that of tempered solar glass $(22.6 \mathrm{kPt})$ in Ecoinvent. The printing step to obtain the multi-coloured glass only contributes $3 \%$ to the total impact.

The raw float glass input incurs a major contribution (79\%) to the total eco-points of the multi-coloured glass sheet production. This is attributed to the energy and $\mathrm{CO}_{2}$ intensive, which has a strong weighing in eco-points, float glass production process and the losses and breakages in the solar glass production. The electricity and digital printing account for only $12 \%$ and $3 \%$, respectively. The European electricity mix contributes to not just GWP and eco-points but also the category nuclear waste.

\subsection{Production of Crystalline Silicon Cells}

The LCIA results for the production of the $60 \mathrm{~m}$-Si and s-Si cells for a PV-laminate $\left(1.615 \mathrm{~m}^{2}\right)$ using the latest published data (see Section 2.3.1) that deviate from those in Ecoinvent 3.4 for the same cell types. The eco-points for the m-Si cells increase by $22 \%$ from 311 to $380 \mathrm{kPt}$, while those for s-Si cells are reduced by $5 \%$ from 524 to $496 \mathrm{kPt}$.

\subsection{Production of $P V$ Laminate}

The front and back glass from the Swiss glass manufacturer are transported by road to the German PV laminate manufacturer. The crystalline silicon cells, EVA foil for lamination and the electric components (bus wire, tap wires, junction box and the connecting cable), as well as packaging material, are purchased on the international market. When smart wires [10] are used instead of triple busbars as wiring technology for the c-Si cells, the total amount of copper in the PV laminate increases by $4 \%$, which has a negligible effect on its total eco-points.

Figure 7 shows the eco-points for three different types of PV laminate. In the production of an MCGG m-Si PV laminate (Figure S3), the multi-coloured front and clear back glass accounts only 15\% of the total eco-points $(460 \mathrm{kPt}$ ). For s-Si MCGG PV, the glass contributes 10\% to the total eco-points $(673 \mathrm{kPt})$. The impact of printing is negligible. By contrast, the impact of the PV cells is significant; PV glass laminates using s-Si cells have a $46 \%$ higher impact in eco-points compared to laminates with $\mathrm{m}$-Si cells, while the electric components contribute $7 \%$ and $10 \%$, respectively. The impact of these components stems from the copper. The reference (m-Si glass-foil PV laminate) has lower eco-points 
than an m-Si glass-glass PV laminate due to the lower contribution from the backsheet foil compared to the glass sheet. The proportion of eco-points for take-back and recycling at the PV laminate's end of life is $3 \%$ and included in the Others category.

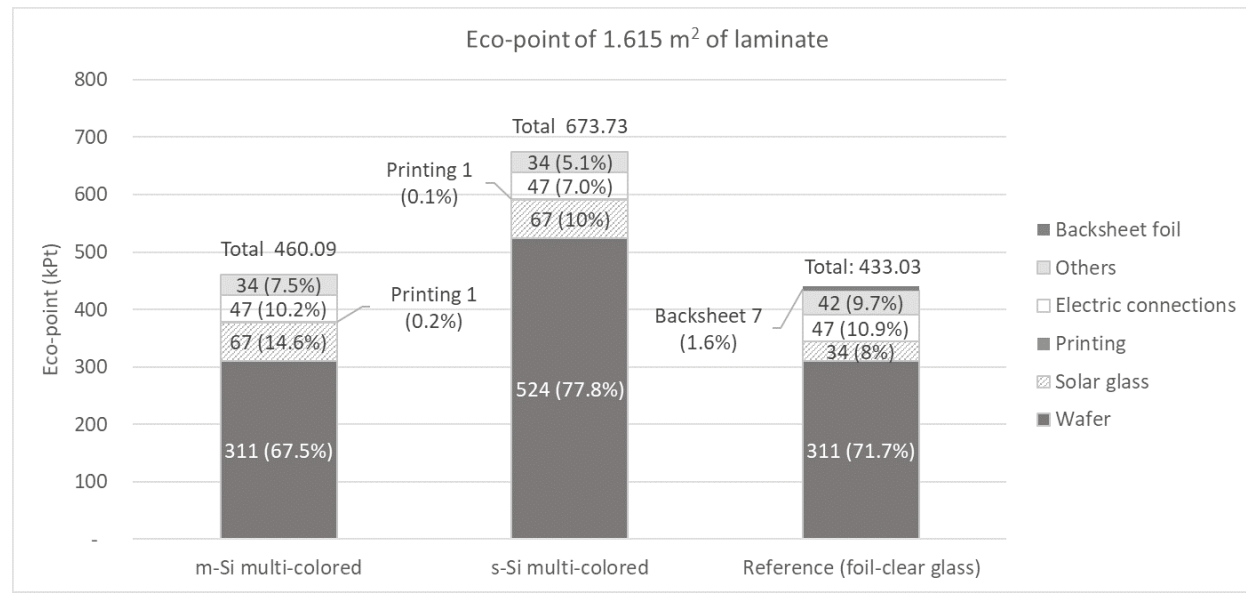

Figure 7. Eco-points for the production for various glass-glass PV laminate configurations. The reference data is for a $1.615 \mathrm{~m}^{2}$ glass-foil.

\subsection{Installation of an Architecturally Integrated Photovoltaic Façade}

For the installation of the façade in Switzerland, 140 modules are delivered by road. The BOS (inverter, mounting system, electric components) are purchased from the international market. The LCIA of the installation of the architecturally integrated photovoltaics façade considers these system components: The transportation, $1 \%$ of rejected PV laminates at the construction site, replacement of $2 \%$ of PV laminates due to early end of life during operation, a one-time replacement of the inverter during the operating lifespan, and furthermore the electric energy for mounting.

The eco-points for the façade with s-Si cells and clear glass is 141,000 kPt. For m-Si cells, it is $22 \%$ lower $(110,000 \mathrm{kPt})$. The solar glass and the mounting system can be excluded from the system boundary and allocated to the building, e.g., if an existing rain cladding glass façade approaches the end of its useful life and needs to be replaced, or the multi-coloured solar glass assumes a function of the building. In this case, the eco-points decrease by $25 \%$ to $83,000 \mathrm{kPt}$ for the $\mathrm{m}-\mathrm{Si}$ configuration, and by $19 \%$ to $114,500 \mathrm{kPt}$ for the s-Si configuration.

Figure 8 shows the breakdown of the eco-points for façade configurations consisting of $24.6 \mathrm{kWp}$ m-Si and $28 \mathrm{kWp}$ s-Si MCGG PV laminates, and $30.8 \mathrm{kWp}$ conventional clear glass-foil PV laminates, containing 140 modules of each component in ratio. The major contributors are the wafers in all three façades, making up $41 \%$ (glass-glass) and $42 \%$ (glass-foil) for $\mathrm{m}-\mathrm{Si}$, and $54 \%$ for s-Si. Front and back glass contributes $9 \%(\mathrm{~m}-\mathrm{Si})$ and $7 \%(\mathrm{~s}-\mathrm{Si})$ for the glass-glass PV façade. By contrast, the foil-glass façade contributes only $5 \%$ for the front glass, and $1 \%$ for the foil. Lastly, the mounting system contributes $13 \%$ resp. $10 \%$, while the inverter contributes $12 \%$ resp. $9 \%$ for the glass-glass PV façade. 


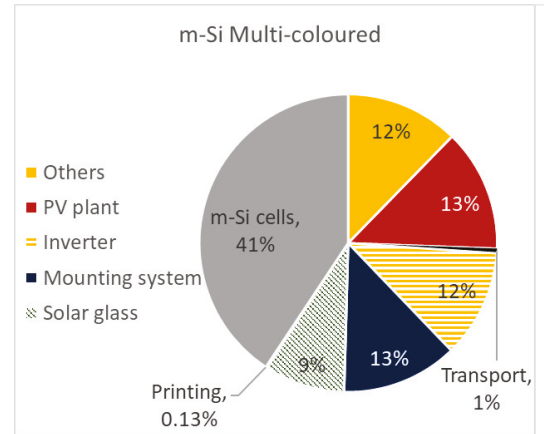

(a)

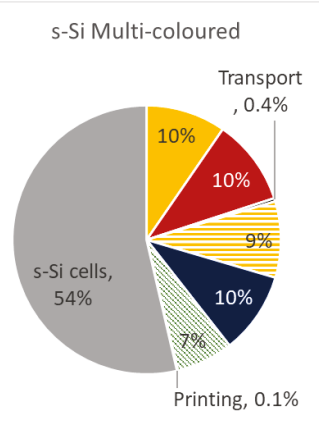

(b)

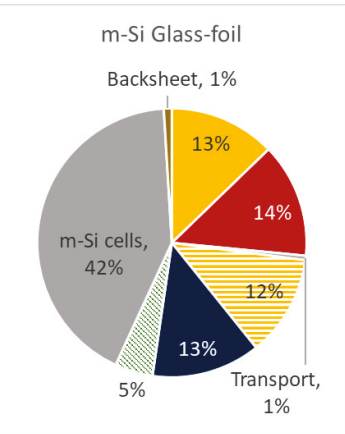

(c)

Figure 8. Percentile breakdown of eco-points for various façade configurations consisting of $140 \mathrm{PV}$ modules: $24.6 \mathrm{kWp}$ m-Si (a) and $28 \mathrm{kWp} \mathrm{s-Si} \mathrm{(b)} \mathrm{multi-coloured} \mathrm{glass-glass,} \mathrm{and} 30.8 \mathrm{kWp}$ traditional foil-glass (c).

\subsection{Electricity Generation Based on Façade Orientation}

All environmental impact of the façades are allocated to electricity generated, so the percentage of eco-points contributions of the façades (Figure 8) also can be applied to $1 \mathrm{kWh}$ electricity. A recommended functional unit for the LCA of the electricity generating system is $1 \mathrm{kWh}$, facilitating comparisons irrespective of size and capacity. The environmental impact of $1 \mathrm{kWh}$ electricity can be decreased if that of any contributors are decrease. For example, to decrease the impact by $10 \%$, the following options are viable:

- Increase electricity production by 3\% (for example, by improving c-Si cell efficiency)

- Reduce impact during façade installation by $3 \%$ (for example, mounting system with lower eco-points)

- Reduce impact during lamination processes by $4 \%(0.04 \times 0.6=2.4 \%$, since 140 laminates contribute $60 \%$ of the total eco-points) (for example, reducing electricity consumption)

- Decrease solar glass impact by $20 \%(0.2 \times 0.09=1.8 \%$, since glass contributes $9 \%$ to the total $)$ (for example, reducing loss and breakage)

In the same way, magnitude of the uncertainty of data in each contributor affecting to $1 \mathrm{kWh}$ of electricity also calculated. For example, $20 \%$ of uncertainty of solar glass data affects $1.8 \%$ of impact (eco-points) of $1 \mathrm{kWh}$ electricity. The float glass contributes $79 \%$ of the solar glass, so $20 \%$ of float glass reduction reduces the total impact of electricity by $1.4 \%$.

Depending on the façade orientation, the amount of electricity generated by a PV system varies, along with its environmental impact per $\mathrm{kWh}$. Therefore its orientation is considered when comparing the façade to the Swiss low voltage electricity grid as reference. The reference electricity has an impact of $0.273 \mathrm{kPt}$ per $\mathrm{kWh}$. In this study, this is derated by $6 \%$ to $0.257 \mathrm{kPt}$ to account for the grid loss of electricity generated by the façade. Thus, the environmental impact of the reference electricity is decreased instead of reducing the amount of electricity generated by the façade.

The GWP and eco-points per kWh generated according to façade orientation are shown in Figure 9. In terms of eco-points, all configurations facing south are superior to the reference. In the façade facing east/west, only the m-Si configurations are viable. In general, GWP indicates less favourable results than eco-points compared to the Swiss low voltage electricity grid. Consequently, the discussion that follows focuses on the former indicator.

The Swiss grid electricity mix (GWP of $0.13 \mathrm{~kg} \mathrm{CO}_{2}$ eq), used as reference in this study, has a lower share of carbon-based electricity, but a higher share of nuclear and hydro power than the European electricity mix. This contrasts with the German grid electricity mix (GWP of $0.61 \mathrm{~kg} \mathrm{CO}_{2} \mathrm{eq}$ ) used as reference in [20], which is dominated by high-impact coal sources. Almost all the façade 
configurations in Figure 9, except s-Si multi-coloured facing north, outperform the German electricity mix. Furthermore, the figure reveals that:

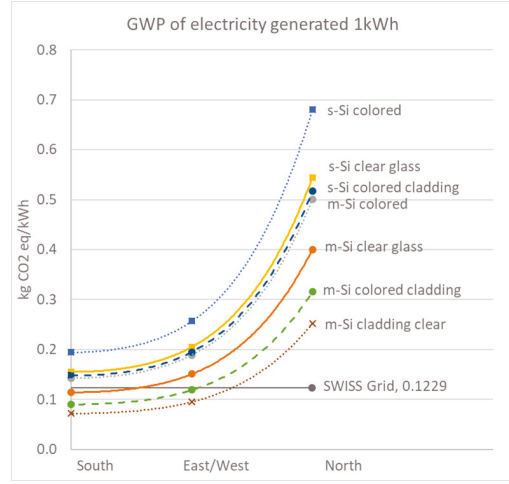

(a)

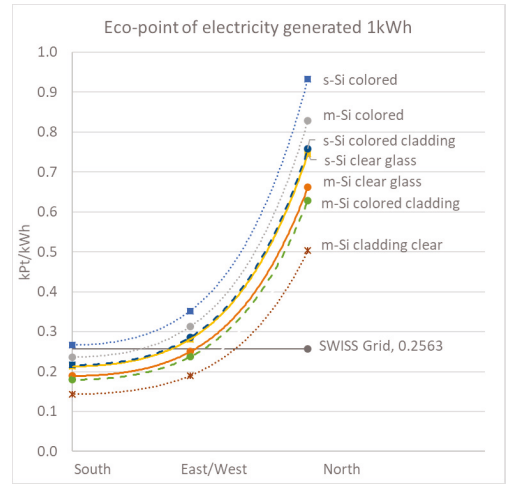

(b)

Figure 9. Environmental impact of $1 \mathrm{kWh}$ of electricity generated from each configuration and orientation of the PV façade in terms of global warming potential (GWP) (a) and eco-points (b).

- The north facing façade has the 2-5-fold GWP of the reference, and is unsuitable in any configuration. The worst-case GWP is infact comparable to that of coal power plants. The best-case GWP is, on the other hand, comparable to that of gas power plants.

- S-Si cells (with an efficiency of $17 \%$ in this study) are unsuitable under all conditions. They produce $13 \%$ more electricity than $\mathrm{m}-\mathrm{Si}$, but their GWP is also $54 \%$ higher. (see Table A1).

- Multi-coloured PV systems are superior to the Swiss low voltage electricity grid only when the laminates replace part of an existing rain cladding system. In this case, the GWP decreases by $36 \%$ : Solar glass (13\%); the mounting system (19\%); glass take-back and transportation (4\%); and printing $(0.4 \%)$.

- Clear glass m-Si photovoltaic on south facing façade is superior to the reference even when all the environmental impact is allocated to it.

Jayathissa [20] estimated GWPs of 0.144 to $0.331 \mathrm{~kg} \mathrm{CO}_{2}$ eq per $\mathrm{kWh}$ of electricity generated by a façade installation in Germany using different BIPV technologies (thin film and crystalline), disregarding the energy load of the building. In contrast, the GWP of all BIPV façade components in Table A1 of this study lies between 0.114 and $0.194 \mathrm{~kg} \mathrm{CO} 2$ eq per $\mathrm{kWh}$, which reduces to $0.072-0.148 \mathrm{~kg} \mathrm{CO}_{2}$ eq per $\mathrm{kWh}$ when replacing the rain cladding. However, in relating these results, we note the following constraints, which only permit an indirect comparison:

- $\quad$ Different datasets (Ecoinvent 3.1 vs. 3.4)

- $\quad$ Lifespans of 20 years instead of 30 in this work.

- Annual yield of $855 \mathrm{kWh} / \mathrm{m}^{2}$ (irradiation) $\times 0.11$ (efficiency) $\approx 94 \mathrm{kWh} / \mathrm{m}^{2} \mathrm{vs}$. annual yield of $700 \mathrm{kWh}$ (facing south) $\times 24.6 \mathrm{kWp} / 252 \mathrm{~m}^{2} \approx 68 \mathrm{kWh} / \mathrm{m}^{2}$.

Figure 10 shows the non-renewable CED per kWh of electricity generated by the façade. It decreases over time from its initial value of ca. $900 \mathrm{GJ}$ prior to electricity production, which is the total CED of the m-Si façade. After a projected 30-year lifespan, this is reduced to 1.92 MJ/kWh. The EPBT of the south-facing multi-coloured PV system is 8 years, but when replacing a part of a rainscreen wall system, this drops to just 5.3 years. Other EPBT results are summarised below. 


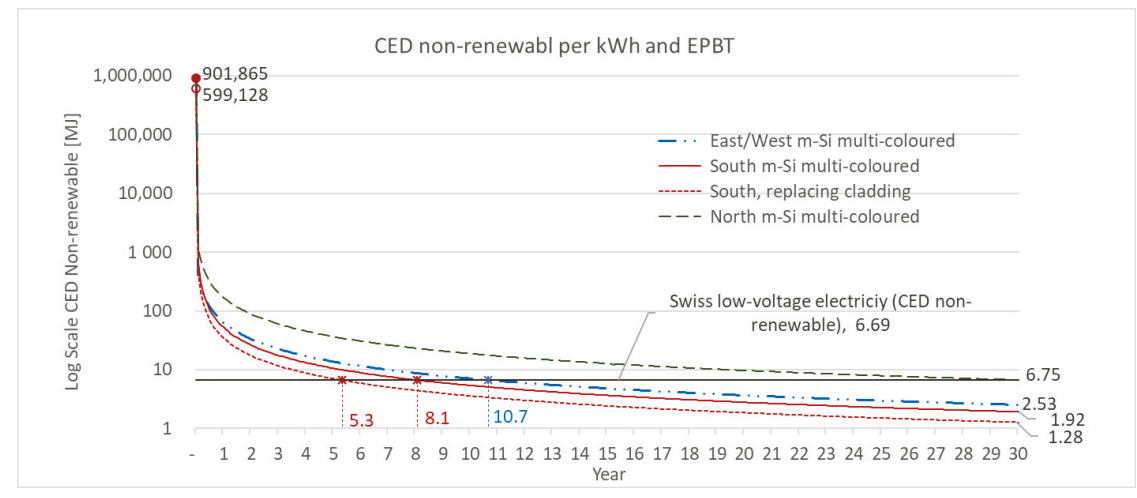

Figure 10. Cumulative energy demand (CED) non-renewable of an MCCG, m-Si PV façade over time, and energy pay-back time (EPBT) compared to Swiss low voltage electricity grid as reference.

- $\quad$ EPBT m-Si: The EBPT of a PV façade facing south with clear and coloured glass is 6 and 8 years, respectively. Facing east/west, this increases to 8 and 11 years, respectively, while facing north, the EBPT exceeds 20 years.

- $\quad$ EPBT s-Si: The EBPT of a PV façade facing south with clear and coloured glass is 8.4 and 10.6 years, respectively. Facing east/west, this increases to 11.2 and 14 years, respectively, while facing north, the invested energy does not pay off at all.

\section{Conclusions}

To achieve the goal of the Swiss energy strategy, namely to increase contribution of PVs to the national electricity supply by up to $20 \%$ by 2050 , BIPVs need to be aesthetically appealing for visual integration while generating electricity with a lower environmental impact than that of the existing Swiss low-voltage grid. These results compare favourably with those of a similar study using the German grid electricity as reference [20].

The primary aim of this study was to support the BIPV industry by providing previously unavailable and updated LCI data and LCA results of a glass-glass PV laminate as a reference. This reference can be used in the future to assess the environmental impact of novel BIPV laminates. The secondary aim of this study was to provide a holistic view of the entire life cycle and supply chain of BIPV and relevant information to each involved party, by presenting the LCA results and LCI data in an organised manner suitable for upstream building industries.

The LCA was carried out based on the latest published data of crystalline silicon cell production (currently omitted in LCI databases), the actual material and energy flow data from the glass and PV laminate suppliers, and lastly a realistic façade use case suitable for practical installation planning to identify a viable application as electricity generation system.

The most obvious findings to emerge from the LCA is that printing on glass is negligible as it accounts for less than $0.2 \%$ of the total impact (in eco-points) of a PV façade and $1 \mathrm{kWh}$ of electricity generated. By contrast, the impacts of the PV cells are significant, making up $41 \%$ for $\mathrm{m}-\mathrm{Si}$ and $54 \%$ for s-Si. Single crystalline cells are not suitable in general cases as s-Si types contribute $68 \%$ higher eco-points than $\mathrm{m}-\mathrm{Si}$, while their efficiency is only $13 \%$ higher. Moreover, a north-facing PV façade generates far too little electricity to justify its environmental impact compared other façade orientations, as well as the Swiss low voltage electricity grid as reference.

The itemised LCA results revealed enormous optimisation potential in future glass production processes, for instance by reducing the idle time and losses, ideally due to increased demand and production volume. The dominant contributor to the impact of solar glass production in terms of 
eco-points is the float glass input with 79\%. Lesser contributors are cutting and breakage losses with $25 \%$ of the input, while electricity consumption contributes $12 \%$ to the total eco-points.

Overall, the results support the notion that an itemised LCA can contribute to the building industry by presenting a holistic view to identify aggregated optimisation potential in the context of an individual BIPV product or a process in terms of its location and influence. However, to achieve progressive optimisation requires an iterative approach to LCA. The fragmented nature of the building industry hinders the gathering and arranging of data towards a collective effort. This therefore necessitates a systematic, inter-organisational approach to LCA.

The biggest limitation of the study may lie in the uncertainties inherent in LCA. Their quantitative effect is indicated by the exemplary options to reduce the environmental impact of the façade presented in Section 3.5: A relatively large deviation of $20 \%$ in solar glass production, for example, only affects $1.8 \%$ of the total. These interactions need to be further investigated in a systematic analysis. However, such an analysis is hampered by the lack of directly comparable data to confirm its veracity, which further emphasises the importance of a systematic LCA for the building industry.

Supplementary Materials: The following are available online at http:/ /www.mdpi.com/2075-5309/9/1/8/s1, Figure S1: Environmental impact (eco-points) of multi-coloured solar glass production, Figure S2: Figure S1 with impact of glass suppressed to highlight that of other flows, Figure S3: Eco-points $(\mathrm{kPt})$ to produce a multi-coloured glass-glass PV laminate, Table S1: Itemised energy and material flows for the production of a clear and multi-coloured solar glass.

Author Contributions: S.W. initiated this research, supported it with consultations, devised the use case, and wrote the abstract. D.H. gathered the LCI data, modelled and advised on the LCA, ran the software calculations and wrote the relevant sections. J.P. reviewed and compiled the inventory data, visualised and interpreted the results, and wrote the relevant sections comprising the bulk of the paper. All authors reviewed the publication.

Funding: This research was supported by the Swiss National Science Foundation as part of the projects ACTIVE INTERFACES-Holistic strategy to simplify standards, assessments and certifications for building integrated photovoltaics (\#153849) and ACTIVE INTERFACES - Holistic strategy for PV adapted solutions embracing the key technological issues (\#153762).

Acknowledgments: Roland Schregle reviewed the paper. Peter Schaad (Glas Trösch AG, Bützberg, Switzerland) provided the LCI for the solar glass. Joachim Höhne (GES Gebäude- und Energiesysteme GmbH, Korbußen, Germany provided the LCI for the PV laminates.

Conflicts of Interest: The authors declare no conflict of interest.

\section{Appendix A. BIPV Façade Results}

Table A1. Lifetime electricity production and environmental impact by system configuration and orientation. If a configuration outperforms the reference (the Swiss grid electricity mix), it is marked in red.

\begin{tabular}{lcccc}
\hline & $\mathbf{m}-\mathbf{S i}$ & $\mathbf{m}-\mathrm{Si}$ & $\mathbf{s}-\mathrm{Si}$ & $\mathbf{s}-\mathbf{i}$ \\
\cline { 2 - 5 } & Clear Glass & Multi-Coloured & Clear Glass & Multi-Coloured \\
\hline Capacity [kWp] & & & \\
Laminate & 0.22 & 0.176 & 0.25 & 0.2 \\
System & 30.8 & 24.64 & 35 & 28 \\
\hline Lifetime electricity generation [kWh] & & & \\
South (700 kWh/kWp) & 582,054 & 465,643 & 661,425 & 529,140 \\
East/West (530 kWh/kWp) & 440,698 & 352,559 & 500,793 & 400,635 \\
North (200 kWh/kWp) & 166,301 & 133,041 & 188,979 & 151,138 \\
\hline Environmental Impact of all system components & & & \\
GWP [kg CO 2 eq] & 66,503 & 66,620 & 102,758 & 102,876 \\
UBP [kPt] & 110,062 & 110,202 & 140,926 & 141,065 \\
CED [MJ] & 899,456 & 901,865 & $1,353,856$ & $1,356,286$ \\
\hline
\end{tabular}


Table A1. Cont.

\begin{tabular}{|c|c|c|c|c|}
\hline & m-Si & m-Si & s-Si & s-Si \\
\hline & Clear Glass & Multi-Coloured & Clear Glass & Multi-Coloured \\
\hline \multicolumn{5}{|c|}{ Environmental impact for rain cladding replacement (without glass, mounting system and transport) } \\
\hline $\mathrm{GWP}[\mathrm{kg} \mathrm{CO} 2 \mathrm{eq}]$ & 41,965 & 41,965 & 78,221 & 78,221 \\
\hline $\mathrm{UBP}[\mathrm{kPt}]$ & 83,634 & 83,634 & 114,497 & 114,497 \\
\hline CED [MJ] & 599,128 & 599,128 & $1,053,533$ & $1,053,533$ \\
\hline \multicolumn{5}{|c|}{ GWP $\left[\mathrm{kg} \mathrm{CO} \mathrm{CO}_{2} \mathrm{eq} / \mathrm{kWh}(\%)\right]$ for all components vs. reference $\left(0.123 \mathrm{~kg} \mathrm{CO} \mathrm{Co}_{2}\right)$} \\
\hline South & $0.114(-7.1 \%)$ & $0.143(16 \%)$ & $0.155(26 \%)$ & $0.194(58 \%)$ \\
\hline East/West & $0.151(23 \%)$ & $0.189(54 \%)$ & $0.205(67 \%)$ & $0.257(109 \%)$ \\
\hline North & $0.399(225 \%)$ & $0.501(307 \%)$ & $0.544(342 \%)$ & $0.681(453 \%)$ \\
\hline \multicolumn{5}{|c|}{ Eco-points $[\mathrm{kPt} / \mathrm{kWh}(\%)]$ for all components vs. reference $(0.256 \mathrm{kPt})$} \\
\hline South & $0.189(-26 \%)$ & $0.237(-7.7 \%)$ & $0.213(-17 \%)$ & $0.267(4.0 \%)$ \\
\hline East/West & $0.250(-2.6 \%)$ & $0.313(22 \%)$ & $0.281(9.8 \%)$ & $0.352(37 \%)$ \\
\hline North & $0.662(158 \%)$ & $0.828(223 \%)$ & $0.746(191 \%)$ & $0.933(264 \%)$ \\
\hline \multicolumn{5}{|c|}{ GWP $\left[\mathrm{kg} \mathrm{CO} \mathrm{CO}_{2} \mathrm{eq} / \mathrm{kWh}(\%)\right]$ for rain cladding replacement vs. reference } \\
\hline South & $0.072(-41 \%)$ & $0.090(-27 \%)$ & $0.134(9.3 \%)$ & $0.148(20 \%)$ \\
\hline East/West & $0.095(-23 \%)$ & $0.119(-3.2 \%)$ & $0.178(44 \%)$ & $0.195(59 \%)$ \\
\hline North & $0.252(105 \%)$ & $0.315(157 \%)$ & $0.470(283 \%)$ & $0.517(321 \%)$ \\
\hline \multicolumn{5}{|c|}{ Eco-points $[\mathrm{kPt} / \mathrm{kWh}(\%)]$ for rain cladding replacement vs. reference } \\
\hline South & $0.144(-44 \%)$ & $0.180(-30 \%)$ & $0.197(-23 \%)$ & $0.216(-16 \%)$ \\
\hline East/West & $0.190(-26 \%)$ & $0.237(-7.4 \%)$ & $0.260(1.4 \%)$ & $0.286(12 \%)$ \\
\hline North & $0.503(96 \%)$ & $0.629(145 \%)$ & $0.689(169 \%)$ & $0.758(196 \%)$ \\
\hline
\end{tabular}

\section{References}

1. Kaufmann, U. Schweizerische Statistik der Erneuerbaren Energien, Ausgabe 2016. Technical Report 2017.1002.01, Bundesamt für Energie BFE, 2017. Available online: http://www.bfe.admin.ch/php/modules /publikationen/stream.php?extlang=de\&name=de_729286095.pdf (accessed on 30 August 2018).

2. Swiss Federal Office of Energy SFOE-Nuclear Energy. Available online: http://www.bfe.admin.ch/theme $\mathrm{n} / 00511 /$ index.html?lang=en (accessed on 7 November 2018).

3. Wittkopf, S. Architektonische Veredelung von Photovoltaik für die Gebäudeintegration. In Proceedings of the 16th Nationale Photovoltaik-Tagung, Bern, Switzerland, 19-20 April 2018; Available online: https://www.swissolar.ch/fileadmin/user_upload/Tagungen/PV-Tagung_2018/Praesentationen/PVT 18_5.2_Stephen_Wittkopf.pdf (accessed on 3 September 2018).

4. Ballif, C.; Perret-Aebi, L.E.; Lufkin, S.; Rey, E. Integrated Thinking for Photovoltaics in Buildings. Nat. Energy 2018, 3, 438-442, doi:10.1038/s41560-018-0176-2. [CrossRef]

5. Wittkopf, S. Coloured Cover Glass for Photovoltaic Module. Patent DE 102016001628 A1, 2017. Available online: https:/ / patents.google.com/patent/DE102016001628A1/en (accessed on 19 October 2018).

6. Schregle, R.; Krehel, M.; Wittkopf, S. Computational Colour Matching of Laminated Photovoltaic Modules for Building Envelopes. Buildings 2017, 7, 72, doi:10.3390/buildings7030072. [CrossRef]

7. Schregle, R.; Wittkopf, S. An Image-Based Gamut Analysis of Translucent Digital Ceramic Prints for Coloured Photovoltaic Modules. Buildings 2018, 8, 30, doi:10.3390/buildings8020030. [CrossRef]

8. Masson, G.; Kaizuka, I. Trends 2017 in Photovoltaic Applications-Survey Report of Selected IEA Countries between 1992 and 2016. Technical Report IEA PVPS T1-32:2017, International Energy Agency Photovoltaic Power Systems Programme, 2017. Available online: http://www.iea-pvps.org/fileadmin/dam/public/re port/statistics/IEA-PVPS_Trends_2017_in_Photovoltaic_Applications.pdf (accessed on 30 October 2018).

9. Green, M.A. Commercial progress and challenges for photovoltaics. Nat. Energy 2016, 1, 15015, doi:10.1038/nenergy.2015.15. [CrossRef]

10. Söderström, T.; Papet, P.; Ufheil, J. Smartwire Connection Technology. In Proceedings of the 28th European Photovoltaic Solar Energy Conference and Exhibition, Paris, France, 30 September-4 October 2013; pp. 495-499, doi:10.4229/28thEUPVSEC2013-1CV.2.17. [CrossRef] 
11. Chown, A.; Brown, W.; Poirier, G. Evolution of Wall Design for Controlling Rain Penetration. Construction Technology Update 1997, No 9. Available online: https:/ /pdfs.semanticscholar.org/7b84/6cc2d5d7d5fbcd 0f7244a454b4f9b2ab5445.pdf (accessed on 10 September 2018).

12. CPD 10 2017: Glass Rainscreen Cladding Systems. Available online: https://www.building.co.uk/cpd/cpd -10-2017-glass-rainscreen-cladding-systems/5088631.article (accessed on 13 September 2018).

13. Ayres, R.U. Life Cycle Analysis: A Critique. Resour. Conserv. Recycl. 1995, 14, 199-223, doi:10.1016/0921-3449(95)00017-D. [CrossRef]

14. Passell, P. The Garbage Problem: It May Be Politics, Not Nature. The New York Times, 26 February 1991. Available online: https://www.nytimes.com/1991/02/26/science/the-garbage-problem-it-may-be-polit ics-not-nature.html (accessed on 5 November 2018).

15. Technical Committee ISO/TC 207/SC 5. Environmental Management-Life Cycle Assessment_Principles and Framework. Technical Report ISO 14040:2006(en), International Standards Organisation ISO, 2006. Available online: https://www.iso.org/obp/ui/\#iso:std:iso:14040:ed-2:v1:en (accessed on 7 November 2018).

16. Technical Committee ISO/TC 207/SC 5. Environmental Management-Life Cycle Assessment-Requirements and Guidelines. Technical Report ISO 14044:2006(en), International Standards Organisation ISO, 2006. Available online: https://www.iso.org/obp/ui/\#iso:std:iso:14044:ed-1:v1:en (accessed on 7 Novermber 2018).

17. Wang, Y.; Tian, W.; Ren, J.; Zhu, L.; Wang, Q. Influence of a building's integrated-photovoltaics on heating and cooling loads. Appl. Energy 2006, 83, 989-1003, doi:j.apenergy.2005.10.002. [CrossRef]

18. Baljit, S.; Chan, H.Y.; Sopian, K. Review of building integrated applications of photovoltaic and solar thermal systems. J. Clean. Prod. 2016, 137, 677-689, doi:10.1016/j.jclepro.2016.07.150. [CrossRef]

19. Zhang, T.; Wang, M.; Yang, H. A Review of the Energy Performance and Life-Cycle Assessment of Building-Integrated Photovoltaic (BIPV) Systems. Energies 2018, 11, 34, doi:110.3390/en11113157. [CrossRef]

20. Jayathissa, P.; Jansen, M.; Heeren, N.; Nagy, Z.; Schlueter, A. Life cycle assessment of dynamic building integrated photovoltaics. Sol. Energy Mater. Sol. Cells 2016, 156, 75-82, doi:10.1016/j.solmat.2011.12.016. [CrossRef]

21. Ng, P.K.; Mithraratne, N. Lifetime performance of semi-transparent building-integrated photovoltaic (BIPV) glazing systems in the tropics. Renew. Sustain. Energy Rev. 2014, 31, 736-745, doi:10.1016/j.rser.2013.12.044. [CrossRef]

22. Quintana, M.; King, D.; McMahon, T.; Osterwald, C. Commonly observed degradation in field-aged photovoltaic modules. In Proceedings of the Conference Record of the 29th IEEE Photovoltaic Specialists Conference, New Orleans, LA, USA, 19-24 May 2002; pp. 1436-1439, doi:10.1109/PVSC.2002.1190879. [CrossRef]

23. Frischknecht, R.; Heath, G.; Raugei, M.; Sinha, P.; de Wild-Scholten, M. Methodology Guidelines on Life Cycle Assessment of Photovoltaic Electricity, 3rd Edition. Technical Report IEA-PVPS T12-08:2016, International Energy Agency Photovoltaic Power Systems Programme, 2016. Available online: http:/ / www.iea-pvps.org/fileadmin/dam/public/report/technical/Task_12_-_Methodology_Guideline S_on_Life_Cycle_Assessment_of_Photovoltaic_Electricity_3rd_Edition.pdf (accessed on 6 November 2018).

24. Frischknecht, R.; Itten, R.; Sinha, P.; de Wild-Scholten, M.; Zhang, J.; Fthenakis, V.; Kim, H.C.; Raugei, M.; Stucki, M. Life Cycle Inventories and Life Cycle Assessments of Photovoltaic Systems. Technical Report IEA-PVPS T12-04:2015, International Energy Agency Photovoltaic Power Systems Programme, 2015. Available online: http://www.iea-pvps.org/fileadmin/dam/public/report/technical/IEA-PVPS_Ta sk_12_LCI_LCA.pdf (accessed on 30 September 2018).

25. Wernet, G.; Bauer, C.; Steubing, B.; Reinhard, J.; Moreno-Ruiz, E.; Weidema, B. The Ecoinvent Database Version 3, Part I: Overview and Methodology. Int. J. Life Cycle Assess. 2016, 21, 1218-1230, doi:10.1007/s11367-016-1087-8. [CrossRef]

26. Allocation at the Point of Substitution-Ecoinvent. Available online: https://www.ecoinvent.org/data base/system-models-in-ecoinvent-3/apos-system-model/allocation-at-the-point-of-substitution.html (accessed on 6 November 2018).

27. De Wild-Scholten, M. Life Cycle Assessment of Photovoltaics Status 2011, Part 1: Data Collection. Technical Report; SmartGreenScans: Groet, The Netherlands, 2014. Available online: 
http:/ / smartgreenscans.nl/publications/SmartGreenScans-2014-Life-Cycle-Assessment-of-Photovoltaic s-Status-2011-Part-1-Data-Collection--Sample-Pages.pdf (accessed on 7 November 2018).

28. Pilkington, L.A.B. Review Lecture: The Float Glass Process. Proc. R. Soc. Lond. A 1969, 314, 1-25, doi:10.1098/rspa.1969.0212. [CrossRef]

29. ift Rosenheim GmbH. Umweltdeklaration (EDP) für Flachglas, Einscheibensicherheitsglas, Verbundsicherheitsglas. Technical Report M-EPD-FEV-002005, Euroglas GmbH, 2017. Available online: https://www.glastroesch.ch/fileadmin/content/euroglas/Deutsch/Service/Zertifizierungen/EPD/201 8-03-20_Euroglas_M-EPD_FG_ESG_VSG_002_pdf (accessed on 16 September 2018).

30. Usbeck, V.C.; Pflieger, J.; Sun, T. Life Cycle Assessment of Float Glass. Technical Report, Glass for Europe, 2010. Available online: https://www.agc-yourglass.com/agc-glass-europe/au/de/pdf/lca/LCA.pdf (accessed on 7 November 2018).

31. Tschümperlin, L.; Stolz, P.; Wyss, F.; Frischknecht, R. Life Cycle Assessment of Low Power Solar Inverters (2.5 to $20 \mathrm{~kW}$ ). Technical Report 174-Update Inverter_IEA PVPS_v1.1, Swiss Federal Office of Energy SFOE, 2016. Available online: http://www.treeze.ch/fileadmin/user_upload/downloads/Publications/Case_Stu dies/Energy/174-Update_Inverter_IEA_PVPS_v1.1.pdf (accessed on 7 November 2018).

32. Wambach, K. Life Cycle Inventory of Current Photovoltaic Module Recycling Processes in Europe. Technical Report IEA-PVPS T12-12:2017, International Energy Agency Photovoltaic Power Systems Programme, 2017. Available online: http:/ / www.iea-pvps.org/index.php?id=369\&eID=dam_frontend_push\&docID=4239 (accessed on 26 October 2018).

33. Intergovernmental Panel on Climate Change. Anthropogenic and Natural Radiative Forcing. In Climate Change 2013-The Physical Science Basis; Cambridge University Press: Cambridge, UK, 2014; pp. 659-740, doi:10.1017/CBO9781107415324.018. [CrossRef]

34. Frischknecht, R.; Büsser Knöpfel, S. Ökofaktoren Schweiz 2013 gemäss der Methode der ökologischen Knappheit-Methodische Grundlagen und Anwendung auf die Schweiz. Technical Report UW-1330-D, Bundesamt für Umwelt BAFU, 2013. Available online: https://www.bafu.admin.ch/bafu/de/home/t hemen/wirtschaft-konsum/publikationen-studien/publikationen/oekofaktoren-2015-knappheit.html (accessed on 30 August 2018).

(C) 2018 by the authors. Licensee MDPI, Basel, Switzerland. This article is an open access article distributed under the terms and conditions of the Creative Commons Attribution (CC BY) license (http:/ / creativecommons.org/licenses/by/4.0/). 
Article

\title{
Heat Stress Pattern in Conditioned Office Buildings with Shallow Plan Forms in Metropolitan Colombo
}

\author{
Upendra Rajapaksha \\ Department Architecture, Faculty of Architecture, University of Moratuwa, Moratuwa 10400, Sri Lanka; \\ upendra@uom.lk; Tel.: +94-773-466-346
}

Received: 30 November 2018; Accepted: 23 January 2019; Published: 30 January 2019

check for updates

\begin{abstract}
This paper critically evaluates indoor overheating of multilevel office buildings in Colombo-a tropical warm humid city. The work questions the building morphological characteristics on thermal performance and indoor climate, thus the levels of Building Energy Indices (BEI) of air conditioned buildings. Pattern of heat stress on buildings due to building characteristics and its relationship to the BEI were identified. A study of 87 multilevel office buildings contributed to identify two critical cases in shallow plan form with similar morphological characteristics such as wall-to-window ratio, aspect ratio, orientation, occupant and equipment density, and façade architecture. A comprehensive thermal performance investigation on these two critical cases quantified the heat stress patterns on their facades and thus indoor thermal environments. Indoor air temperature during office hours in $3 \mathrm{~m} \times 3 \mathrm{~m}$ multizones across the depths and lengths in these two buildings showed deviations up to $10.5^{\circ} \mathrm{C}$ above the set point temperature level $\left(24{ }^{\circ} \mathrm{C}\right)$. Findings highlight the severity of heat stress on air conditioned indoor environments and the need to address this issue for energy sustainability of urban office buildings in the tropics.
\end{abstract}

Keywords: Multilevel buildings; indoor overheating; operational energy; shallow plan forms

\section{Introduction}

The IPCC's Fifth Assessment Report notes that continued GHG emissions due to human-induced contribution at or above current rates would cause further warming and induce many adverse changes in the global climate system [1]. Studies that have quantified the effects of global warming and projections of ambient temperature increases [1] indicate that more warm days are expected in most parts of subtropics and tropics [2]. Warming climates increase internal temperatures of buildings and studies have shown that this relationship is linear [3]. Increase of extreme air temperatures may considerably impact the electricity demand for cooling [4] and thus emissions [5]. With the warming of cities [6], both free running and air conditioned office buildings designed for existing climatic conditions are increasingly prone to indoor overheating in future. With the projected increase in energy use and the demand for more comfortable indoor environments in office buildings, there is a growing concern for high energy consumption and its likely adverse impacts on the environment [7]. Further, overheating cannot be avoided completely under expected warming climate scenarios [8]. These behaviors would obstruct the efforts of emission reduction strategies and targets for the building sector [9] and require the understanding of thermal behavior patterns of buildings in warming climates if strategies need to be identified to control unnecessary indoor overheating [10].

A linear correlation between the increase of average external air temperature and the increase of building cooling load, and thus the total energy use, is established for air conditioned buildings [11,12]. The average energy consumption in most countries varies between 100 and $500 \mathrm{kWh} / \mathrm{m}^{2} / \mathrm{a}$ due to many reasons including climate type, climate change factor, building characteristics, HVAC and lighting systems, office equipment, and operational schedules [13]. Further, urban environments are 
faced with the challenge of population inflation resulting in urban heat island (UHI) effects [14]. Hence, buildings, infrastructure and open spaces must be adequately "climate change proofed" to counter long term effects of urbanization and climate change effects [15]. Colombo, the commercial capital of Sri Lanka is no exception to high temperatures resulting from global warming and surface urban heat island (SUHI) effects due to the increase of building density, population and anthropogenic heat from traffic congestion, etc. [16].

Electricity use in the commercial building sector of Sri Lanka contributes $24 \%$ to the total consumption [17]. The annual energy consumption in office buildings in Colombo, which is known as a typical warm humid city in Asia, is $\sim 250 \mathrm{kWh} / \mathrm{m}^{2} /$ a [17]. Studies that do exist for Sri Lanka highlights that demand side management of operational energy use by buildings are primarily focused on highly sophisticated end use equipment which may be commercially available but not financially viable due to negative cost options. Further, it is also highlighted that apart from limited hydropower capacity, other available technologies such as wind and dendro power impose a cost penalty on GHG mitigation [18].

\subsection{Climate Response for Energy Sustainability: An Adaptation and Mitigation Option}

Adaptation [19] and mitigation are complementary approaches for reducing global warming impacts on buildings and thereby emissions [1,20]. Improving energy sustainability of building operations through climate responsive building design is definitely the most significant and cost effective action the commercial office-building sector can take in its direction to reduce dependency on non-renewable energy resources and GHG emissions. Energy in buildings is consumed mainly for cooling, heating, and lighting [21] while a portion is used for equipment. Integration of energy conservation interventions involves both technological and nontechnological aspects of building design and operation.

Many believe that a well implemented mix of regulatory instruments such as mandatory codes, carbon energy tax policies and tradable permits, and voluntary instruments such as unilateral and negotiated agreements and voluntary programs are effective nontechnological aspects for achieving energy efficiency which could incur lower implementation costs as well [8].

Bioclimatic design $[22,23]$ is seen as an appropriate basis for technological aspects of climate responsive design which involves the way buildings filter the climate for occupants' comforts involving four equally important interlocking variables-climate, biology, technology, and architecture. Bioclimatic design involves the conscious decision to operate buildings in the "selective mode", where the external environment impinges on the building and indoor environments are achieved from building-climate interplay. The "exclusive mode", which seeks to barricade the indoor environment from climate influence, effectively excludes benefits such as passive cooling and passive heating [24].

The building envelope, cross-section, and form are main bioclimatic drivers that foster interventions to reduce negative impacts of outdoor air temperature, summer heat gain, winter heat loss, optimization of daylight, and appropriate solar control. Morphological characteristics of buildings in terms of plan form, sectional form, envelope, orientation, and fenestration details and their effects on energy consumption are known [25]. Of them, plan form is a major contributor that controls the level of "building-climate interplay" [26] and thus the indoor air temperature levels in buildings.

Consideration of a building's geometry as an application of "air fluid composition" based on "plan form" consists of several design drivers such as structure, space planning, number of floor plates, disposition of open plan cellular spaces, the number of stacks, and style of atriums and light wells; this seemingly offers benefits for operational energy saving, indoor air quality improvement and, likely, tolerance to climate change effects in buildings [27].

In multilevel buildings, height and lesser roof area in relation to external facade area means that the heat transfer between indoor environment and outdoor climate is significant through the façade and fenestration. Three ways of heat gain due to environmental and internal load transfer are known—conduction through opaque surfaces, conduction through glazed areas, and 
radiation through glazed areas [28]. The bioclimatic approach in heat gain control offers an excellent opportunity to enhance a modified indoor environment as well by improving quality of daylight without heat gain, reducing conductive environmental heat gain through envelope, and better control of indoor temperature.

Heat gain due to internal loads from equipment and higher occupancy rates can be greater in office buildings in certain climates with daytime ambient temperatures ranging within the comfort zone. Gaun's $[6,24]$ simulation study predicts more indoor overheating potentials primarily due to internal loads in commercial office buildings in moderate climates, where summer air temperatures move closer to the comfort zone. In these climates, a reduction in summertime air conditioning use could be dominated by the use of internal thermal mass [29]. On the other hand, in tropical zones with severe warm humid conditions, controlling sun penetration offers better opportunities for delivering improved energy efficiency in conditioned buildings. The bottom line is that we should be in a position to make a deliberate and positive impact on improving energy efficiency through building facades [30-32] and plan depths [33]. Acquiring the most effective plan depth and envelope has value for climate responsiveness and thus advanced energy performance, increased human thermal comfort and climate sensitive role of buildings [34].

\subsection{Heat Stress through Building Façades in Tropics}

Heat stress [35] on building occupants is usually measured in terms of Wet Bulb Globe Temperature (WBGT) that combines air temperature, humidity, radiation, and air flow into a single value. Studies have quantified that in warm humid climates, levels of heat stress for occupants in free running buildings are mostly higher than the preferred comfort level of WBGT in the whole year [36]. This suggests the criticality of the climate in tropics and the need for careful integration of appropriate design interventions to avoid environmental heat stress through building facades.

Patterns of environmental heat gain through building facades due to direct radiation on different types of plan forms are known $[37,38]$. Shallow and linear plan forms with narrower facades along east-west axis promote least direct exposure to direct solar heat gain in equatorial climates. However, with high levels of cloud cover in tropics, presence of diffused radiation is a major challenge in making a building resistant to heat stress.

Percentage of glazing area of a wall know as window-to-wall ratio (WWR) of a façade can have a significant impact on heat gain potential and thus energy consumption levels in terms of cooling and heating in buildings [39]. Aspect ratio of a plan form is another key geometric parameter that defines the building surface area by which heat is transferred between the interior and exterior environment [40] and the amount of façade area that is subject to solar gain. The extent to which this can be beneficial or detrimental depends on the climate type. Heat transfer through opaque materials in the façade is another concern to be addressed.

In Sri Lanka, building heat stress remains a largely less investigated area. The few studies that do exist are focussed on energy efficiency measures of orientation, building envelope and lighting on free running indoors. Particularly, heat stress through facades has been least investigated for air conditioned buildings of any form. Reducing the risk of heat gain into air conditioned buildings is an essential phenomenon to study. When a building is air conditioned, the excessive heat gains through facades may not be perceptive to the occupants due to the conditioned environment inside, but nevertheless contribute to the increase of air conditioning energy load, thus exacerbating the emissions and global warming problem [41-43]. An in-depth understanding of performance improvement for building design for air conditioned indoors in tropics is yet to be achieved.

\section{Climate in Colombo}

Warm humid tropical climates are found in the region extending $15^{\circ}$ North and South of the equator (Figure 1). Colombo (latitude $5^{\circ} 55^{\prime}$ to $9^{\circ} 49^{\prime} \mathrm{N}$ and longitude $79^{\circ} 51^{\prime}$ and $81^{\circ} 51^{\prime} \mathrm{E}$ ) is an example of this climate and is characterised by lack of seasonal variations in temperature. The mean monthly 
temperatures range from $27^{\circ} \mathrm{C}$ in November to $30{ }^{\circ} \mathrm{C}$ in April and relative humidity varies from $70 \%$ to $80 \%$ during a typical year. The daily maximum temperatures are high as $25^{\circ} \mathrm{C}$ to $38{ }^{\circ} \mathrm{C}$ and the daily pattern in the dry season (September to November and March to May) has diurnal temperature range of 7 to $8^{\circ} \mathrm{C}$. Air temperature in these climates does not vary substantially over the daily typical cycle, thus limiting the opportunity for thermal mass for passive cooling. While solar effects are consistent, seasonal rain patterns affect temperature level (perceptions), but rainfall is increasingly unpredictable.

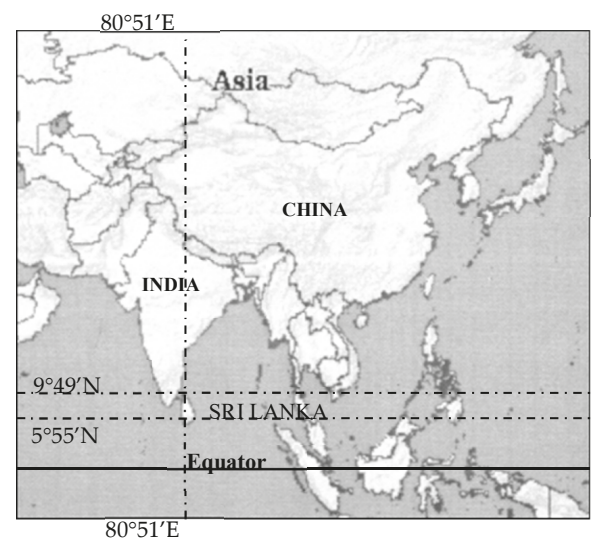

(a)

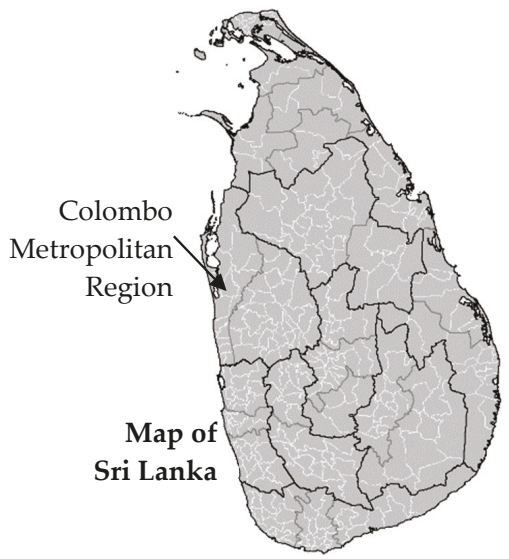

(b)

Figure 1. (a) Sri Lanka in the world map. It is situated between $9^{\circ} 49^{\prime} \mathrm{N}$ and $5^{\circ} 55^{\prime} \mathrm{N}$ of Equator. (b) Sri Lanka.

KÖppen Geiger climate classification demonstrates that nearly $60 \%$ of the geographical area of Sri Lanka represents type "Af" —an equatorial fully humid climate. Of the 8760 hourly data points of dry bulb temperature in the psychrometric chart developed for this study using Climate Consultant 5.5 software, nearly $60 \%$ and $40 \%$ of data points represent air temperatures in the range of $27-38{ }^{\circ} \mathrm{C}$ and $21-27^{\circ} \mathrm{C}$ respectively (Figure 2). Annual monthly mean, maximum temperature, and relative humidity in Colombo vary within the ranges of 26.2 to $28.8^{\circ} \mathrm{C}, 29.2$ to $31.4{ }^{\circ} \mathrm{C}$, and 73.8 to 83.6 , and 90.2 to $97.9 \%$, respectively.

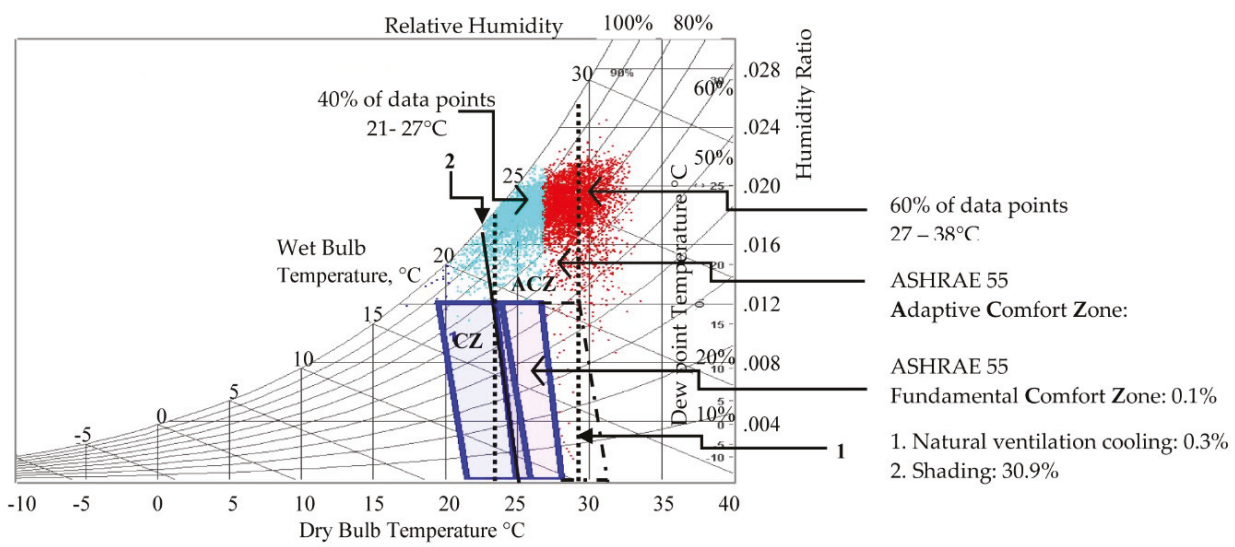

Figure 2. Psychrometric chart for Colombo developed from Climate Consultant 5.5 during the study. 
The main characteristic of the warm humid climate in Colombo, from the human comfort and building design viewpoint, is a combination of high temperature and high humidity which in turn reduces the dissipation of body's surplus heat. Irradiation in Colombo ranges from 400 to $6000 \mathrm{~W} / \mathrm{m}^{2}$ throughout the year. Olgyays [22] criterion of "optimum shape" - taking into account solar radiation, temperature, and other climatic conditions-calls for buildings freely elongated in the east-west direction. This provides shelter from the Sun for north-south facades and, in addition, facilitates the air movement entering from the south-west of buildings. Moreover, the directional effects of airflow inlets and building orientation can help to ameliorate the indoor airflow situation [38]. The presence of solar radiation relates to the temperature increase in the ambient air. Thus, prior to incoming air travelling through the indoor spaces, its sol-air temperature should always be reduced at the source by shading. The most efficient way of protecting a building is to shade the windows and other openings to improve immediate microclimate $[44,45]$. Shading against solar radiation reduces the effective temperature experienced by an occupant by up to $8^{\circ} \mathrm{C}$ and could reduce the environmental heat transfer as well.

\subsection{The Urban Climate and Building Stock in Colombo}

World's urban population is expected to increase to $68 \%$ by 2050 and projections show that $70 \%$ of global urbanization will concentrate in countries of Asia and Africa by the year 2050 [46]. Urbanization in tropics accounts for a significant proportion in Global GHG emissions [47]. Colombo Metropolitan Region (CMR) is no exception to this, and indicates Surface Urban Heat Island (SUHI) effects intensifying from 2007 to 2017 due to rapid urbanization [16]. In 2005 the extent of UHI was $42 \%$ of the total land area of CMR. This UHI is growing and predicted for an annual increase of $1.75 \%$. Moreover, an increasing trend is apparent in the extent of built-up area, which increased from $74 \%$ in the year 2005 to $97.3 \%$ in the year 2013 [48]. Scientific disclosure of the influence of UHI on increasing energy demand is well established.

Building stocks in many developed countries have been evaluated for the relationship between energy consumption and built characteristics $[26,49,50]$. They have been further investigated to identify the effect of building morphology such as shape, composition, orientation, and fenestration details for assessment of building performance and the end user energy demand [51-53]. However, similar studies on building stocks in Sri Lanka are less prioritized. The available few studies on energy consumption of buildings have focused on energy efficiency measures of lighting and simulations to assess indoor environmental quality of residential buildings [54,55]. Furthermore these studies are based on secondary data, which evidences the lack of a comprehensive national database that integrates the characteristics of the building stock and the energy utility intensities.

CMR, which has the highest office building density in Sri Lanka, was selected to explore the national urban building stock in respect to thermal performance and end-user energy demand.

\section{Method of Study}

The study was conducted in 3 phases involving 87 commercial multilevel office buildings covering an approximate floor area of $73,000 \mathrm{~m}^{2}$. Phase I consisted of a walk through survey of all buildings and an onsite thermal performance investigation of selected buildings to evaluate the impact of building morphology on Building Energy Index (BEI), for which office buildings of each division is presented as the mean BEI. It was defined as the ratio of total annual energy used in kWh per Meter Square per annum. A walkthrough field investigation was performed in 35 Grama Niladhari (GN) divisions in the CMR (GN division is the smallest administrative division in Sri Lanka). Data collection protocol was structured with the use of geographical information system (GIS) data and activity zone maps of the CMR. The identified office building stock excluded mixed administrative buildings but included buildings exclusively used for administrative activities of private and government organizations including banks and other financial offices. Building morphology data was focused on building design parameters such as orientation, plan shape, construction materials, and fenestration characteristics such as WWR and aspect ratio (façade length/depth). Technical and operational characteristics were 
recorded as working hours, space conditioning systems, and usage of office equipment. Occupied hours, occupancy profiles, air conditioning systems, and type and number of equipment used were observed as nearly similar in these buildings. Thermal variables of indoor air and surface temperatures were recorded using HOBO UX100-003 data loggers, and monitored continuously for a week in randomly selected samples from the 87 buildings during one of the hottest months of March 2017. Climatic data of Meteorological Department of Sri Lanka shows that March and April as the hottest months in a typical year. A statistical analysis of the entire building stock in respect to BEI and morphological characteristics was conducted at the end of Phase I, developing a classification of the building stock in terms of BEI in an integrated framework of orientation, plan shape, WWR and Aspect Ratio.

Phase II of the research project involved a comprehensive thermal performance investigation of two critical case buildings identified from the statistical analysis of Phase I. The two buildings were identified as having two extreme levels of BEIs despite having similar morphological characteristics, occupant and equipment densities with shallow plan forms with perfect orientations along the east-west axis. Indoor air temperature variations across the depths of their shallow plan forms from perimeter to perimeter were quantified in air conditioned mode using 22 HOBO UX 100-003 meters from 6 am to $6 \mathrm{pm}$ over a week in April 2018. A typical floor plate was considered as a collection of $3 \mathrm{~m} \times 3 \mathrm{~m}$ multizones and each zone had a HOBO meter. Measuring $3 \mathrm{~m} \times 3 \mathrm{~m}$ zones contributed to give one average value for the entire floor plate and was considered more accurate than considering just one or few points in the respective floor plates. The two critical cases are orientated with the longer facades facing north and south, due to which it can be assumed that heat stress on facades due to direct solar exposure is minimal. The objective of Phase II was to investigate the levels of indoor air temperature inside these two buildings and then to judge any correspondence between BEI and level of indoor air temperature in constant conditioned mode.

Phase III was an extension to Phase II and continued for further two weeks, day and night from 26th July to 16th August 2018 and measurements were taken in multizones of $3 \mathrm{~m} \times 3 \mathrm{~m}$ at 10-min intervals. Measurements included both inside and outside perimeter wall surface temperatures, indoor air temperatures and $\mathrm{RH}$ in all $3 \mathrm{~m} \times 3 \mathrm{~m}$ multizones, and air temperature just outside the exterior walls on all four orientations. Wall surface temperatures were taken using ONSET thermo couples UX120-014M.

\section{Phase I of the investigation}

\subsection{Dispersion of the Office Building Stock}

The office building stock is concentrated towards Northwest and West locations of the CMR. Figure 3 shows the distribution of the stock and BEIs of the critical GN divisions in CMR. Thirteen of 35 GN divisions have a substantial number of office buildings as shown in Figure 3a. The percentage of office buildings to total buildings of these GN divisions varies from 5 to $19 \%$. The highest building stock of offices is in Keselwatte GN Division and the lowest is visible in Milagriya GN Division with percentages of 19 and 5, respectively. Descending order of GN divisions from the 2nd highest percentage of 16 up to $10 \%$ of the office stock are Suduwella, Colpetty, Bambalapitiya, Hunupitiya, Slave Island, Fort, and Wekanda. Positioning of office buildings along high-density traffic arteries is common in these zones, and the corresponding roads are Galle road, Dharmapala Mawatha, Sangharaja Mawatha, Sir James Peiris Mawatha, and D.R Wijewardana Mawatha. Thus the "road side sealed offices" represent the overarching character of national urban office building stock in CMR.

Phase I included three main Steps of investigations. The objective of the 3 steps is to sample the identified building population in the following manner:

- Identifying dispersion pattern of office building stock in CMR-Step 1. 
- Characterizing 87 selected buildings in concentrated, dense areas in CMR in respect to BEI with plan forms, façade configurations/orientations, and compositions with neighboring buildings-Step 2.

- Statistical analysis to sample the building population mentioned in Step 2 in respect to BEI, orientation, and morphological characteristics of WWR and Aspect Ratio-Step 3.

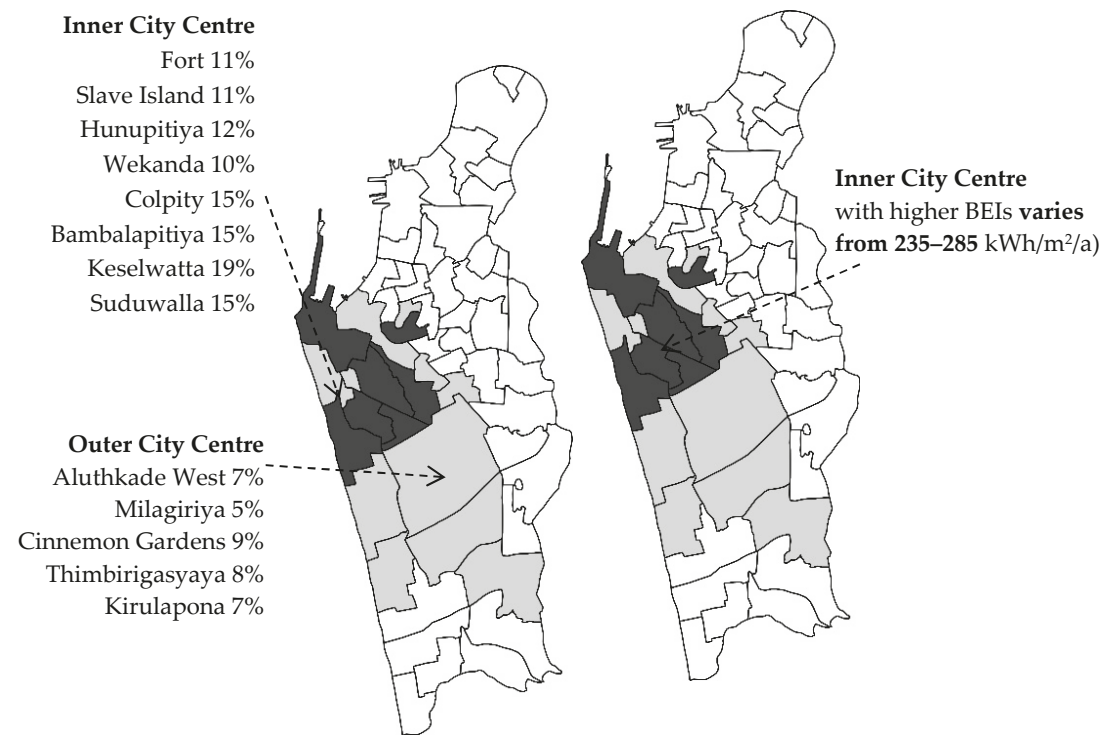

(a)

(b)

Figure 3. Map of Colombo Metropolitan Region showing (a) dispersion of the office building stock and (b) an inner city center with buildings with higher Building Energy Indices (BEIs).

\subsection{Percentage Distribution of the Building Stock in Terms of BEI-Step 1}

BEIs of the office building stock were assessed for 06 critical GN divisions. These six GN divisions represent a considerable number of office buildings and correspond to a range of 19 to 10 percent of office buildings in each division. BEI for office buildings of each division is presented as the mean value. Figure $3 b$ presents the BEIs of six critical GN divisions. The results indicate that the annual BEI varies from 235 to $285 \mathrm{kWh} / \mathrm{m}^{2} / \mathrm{a}$. The highest demand is apparent in Kollupitiya GN Division followed by Hunupitiya GN Division with an office building stock of $15 \%$ and $12 \%$, respectively. Results prove that there is no relationship between the percentage of the building stock and BEI (Table 1), demanding the importance of investigating morphology of office buildings in critical GN divisions.

Table 1. Percentage distribution of three ranges of BEIs of the building stock.

\begin{tabular}{ccc}
\hline Levels of BEI Ranges & Values of BEI Ranges & Percentage Distribution \\
\hline Lower Range (LR) & $100-150 \mathrm{kWh} / \mathrm{m}^{2}$ per annum & $35.72 \%$ \\
\hline Average Range (Av.R) & $150-250 \mathrm{kWh} / \mathrm{m}^{2}$ per annum & $54.08 \%$ \\
\hline Critical Range (CR) & Above $250 \mathrm{kWh} / \mathrm{m}^{2}$ per annum & $10.20 \%$ \\
\hline
\end{tabular}

Three levels of BEI ranges were identified in the pilot investigation. They are Lower Range (LR), Average Range (AvR) and Critical Range (CR), see Table 1. 
The lower range was decided to be 110 to $120 \mathrm{KWh} / \mathrm{m}^{2} / \mathrm{a}$-a commonly known acceptable practice [56]. Nearly $36 \%$ of buildings are found to be in this region. The average range claims BEIs between 150 and $250 \mathrm{kWh} / \mathrm{m}^{2} / \mathrm{a}$, which is the national average of office buildings in Sri Lanka [17] but still considered as high. The critical range includes more than $10 \%$ of the stock with BEIs over $250 \mathrm{kWh} / \mathrm{m}^{2} / \mathrm{a}$.

a. Dispersion of BEIs in the Office Building Stock

The annual BEI in these office buildings varies within a range from 91 to $412 \mathrm{kWh} / \mathrm{m}^{2} / \mathrm{a}$ and $95 \%$ of the buildings are above $110 \mathrm{kWh} / \mathrm{m}^{2} / \mathrm{a}$, which represents the accepted standard for energy efficient building codes [56]. Within this building stock, $56 \%$ of the buildings show an annual BEI above $200 \mathrm{kWh} / \mathrm{m}^{2} / \mathrm{a}$, of which almost half of the buildings are above $250 \mathrm{kWh} / \mathrm{m}^{2} / \mathrm{a}$. The mean BEI for critical office building stock in CMR is $212 \mathrm{kWh} / \mathrm{m}^{2} / \mathrm{a}$ and thus solidifies that the building stock is energy obsolete beyond the standards (Figure 4). The outcome advises further investigation of the thermal performance of the building stock and related parameters, which has an effect in the end use energy demand of this stock.

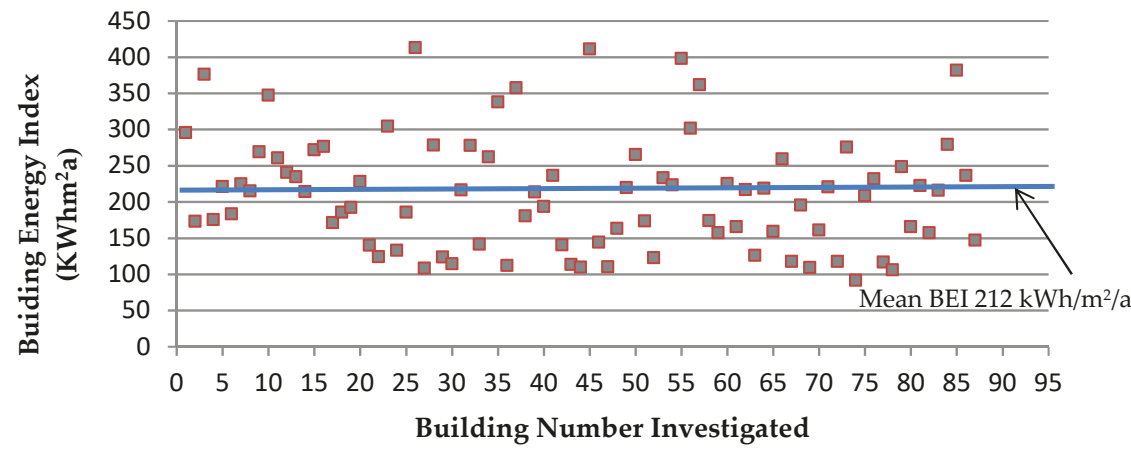

Figure 4. Building energy indices of 87 buildings.

\subsection{Characteristics of the Building Morphology and Sampling-Step 2}

Characterizing building morphology with specific concerns to plan form, fenestration material details, orientation and composition with neighboring buildings was assessed.

\section{a. Plan Forms}

This study proposes to categorize the office building stock into the predominant six types. These can be generalized as basic plan forms and composite plan forms. The basic plan forms consist of square, linear, and circular forms, while composite plan forms are derived from a combination of these and demonstrate the shapes $\mathrm{L}, \mathrm{U}$, and trapezium. Table 2 depicts the identified classification and its percentage distribution within the stock. Basic plan forms are commonly used, and of these, $85.05 \%$ demonstrate linear and square forms of $62.07 \%$ and $22.98 \%$, respectively.

Among the composite plan forms, $\mathrm{L}$ shape is prominent with a percentage distribution of $8.1 \%$. Although there are office buildings with circular, trapezium and U-shape plan forms they have not been used widely. Circular and trapezium plan forms are equal percentage of $2.30 \%$ in the building stock. Composite built form of $\mathrm{L}$ shape is a combination of two linear plan forms or a linear and a square plan form. Moreover the amalgamation of three linear plan forms represents the U-shape. These composite plan forms in CMC region consists of $2.3 \%$ of $\mathrm{U}$ and $8.0 \%$ of $\mathrm{L}$ shape plan forms, respectively. 
Table 2. Common plan form classification of the building stock in Colombo-linear and shallow plan forms are more common in the stock.

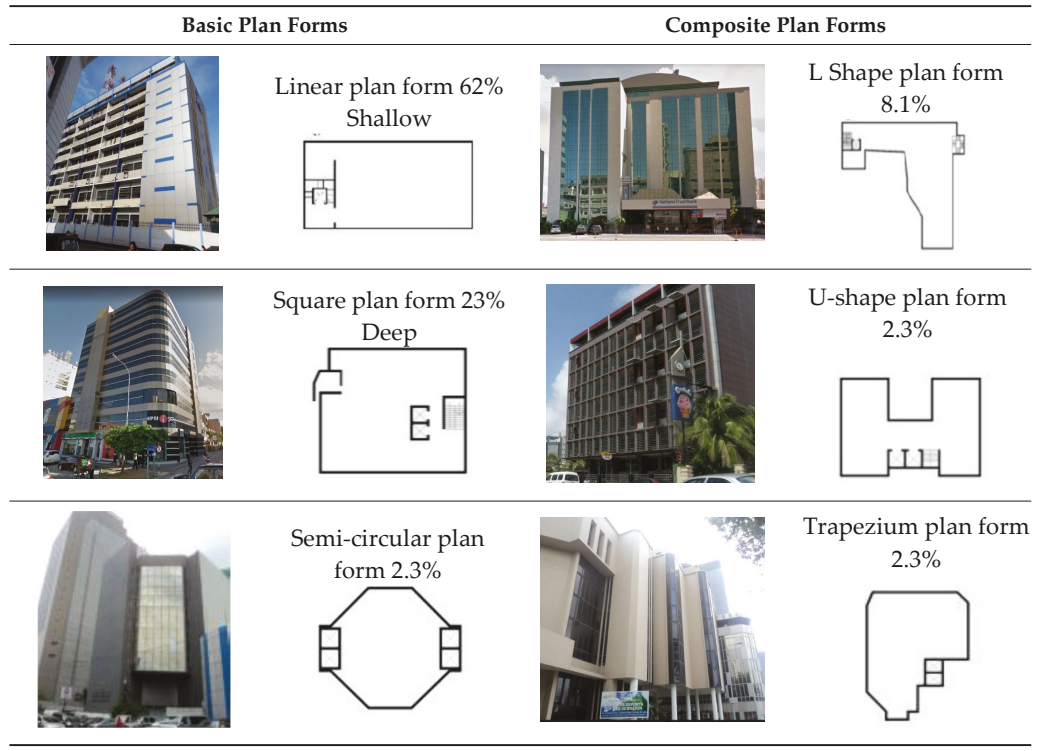

b. Building Facade Detailing and Orientation

Building facade detailing demonstrates a significant impact on the thermal behavior of a building determined by "glazed to wall" ratio and facade orientation [56]. Increased glazing proportions of the facades facing critical orientations of hot climates promotes higher gain in solar radiation and the overheated interiors increase the cooling load of air conditioned offices. On the other hand, perimeter areas benefit from the higher percentage of glazing in terms of daylight. However, the large amount of daylight, which enters a space through highly glazed areas, often reduces the quality of visual comfort due to glare problems. Therefore, this study identified a characterization of the building stock in this respect. Table 3 presents material compositions of front facades and percentage distribution of each facade type within the office building stock.

Table 3. Fenestration details of road facing façades and percentage distribution within the stock.

Glazed with Solid Facades $\quad$ Aluminum Cladding Facades


Facades are predominantly composed of glass and aluminum cladding. The percentage distribution of these materials in front facades is $17 \%, 26 \%$, and $57 \%$, respectively. Glazed facades are primarily curtain walls and composed of fixed and few operable panels with blinds to control direct solar radiation. These facades are orientated in different directions within the building stock. Table 4 represents the details of the facade orientations, their percentage distributions, and the relationship between the orientation and mean BEI. Office buildings in this stock represents four main orientations such as East-west (EW), North-south (NS), Northeast-Southwest (NE-SW), and Northwest-Southeast (NW-SE). Building forms have similar envelope properties of high mass concrete and brick. Floor to floor height varies between 3 and $3.5 \mathrm{~m}$ in all buildings.

Table 4. Prevalent orientations of front façade facing the road and mean building energy index (BEI).

\begin{tabular}{ccc}
\hline Façade Orientation & Percentage Distribution & Mean BEI kWh/m $\mathbf{m}^{2} / \mathbf{a}$ \\
\hline East-west & $41.4 \%$ & 211.6 \\
\hline North-south & $13.8 \%$ & 200.2 \\
\hline Northeast-Southwest & $25.6 \%$ & 200.1 \\
\hline Northwest-Southeast & $19.2 \%$ & 205.7 \\
\hline
\end{tabular}

Table 4 presents the percentage distribution of office buildings for EW, NS, NE-SW, and NE-SW orientations which are $41 \%, 14 \%, 26 \%$, and $19 \%$, respectively. The major characteristic is the orientation of the front façade towards East or West direction along the major roads running from north to south. This has become a design challenge for architects but no efforts are seen in making these facades more defensive from direct solar gain from east and west in the inevitable situation of having to use this specific orientation. Thus the building stock is evident for less attention on climate responsive design strategies which has affected the end use energy demand. Buildings with EW-oriented front facades demonstrate the highest mean BEI of $212 \mathrm{kWh} / \mathrm{m}^{2} / \mathrm{a}$. These findings confirm the criticality of the building morphology in addition to inappropriate orientation and material usage irrespective to climatic forces of the locality.

\section{c. Composition with Other Buildings}

Buildings within an urban block can be either attached to other buildings or exist independently, detached. This office building stock consists of a mix of both compositions with $63 \%$ detached buildings and $37 \%$ attached buildings. Attached buildings have variations, such as attached from single and both facades. Varied compositions show marginal differences in annual BEI with 211 and $210 \mathrm{kWh} / \mathrm{m}^{2} / \mathrm{a}$ for detached and attached buildings, respectively. Buildings with both sides attached to other buildings display better control of solar heat gain to office interiors. However, this means that the use of artificial lighting is increased due to daylight restrictions. Lack of difference between BEIs of the two types highlights the energy demand for lighting, and thus informs the importance of a comprehensive study to calculate the tenancy energy demand of this stock. However, lack of regulatory mechanisms to initiate sub metering of the national building stock is a limitation.

\subsection{Statistical Analysis with BEI, WWR, Aspect Ratio, and Orientation}

Multiple linear regression models were applied to identify any nexus between façade composition (window-to-wall ratio-WWR), plan form (aspect ratio), building orientation, and physical configuration to BEIs of the building sample population. Aspect ratio is the footprint in a ratio of length and width relative to the east-west or north-south. A change in the aspect ratio can vary the façade area subject to solar radiation [40]. WWR and aspect ratio define the glazing area of a façade and, therefore, can have a clear impact on cooling or heating [56]. The work attempted to model the relationship between two or more explanatory variables and a response variable by fitting a linear equation to observed data. The multiple linear regression equation is as follows. 


$$
y=B_{0}+b_{1} X_{1}+b_{2} X_{2}+\ldots b_{n} X_{n}
$$

where $y$ is the predicted or expected value for the linear model with regression coefficients of dependent variable $b_{1}$ to $b_{n}$ and $y$ intercept $b_{0}$ when the values for the predictor variables are $X_{1}$ to $X_{n}$, which is the building energy index. $X_{1}$ through $X_{n}$ are $n$ distinct independent variables, which are the building morphological parameters. $B_{0}$ is the value of $y$ when all of the independent variables $\left(X_{1}\right.$ through $X_{n}$ ) are equal to zero, and $b_{1}$ through $b_{n}$ are the estimated regression coefficients. Each regression coefficient represents the change in y relative to a unit change in the respective independent variable.

The regression analysis was carried out in three stages for 87 buildings. First stage was to analyze whether independent variables are correlating with each other to prevent multi colinearity in the regression models. The evaluation of independent variables was based on analyzing correlation coefficient and $p$-values. Second stage was to perform subset regression analysis to ascertain the relationship between dependent variable of BEI with independent variables of building morphological characteristics such as WWR, aspect ratio, and orientation. Subset regression analysis helped to evaluate all possible regression models. These models were revaluated based on $R^{2}$ value, $R^{2}$ adjusted value, and Mallow's $C p$ value. The highest $R^{2}$ value and $R^{2}$ adjusted value with lesser Mallow's C $p$ value was taken into account when determining the best fit models. The minimum $\mathrm{R}^{2}$ value was taken as $50 \%$, where $50 \%$ of the predicted value of BEI was explained by the model. Stepwise regression was conducted to evaluate the predictors in the selected models. $\mathrm{R}^{2}$ value and $p$-value were considered when reviewing the best fit models. Polynomial regression analysis was preceded during the occasions when $\mathrm{R}^{2}$ value was marginal.

$p$-values of the independent variables, namely WWR of all four facades, the aspect ratio of the plan, and building orientation with the BEI, remained less than 0.05 in $95 \%$ of confidence intervals in regression models with four major prevailing orientations of the sample building stock. The four orientations were North-South axis, East-West axis, Northwest-Southeast axis, and Northeast-Southwest axis. The analysis was carried out for all three groups based on the BEIs of the stock namely Lower Range, Average Range and Critical Range. Table 5 shows summative results of the analysis showing a nexus between BEIs, WWRs and orientations.

Plan forms with longer facades facing north and south directions maintain relatively lower BEIs compared to other orientations in all three groups of BEI ranges. Results show that façade orientations have greater impacts on the BEIs and thus plan forms on the east-west axis performs better. However, it is interesting to note that few buildings in this group claim BEIs as high as $250.31 \mathrm{kWh} / \mathrm{m}^{2} / \mathrm{a}$, falling in to the critical range.

With two orientations of plan forms on NS (north-south) and EW (east-west) axes, BEIs claim a diversity showing a significant change of impact from facades facing NS and EW orientations. This was a common behavior in all three ranges, i.e., lower, average, and critical. The change of impact due to other orientations was less significant. Multiple regression models developed to configure a nexus between aspect ratio and WWR of NS- and EW-oriented buildings in all three BEI ranges highlight a criticality of plan form with higher aspect ratios. This was evident with high BEI averages and they can be identified as shallow plan forms orientated on EW orientations. Despite these forms are ideal for tropics, an increase of the aspect ratio is seen as a strong independent variable contributing to higher BEIs, the critical range (Table 6). Outcome demands a field investigation of these buildings. 
Table 5. Summative results of the analysis showing a nexus between BEIs, window-to-wall ratios (WWRs), and orientations.

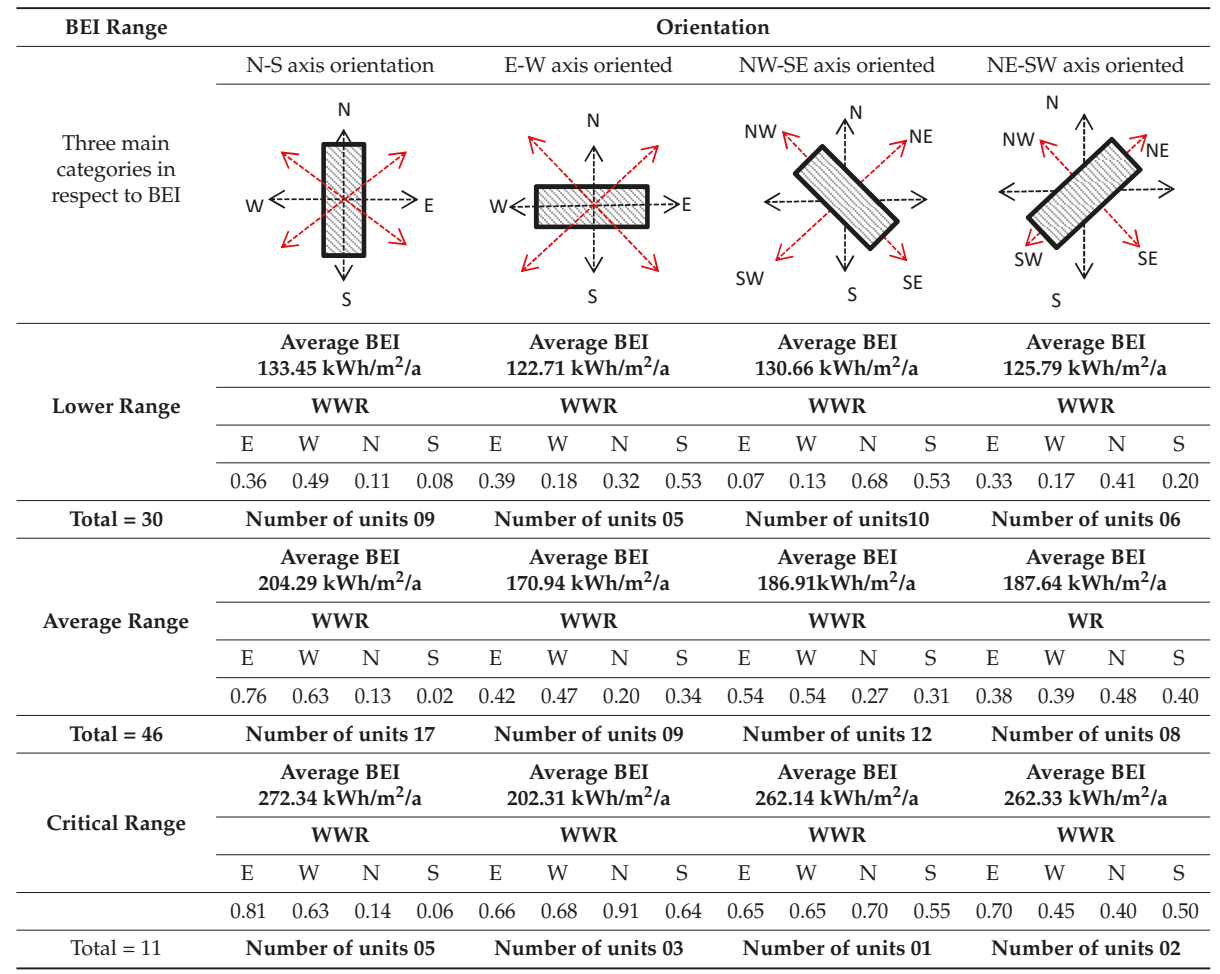

Table 6. Summative results of the nexus between aspect ratios, BEIs, WWRs, and orientations of buildings on the North-South and East-West axes.

\begin{tabular}{|c|c|c|c|c|c|c|c|c|c|c|c|c|}
\hline $\begin{array}{c}\text { Orientation and Plan } \\
\text { Form }\end{array}$ & \multicolumn{12}{|c|}{ WWR and Aspect Ratio in Three BEI ranges in East and West Orientations } \\
\hline \multirow{2}{*}{ East-West axis } & \multicolumn{4}{|c|}{$\begin{array}{c}\text { Lower Range } \\
100-150 \mathrm{kWh} / \mathrm{m}^{2} / \mathrm{a}\end{array}$} & \multicolumn{4}{|c|}{$\begin{array}{c}\text { Average Range } \\
150-250 \mathrm{kWh} / \mathrm{m}^{2} / \mathrm{a}\end{array}$} & \multicolumn{4}{|c|}{$\begin{array}{c}\text { Critical Range } \\
\text { Above } 250 \mathrm{kWh} / \mathrm{m}^{2} / \mathrm{a}\end{array}$} \\
\hline & \multicolumn{4}{|c|}{ WWR Glazing exposure } & \multicolumn{4}{|c|}{ WWR Glazing exposure } & \multicolumn{4}{|c|}{ WWR Glazing exposure } \\
\hline w & $\mathrm{E}$ & W & $\mathrm{N}$ & S & $\mathrm{E}$ & W & $\mathrm{N}$ & S & $\mathrm{E}$ & W & $\mathrm{N}$ & $\mathrm{S}$ \\
\hline & 0.36 & 0.49 & 0.11 & 0.08 & 0.76 & 0.63 & 0.13 & 0.02 & 0.81 & 0.63 & 0.14 & 0.06 \\
\hline$=5$ & \multicolumn{4}{|c|}{$\begin{array}{l}\text { Aspect Ratio along NS axis } \\
\text { (Length/width) } 0.70\end{array}$} & \multicolumn{4}{|c|}{$\begin{array}{l}\text { Aspect Ratio along NS } \\
\text { (Length/width) } 0.30\end{array}$} & \multicolumn{4}{|c|}{$\begin{array}{l}\text { Aspect Ratio along NS } \\
\text { (Length/width) } 0.26\end{array}$} \\
\hline & \multicolumn{4}{|c|}{ Average no of floors 5} & \multicolumn{4}{|c|}{ Average no of floors 6} & \multicolumn{4}{|c|}{ Average no of floors 6} \\
\hline layou & \multicolumn{4}{|c|}{$\begin{array}{c}\text { Average BEI } \\
133.45 \mathrm{kWh} / \mathrm{m}^{2} / \mathrm{a}\end{array}$} & \multicolumn{4}{|c|}{$\begin{array}{c}\text { Average BEI } \\
204.29 \mathrm{kWh} / \mathrm{m}^{2} / \mathrm{a}\end{array}$} & \multicolumn{4}{|c|}{$\begin{array}{c}\text { Average BEI } \\
272.34 \mathrm{kWh} / \mathrm{m}^{2} / \mathrm{a}\end{array}$} \\
\hline INOI & \multicolumn{12}{|c|}{ WWR and Aspect Ratio in three BEI ranges in North and South orientations } \\
\hline & \multicolumn{4}{|c|}{ WWR Glazing exposure } & \multicolumn{4}{|c|}{ WWR Glazing exposure } & \multicolumn{4}{|c|}{ WWR Glazing exposure } \\
\hline & $\mathrm{E}$ & W & $\mathrm{N}$ & $\mathrm{S}$ & $\mathrm{E}$ & W & $\mathrm{N}$ & $\mathrm{S}$ & $\mathrm{E}$ & W & $\mathrm{N}$ & $\mathrm{S}$ \\
\hline & 0.03 & 0.18 & 0.32 & 0.53 & 0.42 & 0.47 & 0.20 & 0.34 & 0.76 & 0.68 & 0.91 & 0.64 \\
\hline Street & \multicolumn{4}{|c|}{$\begin{array}{l}\text { Aspect Ratio along EW axis } \\
\text { (Length/width) } 1.49\end{array}$} & \multicolumn{4}{|c|}{$\begin{array}{l}\text { Aspect Ratio along EW axis } \\
\text { (Length/width) } 3.22\end{array}$} & \multicolumn{4}{|c|}{$\begin{array}{l}\text { Aspect Ratio along EW axis } \\
\text { (Length/width) } 4.4\end{array}$} \\
\hline & \multicolumn{4}{|c|}{ Average no of floors 5} & \multicolumn{4}{|c|}{ Average no of floors 6} & \multicolumn{4}{|c|}{ Average no of floors 6} \\
\hline & \multicolumn{4}{|c|}{$\begin{array}{c}\text { Average BEI } \\
122.71 \mathrm{kWh} / \mathrm{m}^{2} / \mathrm{a}\end{array}$} & \multicolumn{4}{|c|}{$\begin{array}{c}\text { Average BEI } \\
170.94 \mathrm{kWh} / \mathrm{m}^{2} / \mathrm{a}\end{array}$} & \multicolumn{4}{|c|}{$\begin{array}{c}\text { Average BEI } \\
202.31 \mathrm{kWh} / \mathrm{m}^{2} / \mathrm{a}\end{array}$} \\
\hline
\end{tabular}




\section{Phase II and Phase III of the Investigation}

Phase II was more focused on the shallow plan forms. As discussed in the Phase I, buildings with higher aspect ratios on the East-West direction have a shallow plan form with two extremes of BEI values, i.e., lower and critical ranges.

\subsection{Sampling of the Building Stock for Phase II}

Conducting a thermal performance investigation on two sample buildings with shallow plan forms was aimed at in Phase II. The classification of building morphological characteristics showed that $63 \%$ of building stock has shallow plan forms, compared to $26 \%$ of deep and $12 \%$ of composite forms. Of the shallow forms, 17 buildings are seen orientated on the EW axis in different locations. Two buildings were then sampled from these 17 buildings that showed different levels of BEIs ranging from 110 to $320 \mathrm{kWh} / \mathrm{m}^{2} / \mathrm{a}$ in the outcome of statistical analysis in Phase I.

Buildings attached or close to other structures were eliminated from the beginning of the study. Only free standing buildings were considered so that impact of urban climate on all facades of any particular building could be assessed.

The two sample office buildings—" $\mathrm{A}$ " and "B"—are composed of similar morphological character (WWR and aspect ratio), orientation, operational profile, and occupant and equipment density but extensively different from the BEI point of view (Table 7). Both buildings are occupied from 8 am to $6 \mathrm{pm}$ on weekdays and are located in similar urban contexts just a kilometre apart.

Table 7. Plan form and physical characteristics of two investigated buildings in Phase II and I.

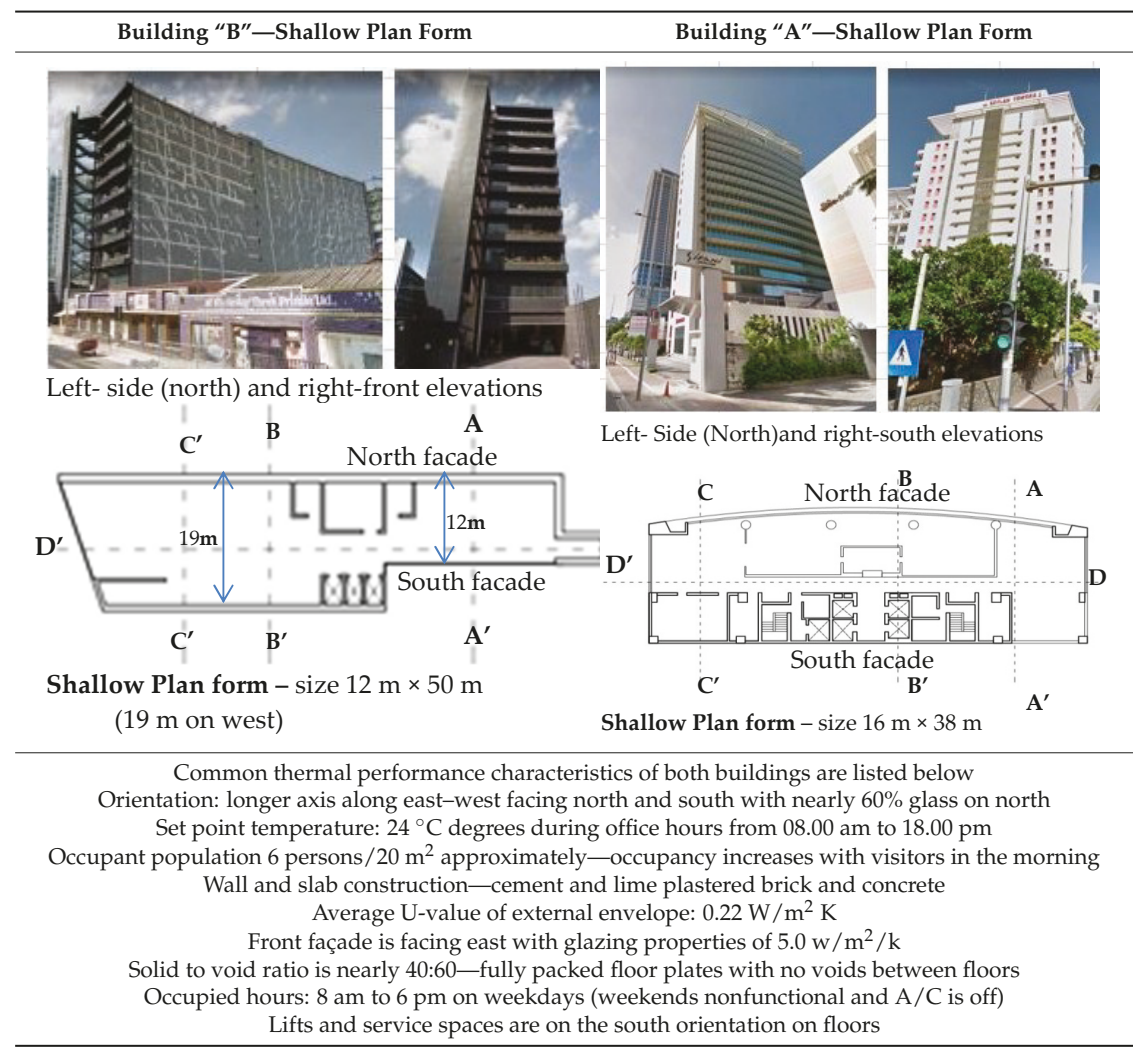


The objective of the focused field investigation was to assess the distribution pattern of heat stress on indoor environment depending on the plan depth. Building " $\mathrm{A}$ " has BEI as high as $340 \mathrm{kWh} / \mathrm{m}^{2} / \mathrm{a}$ whereas the Building " $\mathrm{B}$ " has a moderate level of $120 \mathrm{~kW} / \mathrm{hm}^{2} / \mathrm{a}$, which is close to acceptable level. Front narrower façade with the main entrance is positioned facing east orientation in both cases. Table 7 explains similarity of the operational and physical characteristics of the two buildings. The only difference between the two building forms is the floor area where a typical floor plate of Building " $\mathrm{B}$ " is relatively larger than the same of Building " $\mathrm{A}$ ". However, occupant and equipment density are comparatively similar in both cases.

Multizone indoor air temperature reading in $3 \mathrm{~m} \times 3 \mathrm{~m}$ zones across the plan depth (and along the building length as explained in the method) were taken using $\mathrm{HOBO}$ data loggers during three working days in the month of April 2018 (23rd-27th of April 2018) at 10 min intervals and then averaged to hourly values. The measurement rationale was to ascertain a number of comparisons that are as follows.

- Dynamics of air temperature distribution in peripheral and central zones on a typical floor plate to assess the collective heat stress effect of façades and plan depth.

- Dynamics of air temperature deviation from the set point temperature to assess the thermal load on the air conditioning system.

The study acknowledges that any dynamics in the indoor air temperature demonstrates an effect of environmental loads on air conditioning and the indoor thermal behaviour. Microclimatic data just outside the building were recorded onsite. The central air conditioning system of both cases is similar in specifications (15 tons per $1 \mathrm{AHU}$ ). However, Building " $\mathrm{A}$ " has a higher number of diffusers (1 for each $13 \mathrm{~m}^{2}$ ) than in Building "B" (1 for each $36 \mathrm{~m}^{2}$ ) per floor. Readings were taken in three typical floors above 6 th level in both buildings. Temperature fluctuations on the day that the study was conducted when the building was in non-functional mode (weekends) demonstrates the effect of environmental load on indoor thermal behaviour.

\subsection{Phase III}

Phase III was aimed at repeating the investigation performed in Phase II but continuously over 20 days from 26th July to 16th August 2018. Measurements of each $3 \mathrm{~m} \times 3 \mathrm{~m}$ multi-zones recorded at 10-mi intervals were later averaged to hourly values, which in turn averaged to a single value for the entire floor. Objective of Phase III was to ascertain the following.

- Hourly pattern of dynamics of average indoor air as a single value in a typical floor against the coordinating set point temperatures.

- Quantify the extremes of heat stress on air conditioned environments and identify contributing factors.

\section{Results and Discussion}

Set-point temperature of all office and useable floors of both buildings is $24^{\circ} \mathrm{C}$ degrees. Despite this, indoor air temperature dynamics in varied levels were seen during the daytime in both buildings.

Results show that an increase of indoor air temperature up to 31 to 32 degrees $C$ across all $3 \mathrm{~m}$ $\times 3 \mathrm{~m}$ zones along sections-A-A, B-B, and C-C-in Building "B" (see Table 7) while temperature readings in the internal zone close to west façade and east facades along D-D remained at 34 and 31, respectively, at midday (Figure 5) when the sun was just above the building and no direct radiation could penetrate through the sides. Solar axis to buildings in Colombo between the 23rd and 27th April is normally over the head, therefore there is no way of entering solar access from sides. However, a middle floor was investigated in this study so that effect of heat from vehicular traffic was considered minimal. This thermal behaviour explicitly suggests the presence of heat stress on the air conditioning system from the façade. Office equipment inside the three floors remained switched off from the 
morning to assist the research, so that indoor heat generation was limited to a minimum. As mentioned in a previous section, the BEI of this building was approximately $120 \mathrm{kWh} / \mathrm{m}^{2} / \mathrm{a}$, but heat stress of $10.7^{\circ} \mathrm{C}$ indoor air temperature above the set-point is an issue to be addressed.

\section{Point Temperature Measurements}

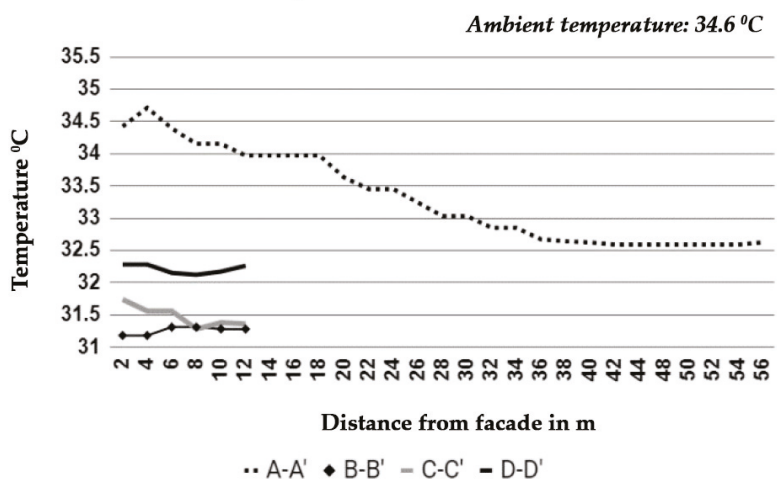

Figure 5. Multizone air temperature behavior in this air conditioned Building " $\mathrm{B}$ "- move between 31.5 and $34.7^{\circ} \mathrm{C}$ despite set point temperature at $24^{\circ} \mathrm{C}$; BEI is around $120 \mathrm{k} / \mathrm{Whm}^{2} / \mathrm{a}$, but high risk of heat gain is visible.

The set-point temperature of both buildings was at $24{ }^{\circ} \mathrm{C}$. Despite similarities in set point temperatures, Building " $\mathrm{A}$ " was assessed with lesser elevation of indoor air temperature ranging between 24.4 and $25.1^{\circ} \mathrm{C}$ (Figure 6). It has a highly dense AC diffuser system than Building "B" and results show that it is capable of maintaining indoor air temperature closer to the set point temperature, but at a much higher energy cost at a BEI of $320 \mathrm{kWh} / \mathrm{m}^{2} / \mathrm{a}$. Results suggest the criticality of shallow plan forms on end user energy demand of the building stock.

\section{Point Temperature Measurements}

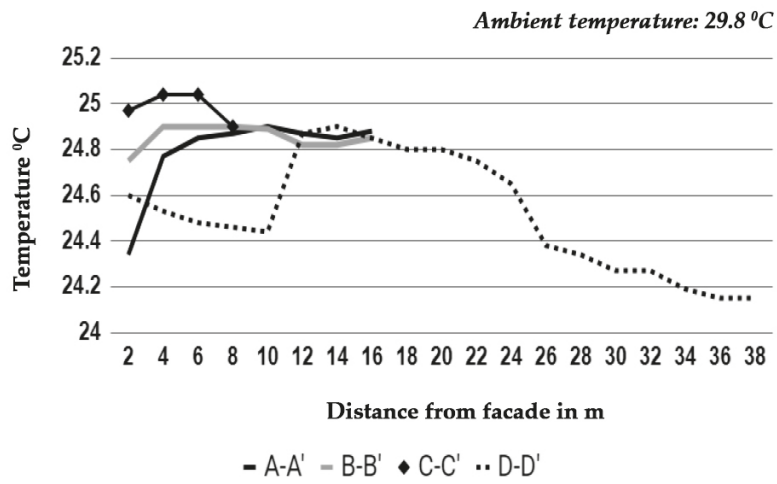

Figure 6. Multizone air temperature behavior of this air conditioned Building " $\mathrm{A}$ " moves just $1.1^{\circ} \mathrm{C}$ above set point temperature of $24^{\circ} \mathrm{C}$ but at a very high energy cost of nearly $340 \mathrm{kWh} / \mathrm{m}^{2} / \mathrm{a}$.

Shallow plan depths of Building " $\mathrm{B}$ " and " $\mathrm{A}$ " are $12 \mathrm{~m}$ and $16 \mathrm{~m}$, respectively. Length of the floor plates of Buildings " $\mathrm{B}$ ' and $\mathrm{A}^{\text {" are }} 50 \mathrm{~m}$ and $38 \mathrm{~m}$, respectively. Multizone air temperature distribution across the depths and lengths of floor plates are shown in the two graphs above (Figures 5 and 6). Considerable dynamics of air temperatures well above set point temperature in all zones across these 
depths and lengths demonstrate increased demand on cooling energy due to high levels of external gains through facades.

Performance behavior of Buildings "B" and "A" in Phase III are shown in Figures 7 and 8 respectively. During this period maximum ambient moved around $28^{\circ} \mathrm{C}$, an ambient climatic situation which is not extreme and also lower than the ambient levels during Phase II, (which fluctuated between 31 and 34 degree C). Air just outside the building, measured at the 8th floor level revealed a heat built up situation just outside the façade, suggesting solar gain from outside.

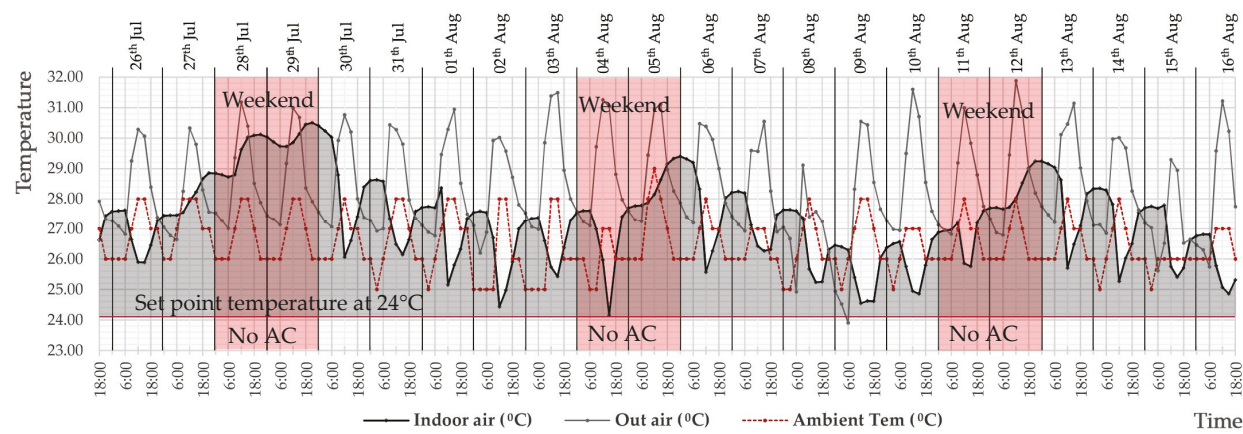

Figure 7. Building " $\mathrm{B}$ ": Hourly severe heat stress behavior in terms of air temperature on the 8th floor over a period of 20 days in July-August 2018; indoor air moved well above set point temperature.

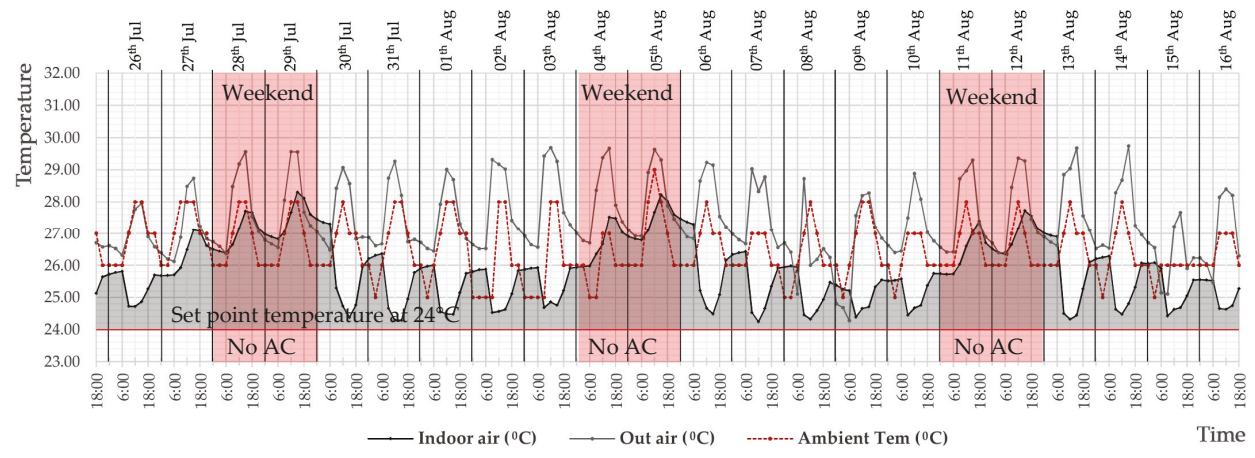

Figure 8. Building " $\mathrm{A}$ ": Hourly moderate heat stress behavior in terms of air temperature in the 8th floor over a period of 20 days in July-August 2018. Indoor air moved closer to set point but at a much higher energy cost of BEI.

Cooling system of the building has been able to control the indoor air to keep its temperature at approximately $26-26.5{ }^{\circ} \mathrm{C}$ during midday, but results show an overheating situation in nights and during weekends. Overheating situation in the night indicates a level of heat stress from the heat released from the envelope. Overheated situations in the weekends show a greater level of heat stress from the facades.

Thermal behavior of Building " $A$ " followed a similar pattern to the Building " $B$ " but showed relatively a smaller dynamics from the set point temperature at a much higher energy cost at a BEI of $320 \mathrm{kWh} / \mathrm{m}^{2} /$ a (see Figure 8), similar to Phase II outcome. Situations in weekends showed a severe heat stress due to environmental gain on the indoor air. The results indicate the following.

- Overheated microclimates, well above the ambient, outside the buildings at high elevations

- Severe heat stress and indoor overheating during weekends (nonfunctional hours) 
- Higher indoor air temperature levels than the set point temperature through daytime AND elevation of indoor air above ambient in early morning hours

Wall surface temperature behavior was quantified during Phase III. Hourly values of internal wall surface temperatures of four exterior facades were averaged to a single wall surface value in hourly terms and then compared with corresponding indoor air. Results show a close interaction of indoor air with internal wall surface temperatures reflecting a heat stress impact from facades (Figures 9 and 10). Despite air conditioning, internal wall surfaces reach higher values up to $28.5-29.5^{\circ} \mathrm{C}$ until noon indicating heat gain from outside. Internal wall surface starts to drop after $3 \mathrm{pm}$ when direct exposure of facades to outside radiation starts diminishing indicating a release of stored heat to indoors from walls. Heat sink capacity of thermal mass in the envelope was not observed. Indoor air and surface temperatures reach close to each other by early morning at $\sim 6 \mathrm{am}$.

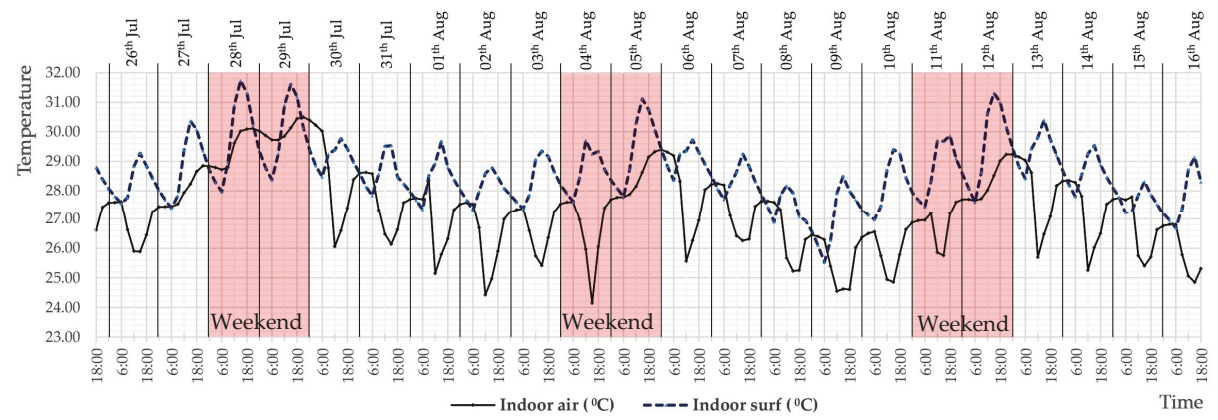

Figure 9. Wall surface and indoor air temperature behavior in Building " $\mathrm{B}$ ".

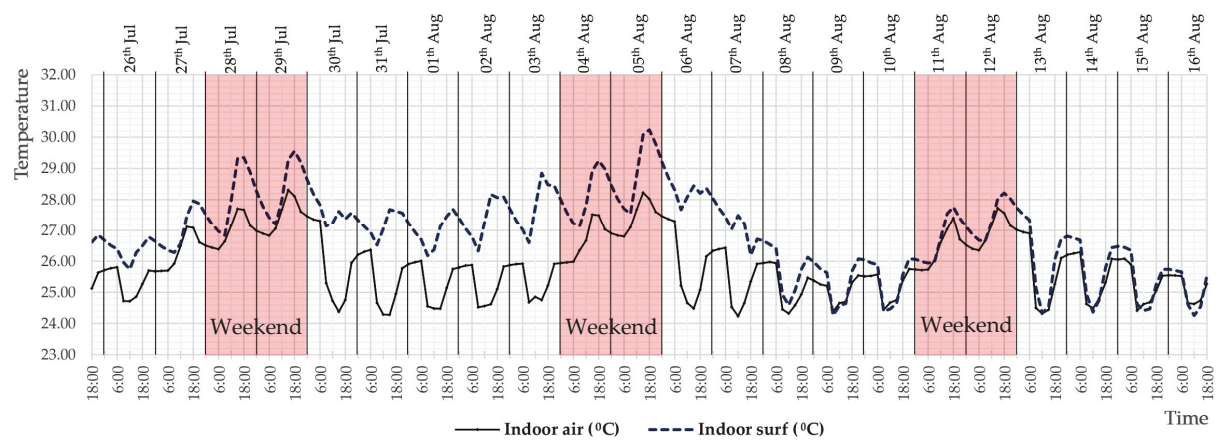

Figure 10. Wall surface and indoor air temperature behavior in Building "A".

\section{Conclusions-Generalized Findings}

Results suggest a problem associated with shallow plan form buildings. Although the work is mainly focused on two specific buildings, they represent most of the thermophysical characteristics of the larger building population in Colombo. Inward heat transfer across the plan depth up to $16 \mathrm{~m}$ in Building " $\mathrm{A}$ " and $12 \mathrm{~m}$ in Building " $\mathrm{B}$ " from the façade is a critical problem that may be addressed through appropriate façade design. Findings suggest that presence of heat stress in terms of higher air temperature in air conditioned indoors along the length of the plan form is visible.

Elevation of indoor air temperature in air conditioned environments by $10.5^{\circ} \mathrm{C}$ above the set point temperature is considered critical in respect to energy demand. The two buildings investigated fall within the following two extremes of thermal performance scenarios: 
1. Air conditioned buildings with shallow plan forms may be able to maintain indoor air temperatures close to set point temperatures at $24{ }^{\circ} \mathrm{C}$ but at a very high energy cost.

2. Air conditioned buildings with shallow plan forms can maintain a building energy index of $\sim 120 \mathrm{kWh} / \mathrm{m}^{2} / \mathrm{a}$, but maintaining indoor air temperature close to set point temperature becomes problematic and sometime an elevation of indoor air temperature by even $10.5^{\circ} \mathrm{C}$ above the set point temperature could be visible.

More research is underway to further strengthen these findings for a wider section of buildings in warm humid climates. The survey on plan form characteristics and orientation of a multi-level office building population in Colombo showed that nearly 80 per cent of buildings do not have appropriate orientation for solar defense. Their main building facades are facing either east or west orientations. A sound repositioning effort that focuses on minimizing environmental heat stress on building facades and thus exploring energy efficiency in multi-level commercial office building sector for the life of both exiting stock and new buildings is critical. This provides a level of opportunity for the building stakeholders to improve their asset values for the life of buildings and contribute to emission reduction targets.

While it is important to recognize that the results from the field investigations are not fully generalized due to limitations, the outcome on the heat stress behavior on conditioned office environments serves as a detailed comprehension for energy sustainability of office buildings. The better that architects and engineers understand the indoor thermal environment inside conditioned office buildings, the better design research will be able to link technological characteristics of envelope and plan form with energy consumption levels from heat stress on envelope towards a deeper comprehension of how best to reduce environmental heat stress on facades in the face of warming climates.

Author Contributions: U.R., Conceptualization, Methodology, Formal Analysis, Investigation, Draft Preparation, Final Writing, Project administration, U.R.

Funding: This research received a grant from National Research Council of Sri Lanka in order to purchase equipment. The grant number NRC/109/13.

Acknowledgments: The author acknowledges Grant No 109-13 of National Research Council of Sri Lanka for funding of equipment, as well as Indrika Rajapaksha and Waruni Jayasinghe for assisting the project administration; Ruksala Ishani, and Supun Rodrigo who have provided assistance in data collection.

Conflicts of Interest: The author declares no conflict of interest.

\section{References}

1. IPCC. Contribution of Working Groups I, II and III to the Fifth Assessment Report of the Intergovernmental Panel on Climate Change. In Climate Change 2014: Synthesis Report; Core Writing Team, Pachauri, R.K., Meyer, L.A., Eds.; IPCC: Geneva, Switzerland, 2014.

2. Seo, S.; Mendelsohn, R.; Munasinghe, M. Climate change and agriculture in Sri Lanka: A Ricardian valuation. Environ. Dev. Econ. 2005, 10, 581-596. [CrossRef]

3. Garnaut., R. The Garnaut Climate Change Review; Final Report; The Cambridge University Press: Cambridge, UK, 2008. Available online: http:/ / www.garnautreview.org.au (accessed on 12 November 2017).

4. Coley, D.; Kershaw, T. Changes in internal temperatures within the built environment as a response to a climate change. In Building and Environment; Elsevier Science: Amsterdam, The Netherlands, 2010; Volume 45, pp. 89-93.

5. Torcellini, P.; Pless, S.; Deru, M.; Crawley, D. Zero Energy Buildings: A Critical Look at the Definition; Conference Paper NREL/CP-550-39833; U.S. Department of Energy: Washington, DC, USA, June 2006.

6. Guan, L. Preparation of future weather data to study the impact of climate change on buildings. Build. Environ. 2009, 44, 793-800. [CrossRef] 
7. Howden, S.M.; Crimp, S. Effect of Climate and Climate Change on Electricity Demand in Australia. In Proceedings of the Integrating Models for Natural Resources Management Across Discipline, Issue and Scales, Canberra, Australia, 10-13 December 2001; Ghassemi, F., Whetton, P., Little, R., Littleboy, M., Eds.; MSSANZ Inc.: Canberra, ACT, Australia, 2001; pp. 655-660.

8. Lee, W.L.; Yik, F.W.H. Regulatory and voluntary approaches for enhancing building energy efficiency. Prog. Energy Combust. Sci. 2004, 30, 377-499. [CrossRef]

9. GBCA (Green Building Council of Australia. The Value of Green Star-A Dacade of Environmental Benefits, May 2013. Available online: http:/ / www.gbca.org.au (accessed on 22 January 2019).

10. Hyde, R.; Rajapaksha, I.; Groenhout, N.; Barram, F.; Rajapaksha, U.; Shahriar, A.N.M.; Candido, C. Towards a methodology for retrofitting commercial buildings using bioclimatic principles. In Proceedings of the 43rd ANZAScA Conference, The University of Tasmania, Hobart, Australia, 25-27 November 2009. Available online: http:/ / trove.nla.gov.au/version/170149721 (accessed on 20 January 2019).

11. De Wilde, P.; Coley, D. The implications of a changing climate for buildings. Build. Environ. 2012, 55, 1-7. [CrossRef]

12. Levin, M.D.; Price, L.; Martin, N. Mitigation options for carbon dioxide emissions from buildings. Energy Policy 1996, 24, 937-949. [CrossRef]

13. Burton, S.; Sala, M. Energy Efficient Office Refurbishment; Earthscan: London, UK, 2001.

14. Jenerette, G.D.; Harlan, S.L.; Brazel, A.; Jones, N.L.; Stefanov, W.L. Regional relationships between surface temperature, vegetation, and human settlement in a rapidly urbanizing ecosystem. Landsc. Ecol. 2007, 22, 353-365. [CrossRef]

15. McEvoy, D. Climate change and cities. In Built Environment; Alexandrine Press: Marcham, UK, 2007; Volume 33, No. 01; pp. 5-9.

16. Manjula, R.; Estoque, R.C.; Murayama, Y. An Urban Heat Island Study of the Colombo Metropolitan Area, Sri Lanka, Based on Landsat Data (1997-2017). ISPRS Int. J. Geo-Inf. 2017, 6, 189.

17. SLSEA. Energy Consumption in Buildings, Website of Sri Lanka Sustainable Energy Authority. 2017. Available online: www.energy.gov.lk (accessed on 27 September 2018).

18. Wijayatunga, P.D.C.; Fernando, W.J.L.S.; Shrestha, R.M. Greenhouse gas emission mitigation in the Sri Lanka power sector supply side and demand side options. Energy Convers. Manag. 2003, 44, 3247-3265. [CrossRef]

19. De Dear, R. The Adaptive Model of Thermal Comfort: Macquarie University's ASHRAE RP-884 Project. 2004. Available online: http:/ / aws.mq.edu.au/rp-884/ashrae_rp884_home.html (accessed on 28 August 2018).

20. Kwok Alison, G.; Rajkovich Nicholas, B. Addressing climate change in comfort standards. Build. Environ. 2010, 45, 18-22. [CrossRef]

21. LaSalle. Commercial Buildings Going Green. 2004. Available online: www.joneslasalle (accessed on 20 November 2017).

22. Olgyay, V. Design with Climate: Bioclimatic Approach to Architectural Regionalism; Princeton University Press: Princeton, NJ, USA, 1963.

23. Hyde, R. Climate Responsive Design: A Study of Buildings in Moderate and Hot Humid Climates; E and FN Spon: London, UK, 2000.

24. Hawkes, D. The theoretical basis of comfort in the selective control of environment. Energy Environ. 1982, 5, 127-134. [CrossRef]

25. Guan, L. Implication of global warming on Air- Conditioned office buildings in Australia. Build Res. Inf. 2009, 37, 43-54. [CrossRef]

26. Dascalaki, E.G.; Droutsa, K.; Gaglia, A.G.; Kontoyiannidis, S.; Balaras, C.A. Data collection and analysis of the building stock and its energy consumption. Energy Build. 2010, 42, 1231-1237. [CrossRef]

27. Lomas, K.J. Architectural design of an advanced naturally ventilated building form. Energy Build. 2007, 39, 166-181. [CrossRef]

28. Szokolay, S.V. An Introduction to Architectural Science: The Basis of Sustainable Design, 3rd ed.; Routledge, Taylor and Francis Group: New York, NY, USA, 2014.

29. Peterkin, N. Rewards for passive solar design in the Building Code of Australia. Renew. Energy 2009, 34, 440-443. [CrossRef]

30. Kabre, C. Trends in solar control in contemporary buildings. In Proceedings of the Thermal Performance and Comfort-ANzAScA 97 International Conference Session 2, The University of Queensland, Australia, 29 September-3 Octomber 1997; pp. 19-26. 
31. Haase, M.; da Silva, F.M.; Amato, A. Simulation of ventilated facades in hot and humid climates. Energy Build. 2009, 41, 361-373. [CrossRef]

32. Eskin, N.; Turkmen, H. Analysis of annual heating and cooling energy requirements for office buildings in different climates in Turkey. Energy Build. 2008, 40, 763-773. [CrossRef]

33. Napier, J. Climate Based Façade Design for Business Buildings with Examples from Central London. Buildings 2015, 5, 16-38. [CrossRef]

34. Trubiano, F. Performance Based Envelopes: A Theory of Spatialized Skins and the Emergence of the Integrated Design Professional. Buildings 2013, 3, 689-712. [CrossRef]

35. Parsons, K. Heat stress standards ISO 7243 and its global application. Ind. Health 2006, 44, 368-379. [CrossRef]

36. Chowdhury, S.; Hamada, Y.; Ahmed, K.S. Prediction and comparison of monthly indoor heat stress (WBGT and PHS) for RMG production spaces in Dhaka, Bangladesh. Sustain. Cities Soc. 2017, 29, 41-57. [CrossRef]

37. Lam, J.C. Energy analysis of commercial buildings in subtropical climates. Build. Environ. 2000, 35, 19-26. [CrossRef]

38. Baker, N.V. Passive and Low Energy Building Design for Tropical Island Climates; Commonwealth Secretariate: London, UK, 1987.

39. Feng, G.; Chi, D.; Xu, X.; Dou, B.; Sun, Y.; Fu, Y. Study on the Influence of Window-wall Ratio on the Energy Consumption of Nearly Zero Energy Buildings. Procedia Eng. 2017, 205, 730-737. Available online: www.sciencedirect.com (accessed on 18 November 2018). [CrossRef]

40. McKeen, P.; Fung, A.S. The Effect of Building Aspect Ratio on Energy Efficiency: A Case Study for Multi-Unit Residential Buildings in Canada Philip. Buildings 2014, 4, 336-354. [CrossRef]

41. Rajapaksha, I.; Rajapaksha, U. Criticality of Building Morphology on End Use Energy Demand: Evidence based assessment of urban office stock in Colombo Metropolitan Region. In Proceedings of the Symposium of Sri Lanka Sustainable Energy Authority, Colombo, Sri Lanka, 6-7 December 2017.

42. Lee, W.V.; Steemers, K. Exposure duration in overheating assessment: A retrofit modeling study. Build. Res. Inf. 2017, 45, 6-12.

43. Jayatilake, K.; Rajapaksha, U. Interactive architecture and contextual adaptability: Issues of energy sustainability in contemporary tall office buildings in Colombo. In Building the Future-Sustainable and Resilient Built Environments, Proceedings of 9th FARU International Research Conference, Colombo, Sri Lanka, 9-10 September 2016; Rajapaksha, U., Ed.; University of Moratuwa: Moratuwa, Sri Lanka, 2016; pp. 354-366.

44. Yau, Y.H.; Hasbi, S. A review of climate change impacts on commercial buildings and their technical services in the tropics. Renew. Sustain. Energy Rev. 2013, 18, 430-441. [CrossRef]

45. Goulding, J.R.; Lewis, J.O.; Steemers, T.C. (Eds.) Energy Conscious Design; BT. Batsford for the Commission of the European Communities: London, UK, 1992.

46. UN DESA. 2018 Revision of World Urbanization Prospects; United Nations-Department of Economic and Social Affairs, Multimedia Library Publications, 16 May 2018; Population Division of UN. Available online: www.un.org (accessed on 20 January 2018).

47. UNFPA. UNFPA Report on 'State of the World's Population 2007; UNFPA: New York, NY, USA, 2007.

48. Ukkwatta, N.L.; Dayawansa, N.D.K. Urban Heat Islands and the Energy Deamn: An Analysis for Colombo City of Sri Lanka Using Thermal Remote sensing data. Soc. Soc. Manag. 2012, 1, 124-131.

49. Mortimer, N.D.; Ashley, A.; Elsayed, M.; Kelly, M.D.; Rix, J.H.R. Developing a database of energy use in the UK non-domestic building stock. Energy Policy 1999, 27, 451-468. [CrossRef]

50. Choudhary, R.; Tiran, W. Influence of district features on energy consumption in non-domestic buildings. Build. Res. Inf. 2014, 42, 32-46. [CrossRef]

51. Depecker, P.; Menezo, C.; Virgone, J.; Lepers, S. Design of building shapes and energetic consumption. Build. Environ. 2001, 36, 627-635. [CrossRef]

52. Catalina, T.; Virgone, J.; Iordach, V. Study on the impact of building form on the energy consumption. In Proceedings of the Building Simulation, 12th Conference of International Building Performance Simulation Association, Sydney, Australia, 14-16 November 2011; pp. 1726-1729.

53. Tsikaloudaki, K.; Laskos, K.; Bikas, D. On the establishment of climatic zones in Europe with reagrd to the energy performance of buildings. Energies 2012, 5, 32-44. [CrossRef]

54. Wijayatunga, P.; Attalage, R. Analysis of rural households energy supplies in Sri Lanka: Energy efficiency, fuel switching and barriers to expansion. Energy Convers. Manag. 2003, 44, 1123-1130. [CrossRef] 
55. Ratnaweera, C.; Hestnes, A.G. Enhanced cooling in typical Srilankan dwellings. Energy Build. 1996, 23, 183-190. [CrossRef]

56. ECG19. Energy Consumption Guide: Energy Use in Offices. 2003. Available online: http:www.cibse.org (accessed on 9 September 2018).

(c)

(C) 2019 by the author. Licensee MDPI, Basel, Switzerland. This article is an open access article distributed under the terms and conditions of the Creative Commons Attribution (CC BY) license (http:/ / creativecommons.org/licenses/by/4.0/). 
Article

\title{
Impact of Heat Pump Flexibility in a French Residential Eco-District
}

\author{
Camille Pajot ${ }^{1, *}$, Benoit Delinchant ${ }^{1}$ (D), Yves Maréchal ${ }^{1}$ and Damien Frésier ${ }^{2}$ \\ 1 University Grenoble Alpes, CNRS, Grenoble INP, G2Elab, 38000 Grenoble, France; \\ benoit.delinchant@g2elab.grenoble-inp.fr (B.D.); yves.marechal@g2elab.grenoble-inp.fr (Y.M.) \\ 2 Gaz et Electricité de Grenoble, 57 Rue Pierre Semard, 38000 Grenoble, France; d.fresier@geg.fr \\ * Correspondence: camille.pajot1@g2elab.grenoble-inp.fr; Tel.: +3-347-682-7080
}

Received: 23 August 2018; Accepted: 17 October 2018; Published: 19 October 2018

check for updates

\begin{abstract}
This paper investigates the impact of load shedding strategies on a block of multiple buildings. It particularly deals with the quantification of the factors i.e., peak shaving, occupants' thermal comfort or $\mathrm{CO}_{2}$ emission reduction and how to quickly quantify them. To achieve this goal, the paper focuses on a new residential district, thermally fed by heat pumps. Four modeling approaches were implemented in order to estimate buildings' response towards load shedding. Two schemes were combined in order to study an overall load shedding. This strategy for the neighborhood has proved itself efficient for both peak shaving and thermal comfort. Most of the clipped heating load during the peak period is shifted to low-consumption periods, providing an effective peak shaving. The thermal comfort is guaranteed for at least $96 \%$ of the time. For $\mathrm{CO}_{2}$ emissions reduction, the link between consumption reduction and $\mathrm{CO}_{2}$ emissions savings should be realized carefully, since shifting the consumption could increase these emissions.
\end{abstract}

Keywords: peak shaving; demand response; block of buildings; thermal model; TEASER

\section{Introduction}

\subsection{Background}

Within three years of the 21st United Nations Climate Change Conference (COP21), a number of energy transition policies have been carried out in order to respect the Paris Agreement in keeping the global average temperature below $2{ }^{\circ} \mathrm{C}$ of pre-industrial levels [1]. The massive integration of renewable energy sources, together with the electrical peak consumption augmentation put load flexibility in a central position in regards to energy transition strategies, as it could help to guarantee grid stability [2].

Many new stakeholders, as well as new markets, appear in order to modulate electrical consumption [3]. However, aggregators mostly apply these demand response strategies on electricity-intensive industries, excluding lower power level sites such as buildings. Nevertheless, the latter represents a large share of global energy consumption. Owing to their thermal inertia, different load shedding schemes (recurring or non-recurring) can be implemented on the buildings; yet the flexibility of these schemes is hard to evaluate quickly.

Therefore, it became one of the key points studied in the European project City-zen [4]. Our collaborative effort with the local Distribution System Operator (DSO), Grenoble Electricity and Gas (GEG), takes place in this context and focuses on a new residential eco-district. This district consists of 23 residential buildings having 264 apartments and is thermally fed by ground source heat pumps (GSHP); thus emphasizing the primary use of electrical energy for heating purposes. Indeed, GSHP represent a significant research field [5,6], so that they are at the cutting edges of research with the demand side management (DSM) in order to manage electric grid constraints [7]. 


\subsection{Literature Review}

On the one hand, peak-shaving strategies are widely studied in order to deal with electric grid constraints [8]. On the other hand, DSM becomes more studied at a local scale [9], focusing on local energy integration [10], demand curve smoothing [11] or economic purposes [12]. These two combined lead to an increase of research papers on the field of peak-shaving for better management of local electric grid constraints through DSM [13].

The idea of using buildings' thermal inertia in order to modulate the heating load is also vastly studied. While buildings' flexibility is studied with several aims such as increasing district heating efficiency $[14,15]$ or for a better integration of local production sources [16], it is also investigated with the objective to evaluate what could be their future impact in smartgrids [17] and to compare them to storage solutions [18]. Several methodologies have been developed in order to quantify this flexibility but only three are commonly applied using building structural mass [19]. Moreover, only a few of these papers evaluate the impact on thermal comfort as they mostly consider it as a constraint [20]. In our case, the possibility to be out of the comfort zones will be considered, usually defined by set-point temperature ranges $[18,21]$, while estimating this impact by standing on comfort ranges as defined in [22].

Most of the time, estimating the building temperature is possible as the building thermal flexibility quantification is based on thermal models. These models can be from low-order RC models [23] to higher-detailed models often based on widespread tools such as EnergyPlus [18,24] or based on the Modelica language such as the library IDEAS [25]. Even the district scale becomes more and more widespread in the energetic dynamic simulation software, like DIstrict MOdeller and SIMulator (DIMOSIM) developed by CSTB [26], City Energy Analyst (CEA) developed by ETH Zurich [27] or Tool for Energy Analysis and Simulation for Efficient Retrofit (TEASER) developed by RWTH Aachen [28]. It was observed that this scale change could be impractical by being relevant to annual heating needs, but not anymore when focusing on power analysis [29]. For this reason, models with different levels of detail have been studied.

\subsection{Context and Aims of the Study}

In the local context of Grenoble, an electrical consumption peak appears between 5 a.m. and 10 a.m. GEG is interested in peak shaving during this morning period by implementing effective load shedding scheme. However, it could be hard to quickly quantify the impact of load shedding strategies through peak shaving while avoiding thermal discomfort for occupants and an increase in carbon footprint simultaneously.

Indeed, the problem is complex to model. In order to maintain occupants' thermal comfort, load shedding can be realized after an over-heating so that the building could store heat before disconnecting the heating system. As it induces an over-consumption, this over-heating should be performed before the peak period (i.e., between 5 a.m. and 10 a.m. in our case), with the purpose of reducing the consumption peak. In order to study a strategy of district peak reduction by deliberate load shedding building by building, two load shedding strategies (with or without over-heating) will be compared.

This paper aims to quickly quantify the influence of this district heat load shedding strategy on the heat load curve, thermal comfort and greenhouse gases emissions reduction. Moreover, the study will try to quantify the impact of heat load profiles modeling on the results.

\subsection{Paper Structure}

The first section of this paper describes the methods used for load shedding impact quantification. At first, the impact indicators in terms of peak shaving, thermal comfort and $\mathrm{CO}_{2}$ reduction will be defined. Then, the heat load profiles modeling will be presented. Finally, the load shedding scenarios studied in the paper will be introduced. In the 'Results' section, the two load shedding strategies will 
be analyzed on a building with respect to the indicators introduced earlier. The results will show the impact on three aspects: peak-shaving, thermal comfort, and $\mathrm{CO}_{2}$ emissions while analyzing the effect of the heat load profiles modeling. A conclusion will be drawn at the end of the paper based on the observed results.

\section{Methods for Impact Quantification of Load Shedding}

\subsection{Indicators for Impact Quantification of Load Shedding}

\subsubsection{Peak Shaving}

In order to quantify the amount of load reduction in a district, the key indicators will be defined first. Many studies show some rebound effects after a load shedding, related to the restart of the consumption [30]. This behavior could not only affect the energy conservation by providing any (or few) consumption reductions at a daily scale, but it could also lead to failure of peak shaving strategy. Indeed, if concentrated during a short period, a load shifting could cause bigger grid constraints during this time period. For this reason, in order to quantify the impact of load shedding strategies for peak shaving purpose, the consumption behaviour after the load shedding period has to be analyzed. To do so, the study is based on one indicator used by the French TSO RTE [31] (cf. Equations (1)-(4) and (8)). The daily Load Shifting rate $\left.\left(L S_{\text {rate }}^{d}\right)\right)$ is defined in Equation (1) from the ratio of the addition of anticipated energy and delayed energy, by the cut-off energy. These three energies are defined in Equations (2)-(4) by the integral in a given period of the consumption power $\left(P_{t}\right)$ and its reference value without operation $\left(P_{t}^{r e f}\right)$. These energies are also visible in Figure 1.

$$
L S_{\text {rate }}^{d}=\frac{E_{\text {anticipated }}+E_{\text {delayed }}}{E_{\text {cut_off }}}
$$

where:

$$
\begin{gathered}
E_{\text {cut_off }}=\int_{\tau_{l s}^{b}}^{\tau_{l s}^{e}} P_{t}^{r e f} \mathrm{~d} t \\
E_{\text {anticipated }}=\int_{\tau_{l s}^{b}-1}^{\tau_{l s}^{b}}\left(P_{t}-P_{t}^{r e f}\right) \mathrm{d} t \\
E_{\text {delayed }}=\int_{\tau_{l s}^{e}}^{\tau_{l s}^{e}+23}\left(P_{t}-P_{t}^{r e f}\right) \mathrm{d} t
\end{gathered}
$$

By taking into account the energy reported during the $23 \mathrm{~h}$ following the load shedding, this indicator gives information at a daily scale. However, in order to get a better understanding of the dynamic behavior of this energy report, the study will rather focus on an adapted form of this load shifting rate, that we proposed, defined in Equation (5). This indicator will be calculated on an hourly basis in order to quantify the distribution of energy report, hour by hour, as shown in Figure 1.

$$
L S_{\text {rate }}^{h}=\frac{\int_{h}^{h+1}\left(P_{t}-P_{t}^{r e f}\right) \mathrm{d} t}{E_{\text {cut_off }}}
$$

Defined as such, the load shifting rate can be used to study dynamically the load variations and gives information on the efficiency of the load shedding strategy to reduce a long peak period (more than one hour). 


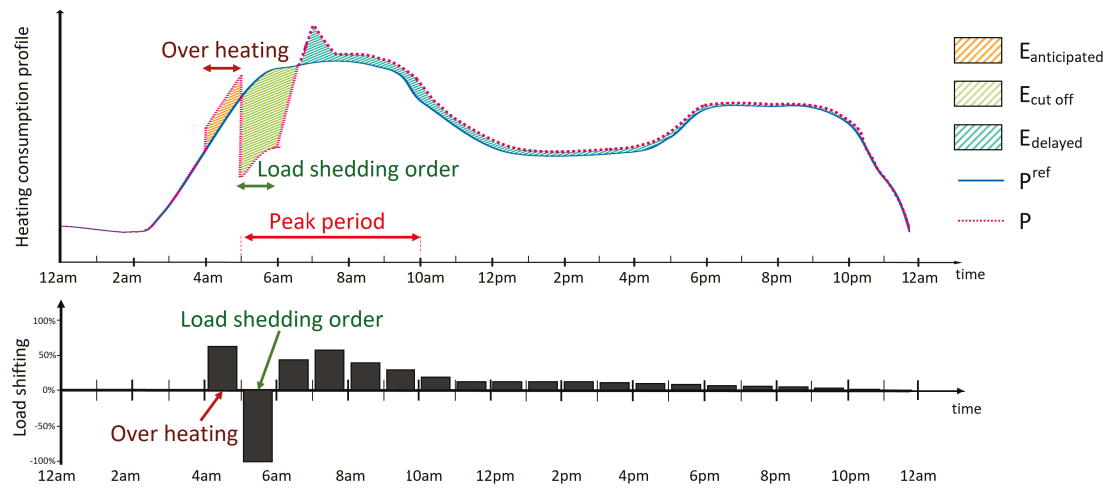

Figure 1. Representation of a daily heating load curve modification with a load shedding order and associated load shifting rates.

\subsubsection{Thermal Comfort}

It is important to keep in mind that turning off the heat supply can affect the thermal comfort so that this aspect has to be estimated too. When the thermal supply of a building is turned off, the internal temperature does not decrease instantaneously to the level of external temperature. This building dynamic can be explained by the possibility for buildings to store heat in their heavy components, such as walls. Indeed, due to their significant inertia, walls will cool later than the air, in cases of heating load shedding. The phenomena are important in terms of comfort, as walls and air temperatures respectively reflect radiation and convection effects perceived by the occupants of the building. Since the feeling of thermal comfort is related to this perception of both air and wall temperature, studies analyzed the relationship between thermal comfort and the operative temperature ( $T_{o p}$, defined Equation (6)) [32].

$$
T_{o p}=\frac{T_{\text {walls }}+T_{\text {air }}}{2}
$$

In this study, this operative temperature will be taken as an indicator in order to estimate the comfort level, according to levels defined in [22]:

- Comfortable: A range of $+/-1^{\circ} \mathrm{C}$ about the temperature set-point $\left(T_{\text {set }}\right)$

- Slightly uncomfortable: A range of $+/-1{ }^{\circ} \mathrm{C}$ and $+/-2{ }^{\circ} \mathrm{C}$ about $T_{\text {set }}$

- Uncomfortable: A difference of more than $2{ }^{\circ} \mathrm{C}$ with $T_{\text {set }}$

\subsection{3. $\mathrm{CO}_{2}$ Emissions Reduction}

Finally, the impact of the different load shedding methods on $\mathrm{CO}_{2}$ emissions will be studied. To do so, the work will rely on the actual $\mathrm{CO}_{2}$ emissions from the French power generation in January 2016 [33]. This will allow us to estimate the gross $\mathrm{CO}_{2}$ emissions variation when the load shedding strategies will be applied while taking into account hourly and daily variation (see Equation (7)).

$$
\mathrm{CO}_{2} \mathrm{~S}^{m}=\frac{\int_{\text {month }}\left(\mathrm{CO}_{2_{t}}^{\text {ref }}-\mathrm{CO}_{2_{t}}\right) \mathrm{d} t}{\int_{\text {month }}\left(\mathrm{CO}_{2_{t}}^{\text {ref }}\right) \mathrm{d} t}
$$

This variation not only takes into account the load shifting, but also the consumption reduction. Moreover, it is very common to conclude that $\mathrm{CO}_{2}$ emissions will obviously decrease with load 
shedding strategies when there is energy saving. A widespread indicator for energy saving [31] is the daily Energy Saving rate $\left(E S_{\text {rate }}^{d}\right)$ defined as follows:

$$
E S_{\text {rate }}^{d}=\frac{E_{\text {cut_off }}-E_{\text {anticipated }}-E_{\text {delayed }}}{E_{\text {cut_off }}}
$$

This energy saving rate is commonly used to quantify energy balance in the long-run by showing the amount of non-reported energy $23 \mathrm{~h}$ after [31]. The energy saving rate should be put into perspective, as it represents saving in regard to cut-off energy. Since the energy saving of an entire day is much lower than $E S_{\text {rate }}^{d}$, the reduction of daily $\mathrm{CO}_{2}$ emissions would be lowered too.

$$
E S^{m}=\frac{\int_{\text {month }}\left(P_{t}^{r e f}-P_{t}\right) \mathrm{d} t}{\int_{\text {month }}\left(P_{t}^{r e f}\right) \mathrm{d} t}
$$

Nevertheless, this does not prevent us from expecting that $\mathrm{CO}_{2}$ emissions would decrease as much as daily consumption. To deeply examine the impact on district carbon footprint, it is crucial to consider the daily and intra-day $\mathrm{CO}_{2}$ emission variability for the electrical energy generation. Shifting the electrical consumption from one time period to another could increase the $\mathrm{CO}_{2}$ emissions if local peaks do not match the total electricity generation.

For all these reasons, the paper will compare the total consumption reduction $\left(E S^{m}\right)$ to the total $\mathrm{CO}_{2}$ emissions reduction during the month $\left(\mathrm{CO}_{2} S^{m}\right)$. Doing this will help us in combining the two reduction factors (energy consumption and $\mathrm{CO}_{2}$ emissions) into a single indicator, the Expected Gain reduction $\left(E G_{r e d}\right)$, defined as follows:

$$
E G_{r e d}=\frac{E S^{m}-\mathrm{CO}_{2} S^{m}}{E S^{m}}
$$

\subsection{Heat Load Profiles Models}

According to the previously defined indicators, the thermal load variation between no-load shedding and the applied load shedding strategy need to be assessed in order to quantify the impact on peak shaving and $\mathrm{CO}_{2}$ emissions. In the present study, two modeling approaches will be compared. At first, a standard load shifting profile will be established with experimental data. Then, thermal models with several levels of details will be introduced in order to assess thermal comfort.

\subsubsection{Experimental Load Shifting Profile}

A first estimation can rely on experimental results from similar buildings and load shedding strategies. The main advantage of this method is to assess very quickly the peak shaving indicator. To do so, a standard load shifting rate profile was defined, based on experimental results from the French GreenLys project [34] and from a study led by the French TSO RTE [31]. As the experimental building stock contains two new eco-districts [34], the use of the resulting standard profile is considered suitable for our new residential district. The experimental results show an energy saving rate around $90 \%$. The load shifting rate profiles are plotted below.

Figure $2 \mathrm{a}$ is representing the hourly load shifting rates for a one-hour residential heat load shedding without pre-heating, while Figure $2 \mathrm{~b}$ shows it after an over-heating of one hour, consuming $50 \%$ of the cut-off energy. 


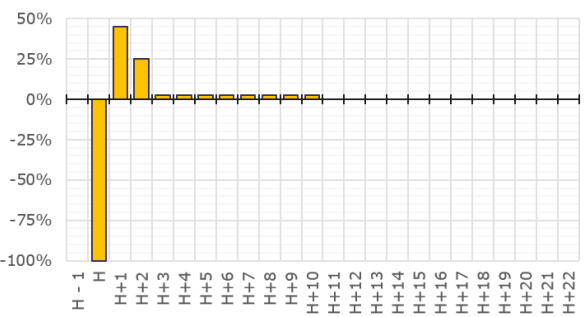

(a)

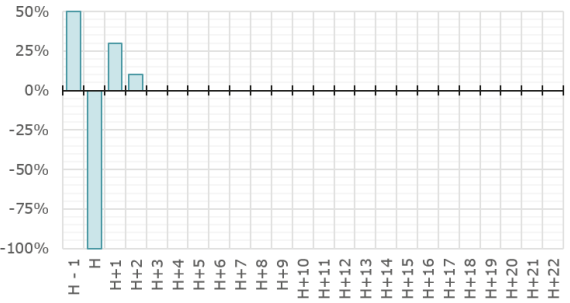

(b)

Figure 2. Load shifting rate profiles. (a) One-hour residential heat load shedding without pre-heating (b) One-hour residential heat load shedding after one-hour pre-heating.

\subsubsection{Thermal Models}

In order to quantify the impact on thermal comfort, it is also necessary to estimate $T_{o p}$ (cf. Equation (6)). For this reason, two thermal models with identified parameters were used in order to simulate the building dynamic during and after the load shedding.

In order to manage both modelings (thermal model of the building and electric model of the grid), an open-source tool, TEASER [35] was chosen for the first thermal model creation. It allows to automatically generate RC thermal models in the Modelica language for the AixLib [36] and the Annex60 [37] libraries.

The thermal model can be created thanks to building envelope information (wall areas, orientations, thickness, materials, etc.). As it can be difficult to access the specific data about each building envelope at district level, it can be realized with at least 5 input data: year of construction, net area, type of use, number of floors and height of each floor [35], making the tool very useful for saving time. If only this data is given, the tool enriches the dataset based on pre-defined statistical data, whose use in a French context will be analyzed in this study case.

For the same thermal model structure (see Figure 3), two precision levels can be achieved depending on the input data. In order to compare the impact of dataset enrichment, both the model generated with the 5 minimal parameters and the model enriched with the building envelope data were analyzed. The first one will further be referred to as the 'Simple' model, while the second one enriched with data used for the regulatory Building Energy Simulation (BES) will further be referred to as the 'Enriched' model.

The second one is the fully detailed thermal model used for the mandatory study. Indeed, in a French context, since each building construction requires an energy requirement study based on a fully detailed thermal model, existing thermal models from this mandatory study can also be re-used. In this study, a Pleiades tool [38] has been used to build a detailed model (each room is considered as a thermal zone), that will be called 'Complex' model afterward.

For all heat load profiles from simulation models, the result from a thermal dynamic simulation of a building in our district was considered as reference heat load profile $\left(P_{t}^{r e f}\right)$. The building behavior in the case of a temperature set-point of $20^{\circ} \mathrm{C}$ was simulated during the month of January. All other data: weather, occupancy schedules, internal gains for lightning etc. have been set to the same values in order to obtain a better comparison between simulation results. However, the set-point temperatures for the 'Simple' and 'Enriched' models are ambient temperatures, while the one in 'Complex' model is on the operative temperature, and cannot be changed. Therefore, small differences between the results could still be expected. 


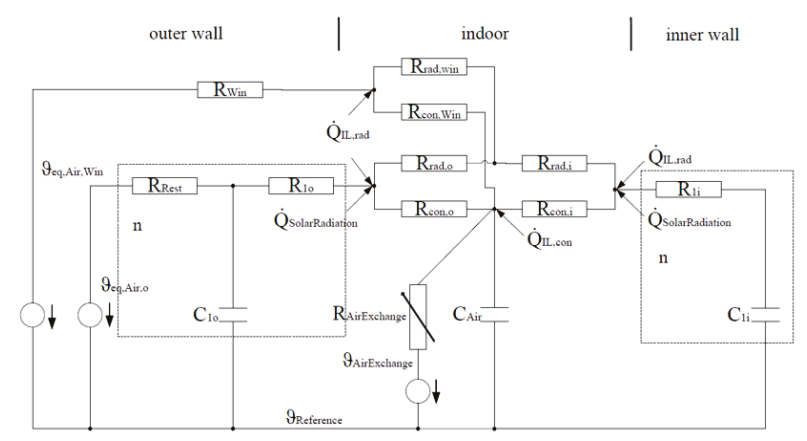

Figure 3. Scheme of the RC (Resistance Capacity) equivalent model generated by Tool for Energy Analysis and Simulation for Efficient Retrofit (TEASER).

\subsubsection{Summary of Modeling Approaches}

To summarize, four modeling approaches are considered in order to estimate the load shifting rates is this paper:

- The 'Standard' model: the statistical model from experimental data

- The 'Simple' model: thermal model generated by TEASER (Figure 3) with database

- The 'Enriched' model: thermal model generated by TEASER (Figure 3) with building envelope data

- The 'Complex' model: multi-zone thermal model created with a Pleiades tool.

\subsection{Modeling of Load Shedding Scenarios}

For the aforementioned models, two scenarios will be studied:

- One-hour thermal load shedding after one-hour over-heating: In order to over-heat the building outside of the peak period ( 5 a.m. to 10 a.m.), the load shedding order will be applied from 5 a.m. to 6 a.m.

- Simple one-hour thermal load shedding: In this scenario, the load shedding will be applied in the middle of the peak period, from 7 a.m. to 8 a.m. without any over-heating.

Each load shedding will be obtained by a very low set-point temperature (around $0{ }^{\circ} \mathrm{C}$ ) in order to cut the heat supply. The aim of these two scenarios is to represent the two load shedding approaches that could be made building by building in the district. For instance, by applying the first strategy (with over-heating) to a first building and then applying the second strategy to each of the four other buildings hour by hour, the resulting load shedding on the entire district would be obtained by adding the individual effects (see Figure 4).

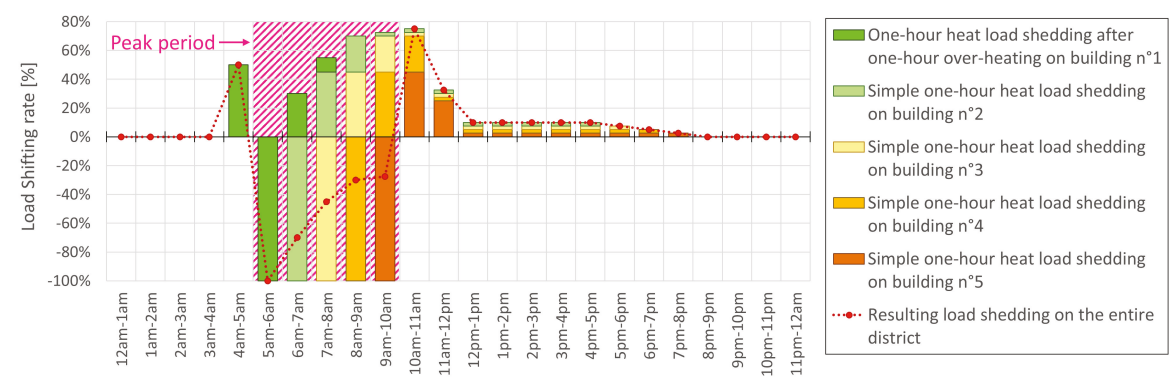

Figure 4. Load shifting rate profiles during a day for the multiple one-hour thermal load shedding from 5 a.m. to 10 a.m. Example of the 'Standard' model for load shifting rate profiles for 5 buildings. 


\section{Results and Discussion}

The load shedding impact in terms of peak shaving, thermal comfort and $\mathrm{CO}_{2}$ emissions will be analyzed in this section. As explained previously, the district load-shedding strategy consists in shedding thermal load for the buildings one by one for one hour. The first load shedding would integrate a one-hour over-heating during the previous hour, while all the following hours will face simple one-hour thermal load shedding. Two different building behaviors are thus expected for these two strategies.

\subsection{Results for Peak Shaving}

In order to reduce the mean power during the peak period, the load shifting rate would have to be the most diffused as possible to shift most of the consumption out of the peak period. Thus, the lower load shifting rates are, the higher the efficiency of peak shaving. As two dynamic responses are expected from the building depending on whether it has been previously over-heated or not, results will be demonstrated for both load shedding strategies. At first, results for a simple thermal load shedding happening from 7 a.m. to 8 a.m. each day of the month of January will be drawn. Then, the second load shedding strategy with a one-hour over-heating before cutting the heat supply will be shown. This load shedding will be applied from 5 a.m. to 6 a.m., in order to shift the anticipated consumption before the peak period.

\subsubsection{Thermal Load Shedding from 7 a.m. to 8 a.m.}

The results of the simple one-hour load shedding applied all days of January are displayed in Figure 5. The mean load shifting can be found for all of the four modeling approaches ('Standard', 'Simple', 'Enriched' and 'Complex'). The mean operative temperatures are also drawn with their variation range during the month.

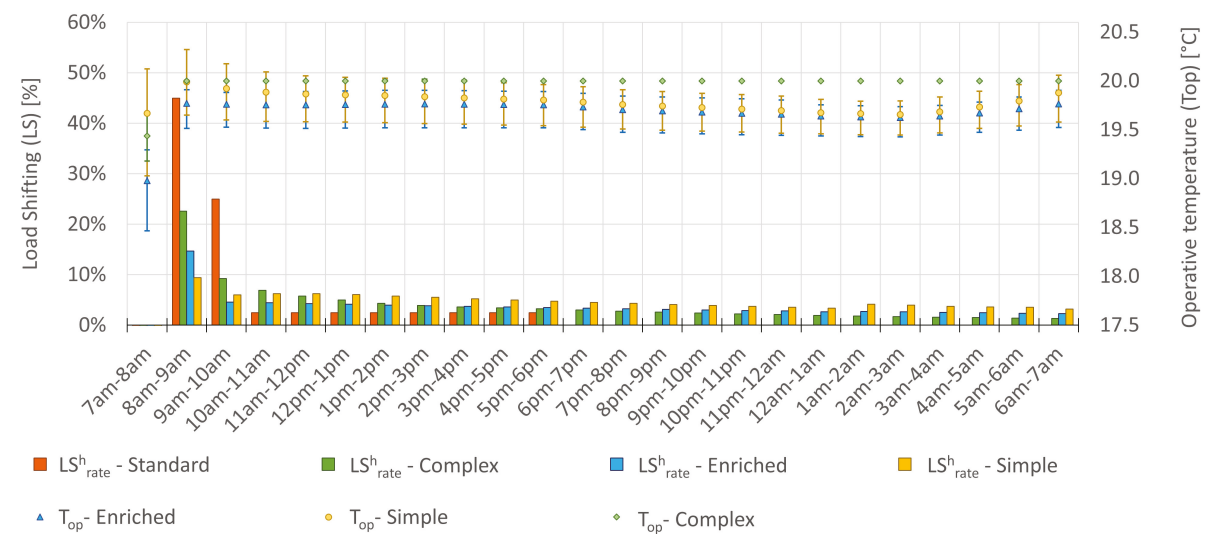

Figure 5. One-hour thermal load shedding.

Two different building behaviors can be observed for this strategy:

- Most of the rebound effect appears within the two hours following the load shedding (experimental load shifting profile)

- $\quad$ The shed consumption is shifted during the entire day (load shifting profiles from thermal models)

Here, it can be noticed that all the simulation results from thermal models show a slower dynamic than the experimental load shifting profile. 


\subsubsection{Heat Load Shedding from 5 a.m. to 6 a.m. after an Over-Heating in Preceding Hour}

The results of the complex one-hour thermal load shedding strategy, taking place from 5 a.m. to 6 a.m. after a one-hour over-heating are presented in Figure 6. The strategy was applied each day of January and results are the average value for each time slot and each modeling, like those presented in Figure 5. As seen before, there is a big difference between experimental and simulated buildings behaviors for simple heat load shedding strategy. This gap between models is therefore confirmed for this complex strategy too.

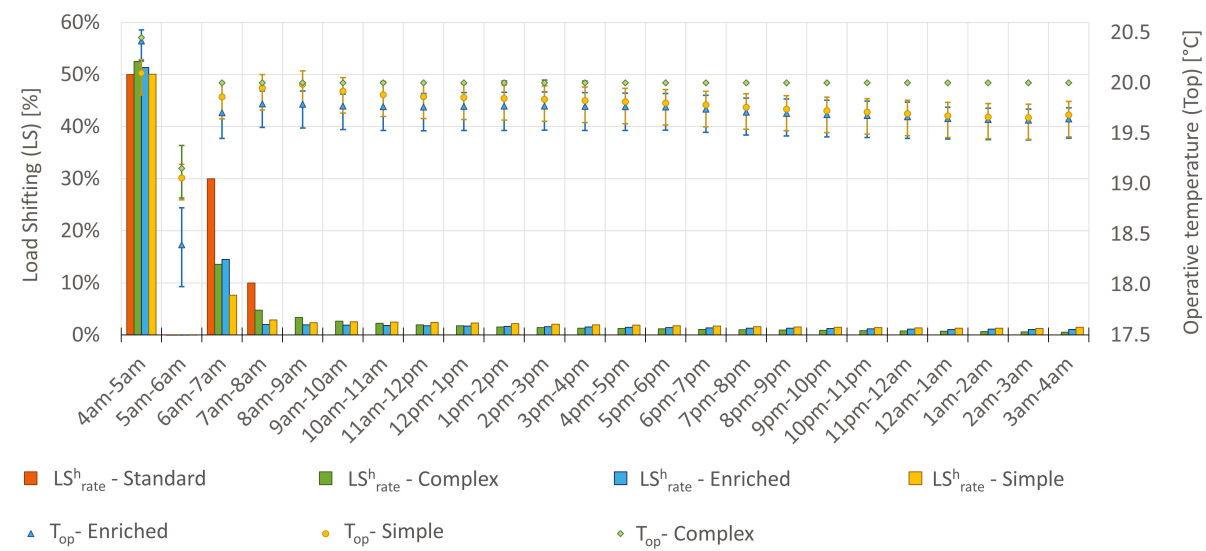

Figure 6. One-hour thermal load shedding after one-hour over-heating.

Although this standard profile was established from real measurement, it remains difficult to consider it as more reliable than simulated profiles. Indeed, weather and occupancy data differ and several types of buildings are aggregated. Even with fewer old buildings than new ones in the experiment, consumption values for heating tend to be higher for the first category and mean values could be strongly affected. In spite of this conclusion, the standard model reminds that occupancy behavior could play a great role in the rebound effect. In our study case, the thermal load is entirely controlled by the building manager, so this effect can be neglected.

Thus, conclusions on the effect of the overall strategy (starting with the complex strategy and continuing, building by building, with the simple load shedding) could be realized by analyzing the building behaviors predicted by thermal models. These three modeling approaches all lead to diffused energy reports so that it can be concluded that this load shedding strategy could be efficient in regards to a peak shaving objective, even if thermal comfort still needs to be looked at.

\subsection{Results for Thermal Comfort}

As explained above, the study focuses on the building operative temperature as thermal comfort indicator. With a set-point temperature fixed to $20^{\circ} \mathrm{C}$, the comfort zone is reached over $19{ }^{\circ} \mathrm{C}$ and below $21^{\circ} \mathrm{C}$. Results obtained for the month of January are presented in Figures 5 and 6 . Mean operative temperatures are represented, with their variation intervals, so that it can be noticed that:

- $\quad$ On average, load shedding hours are slightly uncomfortable

- On average, other hours of the days are comfortable

Distribution of comfort level for occupants for the load shedding strategy after an over-heating is presented in Table 1: 
Table 1. Thermal comfort levels distribution for the load shedding after over-heating strategy.

\begin{tabular}{cccc}
\hline & \multicolumn{3}{c}{ Load Shedding after over-Heating } \\
\hline Comfort level/Models & Reduced & Enriched & Complex \\
Comfortable & $98.5 \%$ & $96 \%$ & $100 \%$ \\
Slightly uncomfortable & $1.5 \%$ & $3.6 \%$ & $0 \%$ \\
Uncomfortable & $0 \%$ & $0.4 \%$ & $0 \%$ \\
\hline
\end{tabular}

Similar results are obtained for the load shedding strategy without over-heating. Most of the hours are "comfortable" (at least $96 \%$ of the time for all models) and "uncomfortable" level is rarely reached $(0.4 \%$ of the time and only with the 'Enriched' model). However, further studies on the impact of heating systems (as shown in [16]) or on the perception of this comfort could be needed to consolidate these results (as studied in [39]). As internal gains and external temperatures differ each hour, each time slot should be considered individually for further studies in the entire district impact. Finally, requiring less energy for heating purposes, new low-consumption buildings could get a large part of their heating needs from internal gains (lightning, devices, occupation, etc.). This would also have to be considered carefully in order to avoid an under-evaluation of thermal discomfort in buildings.

\subsection{Results for $\mathrm{CO}_{2}$ Emissions Reduction}

In this last section, the results for the impact on the carbon footprint are presented. The chosen indicator for the effect is the expected gain reduction $\left(E G_{r e d}\right)$, representing the difference between $\mathrm{CO}_{2}$ emission reduction expected by looking at the energy consumption savings $\left(E S^{m}\right)$ and the effective $\mathrm{CO}_{2}$ emission diminution $\left(\mathrm{CO}_{2} \mathrm{~S}^{m}\right)$. In order to put into perspective the feeling of savings obtained by looking at the mean $E S_{\text {rate }}^{d}$, the following Table 2 will also integrate it in comparison to the effective consumption reduction during the month $\left(E S^{m}\right)$.

Table 2. Consumption and $\mathrm{CO}_{2}$ emission reduction in January for the simple load shedding strategy (a) and for the load shedding after over-heating strategy (b).

\begin{tabular}{|c|c|c|c|}
\hline & \multicolumn{3}{|c|}{ (a) Load Shedding } \\
\hline Models & Simple & Enriched & Complex \\
\hline$E S_{\text {rate }}^{d}$ & $-10.0 \%$ & $13.1 \%$ & $5.5 \%$ \\
\hline$E S^{m}$ & $0.40 \%$ & $0.50 \%$ & $0.22 \%$ \\
\hline $\mathrm{CO}_{2} \mathrm{~S}^{m}$ & $0.38 \%$ & $0.50 \%$ & $0.16 \%$ \\
\hline \multirow[t]{2}{*}{$E G_{r e d}$} & $3.2 \%$ & $0.70 \%$ & $28 \%$ \\
\hline & \multicolumn{3}{|c|}{ (b) Load Shedding after over-Heating } \\
\hline Models & Simple & Enriched & Complex \\
\hline$E S_{\text {rate }}^{d}$ & $3.1 \%$ & $2.1 \%$ & $2.4 \%$ \\
\hline$E S^{m}$ & $0.21 \%$ & $0.22 \%$ & $0.14 \%$ \\
\hline $\mathrm{CO}_{2} S^{m}$ & $0.01 \%$ & $0.05 \%$ & $-0.06 \%$ \\
\hline$E G_{\text {red }}$ & $94 \%$ & $76 \%$ & $144 \%$ \\
\hline
\end{tabular}

For the load shedding between 7 a.m. and 8 a.m. (simple load shedding), the intuition is confirmed since the overall consumption reduction leads to the reduction of the $\mathrm{CO}_{2}$ emission, though a little less than expected. However, for the second strategy with overheating, reduction of $\mathrm{CO}_{2}$ emission is not so obvious anymore. Depending on the models, the expected $\mathrm{CO}_{2}$ emission reduction is lower than the calculated one. It goes from $76 \%$ less than expected to an increase of $44 \%$ of $\mathrm{CO}_{2}$ emissions. In terms of avoided $\mathrm{CO}_{2}$ emissions, the savings go from $245 \mathrm{~g}\left(\mathrm{CO}_{2} \mathrm{~S}^{m}=0.01 \%\right)$ to $7.82 \mathrm{~kg}\left(\mathrm{CO}_{2} \mathrm{~S}^{m}=0.38 \%\right)$ The reason for these differences is that the load is transferred from a low- $\mathrm{CO}_{2}$ emissions time slot to higher $\mathrm{CO}_{2}$ emissions times of the day. In order to be consistent with energy transition strategies, it is 
important to consider this aspect into load shedding impact evaluation to avoid a local amelioration to the detriment of general interest.

\section{Conclusions}

With often few data available at the district level, thermal models with parameters from the statistical database could provide coherent load shedding impacts results, in respect to those available with detailed thermal simulation models. However, a comparison between simulation results and measurements would be necessary to validate the accuracy of the results, although it was unfortunately impossible due to lack of data on the considered buildings and external factor such as occupation schedules and weather data. For our study case, thermal models are considered as reliable for trend estimation on the effects on peak shaving, thermal comfort and $\mathrm{CO}_{2}$ emissions reduction for a first approach at a district scale. The overall strategy for the district studied in this paper relies on two load shedding approaches:

- An overheating from 4 a.m. to 5 a.m. before load shedding from 5 a.m. to 6 a.m.

- One-hour load shedding building by building beginning from 6 a.m. to 9 a.m.

The two approaches were analyzed separately for these three aspects:

- Peak shaving

Turning off the heating supply for one hour successively for building by building in an entire district seems to be effective for peak-shaving. Indeed, the transferred load is very diffused ( $L S_{\text {rate }}^{h}<25 \%$ the first hour and $L S_{\text {rate }}^{h}<10 \%$ the following hours) so that the rebound effects of the previous buildings do not cancel the peak reduction obtained by the current load shedding. These results are crucial in the case of a long peak (more than an hour), offering the possibility to shift the load outside consumption peak period.

- Thermal comfort

Thermal comfort is reduced during the load-shedding hours. Measurements would have to be realized in order to determine if operative temperature evaluation is more reliable when based on the 'Simple' model, the 'Enriched' model or the 'Complex' model. Indeed, the 'Complex' model assessed only $0.8 \%$ of the time as not comfortable, while this discomfort could cover up to $4 \%$ of the time with the 'Enriched' model. Moreover, the 'Enriched' model gives a minimal operative temperature of $18{ }^{\circ} \mathrm{C}$, while the operative temperatures estimated by the 'Simple' and the 'Complex' models never reach values below $18.8^{\circ} \mathrm{C}$. The different modeling approaches used do not allow to estimate precisely how much thermal comfort can be reduced and how it will be perceived by occupants but they help the stakeholder understand what could be the issue. In all cases, one solution to investigate the reduction of thermal discomfort could be to reduce heat loads instead of shedding them, or to turn off the thermal load during shorter duration.

- $\mathrm{CO}_{2}$ emission reduction

In the case of $\mathrm{CO}_{2}$ emission reduction, estimation cannot be based only on consumption reduction as $\mathrm{CO}_{2}$ emission for electrical systems have dynamic variations that have to be taken into account. Only by considering dynamic $\mathrm{CO}_{2}$ variations and by calculating the difference between emissions with or without load shedding strategy could lead to a reliable estimation of $\mathrm{CO}_{2}$ emissions variations. Indeed, even with effective consumption diminution, a load shedding strategy could shift consumption from low- $\mathrm{CO}_{2}$ periods to higher- $\mathrm{CO}_{2}$ time slots, increasing the overall $\mathrm{CO}_{2}$ emissions. For instance, in the case of the load shedding after over-heating, the 'Complex' model assessed $0.14 \%$ of energy saving during the month, while the $\mathrm{CO}_{2}$ emissions increased from $0.06 \%$. Therefore, the link between energy saving and $\mathrm{CO}_{2}$ emission reduction has to be realized carefully.

Finally, the modeling approach will depend on the accuracy required, the data available and the time for the study design, so that mixing modeling approaches for a study at the district scale may be required. A further work will consist in coupling the reduced thermal models together with 
generation parameters tools into an optimization library. This optimization point of view could allow stakeholders such as DSOs to define the best load shedding sequences in a district in order to maximize peak-shaving while minimizing both the occupants' thermal discomfort and $\mathrm{CO}_{2}$ emission.

Author Contributions: Resources, D.F.; Supervision, B.D. and Y.M.; Writing—original draft, C.P.; Writing一review \& editing, B.D., Y.M. and D.F.

Funding: This work has been partially supported by the ANR project ANR-15-IDEX-02.

Conflicts of Interest: The authors declare no conflict of interest.

\author{
Abbreviations \\ The following abbreviations are used in this manuscript: \\ COP21 21th Conference of the Parties \\ CSTB French Scientific and Technical Center for Building \\ DSM Demand Side Management \\ DSO Distribution System Operator \\ GEG Grenoble Gas and Electricity \\ GSHP Ground Source Heat Pumps \\ RTE French transmission system operator \\ TEASER Tool for Energy Analysis and Simulation for Efficient Retrofit \\ TSO Transmission System Operator \\ UNFCCC United Nations Framework Convention on Climate Change
}

\title{
Nomenclature
}

\begin{tabular}{|c|c|c|}
\hline $\mathrm{CO}_{2_{t}}$ & {$[\mathrm{~kg}]$} & $\mathrm{CO}_{2}$ emissions at time $t$ (with load shedding) \\
\hline $\mathrm{CO}_{2_{t}}^{r e f}$ & {$[\mathrm{~kg}]$} & Reference $\mathrm{CO}_{2}$ emissions at time $t$ (without load shedding) \\
\hline $\mathrm{CO}_{2} S^{m}$ & {$[\%]$} & $\mathrm{CO}_{2}$ Saving in a month (Reduction of $\mathrm{CO}_{2}$ emission on the month) \\
\hline Eanticipated & {$[\mathrm{kWh}]$} & Anticipated energy consumption during the hour before the load shedding \\
\hline$E_{\text {cut_off }}$ & {$[\mathrm{kWh}]$} & Cut-off energy consumption during the load shedding \\
\hline$E_{\text {delayed }}$ & {$[\mathrm{kWh}]$} & Delayed energy consumption during the $23 \mathrm{~h}$ after the load shedding \\
\hline$E G_{\text {red }}$ & {$[\%]$} & $\begin{array}{l}\text { Expected Gains Reduction }\left(\mathrm{CO}_{2} \text { emissions diminution expected by looking at the energy }\right. \\
\text { consumption reduction) }\end{array}$ \\
\hline$E S_{\text {rate }}^{d}$ & {$[\%]$} & Energy Saving rate defined $23 \mathrm{~h}$ after the load shedding \\
\hline$E S^{m}$ & [\%] & Energy Saving in a month (Reduction of energy consumption on the month) \\
\hline$L S_{\text {rate }}^{d}$ & [\%] & Load Shifting rate defined during a day \\
\hline$L S_{\text {rate }}^{h}$ & {$[\%]$} & Load Shifting rate defined during an hour \\
\hline$P_{t}$ & {$[\mathrm{~kW}]$} & Power consumed at time $t$ (with load shedding) \\
\hline$P_{t}^{r e f}$ & {$[\mathrm{~kW}]$} & Reference power consumed at time $t$ (without load shedding) \\
\hline$T_{\text {air }}$ & {$\left[{ }^{\circ} \mathrm{C}\right]$} & Ambient temperature \\
\hline$T_{\text {set }}$ & {$\left[{ }^{\circ} \mathrm{C}\right]$} & Set-point temperature \\
\hline$T_{o p}$ & {$\left[{ }^{\circ} \mathrm{C}\right]$} & Operative temperature \\
\hline$T_{\text {walls }}$ & {$\left[{ }^{\circ} \mathrm{C}\right]$} & Walls temperature \\
\hline$\tau_{l s}^{b}$ & {$[\mathrm{~h}]$} & Beginning of the load shedding \\
\hline$\tau_{l s}^{e}$ & {$[\mathrm{~h}]$} & End of the load shedding \\
\hline
\end{tabular}

\section{References}

1. The Paris Agreement/UNFCCC. Available online: https://unfccc.int/process-and-meetings/the-parisagreement/the-paris-agreement (accessed on 10 August 2018).

2. Lund, P.D.; Lindgren, J.; Mikkola, J.; Salpakari, J. Review of energy system flexibility measures to enable high levels of variable renewable electricity. Renew. Sustain. Energy Rev. 2015, 45, 785-807. [CrossRef]

3. Ponds, K.; Arefi, A.; Sayigh, A.; Ledwich, G.; Ponds, K.T.; Arefi, A.; Sayigh, A.; Ledwich, G. Aggregator of Demand Response for Renewable Integration and Customer Engagement: Strengths, Weaknesses, Opportunities, and Threats. Energies 2018, 11, 2391. [CrossRef] 
4. City-zen I New Urban Energy. Available online: www.cityzen-smartcity.eu (accessed on 19 June 2018).

5. Congedo, P.M.; Colangelo, G.; Starace, G. CFD simulations of horizontal ground heat exchangers: A comparison among different configurations. Appl. Therm. Eng. 2012, 33-34, 24-32. [CrossRef]

6. Congedo, P.; Lorusso, C.; De Giorgi, M.; Laforgia, D.; Congedo, P.M.; Lorusso, C.; De Giorgi, M.G.; Laforgia, D. Computational Fluid Dynamic Modeling of Horizontal Air-Ground Heat Exchangers (HAGHE) for HVAC Systems. Energies 2014, 7, 8465-8482. [CrossRef]

7. Razmara, M.; Bharati, G.R.; Hanover, D.; Shahbakhti, M.; Paudyal, S.; Robinett, R.D. Building-to-grid predictive power flow control for demand response and demand flexibility programs. Appl. Energy 2017, 203, 128-141. [CrossRef]

8. Uddin, M.; Romlie, M.F.; Abdullah, M.F.; Halim, S.A.; Bakar, A.H.A.; Kwang, T.C. A review on peak load shaving strategies. Renew. Sustain. Energy Rev. 2018, 82, 3323-3332. [CrossRef]

9. Müller, D.; Monti, A.; Stinner, S.; Schlösser, T.; Schütz, T.; Matthes, P.; Wolisz, H.; Molitor, C.; Harb, H.; Streblow, R. Demand side management for city districts. Build. Environ. 2015, 91, 283-293. [CrossRef]

10. Salpakari, J.; Mikkola, J.; Lund, P.D. Improved flexibility with large-scale variable renewable power in cities through optimal demand side management and power-to-heat conversion. Energy Convers. Manag. 2016, 126, 649-661. [CrossRef]

11. Zhang, Y.; He, Y.; Yan, M.; Guo, C.; Ding, Y.; Zhang, Y.; He, Y.; Yan, M.; Guo, C.; Ding, Y. Linearized Stochastic Scheduling of Interconnected Energy Hubs Considering Integrated Demand Response and Wind Uncertainty. Energies 2018, 11, 2448. [CrossRef]

12. Behrangrad, M. A review of demand side management business models in the electricity market. Renew. Sustain. Energy Rev. 2015, 47, 270-283. [CrossRef]

13. Baeten, B.; Rogiers, F.; Helsen, L. Reduction of heat pump induced peak electricity use and required generation capacity through thermal energy storage and demand response. Appl. Energy 2017, 195, 184-195. [CrossRef]

14. Kensby, J.; Trüschel, A.; Dalenbäck, J.O. Potential of residential buildings as thermal energy storage in district heating systems-Results from a pilot test. Appl. Energy 2015, 137, 773-781. [CrossRef]

15. Romanchenko, D.; Kensby, J.; Odenberger, M.; Johnsson, F. Thermal energy storage in district heating: Centralised storage vs. storage in thermal inertia of buildings. Energy Convers. Manag. 2018, 162, 26-38. [CrossRef]

16. Reynders, G.; Nuytten, T.; Saelens, D. Potential of structural thermal mass for demand-side management in dwellings. Build. Environ. 2013, 64, 187-199. [CrossRef]

17. De Coninck, R.; Helsen, L. Bottom-Up Quantification of the Flexibility Potential of Buildings. In Proceedings of the 13th Conference of International Building Performance Simulation Association, Chambéry, France, 26-28 August 2013.

18. Le Dréau, J.; Heiselberg, P. Energy flexibility of residential buildings using short term heat storage in the thermal mass. Energy 2016, 111, 991-1002. [CrossRef]

19. Reynders, G.; Amaral Lopes, R.; Marszal-Pomianowska, A.; Aelenei, D.; Martins, J.; Saelens, D. Energy flexible buildings: An evaluation of definitions and quantification methodologies applied to thermal storage. Energy Build. 2018, 166, 372-390. [CrossRef]

20. Reynders, G.; Diriken, J.; Saelens, D. Generic characterization method for energy flexibility: Applied to structural thermal storage in residential buildings. Appl. Energy 2017, 198, 192-202. [CrossRef]

21. Aduda, K.O.; Labeodan, T.; Zeiler, W.; Boxem, G.; Zhao, Y. Demand side flexibility: Potentials and building performance implications. Sustain. Cities Soc. 2016, 22, 146-163. [CrossRef]

22. Faria Neto, A.; Bianchi, I.; Wurtz, F.; Delinchant, B. Thermal Comfort Assessment; Final ELECON Workshop Federal Institute of Santa Catarina-IFSC: Florianópolis, Brazil, 2016. [CrossRef]

23. Goy, S.; Ashouri, A.; Maréchal, F.; Finn, D. Estimating the Potential for Thermal Load Management in Buildings at a Large Scale: Overcoming Challenges Towards a Replicable Methodology. Energy Procedia 2017, 111, 740-749. [CrossRef]

24. Hurtado, L.A.; Rhodes, J.D.; Nguyen, P.H.; Kamphuis, I.G.; Webber, M.E. Quantifying demand flexibility based on structural thermal storage and comfort management of non-residential buildings: A comparison between hot and cold climate zones. Appl. Energy 2017, 195, 1047-1054. [CrossRef]

25. Reynders, G.; Diriken, J.; Saelens, D. Quality of grey-box models and identified parameters as function of the accuracy of input and observation signals. Energy Build. 2014, 82, 263-274. [CrossRef] 
26. Perez, N. Contribution à la Conception éNergéTique De Quartiers: Simulation, Optimisation et Aide à la Décision. Ph.D. Thesis, Université de La Rochelle, Rochelle, France, 2017.

27. Fonseca, J.A.; Nguyen, T.A.; Schlueter, A.; Marechal, F. City Energy Analyst (CEA): Integrated framework for analysis and optimization of building energy systems in neighborhoods and city districts. Energy Build. 2016, 113, 202-226. [CrossRef]

28. Remmen, P.; Lauster, M.; Mans, M.; Fuchs, M.; Osterhage, T.; Müller, D. TEASER: An open tool for urban energy modelling of building stocks. J. Build. Perform. Simul. 2018, 11, 84-98. [CrossRef]

29. Frayssinet, L.; Kuznik, F.; Hubert, J.L.; Milliez, M.; Roux, J.J. Adaptation of building envelope models for energy simulation at district scale. Energy Procedia 2017, 122, 307-312. [CrossRef]

30. Morales, D.X.; Besanger, Y.; Sami, S.; Alvarez Bel, C. Assessment of the impact of intelligent DSM methods in the Galapagos Islands toward a Smart Grid. Electr. Power Syst. Res. 2017, 146, 308-320. [CrossRef]

31. RTE. Évaluation des Economies D'éNergie Et Des Effets De Bord AssociéS aux Effacements de Consommation. 2016. Available online: https:/ / clients.rte-france.com/htm/fr/mediatheque/telecharge/ 20160401_Rapport_report_complet.pdf (accessed on 19 October 2018).

32. De Dear, R.; Brager, G.S. Developing an Adaptive Model of Thermal Comfort and Preference; UC Berkeley: Berkeley, CA, USA, 1998.

33. Eco2mix CO2. 2014. Available online: https://www.rte-france.com/fr/eco2mix/eco2mix-co2 (accessed on 20 May 2018).

34. Annuaire des Projets en France / Greenlys. Available online: http://www.smartgrids-cre.fr/index.php?p= greenlys (accessed on 20 June 2018).

35. Fuchs, M.; Teichmann, J.; Lauster, M.; Remmen, P.; Streblow, R.; Müller, D. Workflow automation for combined modeling of buildings and district energy systems. Energy 2016, 117, 478-484. [CrossRef]

36. AixLib: A Modelica Model Library for Building Performance Simulations. 2018. Available online: https:/ / github.com/RWTH-EBC/AixLib (accessed on 10 July 2014).

37. Modelica-Ibpsa: Modelica Library for Building and District Energy Systems Developed within IBPSA Project 1. 2018. Available online: https://github.com/ibpsa/modelica-ibpsa (accessed on 21 September 2013).

38. Logiciel Pleiades-Izuba énergies. Available online: http://www.izuba.fr/logiciels/outils-logiciels/ (accessed on 20 September 2018).

39. Amasuomo, T.; Amasuomo, J.; Amasuomo, T.T.; Amasuomo, J.O. Perceived Thermal Discomfort and Stress Behaviours Affecting Students' Learning in Lecture Theatres in the Humid Tropics. Buildings 2016, 6, 18. [CrossRef]

(C) 2018 by the authors. Licensee MDPI, Basel, Switzerland. This article is an open access article distributed under the terms and conditions of the Creative Commons Attribution (CC BY) license (http:/ / creativecommons.org/licenses/by/4.0/). 


\title{
, nave \\ Comprehensive Evaluation of Carbon Emissions for the Development of High-Rise Residential Building
}

\author{
Stephen Y. C. Yim ${ }^{1}$, S. Thomas $\mathrm{Ng}^{2}{ }^{2 *}$, M. U. Hossain ${ }^{2}$ and James M. W. Wong ${ }^{3}$ \\ 1 Development and Construction Division, Housing Department, Housing Authority Headquarters, \\ Ho Man Tin, Hong Kong, China; stephen.yim@housingauthority.gov.hk \\ 2 Department of Civil Engineering, The University of Hong Kong, Pokfulam, Hong Kong, China; \\ uzzal@hku.hk \\ 3 Research \& Development, Construction Industry Council, 38/F, COS Centre, 56 Tsun Yip Street, Kwun Tong, \\ Kowloon, Hong Kong, China; jameswong@cic.hk \\ * Correspondence: tstng@hku.hk; Tel.: +852-2857-8556
}

Received: 4 September 2018; Accepted: 17 October 2018; Published: 23 October 2018

check for updates

\begin{abstract}
Despite the fact that many novel initiatives have been put forward to reduce the carbon emissions of buildings, there is still a lack of comprehensive investigation in analyzing a buildings' life cycle greenhouse gas (GHG) emissions, especially in high-density cities. In addition, no studies have made attempt to evaluate GHG emissions by considering the whole life cycle of buildings in Hong Kong. Knowledge of localized emission at different stages is critical, as the emission varies greatly in different regions. Without a reliable emission level of buildings, it is difficult to determine which aspects can reduce the life cycle GHG emissions. Therefore, this study aims to evaluate the life cycle GHG emissions of buildings by considering "cradle-to-grave" system boundary, with a case-specific high-rise residential housing block as a representative public housing development in Hong Kong. The results demonstrated that the life cycle GHG emission of the case residential building was $4980 \mathrm{~kg} \mathrm{CO} \mathrm{e} / \mathrm{m}^{2}$. The analysis showed that the majority (over $86 \%$ ) of the emission resulted from the use phase of the building including renovation. The results and analysis presented in this study can help the relevant parties in designing low carbon and sustainable residential development in the future.
\end{abstract}

Keywords: greenhouse gases; residential building; life cycle assessment

\section{Introduction}

Climate change has become an unprecedented challenge for humanity. The annual greenhouse gas (GHG) emissions grew on average by 1.0 giga ton carbon dioxide equivalent $\left(\mathrm{GtCO}_{2} \mathrm{e}\right)$ per year from 2000 to 2010 compared to $0.4 \mathrm{GtCO}_{2}$ e per year from 1970 to 2000, and total anthropogenic GHG emissions were the highest in human history reaching $49.0 \mathrm{GtCO}_{2} \mathrm{e} / \mathrm{y}$ in 2010 [1]. These phenomena are primarily due to various human activities, in particular the use of fossil fuels, deforestation, and change in land use [2]. Any delay in stabilizing and reducing the atmospheric $\mathrm{CO}_{2} \mathrm{e}$ concentration would only exacerbate the global warming crisis and increase the difficulty to tackle the disastrous consequences in the future [3].

Currently, the building sector represents the single largest contributor to GHG emissions $[4,5]$. To help reduce GHG emissions, the building sector has an undeniable role to play as buildings worldwide account for up to one-third of the GHG emissions [6]. For subtropical countries and cities like Hong Kong, buildings can contribute to almost $60 \%$ of final energy consumption [7]. Of this, residential buildings take up a significant portion of total energy consumption and hence the GHG emissions, resulting from energy used for construction, operation, and demolition of buildings. 
With a continuous growth in population, a preference for smaller family sizes, and the desire for a more comfortable living environment, the energy demands and GHG emitted from residential buildings in Hong Kong are expected to escalate even further [8].

Establishing pragmatic policy to encourage the building sector to cut down on GHG emissions is clearly an important goal for governments around the world. This is particularly the case for high-density cities not only because there are lots of high-rise buildings but also due to the rather limited opportunities to adopt emerging renewable energy solutions like photovoltaic panels or wind turbines. For Hong Kong, having committed to reducing the energy intensity by at least $25 \%$ by 2030 compared with the 2005 levels, its government has begun to examine the overall life cycle environmental burdens of buildings under their jurisdiction, and the public housing developments would be an ideal starting point as they share around one-third of the entire residential stock in Hong Kong, which is equivalent to 700,000 flats [9]. In 2008, public housing in Hong Kong consumed 6988 million $\mathrm{kWh}$ of electricity or five million tons (Mt) of $\mathrm{CO}_{2} \mathrm{e}$ [7].

Various studies have been conducted to gauge the environmental impacts of buildings. For example, Chen and $\mathrm{Ng}$ [10] proposed factoring in the embodied GHG emissions when assessing the environmental performance of buildings. De Wolf et al. [11] investigated the GHG emissions from 200 recently completed buildings based on the quantities of structural materials (data were based on different design firms) in the United States, without considering the whole life cycle of buildings. A life cycle assessment model was developed to evaluate the environmental impacts of building construction [12]. Peuportier [13] compared the environmental performance of three types of houses located in France, and a sensitivity analysis was performed based on the choice of alternative construction materials, types of heating energy, and transportation using an EQUER tool. Similar studies were conducted in France [14], the Netherlands [15], Japan [16], the United Kingdom [17], and China [18]. Some of the reviews were conducted in assessment of GHG emissions, energy consumption, and other environmental impacts of buildings [19-22].

Focusing on the assessment of GHG emissions generated from the building sector, Suzuki and Oka [23] proposed quantifying the energy consumed and carbon emitted due to the construction, operation, and renovation of office buildings in Japan using input/output tables. On the other hand, Seo and Hwang [24] estimated the life cycle $\mathrm{CO}_{2}$ emissions of different types of residential buildings. Similarly, Bastosa et al. [25] presented a life cycle energy and GHG analysis of three residential building types in Lisbon. Some studies have also focused on the specific stage of the buildings, such as the material level [26,27], building construction [28,29], renovation [30,31], demolition, and end-of-life treatment [32]. The collection of a large variety of data to model a comprehensive assessment is not only time consuming but also, is often impossible. However, a few studies focused on assessing the GHG emissions of the whole building by considering different stages, but excluding the renovation and end-of-life waste treatment [33-37]. Recent reviews also concluded that the occupancy and end-of-life phases are overlooked in most of the life cycle assessment (LCA) studies of building assessment [19,38-40].

In addition, environmental impacts of buildings can significantly vary among the studies depending upon the regions or countries [38,39]. A few studies were conducted on environmental assessment, including GHG emissions of buildings in Hong Kong [12,41,42]. However, these studies have excluded some important aspects in their assessment, e.g., considerations of use, renovation, and end-of-life phases of the building. The aim of this research therefore, is to evaluate the life cycle GHG emissions of high-rise residential building comprehensively by including the construction, use and renovation, and end-of-life phases as a case in Hong Kong. The results of the study can be used as a benchmark for comparing and setting up mitigation measures for new building construction.

\section{Methodology}

The life cycle assessment (LCA) method has been used for assessing the GHG emissions of high-rise public housing blocks in this study. LCA enables the quantification and evaluation of 
environmental impacts of a building [41]. Governed by the ISO 14040 standard [43], an analytical skeleton is applied in this study which consists of four main phases; goal and scope definition, life cycle inventory analysis, life cycle impact assessment, and interpretation.

\subsection{Goal and Scope of Study}

This study aimed to evaluate the GHG emissions (in terms of $\mathrm{CO}_{2} \mathrm{e}$ ) from cradle-to-grave of a public housing block as shown in Figure 1. The GHG emissions are calculated by assessing the GHGs as defined in the Kyoto Protocol of the United Nations Framework Convention on Climate Change (UNFCC), including carbon dioxide $\left(\mathrm{CO}_{2}\right)$, methane $\left(\mathrm{CH}_{4}\right)$, nitrous oxide $\left(\mathrm{N}_{2} \mathrm{O}\right)$, hydro fluorocarbons (HFCs), perfluorocarbons (PFCs), and sulphurhexafluoride $\left(\mathrm{SF}_{6}\right)[44,45]$. These GHG emissions are converted into $\mathrm{kg}$ or $\mathrm{tCO}_{2} \mathrm{e}$ emissions using the Intergovernmental Panel on Climate Change (IPCC) 100-year global warming potential (GWP) coefficients [46]. In this study, the functional unit was the unit of flat and gross floor area (GFA) of the building, i.e., $\mathrm{m}^{2}$.

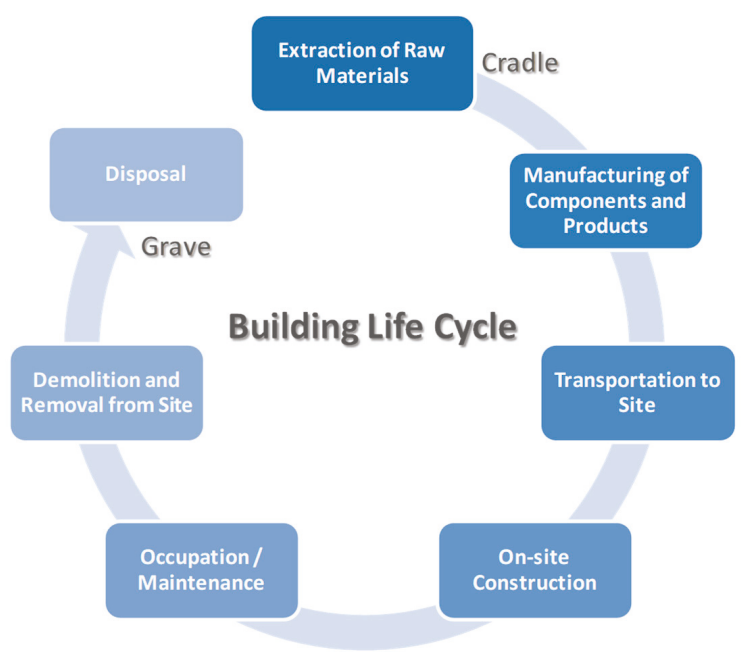

Figure 1. Life cycle process of a building.

A standard housing block design named "New Harmony One" (NH1)—Option 6, as shown in Figure 2, was selected for the analysis and used for setting a benchmark for the life cycle GHG emissions of public residential buildings. The Housing Authority adopted a site specific design approach and the internal floor area since 2004, by applying micro-climate studies at the early planning stage [47]. NH1 is selected as a basis of this study, as such a design can be applied to various sites in Hong Kong on a repetitive basis. Typically, a NH1 block is a reinforced concrete tower of 40 domestic levels which contains 799 flats with a gross floor area of $33,078 \mathrm{~m}^{2}$. The ground floor is used for non-domestic purpose to accommodate the necessary ancillary facilities. There are 16-20 modular flats per floor which are arranged in four groups in a cruciform configuration attached to the central core where building services, lifts, and staircases are located. The compact form of NH1 makes it suitable for use in smaller urban area sites in Hong Kong. 


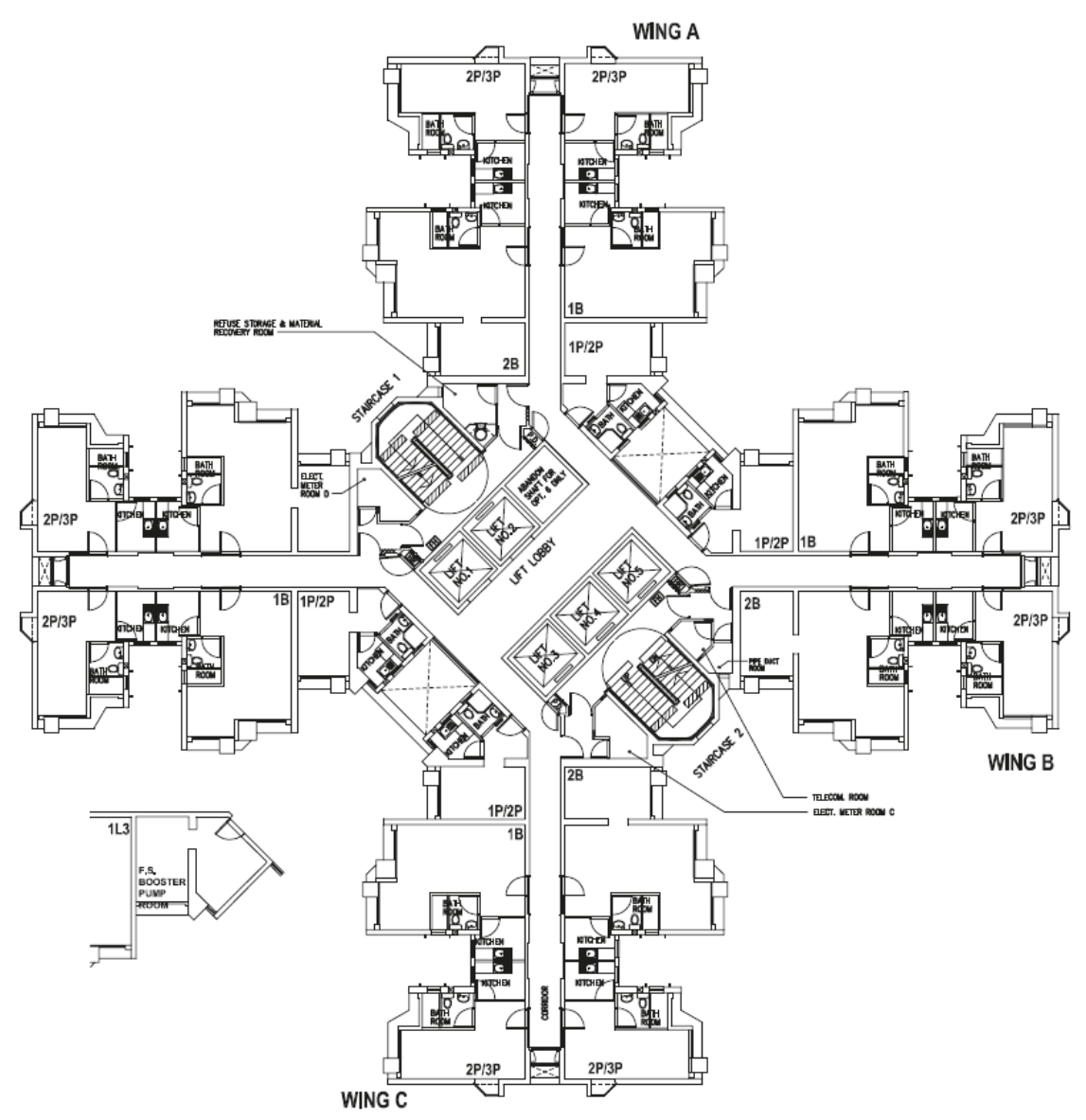

Figure 2. New Harmony One (NH1) residential building design.

The GHG emissions over the building's life cycle are assessed based on their sources and components, so as to evaluate the carbon footprint of the building meaningfully. Based on ISO 21931-1 [48] "Sustainability in Building Construction-Framework for Methods of Assessment of the Environmental Performance of Construction Works-Part 1: Buildings", the scope of a carbon audit study includes eight aspects associated with the following three distinct but interlinked stages: (i) production and construction; (ii) occupation (both energy consumed by tenants and communal installations) and renovation; and (iii) demolition as shown in Table 1 . The guidelines provided by this ISO standard were used to derive the equations (Equations (1)-(7)) in this study. In addition, the said method aligns well with the carbon emission estimation model developed by the Hong Kong Housing Department [9], and Equations (1)-(7) were therefore used for the assessment of each individual stage accordingly. These aspects cover the major sources of GHG emissions of a building's life cycle as suggested by Seo and Hwang [24] and Fieldson et al. [49] which form the system boundary of this study. As a result, a "cradle-to-grave" system boundary with the functional unit of $1 \mathrm{~m}^{2}$ of building floor area was considered in this study. The system boundary covers the production and transportation of principal construction materials; the use stage of buildings including the energy consumed by building services equipment and utilities; renovations including the material's production and transportation; waste transportation and disposal; and the end-of-life stage of buildings including the dismantling of buildings, and transportation of waste materials to the disposal sites (Table 1). However, the energy 
and fuel used on site during construction were excluded, as their emissions are minimal compared with the emissions of the entire building's life cycle. For example, the construction processes contribute to only about $2-5 \%$ of the total emissions (except refurbishments, demolition, and waste treatment) $[28,50]$. Taking into account the quantity and environmental profile, this study initially focused on three major materials, namely concrete, steel, and timber as they are the dominant contributors of embodied carbon of a housing block [51]. An inventory of materials and energy consumed over the sampled building's life cycle is assessed to calculate the associated GHG emissions. However, the inventory given in Table 1 omits non-structural materials and associated emissions over the building's life cycle.

Table 1. Study scope and system boundary of the greenhouse gas (GHG) evaluation.

\begin{tabular}{|c|c|c|c|}
\hline Stage & Aspect & Sou & rces of GHG Emissions \\
\hline \multirow{3}{*}{$\begin{array}{l}\text { Production and } \\
\text { Construction stage }\end{array}$} & $\mathrm{I}$ & $\begin{array}{l}\text { Materials consumed during } \\
\text { construction }\end{array}$ & $\begin{array}{l}\text { Steel formwork for superstructure } \\
\text { Timber formwork for superstructure } \\
\text { Steel formwork for substructure } \\
\text { Timber formwork for substructure }\end{array}$ \\
\hline & II & Materials for structure & $\begin{array}{l}\text { Steel for superstructure } \\
\text { Concrete for superstructure } \\
\text { Steel for substructure } \\
\text { Concrete for substructure }\end{array}$ \\
\hline & III & $\begin{array}{l}\text { Transportation of materials } \\
\text { (in Aspects I and II)-from } \\
\text { factory gate to site }\end{array}$ & - \\
\hline \multirow{2}{*}{ Occupation stage } & IV & $\begin{array}{l}\text { Energy consumption by } \\
\text { communal building services }\end{array}$ & $\begin{array}{c}\text { Lighting } \\
\text { Lift } \\
\text { Security } \\
\text { TV } \\
\text { A/C and ventilation } \\
\text { Fire services } \\
\text { Water supply } \\
\text { Electrical distribution }\end{array}$ \\
\hline & $\mathrm{V}$ & $\begin{array}{l}\text { Energy consumption } \\
\text { by tenants }\end{array}$ & $\begin{array}{c}\text { Cooking } \\
\text { Space conditioning } \\
\text { Hot water } \\
\text { Lighting } \\
\text { Refrigeration } \\
\text { Others (laundry, audiovisual and } \\
\text { miscellaneous equipment) }\end{array}$ \\
\hline
\end{tabular}

\subsection{Inventory Analysis and Analytical Framework}

\subsubsection{Emissions in the Construction Stage (Aspects I, II, and III)}

The construction process of building follows the NH1 design of construction. As indicated, the GHG emissions of the construction process is excluded from this study, as it contributes to a negligible amount of emissions compared to the total emission associated with building. While the energy used and the consequential GHG emissions over the occupation of a building contribute to the majority of its carbon footprint, a considerable amount of GHG is emitted during the manufacturing and transportation of building materials [6]. Equation (1) calculates the embodied GHG emissions of key building materials consumed during construction and for structure (i.e., Aspects I and II, respectively), including concrete, steel, and formwork. This accounts for $84-95 \%$ of the total materials (structural and non-structural) related GHG emissions for a reinforced concrete framed building $[26,52]$. 
This measures the GHG emitted from the extraction, processing and manufacturing of building materials [53].

$$
G H G_{m}=\sum_{i=0}^{n} Q_{i} \times F_{i}^{m},
$$

where $\mathrm{GHG}_{m}$ is the total embodied GHG emissions of concrete, steel, and formwork (in $\mathrm{kg} \mathrm{CO}_{2} \mathrm{e}$ ); $Q_{i}$ is the amount of building material $i\left(\right.$ in $\left.^{3}\right)$; and $F_{i}^{m}$ is the GHG emission factor for building material $i$ (in $\mathrm{kg} \mathrm{CO}_{2} \mathrm{e} / \mathrm{m}^{3}$ ).

The quantities of concrete, steel, and timber employed during the construction of the NH1 housing block were obtained from the tender documents as well as the drawings. Local, regional, and international sources and databases were used to retrieve the GHG emission factors for the selected building materials (Table 2). For example, the GHG emission factor for steel production was extracted from the Inventory of Carbon and Energy (ICE) compiled by Hammond and Jones [54], which is within the range of steel production in China [55]; local concrete production was according to Zhang et al. [56]; and regional (Southern China) timber production was from Zhang [57]. The use of local or regional GHG emission factors for the principal building materials is important for achieving representative results. Therefore, local or regional GHG emission factors for such materials were used in this study.

Table 2. Embodied carbon of materials (unit: $\mathrm{kg} \mathrm{CO}_{2} \mathrm{e} / \mathrm{m}^{3}$ ).

\begin{tabular}{cccc}
\hline References & Timber & Steel & Concrete \\
\hline Hammond and Jones [54] & 468 & $15,210^{\mathrm{b}}$ & 317 \\
Morris [58] & 450 & 14,287 & 326 \\
Eaton and Amato [59] & - & 15,313 & - \\
Zhang et al. [56] & - & - & $426^{\mathrm{c}}$ \\
Zhang [57] & $962^{\mathrm{a}}$ & - & - \\
Alcorn [60] & - & 10,441 & 376
\end{tabular}

Note: a plywood, embodied carbon: $1.78 \mathrm{~kg} \mathrm{CO} \mathrm{CO}_{2} / \mathrm{kg}$ in China with the density as of $540 \mathrm{~kg} / \mathrm{m}^{3}$ [57]; ${ }^{\mathrm{b}}$ steel bar and rod, embodied carbon: $1.95 \mathrm{~kg} \mathrm{CO} 2 \mathrm{e} / \mathrm{kg}$ which is within the range of steel production in China (1.72-1.96 kg CO $2 \mathrm{e} / \mathrm{kg}$ steel) according to Jing et al. [55]; non-EU average recycled content: $35.5 \%$; density is assumed as $7800 \mathrm{~kg} / \mathrm{m}^{3}[61] ;{ }^{c}$ concrete grade is assumed as $32 / 40 \mathrm{MPa}$, embodied carbon: $0.177 \mathrm{~kg} \mathrm{CO} 2 \mathrm{e} / \mathrm{kg}$, density is assumed as $2400 \mathrm{~kg} / \mathrm{m}^{3}$ [61].

Transportation emissions are also an integral part of the LCA study, generated from the transportation of construction materials from cradle-to-gate and from gate-to-site. Aspect III focuses on the latter stage, i.e., the transportation distances from the manufacturing plant to the construction site. The former stage has already been included in the embodied carbon emission factors as shown in Table 2, which embraces all energy required for extraction, manufacturing, and transportation until the materials leave the factory gate. In the case of the NH1 block, 95\% of the building materials can be sourced from Hong Kong or South China, they are therefore transported through the land routes using diesel trucks and by sea [51]. Equation (2) calculates the GHG emissions generated from the transportation of building materials.

$$
G H G_{t}=\sum_{i=0}^{n} \frac{\left(Q_{i}^{l} \times E_{l} \times D_{i}^{l} \times F_{l}^{t}\right)}{5}
$$

where $\mathrm{GHG}_{t}$ is the total GHG emissions from fuel combustion of transportation of the key building materials (in $\mathrm{kg} \mathrm{CO}_{2} \mathrm{e}$ ); $Q_{i}^{l}$ is the amount of building material $i$ transported by land (in $\mathrm{m}^{3}$ ), assuming the loading limit per truck is $5 \mathrm{~m}^{3} ; E_{l}$ is the diesel consumption (in liter $/ \mathrm{km} /$ truck), which is $0.325 \mathrm{~L} / \mathrm{km}$; $D_{i}^{l}$ is the total distances of transporting building materials $i$ by land (in $\mathrm{km}$ ), and the distances between the site and the manufacturing plant in Hong Kong and South China are assumed as $20 \mathrm{~km}$ [52] and $250 \mathrm{~km}$ [62], respectively; and $F_{l}^{t}$ is the emission factors of transporting by diesel truck, which is $2.62 \mathrm{~kg} \mathrm{CO}$ e/liter [52]. 


\subsubsection{Emissions in the Occupation Stage (Aspects IV, V, VI and VII)}

During the occupation phase, heating and electricity account for the major portion of GHG emissions [63]. For this study, the GHG emissions at the occupation stage are quantified and classified into three aspects, namely: Aspect IV—Energy consumption by communal building services; Aspect V—Energy consumption by tenants; Aspect VI—GHG removals; and Aspect VII-Renovation. Equation (3) is used to simulate the GHG emissions from the energy consumption by communal building services and tenants.

$$
G H G_{o}=\sum_{i=0}^{n}\left(E_{i}^{e} \times F_{\mathcal{e}}+E_{i}^{g} \times F_{g}\right) \times 50,
$$

where $G H G_{0}$ is the total GHG emissions due to the energy used over the 50-year building life cycle (in $\mathrm{kg} \mathrm{CO} \mathrm{CO}_{2} \mathrm{e}$; $E_{i}^{e}$ and $E_{i}^{g}$ are the annual quantity of electricity and gas consumption for building services system $i$, in $\mathrm{kWh}$ or in gas unit (i.e., 1 unit as registered by the gas meter $=48$ mega joules consumed), respectively; $F_{e}$ and $F_{g}$ are the emission factors of the energy consumed by electricity and gas, respectively, with the territory-wide default values of $F_{e}$ and $F_{g}$ being $0.7 \mathrm{~kg} \mathrm{CO}_{2} \mathrm{e} / \mathrm{kWh}$ and $0.59 \mathrm{~kg} \mathrm{CO} 2 \mathrm{e} /$ unit of gas purchased, respectively [64].

The electricity consumption data for communal building services installations was calculated from the sampled NH1 housing block. However, the energy consumed by tenants of the sampled housing block was not accessible. Therefore, the energy end-use data of the public housing group (in terajoules) as published by the Electrical and Mechanical Services Department [7] was used for the energy use estimation in this study. It was assumed that $80 \%$ of the tenants used electric water heaters while the rest used gas water heaters [65] and 90\% of tenants used gas for cooking [66].

GHG removals are calculated by assessing the respective GHG absorption by the assimilation of $\mathrm{CO}_{2}$ by plants as shown in Equation (4). According to EPD [64], $23 \mathrm{~kg} \mathrm{CO}$ can be removed by each tree based on Hong Kong's location, woodland types, and estimated density of trees. The figure is applicable to all trees commonly found in Hong Kong which are able to reach at least $5 \mathrm{~m}$ in height. Since this figure is derived as an annual average based on an extended period of time corresponding to the life cycle of the trees, the figure is applicable to trees at all ages.

$$
G H G_{r}=\left(T \times F_{t}\right) \times 50,
$$

where $G H G_{r}$ is the total GHG absorption over the 50-year building life cycle by tree planting (in $\mathrm{kg} \mathrm{CO}_{2} \mathrm{e}$ ); $\mathrm{T}$ is the number of newly planted trees within the building's physical boundary (e.g., within building premises, associated with the surroundings that are used for multipurpose activities including planting trees for a particular housing estate) after the beginning stage of construction which are able to reach at least $5 \mathrm{~m}$ in height; and $F_{t}$ is the GHG removal factor, which is taken as $23 \mathrm{~kg} \mathrm{CO}_{2}$ / tree per annum [64].

In this study, a 50-year service life of a residential block in Hong Kong was considered. As a complex system, buildings would often undergo various changes by means of renovation. Considering the building's service life, typical replacement of principal elements with their number of replacements over the entire life of a building in Hong Kong are shown in Table 3 (adjusted based on Chiang et al. [67]). The production and transport of these materials/elements were included in the LCA. Ecoinvent databases were used for collecting their upstream data, for instance, ceramic tile, emulsion paint, sealing materials, and hardwood doors production. Based on the renovation of typical flats, average per unit $\left(\mathrm{m}^{2}\right)$ was calculated according to Chiang et al. [67]. In addition, the transportation and disposal (in landfills) of materials generated during renovation were also considered in this assessment. 
Table 3. Typical replacement of building elements during renovation in Hong Kong.

\begin{tabular}{ccc}
\hline Element/Material & Service Life (years) & $\begin{array}{c}\text { Number of Replacements over } \\
\text { the Service Life of Building }\end{array}$ \\
\hline Ceramic tiles & 20 & 2 \\
Emulsion paint & 5 & 9 \\
Silicone seal & 10 & 4 \\
Hardwood solid-core doors & 20 & 2 \\
\hline
\end{tabular}

Therefore, the total GHG emissions due to the renovation of the building during its service life can be estimated by Equation (5).

$$
G H G_{R}=\sum_{\text {service life }=50}\left(M_{R} \times N_{R}\right)+T_{M}+D_{L}
$$

where $G H G_{R}$ is the total GHG emissions over the 50 -year service life of building (in $\mathrm{kg} \mathrm{CO} \mathrm{CO}_{2} \mathrm{e}$ ); $M_{R}$ is the materials/elements replacement during renovation; $N_{R}$ is the number of replacements of the respective elements/materials; $T_{M}$ is the transport of the materials; and $D_{L}$ is the disposal into landfill.

\subsubsection{Emissions in the Demolition Stage (Aspects VIII)}

According to ISO [68], recycling of steel and concrete should be assessed in the subsequent loop of a building life cycle. Typically, inert wastes generated from buildings are disposed at public fill sites, whereas non-inert waste are dumped into landfills, in Hong Kong. After transporting to off-site sorting facilities, inert materials are crushed and screened to recycle materials. In addition, a certain amount of concrete is recycled [69]. After screening, the remaining inert materials are sent to public fills, while the non-inert materials are disposed at landfills. However, the impacts of recycling and disposal were excluded due to the complexity of different management strategies and the lack of data in Hong Kong. In this study, the GHG emitted during the demolition stage is mainly due to the energy consumption for the machinery operation at the demolition site and the transportation of building debris from the site to disposal sites [23]. It is also assumed that the saving of GHG emissions due to steel and concrete recovery, and the induced GHG emissions of other materials' disposal (whether to public fills or landfills) would be similar, and thus they were excluded from this analysis. Equation (6) serves as the basis to assess the emissions.

$$
G H G_{d}=Q_{d} \times F_{d}+\frac{Q_{d} \times E_{d} \times D_{i}^{l} \times F_{l}^{t}}{5}
$$

where $G H G_{d}$ is the total GHG emissions in the demolition stage; $Q_{d}$ is the amount of building materials to be dismantled or building debris (in $\mathrm{m}^{3}$ ), for transportation of building debris, $5 \mathrm{~m}^{3}$ load per truck is assumed; $F_{d}$ is the emission factor for dismantling a building, which is $17 \mathrm{~kg} \mathrm{CO}_{2} \mathrm{e} / \mathrm{m}^{3}$ according to Nielsen [70]; $E_{d}$ is the diesel consumption (in liter $/ \mathrm{km} /$ truck), which is $0.325 \mathrm{~L} / \mathrm{km}$ [71]; $D_{i}^{l}$ is the total distance for transporting building materials $i$ by land (in $\mathrm{km}$ ) and the distance is taken as $26 \mathrm{~km}$ [52]; and $F_{l}^{t}$ is the emission factors for transportation by diesel truck, which is $2.62 \mathrm{~kg} \mathrm{CO}_{2} \mathrm{e} /$ liter [52].

Therefore, the total GHG emissions over the NH1's building life cycle can be estimated by Equation (7):

$$
G H G_{N H 1}=G H G_{m}+G H G_{t}+\left(G H G_{o}+G H G_{r}+G H G_{R}\right)+G H G_{d},
$$

\subsection{Limitations}

Conducting an environmental assessment of the whole building is complicated due to the differences in materials, associated transportation, diverse considerations at the use stage, lifespan of the building, and different considerations of the end-of-life of the building. Although this study has attempted to include all these in the assessment, several limitations cannot be avoided. For example, 
this study did not consider the contributions of non-structural materials. Waste material (generated during the construction and end-of-life stages) treatments were not considered in this assessment. During the use stage of building, actual energy consumed by tenants is not accessible. Thus, average energy consumption data was collected from the relevant department [7]. Due to the lack of local/regional data, Ecoinvent databases were used for carbon emissions of the replacement materials for the renovation of building. This study only focused on carbon assessment and excluded other impact categories. However, some of the limitations were further discussed and justified in the Discussion section.

\section{Results}

The result of GHG emissions throughout the life cycle of the standard NH1 public housing block, based on Equation (7), is presented in Table 4. Using the data collected and assumptions, the estimated total life cycle GHG emissions of the block are 186,150 tCO 2 e for the NH1 2000 Edition. The GHG emissions intensity of the sampled building is $232.98 \mathrm{tCO}_{2} \mathrm{e} /$ flat or $5.38 \mathrm{tCO}_{2} \mathrm{e} / \mathrm{m}^{2}$ of GFA. Figure 3 shows the distribution of the emissions in various life cycle phases. The operating energy consumption by communal building services and tenants is clearly impacting the environment the most, accounting for about $85.82 \%$ of the emissions. The materials consumed during construction, though emit considerably less GHGs than that in the operation stage, are taking up about $12.69 \%$ of the life cycle emissions. The remaining aspects, including the renovation, transportation of materials, and the disposal of the block are accounted to $1.14 \%, 0.07 \%$, and $0.28 \%$, respectively, of the building's carbon footprint.

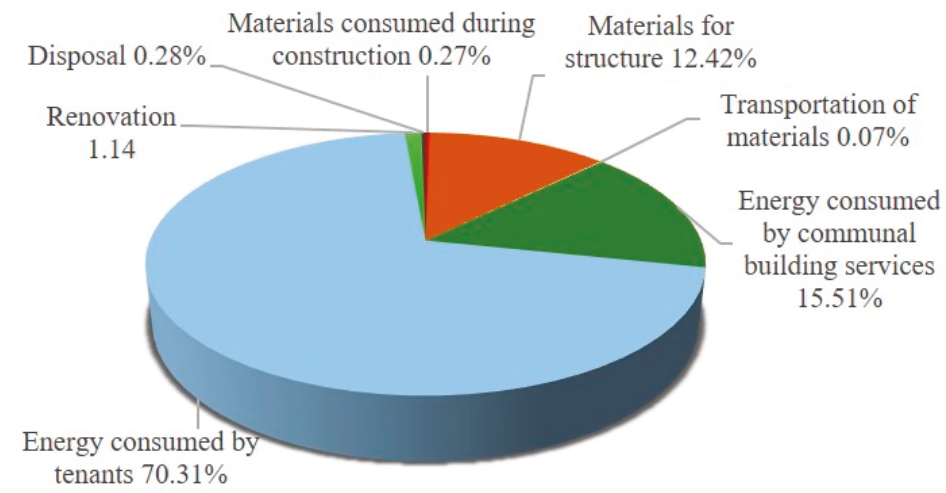

Figure 3. Contribution to the GHG emissions of the sampled housing block.

Hotspots for GHG emissions of building have been highlighted in Figure 3 (i.e., the contribution to GHG emissions). It can be seen that over $85 \%$ of the total GHG emissions is associated with energy consumption of tenants and building services equipment. This supports the results from previous studies $[16,24,72]$. The elements emitting the most significant amount of GHGs are found to be communal lighting and lifts, as well as the energy consumed by tenants for hot water, space conditioning, and refrigeration. This reflects that GHG emitted from a public housing block are strongly dependent not only on the building and occupancy factors such as ventilation and efficiency of appliances, but also on the source of energy. Therefore, it is important to install energy efficient building service equipment, and encourage tenants to use energy efficient appliances to reduce energy consumption and GHG emissions. Apart from reducing the energy consumption and embodied energy in buildings, switching to low carbon fuels and utilizing renewable energy are considered effective in tackling the climate change problem [46]. Materials (including their production and transportation) emit about $13 \%$ of the total emissions. However, it is possible to reduce GHG emissions by sourcing sustainable materials and using low carbon materials. 
During the construction stage, concrete is the dominant building material for the NH1 housing block, not only in terms of quantities but also the embodied carbon. The NH1 housing block studied consumed over $28,600 \mathrm{~m}^{3}$ of concrete, producing over 12 million $\mathrm{kg}$ of $\mathrm{CO}_{2} \mathrm{e}$. Reducing the carbon content of concrete through the manufacturing process is therefore influential. A saving in embodied carbon can be achieved by increasing the proportion of off-site manufacturing of components and/or adopting recycled materials or materials with lower environmental impact [6,52]. For instance, by replacing cement with alternative binding materials (e.g., pulverized fuel ash, ground granulated blast furnace slag, and silica fume) in the concrete mixes can save significant amount of cement and the associated $\mathrm{CO}_{2}$ emissions [51,73]. In addition, the use of alternative or low carbon cement, i.e., eco-glass cement or Portland fly-ash cement, can also considerably reduce the carbon footprint of concrete [74].

The study also estimated the GHG emissions of the residential block according to the latest "Model Client Brief 2010" as presented in Table 4. According to the Hong Kong Energy End-Use Data 2010 provided by the Electrical and Mechanical Services Department of Hong Kong SAR [7], this brief has incorporated the latest development of various communal building services installations. These include the employment of electronic ballasts and two illumination levels in the lighting system, adjusting the capacity and weight of lifts, adopting a variable speed drive system in booster pumps, as well as using more energy efficient motors. As a result, a significant reduction in annual electricity consumption is achieved from $1032 \mathrm{kWh} /$ flat in the Client Brief January 2000 Edition to $596 \mathrm{kWh} /$ flat in 2008 [7]. In addition, the brief requires the planting of one tree for every 15 flats in a newly built public housing estate. Consequently, the annual GHG emissions caused by electricity consumption of communal building services installations have decreased from $577 \mathrm{tCO}_{2} \mathrm{e}$ to $337 \mathrm{tCO}_{2} \mathrm{e}$ (Table 4).

According to the "Model Client Brief 2010", the GHG emissions of the NH1 housing block were $215.69 \mathrm{tCO}_{2} \mathrm{e} /$ flat and $4.98 \mathrm{tCO}_{2} \mathrm{e} / \mathrm{m}^{2}$ per flat and per GFA, respectively. While the energy consumption of tenant areas is beyond the management's control, with Aspect V- “Energy consumption by tenants" being excluded, the GHG emissions were $51.88 \mathrm{tCO}_{2} \mathrm{e} /$ flat and $1.20 \mathrm{tCO}_{2} \mathrm{e} / \mathrm{m}^{2}$ per flat and per GFA, respectively (Table 4). 


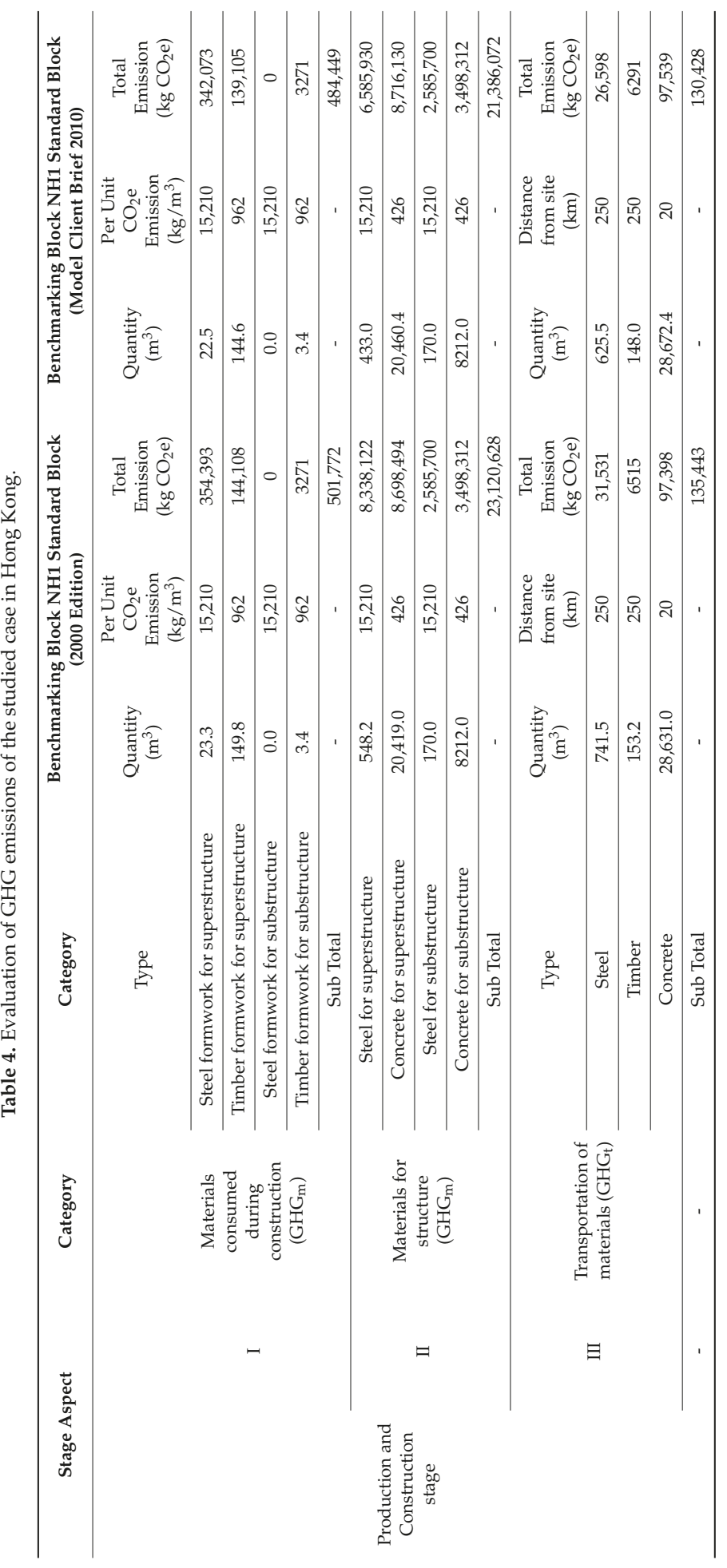




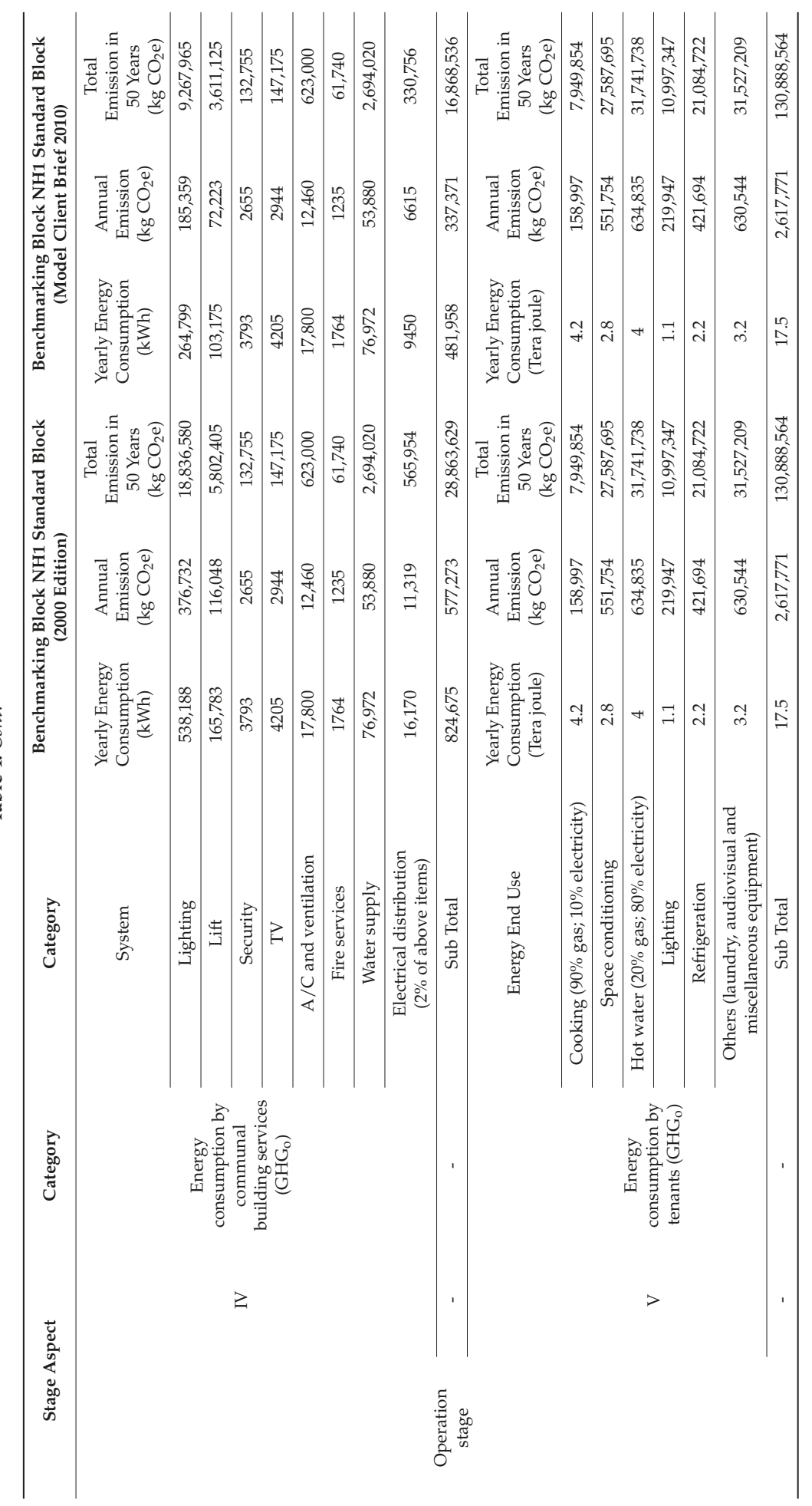




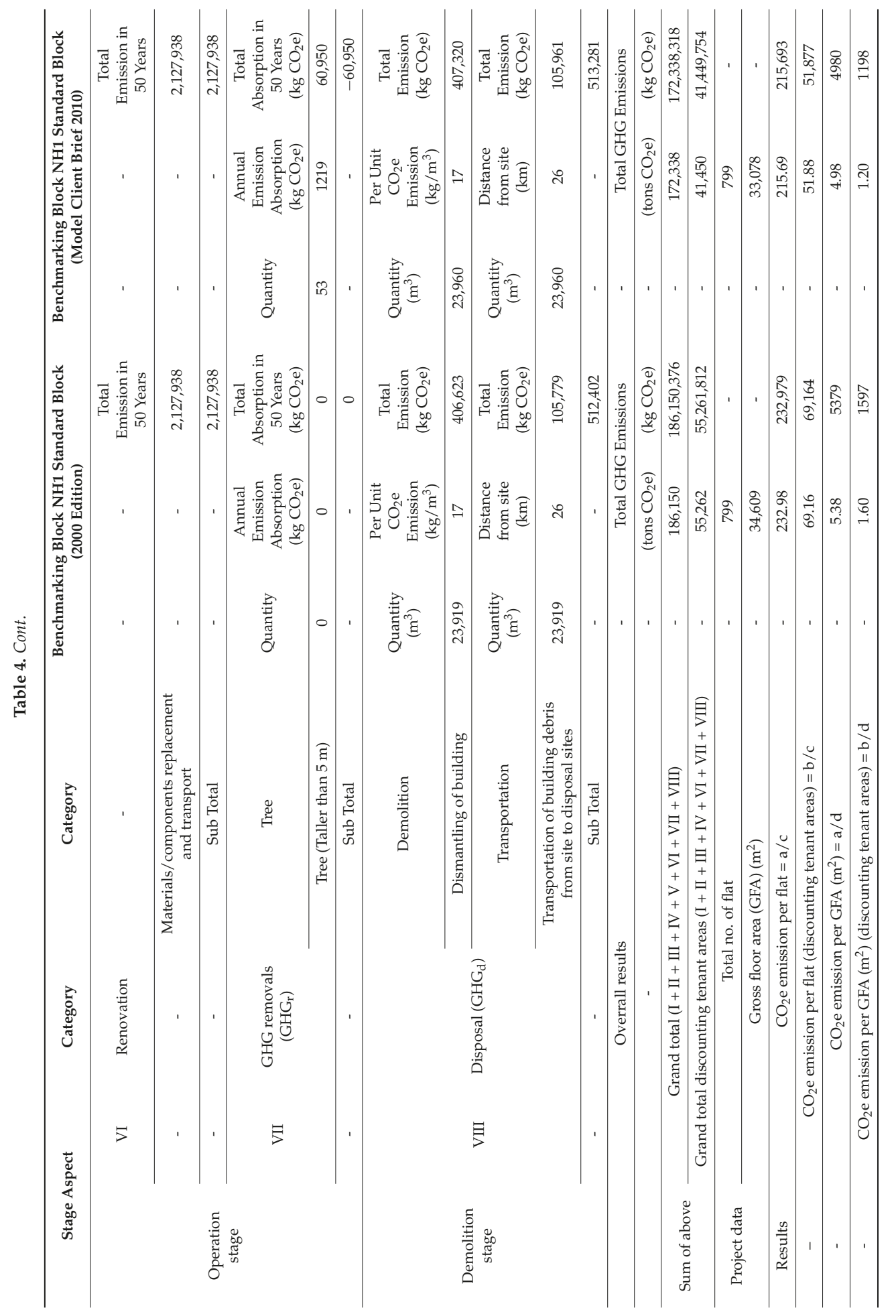




\section{Discussion}

This study has comprehensively evaluated the GHG emissions of a concrete reinforced high-rise residential building in Hong Kong. In addition to the structural materials, the study also considered the carbon emitted from communal building services, tenants due to energy end use, renovation, building demolition, and transportation of waste materials. It can be seen that the GHG emissions of the studied case ranged from $4980 \mathrm{~kg} \mathrm{CO} 2 \mathrm{e} / \mathrm{m}^{2}$ to $5379 \mathrm{~kg} \mathrm{CO} 2 \mathrm{e} / \mathrm{m}^{2}$ (based on design). The comparison of GHG emissions among different studies in different regions per functional unit is given in Figure 4. The variation of GHG emissions is relatively high (which ranges from $1657-6276 \mathrm{~kg} \mathrm{CO} \mathrm{CO}_{2} / \mathrm{m}^{2}$ ) among different studies due to the use of different structural materials (concrete, steel, wood, composite, and so forth), heating and cooling requirements for different regions based on the climate, as well as other considerations. However, the GHG evaluated in this study is in the upper range of the emissions (Figure 4). This may be due to the higher GHG emission factors for different structural materials used in Hong Kong including the long transport distance, as Hong Kong has sourced most of the construction materials from China, which have higher emission factors (Table 2) which is also supported by the previous studies. For instance, De Wolf et al. [11] estimated the GHG emissions of 200 completed buildings based on structural materials quantities in the US, and calculated the GHG emissions range from $150-600 \mathrm{~kg} \mathrm{CO}_{2} \mathrm{e} / \mathrm{m}^{2}$. However, the GHG emissions are even higher than the upper range (for structural materials) found in this study (about $686 \mathrm{~kg} \mathrm{CO}_{2} \mathrm{e} / \mathrm{m}^{2}$, Table 4).

Based on the collected data and assumptions for renovation works in Hong Kong, it is estimated that renovation contributes to $61.50 \mathrm{~kg} \mathrm{CO} 2 \mathrm{e} / \mathrm{m}^{2}$ of the building during its considered service life (e.g., 5 years). The value is considerably higher than $45 \mathrm{~kg} \mathrm{CO} 2 \mathrm{e} / \mathrm{m}^{2}$ estimated by Ortiz-Rodríguez et al. [75] and $38 \mathrm{CO}_{2} \mathrm{e} / \mathrm{m}^{2}$ by Kumanayake and Luo [76]. However, energy efficient and low carbon refurbishments and replacement of building services can significantly help reduce the total embodied $\mathrm{CO}_{2}$ emissions of buildings [30,77].

Although the evaluation of GHG emissions was based on a single case study in this study, the sampled building is a typical design of housing blocks in Hong Kong. Comparison on the emissions of new housing development can be conducted by making references at different building life cycle stages [36]. GHG emissions can also be minimized by using environmentally-friendly materials or energy efficient appliances, lighting, heating, and cooling equipment [78]. While the tenants of public rental housing estates represent almost $28 \%$ of Hong Kong population, their behavior might have a substantial impact on energy use, especially when the building services equipment is controlled manually. Reducing material use as well as specifying the use of localized materials, recycled materials, and/or alternative low carbon material are the options available for implementation during the design stage for reducing the embodied carbon of buildings [79-86].

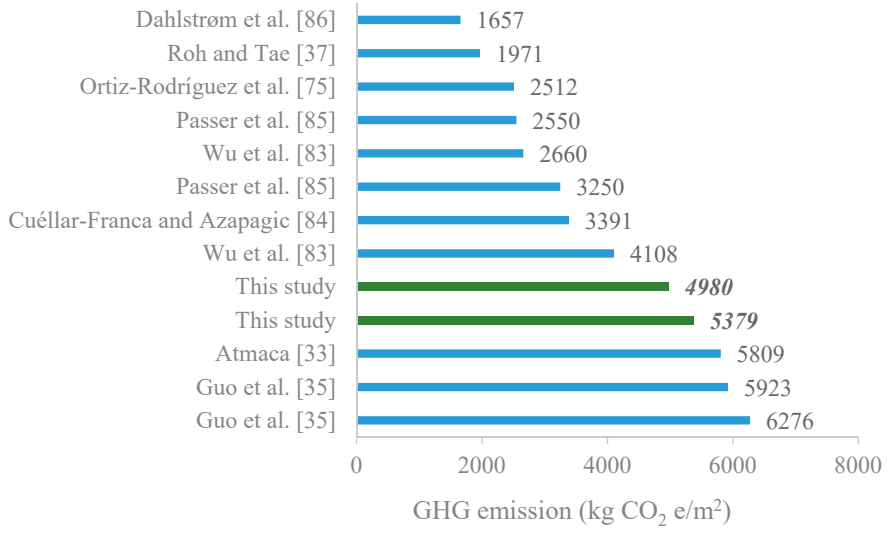

Figure 4. Comparison of GHG emissions of residential buildings. 
The contribution of cladding and other non-structural materials, including windows, doors and roof coverings, internal partitions, and internal cladding was not considered in this study. Although some of the materials used during the construction process are negligible in terms of weight, their impacts can be significant to the total impacts. For example, polyamide safety nets and aluminum are used $<0.1 \%$ by weight, but would contribute $2-3 \%$ towards the total GHG emissions [28]. These aspects were also not considered due to data unavailability despite the fact they can affect the emission inventory. In addition, carbon emissions can be expected with an anticipated growth in building activity and higher performance of buildings due to greater material use [80].

Although demolition and waste transportation were included in this study, the assessment of waste material treatments was not considered due to the different end-of-life considerations and the lack of available data. The demolition phase of buildings including demolition, waste transportation, and waste treatment contributed to about $2-5 \%$ of the total GHG emissions depending on the types of waste treatment [34,36]. However, according to Coelho and de Brito [32], GHG emissions of waste disposal could be about $65-283 \mathrm{~kg} \mathrm{CO}_{2} \mathrm{e} / \mathrm{m}^{2}$ of building (depending on the types of waste treatment). Therefore, the amount is insignificant compared to the total emissions estimated in this study $\left(4980 \mathrm{~kg} \mathrm{CO}_{2} \mathrm{e} / \mathrm{m}^{2}\right)$. More comprehensive investigations on the overall environmental performance of buildings by including other impact categories are desirable.

\section{Conclusions}

Environmental impacts associated with building construction, use, and end-of-life are greatly dependent on the region, climate, and type of buildings. Therefore, a case-specific assessment is important to benchmark the evaluation, as well as to reduce and mitigate the impacts from buildings. In this study, the GHG emissions from a typical high-rise residential building in Hong Kong was comprehensively evaluated using a case-specific analysis with a "cradle-to-grave" system boundary. Through this analytical regime, the GHG emissions were estimated to about $213.03 \mathrm{tCO}_{2} \mathrm{e} /$ flat and $4980 \mathrm{~kg} \mathrm{CO}_{2} \mathrm{e} / \mathrm{m}^{2}$, respectively. Considering the GHG emissions over the service life of the sampled residential building, the operating energy causes over $85.82 \%$ of the emissions, whereas $12.69 \%$ for materials, $1.14 \%$ for renovation, $0.28 \%$ for end-of-life of the building, and $0.07 \%$ for other factors. Therefore, various carbon reduction measures should be attempted and evaluated such as the use of energy efficient equipment, renewable energy, recycled/recyclable materials, and eco-design by utilizing natural lighting and ventilation. Policy and decision makers should explore different low carbon construction initiatives to maximize the opportunity for emission reduction. For future work, the residential buildings including all kinds of public and private buildings should be assessed by considering the limitations of this study on their carbon emissions as well as other environmental impact indicators. Tremendous effort is required to advocate low carbon construction at various levels including building materials, building components, and the entire building through effective incentive and reward schemes. For a more sustainable future, there is an urgent call for immediate, community-wide actions to reduce GHG emissions to help combat climate change.

Author Contributions: The authors contributed equally to this manuscript. S.Y.C.M. and the Housing Department initiated and designed the Carbon and Emission Estimation model, S.T.N. and J.M.W.W. provided suggestions to improve the reliability of the model; and M.U.H. conducted further analysis based on the local data and the developed model.

Acknowledgments: The authors would like to acknowledge the Hong Kong Housing Department as the life cycle building carbon estimation method described in this paper originated from the carbon emission estimation model of the Hong Kong Housing Department.

Conflicts of Interest: The authors declare no conflicts of interest. 


\section{References}

1. IPCC. Climate Change 2014: Synthesis Report. Contribution of Working Groups I, II and III to the Fifth Assessment Report of the Intergovernmental Panel on Climate Change (IPCC); IPCC: Geneva, Switzerland, 2014.

2. Rogner, H.H.; Zhou, D.; Bradley, R.; Crabbé, P.; Edenhofer, O.; Hare, B.; Kuijpers, L.; Yamaguchi, M. Introduction. In Climate Change 2007: Mitigation. Contribution of Working Group III to the Fourth Assessment Report of the Intergovernmental Panel on Climate Change; Cambridge University Press: Cambridge, UK, 2007.

3. Stern, N.H. Stern Review on the Economics of Climate Change; HM Treasury: London, UK, 2006.

4. Ibn-Mohammed, T. Application of mixed-mode research paradigms to the building sector: A review and case study towards decarbonising the built and natural environment. Sustain. Cities Soc. 2017, 35, 692-714. [CrossRef]

5. Emami, N.; Marteinsson, B.; Heinonen, J. Environmental impact assessment of a School building in Iceland using LCA-including the effect of long distance transport of materials. Buildings 2016, 6, 46. [CrossRef]

6. Monahan, J.; Powell, J.C. An embodied carbon and energy analysis of modern methods of construction in housing: A case study using a lifecycle assessment framework. Energy Build. 2011, 43, 179-188. [CrossRef]

7. EMSD. Hong Kong Energy End-Use Data 2010; Electrical and Mechanical Services Department, Government of HKSAR: Hong Kong, China, 2010.

8. Wang, X.; Chen, D.; Ren, Z. Global warming and its implication to emission reduction strategies for residential buildings. Build. Environ. 2011, 46, 871-883. [CrossRef]

9. HKHA. Housing in Figures 2010; The Hong Kong Housing Authority, Government of HKSAR: Hong Kong, China, 2010.

10. Chen, Y.; Ng, S.T. Factoring in embodied GHG emissions when assessing the environmental performance of building. Sustain. Cities Soc. 2016, 27, 244-252. [CrossRef]

11. De Wolf, C.; Yang, F.; Cox, D.; Charlson, A.; Hattan, A.S.; Ochsendorf, J. Material quantities and embodied carbon dioxide in structures. Proc. Inst. Civ. Eng. Eng. Sustain. 2016, 169, 150-161. [CrossRef]

12. Dong, Y.H.; Ng, S.T. A life cycle assessment model for evaluating the environmental impacts of building construction in Hong Kong. Build. Environ. 2015, 89, 183-191. [CrossRef]

13. Peuportier, B.L.P. Life cycle assessment applied to the comparative evaluation of single family houses in the French context. Energy Build. 2001, 33, 443-450. [CrossRef]

14. Hoxha, E.; Habert, G.; Lasvaux, S.; Chevalier, J.; Roy, R.L. Influence of construction material uncertainties on residential building LCA reliability. J. Clean. Prod. 2017, 144, 33-47. [CrossRef]

15. Meijer, A.; Huijbregts, M.; Reijnders, L. Human health damages due to indoor sources of organic compounds and radioactivity in life cycle impact assessment of dwellings. Int. J. Life Cycle Assess. 2005, 10, 383-392. [CrossRef]

16. Gerilla, G.P.; Teknomo, K.; Hokao, K. An environmental assessment of wood and steel reinforced concrete housing construction. Build. Environ. 2007, 42, 2278-2784. [CrossRef]

17. Hacker, J.N.; De Saulles, T.P.; Minson, A.J.; Holmes, M.J. Embodied and operational carbon dioxide from housing: A case study on the effects of thermal mass and climate change. Energy Build. 2008, 40, 375-384. [CrossRef]

18. Li, D.Z.; Chen, H.X.; Hui, E.C.M.; Zhang, J.B.; Li, Q.M. A methodology for estimating the life-cycle carbon efficiency of a residential building. Build. Environ. 2013, 59, 448-455. [CrossRef]

19. Anand, C.K.; Amor, B. Recent developments, future challenges and new research directions in LCA of buildings: A critical review. Renew. Sustain. Energy Rev. 2017, 67, 408-416. [CrossRef]

20. Dixit, M.; Fernández-Solís, J. Need for an embodied energy measurement protocol for buildings: A review paper. Renew. Sustain. Energy Rev. 2012, 16, 3730-3743. [CrossRef]

21. Pomponi, F.; Moncaster, A. Scrutinising embodied carbon in buildings: The next performance gap made manifest. Renew. Sustain. Energy Rev. 2018, 81, 2431-2442. [CrossRef]

22. Teng, Y.; Li, K.; Pan, W.; Ng, S.T. Reducing building life cycle carbon emissions through prefabrication: Evidence from and gaps in empirical studies. Build. Environ. 2018, 132, 125-136. [CrossRef]

23. Suzuki, M.; Oka, T. Estimation of life cycle energy consumption and $\mathrm{CO}_{2}$ emission of office buildings in Japan. Energy Build. 1998, 28, 33-41. [CrossRef]

24. Seo, S.; Hwang, Y. Estimation of $\mathrm{CO}_{2}$ emissions in life cycle of residential buildings. J. Constr. Eng. Manag. 2001, 127, 414-418. [CrossRef] 
25. Bastosa, J.; Battermanb, S.A.; Freirea, F. Life-cycle energy and greenhouse gas analysis of three building types in a residential area in Lisbon. Energy Build. 2014, 69, 344-353. [CrossRef]

26. Cattarinussi, L.; Hofstetter, K.; Ryffel, R.; Zumstein, K.; Ioannidou, D.; Klippel, M. Life cycle assessment of a post-tensioned timber frame in comparison to a reinforced concrete frame for tall buildings. In Expanding Boundaries: Systems Thinking for the Built Environment, Proceedings of the Sustainable Built Environment (SBE) Regional Conference, Zürich, Switzerland, 15-17 June 2016; vdf Hochschulverlag AG an der ETH Zürich: Zürich, Switzerland, 2016; pp. 656-661.

27. Hildebrandt, J.; Hagemann, N.; Thrän, D. The contribution of wood-based construction materials for leveraging a low carbon building sector in Europe. Sustain. Cities Soc. 2017, 34, 405-418. [CrossRef]

28. Hong, J.; Shen, G.P.; Feng, Y.; Lau, W.S.; Ma, C. Greenhouse gas emissions during the construction phase of a building: A case study in China. J. Clean. Prod. 2015, 103, 249-259. [CrossRef]

29. Sandanayake, M.; Lokuge, W.; Zhang, G.; Setunge, S.; Thushar, Q. Greenhouse gas emissions during timber and concrete building construction-A scenario based comparative case study. Sustain. Cities Soc. 2018, 38, 91-97. [CrossRef]

30. Almeida, M.; Ferreira, M. Cost effective energy and carbon emissions optimization in building renovation (Annex 56). Energy Build. 2017, 152, 718-738. [CrossRef]

31. Assefa, G.; Ambler, C. To demolish or not to demolish: Life cycle consideration of repurposing buildings. Sustain. Cities Soc. 2017, 28, 146-153. [CrossRef]

32. Coelho, A.; de Brito, J. Influence of construction and demolition waste management on the environmental impact of buildings. Waste Manag. 2012, 32, 532-541. [CrossRef] [PubMed]

33. Atmaca, A. Life-cycle assessment and cost analysis of residential buildings in South East of Turkey: Part 2-A case study. Int. J. Life Cycle Assess. 2016, 21, 925-942. [CrossRef]

34. Cho, S.-H.; Chae, C.-U. A study on life cycle $\mathrm{CO}_{2}$ emissions of low-carbon building in South Korea. Sustainability 2016, 8, 579. [CrossRef]

35. Guo, H.; Liu, Y.; Meng, Y.; Huang, H.; Sun, C.; Shao, Y. A comparison of the energy saving and carbon reduction performance between reinforced concrete and cross-laminated timber structures in residential buildings in the severe cold region of China. Sustainability 2017, 9, 1426. [CrossRef]

36. Peng, C. Calculation of a building's life cycle carbon emissions based on Ecotect and building information modeling. J. Clean. Prod. 2016, 112, 453-465. [CrossRef]

37. Roh, S.; Tae, S. An integrated assessment system for managing life cycle $\mathrm{CO}_{2}$ emissions of a building. Renew. Sustain. Energy Rev. 2017, 73, 265-275. [CrossRef]

38. Cabeza, L.F.; Rincón, L.; Vilarino, V.; Pérez, G.; Castell, A. Life cycle assessment (LCA) and life cycle energy analysis (LCEA) of buildings and the building sector: A review. Renew. Sustain. Energy Rev. 2014, 29, $394-416$. [CrossRef]

39. Pomponi, F.; Moncaster, A.M. Embodied carbon in the built environment: Management, mitigation, and reduction-What does the evidence say? J. Environ. Manag. 2016, 181, 687-700. [CrossRef] [PubMed]

40. De Wolf, C.; Pomponi, F.; Moncaster, A. Measuring embodied carbon dioxide equivalent of buildings: Areview and critique of current industry practice. Energy Build. 2017, 140, 68-80. [CrossRef]

41. Dong, Y.H.; Ng, S.T. Comparing the midpoint and endpoint approaches based on ReCiPe-A study of commercial buildings in Hong Kong. Int. J. Life Cycle Assess. 2014, 19, 1409-1423. [CrossRef]

42. Gan, V.J.L.; Cheng, J.C.P.; Lo, I.M.C.; Chan, C.M. Developing a $\mathrm{CO}_{2}$-e accounting method for quantification and analysis of embodied carbon in high-rise buildings. J. Clean. Prod. 2017, 141, 825-836. [CrossRef]

43. ISO. ISO 14040-Environmental Management: Life Cycle Assessment Principles and Framework; The International Organisation for Standardization: Paris, France, 2006.

44. ISO. ISO 14064-International Standard on Greenhouse Gases-Part 1: Specification with Guidance at the Organization Level for Quantification and Reporting of Greenhouse Gas Emissions and Removals; The International Organisation for Standardization: Geneva, Switzerland, 2006.

45. WRI/WBCSD. The Greenhouse Gas Protocol: A Corporate Accounting and Reporting Standard, Revised Edition; World Resources Institute and World Business Council for Sustainable Development: Washington, DC, USA, 2010.

46. IPCC. Climate Change 2007: The Physical Science Basis, Summary for Policy Makers; Intergovernmental Panel on Climate Change: Geneva, Switzerland, 2007. 
47. LC. Design of the New Public Housing Flats by the Hong Kong Housing Authority. Legislative Council (LC) Panel on Housing, 2015. Available online: http:/ / www.legco.gov.hk/yr14-15/english/panels/hg/papers/ hg20150706cb1-1037-1-e.pdf (accessed on 22 October 2018).

48. ISO. ISO 21931-1:2010 - Sustainability in Building Construction-Framework for Methods of Assessment of the Environmental Performance of Construction Works_Part 1: Buildings; The International Organisation for Standardization: Geneva, Switzerland, 2010.

49. Fieldson, R.; Rai, D.; Sodagar, B. Towards a framework for early estimation of lifecycle carbon footprinting of buildings in the UK. Constr. Inf. Q. 2009, 11, 66-75.

50. Takano, A.; Pittau, F.; Hafner, A.; Ott, S.; Hughes, M.; De Angelis, E. Greenhouse gas emission from construction stage of wooden buildings. Int. Wood Prod. J. 2014, 5, 217-223. [CrossRef]

51. HKHA. Life Cycle Assessment (LCA) and Life Cycle Costing (LCC) Study of Building Materials and Components; The Hong Kong Housing Authority, Government of HKSAR: Hong Kong, China, 2005.

52. Yan, H.; Shen, Q.P.; Fan, L.C.H.; Wang, Y.; Zhang, L. Greenhouse gas emission in building construction: A case study of One Peking in Hong Kong. Build. Environ. 2010, 45, 949-995. [CrossRef]

53. Ng, S.T.; To, C.; Li, G. Unveiling the embodied carbon of construction materials through a product-based carbon labeling scheme. Int. J. Clim. Chang. Impacts Responses 2015, 7, 1-9. [CrossRef]

54. Hammond, G.; Jones, C. Inventory of Carbon and Energy (ICE); Version 2.0; Sustainable Energy Research Team, Department of Mechanical Engineering, University of Bath: Bath, UK, 2011.

55. Jing, R.; Cheng, J.C.P.; Gan, V.J.L.; Woon, K.S.; Lo, I.M.C. Comparison of greenhouse gas emission accounting methods for steel production in China. J. Clean. Prod. 2014, 83, 165-172. [CrossRef]

56. Zhang, J.; Cheng, J.C.P.; Lo, I.M.C. Life cycle carbon footprint measurement of Portland cement and ready mix concrete for a city with local scarcity of resources like Hong Kong. Int. J. Life Cycle Assess. 2014, 19, 745-757. [CrossRef]

57. Zhang, J. Life Cycle Carbon Measurement of Hong Kong Construction Materials: Cement, Concrete and Plywood. Master's Thesis, The Hong Kong University of Science and Technology University, Hong Kong, China, 2013.

58. Morris, J. The ethics and evaluation of embodied carbon in buildings. Struct. Eng. 2008, 86, 30-34.

59. Eaton, K.J.; Amato, A. A Comparative Environmental Life Cycle Assessment of Modern Office Buildings; Steel Construction Institute: Ascot, UK, 1998.

60. Alcorn, A. Embodied energy and $\mathrm{CO}_{2}$ coefficients for $\mathrm{New}$ Zealand building materials. In Report Series: Centre for Building Performance Research Report; Victoria University of Wellington: Wellington, New Zealand, 2003.

61. Catalonia Institute of Construction Technology (CICT). BEDEC PR/PCT ITEC Materials Database. 2011. Available online: https:/ / en.itec.cat/database/ (accessed on 22 October 2018).

62. EMSD. Life Cycle Energy Analysis of Building Construction; Final Report of Consultancy Study; Electrical and Mechanical Services Department, Government of HKSAR: Hong Kong, China, 2006.

63. Junnila, S. Life cycle assessment of environmentally significant aspects of an office building. Nord. J. Surv. Real Estate Res. Spec. Ser. 2004, 2, 81-97.

64. EPD. Guidelines to Account for and Report on Greenhouse Gas Emissions and Removals for Buildings (Commercial, Residential or Institutional Purposes) in Hong Kong, 2010 ed.; Environmental Protection Department and the Electrical and Mechanical Services Department, Government of HKSAR: Hong Kong, China, 2010.

65. Tso, G.K.F.; Yau, K.K.W. Predicting electricity energy consumption: A comparison of regression analysis, decision tree and neural networks. Energy 2007, 32, 1761-1768. [CrossRef]

66. Wan, K.S.Y.; Yik, F.W.H. Building design and energy end-use characteristics of high-rise residential buildings in Hong Kong. Appl. Energy 2004, 78, 19-36. [CrossRef]

67. Chiang, Y.H.; Li, V.J.; Zhou, L.; Wong, F.; Lam, P. Evaluating sustainable building-maintenance projects: Balancing economic, social, and environmental impacts in the case of Hong Kong. J. Constr. Eng. Manag. 2016, 142, 06015003. [CrossRef]

68. ISO. ISO/TS 14067:2013 - Greenhouse Gases_Carbon Footprint of Products-Requirements and Guidelines for Quantification and Communication; The International Organisation for Standardization: Geneva, Switzerland, 2013.

69. Hossain, M.U.; Wu, Z.; Poon, C.S. Comparative environmental evaluation of construction waste management through different waste sorting systems in Hong Kong. Waste Manag. 2017, 69, 325-335. [CrossRef] [PubMed]

70. Nielsen, C.V. Carbon Footprint of Concrete Buildings Seen in the Life Cycle Perspective; Claus Vestergaard Nielsen of the Danish Technological Institute, Concrete Centre: Taastrup, Denmark, 2008. 
71. Schlitter, M. State-of-the-art and emerging truck engine technologies for optimized performance, emissions, and life-cycle costing. In Proceedings of the 9th Diesel Engine Emissions Reduction Conference, Newport, RI, USA, 24-28 August 2003.

72. Ortiz, O.; Castells, F.; Sonnemann, G. Sustainability in the construction industry: A review of recent developments based on LCA. Constr. Build. Mater. 2009, 23, 28-39. [CrossRef]

73. Hossain, M.U.; Poon, C.S.; Dong, Y.H.; Xuan, D. Environmental impact distribution methods for supplementary cementitious materials. Renew. Sustain. Energy Rev. 2018, 82, 597-608. [CrossRef]

74. Hossain, M.U.; Poon, C.S.; Lo, I.M.C.; Cheng, J.C.P. Comparative LCA on using waste materials in the cement industry: A Hong Kong case study. Resour. Conserv. Recycl. 2017, 120, 199-208. [CrossRef]

75. Ortiz-Rodríguez, O.; Castells, F.; Sonnemann, G. Life cycle assessment of two dwellings: One in Spain, a developed country, and one in Colombia, a country under development. Sci. Total. Environ. 2010, 408, 2435-2443. [CrossRef] [PubMed]

76. Kumanayake, R.; Luo, $\mathrm{H}$. A tool for assessing life cycle $\mathrm{CO}_{2}$ emissions of buildings in Sri Lanka. Build. Environ. 2018, 128, 272-286. [CrossRef]

77. Saynajoki, A.; Heinonen, J.; Junnila, S. A scenario analysis of the life cycle greenhouse gas emissions of a new residential area. Environ. Res. Lett. 2012, 7, 034037. [CrossRef]

78. Dernie, D.; Gaspari, J. Building Envelope Over-Cladding: Impact on Energy Balance and Microclimate. Buildings 2015, 5, 715-735. [CrossRef]

79. Chau, C.K.; Hui, W.K.; Ng, W.Y.; Powell, G. Assessment of $\mathrm{CO}_{2}$ emissions reduction in high-rise concrete office buildings using different material use options. Resour. Conserv. Recycl. 2012, 61, 22-34. [CrossRef]

80. Giesekam, J.; Barrett, J.R.; Taylor, P. Construction sector views on low carbon building materials. Build. Res. Inf. 2016, 44, 423-444. [CrossRef]

81. Ng, T.S.K.; Yau, R.M.H.; Lam, T.N.T.; Cheng, V.S.Y. Design and commission a zero-carbon building for hot and humid climate. Int. J. Low-Carbon Technol. 2016, 11, 222-234. [CrossRef]

82. Colangelo, F.; Forcina, A.; Farina, I.; Petrillo, A. Life cycle assessment (LCA) of different kinds of concrete containing waste for sustainable construction. Buildings 2018, 8, 70. [CrossRef]

83. Wu, X.; Peng, B.; Lin, B. A dynamic life cycle carbon emission assessment on green and non-green buildings in China. Energy Build. 2017, 149, 272-281. [CrossRef]

84. Cuéllar-Franca, R.M.; Azapagic, A. Environmental impacts of the UK residential sector: Life cycle assessment of houses. Build. Environ. 2012, 54, 86-99. [CrossRef]

85. Passer, A.; Kreiner, H.; Maydl, P. Assessment of the environmental performance of buildings: A critical evaluation of the influence of technical building equipment on residential buildings. Int. J. Life Cycle Assess. 2012, 17, 1116-1130. [CrossRef]

86. Dahlstrøm, O.; Sørnes, K.; Eriksen, S.T.; Hertwich, E.G. Life cycle assessment of a single-family residence built to either conventional- or passive house standard. Energy Build. 2012, 54, 470-479. [CrossRef]

(c) 2018 by the authors. Licensee MDPI, Basel, Switzerland. This article is an open access article distributed under the terms and conditions of the Creative Commons Attribution (CC BY) license (http:/ / creativecommons.org/licenses/by/4.0/). 


\title{
Article \\ Impact of Service Life on the Environmental Performance of Buildings
}

\author{
Shahana Y. Janjua ${ }^{1, *}$, Prabir K. Sarker ${ }^{1}{ }^{1}$ and Wahidul K. Biswas ${ }^{2}$ (I) \\ 1 School of Civil and Mechanical Engineering, Curtin University, Perth 6102, Australia; P.Sarker@curtin.edu.au \\ 2 Sustainable Engineering Group, Curtin University, Perth 6102, Australia; W.Biswas@curtin.edu.au \\ * Correspondence: s.janjua@postgrad.curtin.edu.au
}

Received: 30 November 2018; Accepted: 25 December 2018; Published: 2 January 2019

check for updates

\begin{abstract}
The environmental performance assessment of the building and construction sector has been in discussion due to the increasing demand of facilities and its impact on the environment. The life cycle studies carried out over the last decade have mostly used an approximate life span of a building without considering the building component replacement requirements and their service life. This limitation results in unreliable outcomes and a huge volume of materials going to landfill. This study was performed to develop a relationship between the service life of a building and building components, and their impact on environmental performance. Twelve building combinations were modelled by considering two types of roof frames, two types of wall and three types of footings. A reference building of a 50-year service life was used in comparisons. Firstly, the service life of the building and building components and the replacement intervals of building components during active service life were estimated. The environmental life cycle assessment (ELCA) was carried out for all the buildings and results are presented on a yearly basis in order to study the impact of service life. The region-specific impact categories of cumulative energy demand, greenhouse gas emissions, water consumption and land use are used to assess the environmental performance of buildings. The analysis shows that the environmental performance of buildings is affected by the service life of a building and the replacement intervals of building components.
\end{abstract}

Keywords: building; environmental life cycle assessment; service life; environmental performance

\section{Introduction}

A building is a complex product of different components of variable materials, structural importance, functional life, exposure constraints, and damage mechanisms. Each component of a building has a typical functional requirement and it should perform as per the prescribed function in its service life. Life cycle assessment (LCA) studies that have been conducted, to date, consider the service life of building and building components between 30 and 70 years with a most commonly used value of 50 years (Table 1). However, the real picture is quite contradictory to these assumptions as the service life of buildings varies with materials, operation and maintenance and the surrounding environment [1,2]. This discrepancy may lead to inaccuracy of LCA analyses, and material and energy balance. Any building needs regular maintenance and replacement of its non-structural components to keep the building in performing conditions. In second half of the 20th century, a considerable number of buildings were constructed that need annual inspections and maintenance, influencing the national economy and competitive position of the construction industry [3]. The maintenance and replacement intervals of existing buildings need to be optimized to achieve environmental, social and economic benefits. For new constructions, the estimated intervals of maintenance and replacements should be planned as concisely and wisely as possible. The integration of knowledge of building component durability and its structural and functional performance into building LCA could 
help conduct a realistic assessment of the environmental performance of building components [4]. Due to the uncertainty associated with the use of assumed service life of a building, as well as the unavailability of service life data of building components, LCA studies have not frequently addressed the real energy consumed during maintenance and replacement activities. However, this energy (hereafter, named replacement energy) may be as much as $7 \%$ to $110 \%$ of the initial embodied energy, if the service life of building materials is not properly implemented in the design phase of a building [4-7]. The building life span, whether short or long, has discretionary effects on a building's environmental performance. Short service life of buildings results in excessive solid waste, embodied energy and subsequent greenhouse gas (GHG) emissions during pre-use stage (extraction of material to construction). Long service life of buildings increases replacement of building components, resulting in an increase of replacement energy and prolonged use stage, increasing operational energy and GHG emissions [1]. These two constraints need to be taken into account during material selection by considering the service life of the whole building, as well as its components, and is essential to achieve environmental performance while fulfilling social and economic objectives.

Table 1. Existing case studies.

\begin{tabular}{|c|c|c|}
\hline Author & Life Span (Years) & Impact Indicators \\
\hline Ramesh et al. [8] & 75 & Life cycle energy demand \\
\hline Allacker K. [9] & 60 & External costs \\
\hline Audenaert A. [10] & 50 & Waste generation \\
\hline Carre A. [11] & 60 & $\begin{array}{c}\text { Global warming potential (GWP), Cumulative energy demand (CED), } \\
\text { water use, solid waste, photochemical oxidation, eutrophication, land use, } \\
\text { and resource depletion }\end{array}$ \\
\hline Iyer-Raniga U. [12] & 100 & $\begin{array}{c}\text { Carbon emission, energy, photochemical oxidation, eutrophication, } \\
\text { land use and water use }\end{array}$ \\
\hline Rouwette R. [13] & 50 & GHG, CED \\
\hline Cuellar-Franca R.M. [14] & 50 & $\begin{array}{l}\text { GWP, acidification, eutrophication, abiotic depletion, ozone depletion, } \\
\text { photochemical ozone creation, human toxicity }\end{array}$ \\
\hline Nemry F. [15] & 40 & $\begin{array}{c}\text { GWP, primary energy, acidification, eutrophication, ozone depletion, } \\
\text { photochemical, ozone creation }\end{array}$ \\
\hline Ortiz O. [16] & 50 & GWP, acidification, human toxicity, abiotic depletion, ozone depletion \\
\hline Crawford et al. [6] & 50 & Embodied energy, cost, operational energy \\
\hline Cabeza et al. [17] & 30 to 100 mostly 50 & Life cycle energy \\
\hline Biswas W.K. [18] & 50 & GHG emissions, Embodied energy (EE) \\
\hline Islam H. [19] & 50 & Life cycle energy, life cycle cost (LCC) \\
\hline Atmaca A. [20] & 30 to 100 mostly 50 & GHG emissions \\
\hline Lawania K.K. [21] & 50 & GHG emissions, life cycle energy \\
\hline Grant A. [1] & Estimated & GWP, atmospheric ecotoxicity, atmospheric acidification \\
\hline Dixit M.K. [22] & 50 & Embodied energy \\
\hline Vitale P. [23] & 50 & $\begin{array}{l}\text { GWP, respiratory inorganics potential, non-renewable energy potential, } \\
\text { waste framework directive }\end{array}$ \\
\hline Vitale P. [24] & 50 & Respiratory inorganics, GWP, non-renewable energy \\
\hline Balasbaneh A.T. [25] & 50 & $\begin{array}{l}\text { GWP, human toxicity, acidification, eutrophication, LCC, labor wage rate, } \\
\text { job creation }\end{array}$ \\
\hline
\end{tabular}

According to ISO 15686-1, "Service life is the period of time after construction, in which a building and its parts meet or exceed the acceptable minimum requirements of performance established" [26]. The service life of building components largely depends on the materials' properties, damage mechanisms, environment and quality of design, and work execution. This study aims to estimate the service life of buildings and building components and expected replacement intervals of non-structural components, and to assess the impact of this service life on life cycle environmental performance of buildings.

\subsection{Service Life Estimation}

Service life (SL) estimation of buildings is quite a complicated process that involves intensive data analysis as there is no proto-type in buildings. Each building is unique in its composition, material specification and architectural and structural design. Therefore, the SL estimation cannot be generalized and needs to be carried out on a component to component basis. Construction materials have different properties and damage mechanisms and behave differently in different climates. User requirements, 
degradation agents, and building performance against these agents are important factors to consider for service life planning [27]. The state-of-the-art report on performance-based methods on service life prediction states that "Prediction of durability is subject to many variables and cannot be an exact science" [28]. Therefore, efforts should be made to achieve the most likely estimate by considering the most reliable data sources.

SL prediction methods should be generalized, easy to apply to a variety of materials, user friendly and give clear boundary limitations [29]. SL was first studied by Legget and Hutcheon in 1958. However, SL estimation has been under the limelight since the 1990s by different standard institutes. The Guidelines for Service Life Planning were first published by the Architectural Institute of Japan (AIJ) in 1989 followed by British Standard Institute (BSI) in 1992 and Canadian Standards Association (CSA) in 1995. International standard organizations (ISO) published ISO 15686-1, Building and constructed assets-Service Life Planning_Part 1 in 2000 [30]. A series of publications on ISO 15686 were published afterwards, covering different aspects and procedures of service life predictions.

Service life can be estimated by deterministic, engineering and probabilistic methods. The probabilistic method is the research approach considering degradation probability of a building during a prescribed time. The deterministic method is a simple approach utilizing factors influencing the degradation of a building under certain conditions. The factor method, described in standard, ISO 15686-2 [31], is the well-known deterministic approach. Engineering methods lie somewhere in between deterministic and probabilistic methods. Engineering methods are easy, and use the time-based degradation mechanism for interpretation [32]. SL estimation needs a wide range of data from different sources and under different conditions. These information resources may be existing building data, information collected by surveys, manufacturer data, service life modelling, insurance companies and real estate data, and expert opinion [33]. The engineering approach depends on structural properties of materials, loading conditions, chemical composition, and damage mechanisms in a buildings' life time. However, there is a huge variety of chemical compositions in materials, degradation in different environments, and variable human influences, to treat all materials just the same. Accelerated life tests carried out on building components to predict SL give reasonably accurate results. It is still a big challenge to depict the realistic conditions for life tests. In addition, the accelerated tests are quite expensive. There are also some other approaches to predict SL by considering service life models and obsolescence factors [1,34]. This method can be used for existing buildings or to be built buildings with the same material. This method requires empirical data that cannot be collected for innovative materials. Acquiring data for service life models and time constraint can pose a challenge for the SL prediction approach.

The factor method is the deterministic method that uses seven factors to predict the service life behavior of the building in different climatic conditions and geographic locations. The factor method uses reference service life (RSL) of a building component as a baseline and seven factors to modify the RSL to estimated service life (ESL). The service life estimation is different from service life prediction in the sense that the first is meant for particular conditions, and the second is recorded performance over a prescribed time or referenced SL [30,35]. The factor method helps to estimate service life of building and building components using Equation (1) [30].

$$
\mathrm{ESL}=\mathrm{RSL} \times \mathrm{A} \times \mathrm{B} \times \mathrm{C} \times \mathrm{D} \times \mathrm{E} \times \mathrm{F} \times \mathrm{G},
$$

where,

ESL $=$ Estimated service life of building components

RSL $=$ Reference service life of building components

Factor $\mathrm{A}=$ Quality of components including manufacturing, storage, transport and protective coating etc.

Factor $\mathrm{B}=$ Design level including incorporation, sheltering by rest of structure and surrounding buildings Factor $\mathrm{C}=$ Work execution level, site management, workmanship level, weather condition during work 
Factor $\mathrm{D}=$ Indoor environment conditions, humidity, ventilation, and condensation etc.

Factor $\mathrm{E}=$ Outdoor environment, microenvironmental conditions, weathering factors, building elevation etc.

Factor $\mathrm{F}=$ In-use conditions, mechanical impact, wear and tear, category user etc.

Factor $\mathrm{G}=$ Maintenance level, quality and frequency.

The method incorporates the material behavior, human involvement and degradation mechanism to interpret the ESL. The factor method is flexible, and it considers the combined effect of different deteriorating factors. The method needs judgement of factors as protective or deteriorating and requires fair and definite limitations on factors to avoid complexity [36]. Reliable data is required for the RSL and factors for each building component. The availability of data and reliability of data sources play an important role in SL estimation. The data sources may be manufacturers of building products, test laboratories, government agencies reports, existing studies etc., [37]. The most challenging issue in SL estimation is how to use effectively the available data to predict the SL of a structure that is to be built. In this study, the service life was estimated for most likely values ( \pm 5 years) using the factor method.

\subsection{Environmental Life Cycle Assessment}

The environmental life cycle assessment (ELCA), frequently known as life cycle assessment is a comprehensive tool to assess the environmental impacts of a product or system or service, in pre-use, use, and post-use stages [38]. The ELCA was studied for the first time in the 1960s and up until the 1970s, it was used only to compare the packaging options of consumer goods. In 1969, the Midwest Research Institute conducted a study on LCA for a Coca Cola Company for different types of beverage containers [39]. The studies in this period revolved around policy making and enterprises with a focus on solid wastes, energy consumption, and air pollutant impacts. In the 1990s, SETAC, conducted various workshops and published the first code of practice for life cycle assessment in 1993 [40]. Afterwards, the international standards organization (ISO), was involved actively and published generalized procedures and methods for LCA in ISO 14040-44 in 1997-2000 [38].

In the construction sector, ELCA was first applied in 1980s by Bekker to study the environmental implications of the use of renewable resources in buildings [41]. ELCA was used in buildings to assess the environmental impacts of construction materials and is a credible solution to compare material sustainability [42-45]. Now, the ELCA covers a wide range of areas from building materials (i.e., bricks, cement etc.) to urban planning [46]. The life cycle stages that are usually considered from life cycle assessment of buildings and building components include pre-construction, construction, use and end of life stages. Environmental product declarations (EPDs) involved the use of LCA to estimate environmental impacts for environmental declaration purposes for certification purposes [47]. ELCA helps to improve the performance of building in its entire life span by first identifying hotspots and then by applying mitigation strategies $[47,48]$. However, the system boundaries, functional units and scope definition are unique for each building LCA study, resulting in variation in results among studies [49-51].

Environmental performance of buildings is also defined as a quantified relationship between occupant's comfort level and environmental impacts [52-54]. Embodied and operational impacts are usually two main categories of environmental impacts. Embodied impacts are static and further divided into pre-use embodied impacts and replacement embodied impacts [6]. Pre-use embodied impacts are the impacts due to extraction, manufacturing and construction of buildings and replacement embodied impacts are a result of renovations, replacements and maintenance in the active service life of buildings. The operational or use stage impacts are dynamic in nature and occur in the service life of building $[55,56]$. Better building performance can be achieved by considering factors including material selection, construction techniques, cost factors, and cleaner production strategies (CPS). 
Whilst Australia accounts for only $0.32 \%$ of the world's population, its per capita GHG emission is extremely high compared to countries with similar economies (UK, Mexico, South Korea) i.e., 26 tonnes GHG emissions per capita per year as opposed to 13 tonnes per capita GHG emissions for South Korea, 10 tonnes per capita GHG emissions for UK and 20.3 tonnes per capita GHG emissions for Canada [57]. Australia is the second driest continent after Antarctica [58]. The annual rainfall is highly variable and central Australia is mostly arid with only 6\% arable land in coastal areas [59]. Water is the most precious commodity and its scarcity is covered by desalination of sea water [60-62]. Water mapping in the construction industry helped to identify need for reducing the life cycle water demand/footprint of buildings by using renewable resources. In addition, Australia's per capita waste generation is 2.6 tonnes per year as compared to 0.706 tonne per capita per year for US, out of which 0.8 tonnes per capita per year is construction and demolition waste [63]. Therefore, these two issues are inevitable for assessment of the environmental impacts of building and construction industry at the planning stage of buildings using an ELCA to discern strategies to avoid these environmental consequences. This study thus considered these impact categories, including cumulative energy demand, GHG emissions, water consumption and land use to assess the environmental performance of buildings.

\section{Method}

This study focuses on the impact of service life on environmental performance of buildings. The methodology consists of four main steps (Figure 1). Step 1: Twelve residential buildings were selected. All specifications of the buildings including the architectural design, covered area, orientation, and utility were the same except for the difference in building materials. The residential buildings were modelled using three main systems of roof, wall and footing.

Step 1
•Selection Of Building
-Estimation of Service Life of Building and
Building Components
- Selection of Environmental Indicators
Step 4
- Assessment of ELCA results on annual
basis

Figure 1. Building environmental performance assessment procedure.

The roof system comprised of roof cladding, roof frame, and suspended ceiling. The wall system comprised of exterior render, wall frame and interior plaster and the footing system comprised of footing slab and flooring. The variation in buildings was created only in materials of structural components. The materials for non-structural components were unchanged as replacements for these components are considered easy and does not affect the service life of the whole building. Two types of roof frames, two wall frames and three types of slab footings, resulted in 12 combinations of buildings (Table 2) and a conventional building named Building-50 composed of a timber roof frame, double brick walls and conventional concrete was considered as a reference case for comparison with the aforementioned 12 buildings. 
Table 2. Building components of building combinations and the reference building.

\begin{tabular}{ccccc}
\hline \multirow{2}{*}{ Building } & \multirow{2}{*}{$\begin{array}{c}\text { Building } \\
\text { Specifications }\end{array}$} & Building Components \\
\cline { 3 - 4 } & & Roof Frames & Wall Frames & Slab Footing \\
\hline Building-50 & TF-DB-CC & Timber frame & Double Brick & Conventional concrete \\
1 & TF-CB-CC & Timber frame & Concrete Block & Conventional concrete \\
2 & TF-CB-FAGC & Timber frame & Concrete Block & $30 \%$ FA Green concrete \\
3 & TF-CB-GGBFS & Timber frame & Concrete Block & $30 \%$ GGBFS Green concrete \\
4 & TF-DB-CC & Timber frame & Double Brick & Conventional concrete \\
5 & TF-DB-FAGC & Timber frame & Double Brick & $30 \%$ FA Green concrete \\
6 & TF-DB-GGBFS & Timber frame & Double Brick & $30 \%$ GGBF Green concrete \\
7 & SF-CB-CC & Steel Frame & Concrete Block & Conventional concrete \\
8 & SF-CB-FAGC & Steel Frame & Concrete Block & $30 \%$ FA Green concrete \\
9 & SF-CB-GGBFS & Steel Frame & Concrete Block & $30 \%$ GGBFS Green concrete \\
10 & SF-DB-CC & Steel Frame & Double Brick & Conventional concrete \\
11 & SF-DB-FAGC & Steel Frame & Double Brick & $30 \%$ FA Green concrete \\
12 & SF-DB-GGBFS & Steel Frame & Double Brick & $30 \%$ GGBFS Green concrete \\
\hline
\end{tabular}

Step 2: The service life of each building component was estimated using the factor method [37]. The service life of a system was taken as the service life of structural components i.e., ESL of the roof system was the value of service life for the roof frame. The least value of service life among building systems i.e., roof system, wall system and footing system, was taken as the estimated service life of the building [3]. The service life estimation of components was required, not only to determine the service life of the whole building, but also, to find the replacement intervals of non-structural components during the service life of a building. The service life of a reference building, Building-50 was assumed 50 years based on a literature review (Table 1 ).

Step 3: The indicators for environmental objective were selected by consulting existing studies. ELCA of the building was carried out as per ISO 14040-44 [38]. A quantitative life cycle inventory for building materials and transportation was compiled for construction, the subsequent replacements and demolishing activities. The ELCA considered a cradle to grave approach including pre-use (mining to material, transport of material to site and construction), use, post-use (demolition and disposal) and replacement (replacement of building components throughout the active service life of building) stages. ELCA software, SimaPro 8.4 [64], was used to determine the environmental indicators for impact categories of energy, GHG emissions, water consumption and land use.

Step 4: The impact values were presented on an annual basis for a service life of a building as estimated in the second step in order to investigate the impact of SL on environmental performance of buildings.

\section{Case Studies}

A typical house of four bedrooms and two bathrooms, with a covered area of $245.5 \mathrm{~m}^{2}$ located in Perth WA, was selected for the case study. Twelve building combinations were created based on the roof, wall and footing systems, keeping architectural design, orientation, location and covered area constant (Table 2). 
Buildings 2019, 9, 9

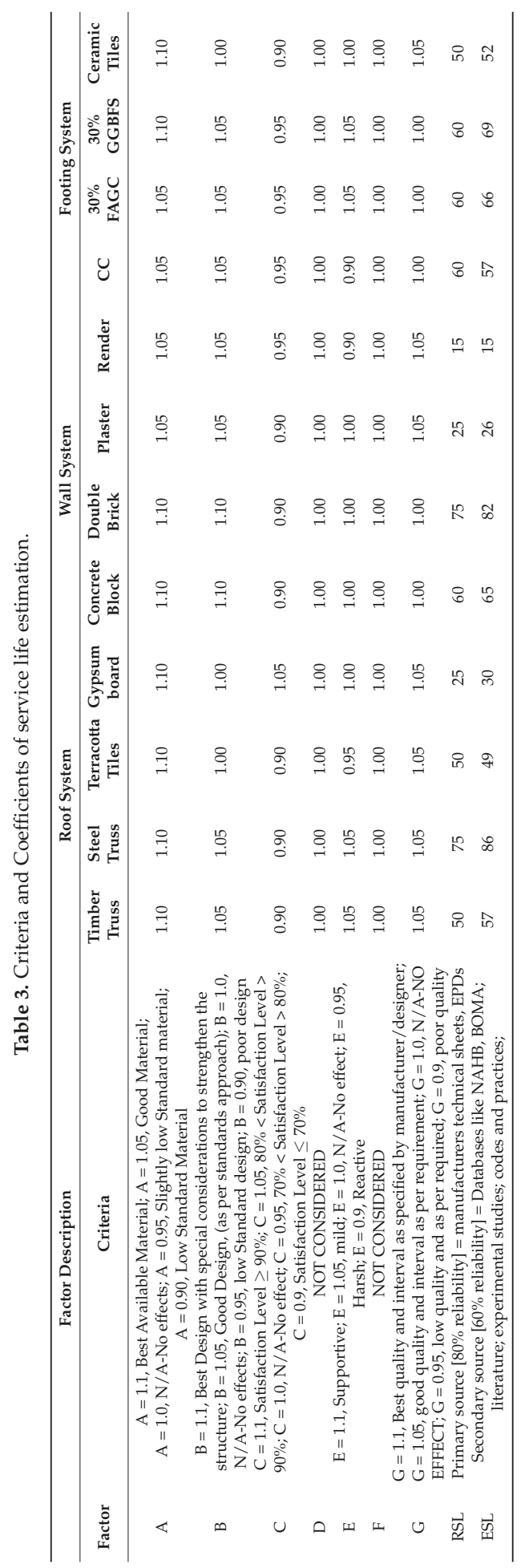


Each of the roof, wall and footing systems was modelled using structural and non-structural building components. Only the non-structural components were selected, that resulted in costly replacements and provided a thermal envelope to the building. However, this aspect of the building enveloping components will be assessed in future study. The roof system included two types of roof assemblies: TF-timber roof frame, terracotta tiles and gypsum board ceiling; and SF-steel roof frame, terracotta tiles and gypsum board ceiling. The wall system consisted of two types of wall assemblies: DB—-double brick wall and interior plaster; and CB—concrete block wall, exterior render and interior plaster.

The footing system comprised of on-grade slab footing and ceramic tile flooring with three types of concrete mixes: CC-conventional concrete; 30\% FA-Green concrete with 30\% replacement of Ordinary Portland Cement (OPC) by class F fly ash; 30\% GGBFS-Green concrete with 30\% replacement of OPC by ground granulated blast furnace slag (GGBFS). The building systems were developed based on the most commonly used materials, in Western Australia with a design life of 50 years as proposed by National Building Codes. A conventional residential building with a timber roof, double brick walls and conventional concrete slab footing and 50-year service life was used as the reference building, Building-50.

A thorough study was conducted to collect the service life data of the building components used in the case study. Based on the gathered information, ranking criteria were set for each factor, to get most likely values (ESL \pm 5 years) of ESL (Table 3). Factor A, B, C, E, G were assigned ranking values from 1.1 to 0.9 [37], and Factor D, F were not considered in the study as these are dependent on occupant behavior and vary greatly. These factors were assigned a value of $1.0 \mathrm{in}$ service life estimation equation. The factor values were reduced to increase the confidence level as compared to previously used values to test the sustainability framework for Building 1 and 2 [65].

The manufacturer data, life expectancy databases of building components and existing case studies were used as data sources for RSL. The manufacturer's technical data sheets were consulted to set the component quality. The factor B values were assigned by considering commonly used practices in building design in Western Australia. Building commission WA annual reports were consulted to estimate the construction works execution level. The climatic conditions, reports of Bureau of Meteorology Western Australia, and inspection reports of residential buildings were considered for weighting outdoor climatic conditions and subsequent effect on the building components.

The life cycle assessment software SimaPro 8.4 was used to assess the environmental impacts of buildings with a grave to cradle approach. Materials required for each building were estimated for building construction and successive replacements. The transportation distances were calculated for nearest available materials retailers and manufacturers. The energy consumption during the use stage was estimated for thermal comfort, hot water, lighting and home appliances. AccuRate sustainability software [66] was used to estimate the annual cooling, heating, and hot water demand. The life cycle inventories for materials, energy consumption and transportation distances were compiled to incorporate in the SimaPro (Tables A1-A5). Table 4 shows the environmental impact categories, impact indicators and methods used to assess the environmental impacts. These impact indicators were selected based on literature review and relevance to the scope of the study.

Table 4. Environmental Impact indicators.

\begin{tabular}{ccc}
\hline Impact Category & Impact Indicators & Impact Assessment Methods \\
\hline Energy & Cumulative energy demand & Cumulative Energy Demand V1.09 \\
GHG emissions & Life cycle GHG emissions & IPCC 2013 GWP 100a V1.02 \\
Land use & Land use & Ecological footprints Australian V1.00 \\
Water consumption & Resource depletion & Pfister et al. 2009 (Eco-indicator 99) V1.02 \\
\hline
\end{tabular}




\section{Results and Discussion}

\subsection{Estimated Service Life}

The ESL of buildings and building components are presented in Table 5. The service life estimation shows that due to the large variation in service life of building components, enough life of building components is compromised. Approximately, 20\% to 35\% of ESL of structural components of 12 buildings, studied in this paper, is wasted. In buildings 4-7, the wall system has 82 years ESL that is $30.5 \%$ more than the ESL of the building. In buildings 10-12, the wall and roof systems both have higher ESL values than the footing system. In buildings 7-9, the roof system has a high ESL value compared to the wall and footing systems.

Table 5. Estimated service life of building systems and buildings.

\begin{tabular}{lcccccccccccc}
\hline $\begin{array}{c}\text { Service Life } \\
\text { (Years) }\end{array}$ & TF-CB-CC & $\begin{array}{c}\text { TF-CB- } \\
\text { FAGC }\end{array}$ & $\begin{array}{c}\text { TF-CB- } \\
\text { GGBFS }\end{array}$ & TF-DB-CC & $\begin{array}{c}\text { TF-DB- } \\
\text { FAGC }\end{array}$ & $\begin{array}{c}\text { TF-DB- } \\
\text { GGBFS }\end{array}$ & SF-CB-CC & $\begin{array}{c}\text { SF-CB- } \\
\text { FAGC }\end{array}$ & $\begin{array}{c}\text { SF-CB } \\
\text {-GGBFS }\end{array}$ & $\begin{array}{c}\text { SF-DB- } \\
\text { CC }\end{array}$ & $\begin{array}{c}\text { SF-DB- } \\
\text { FAGC }\end{array}$ & $\begin{array}{c}\text { SF-DB- } \\
\text { GGBFS }\end{array}$ \\
\hline & $\mathbf{1 .}$ & $\mathbf{2 .}$ & $\mathbf{3 .}$ & $\mathbf{4 .}$ & $\mathbf{5 .}$ & $\mathbf{6 .}$ & $\mathbf{7 .}$ & $\mathbf{8 .}$ & $\mathbf{9 .}$ & $\mathbf{1 0 .}$ & $\mathbf{1 1 .}$ & $\mathbf{1 2 .}$ \\
\hline Roof System & 57 & 57 & 57 & 57 & 57 & 57 & 86 & 86 & 86 & 86 & 86 & 86 \\
Wall System & 65 & 65 & 65 & 82 & 82 & 82 & 65 & 65 & 65 & 82 & 82 & 82 \\
Footing & 57 & 66 & 69 & 57 & 66 & 69 & 57 & 66 & 69 & 57 & 66 & 69 \\
System & 57 & 57 & 57 & 57 & 57 & 57 & 57 & 65 & 65 & 57 & 66 \\
Building & 57 & & & & & & & & & & &
\end{tabular}

In building combinations 1-3, all the three systems have comparable ESLs that makes these the combinations with less material wastage at the post-use stage.

Based on the ESL of building components, the replacements of each building component in the ESL of buildings are specified. These ESLs are calculated conservatively considering that the components maintenance is carried out, strictly on schedule as described by the manufacturer or designer. No replacement is considered in the study for the building components within a range of \pm 5 years of the ESL of buildings [37]. This difference is assumed to be covered by maintenance. The ceramic floor tiles have an ESL of 52 years. As the ESL of ceramic tiles is within a range of \pm 5 years of the ESL of buildings 1-7 and 10, therefore, no replacement for ceramic tiles is suggested in the study. However, in buildings 8-9 and 11-12, one replacement of the ceramic floor tiles is considered. One replacement for terracotta tiles is considered for all buildings. The ESL of gypsum board ceiling needs to be replaced once in the ESL of buildings 1-7, 10 and twice in buildings 8-9, and 11-12. However, exterior rendering and interior plaster of walls need regular replacements after 15 and 26 years respectively, to maintain the aesthetic looks of buildings and to strengthen the concrete block wall against its inherent porous structure. Figure 2 shows the total ESL of building components at post-use stage including replacements. The red line shows the ESL of building and above this line is the remaining ESL of building components at the post-use stage. The remaining ESL is the duration for which a component is still in serviceable condition at the time of demolition of the building. The remaining life for structural components is the ESL of the component, however, the remaining life for non-structural components is calculated by multiplying the ESL of building components with number of replacements and subtracting from the ESL of building. The estimated number of replacements and remaining service life of building components is presented in Tables A6 and A7 in Appendix A section. The study has shown that the lowest remaining life of building components at post-use stage (end of life of building), results in better environmental performance of building, due to reduced material wastage to landfill. 


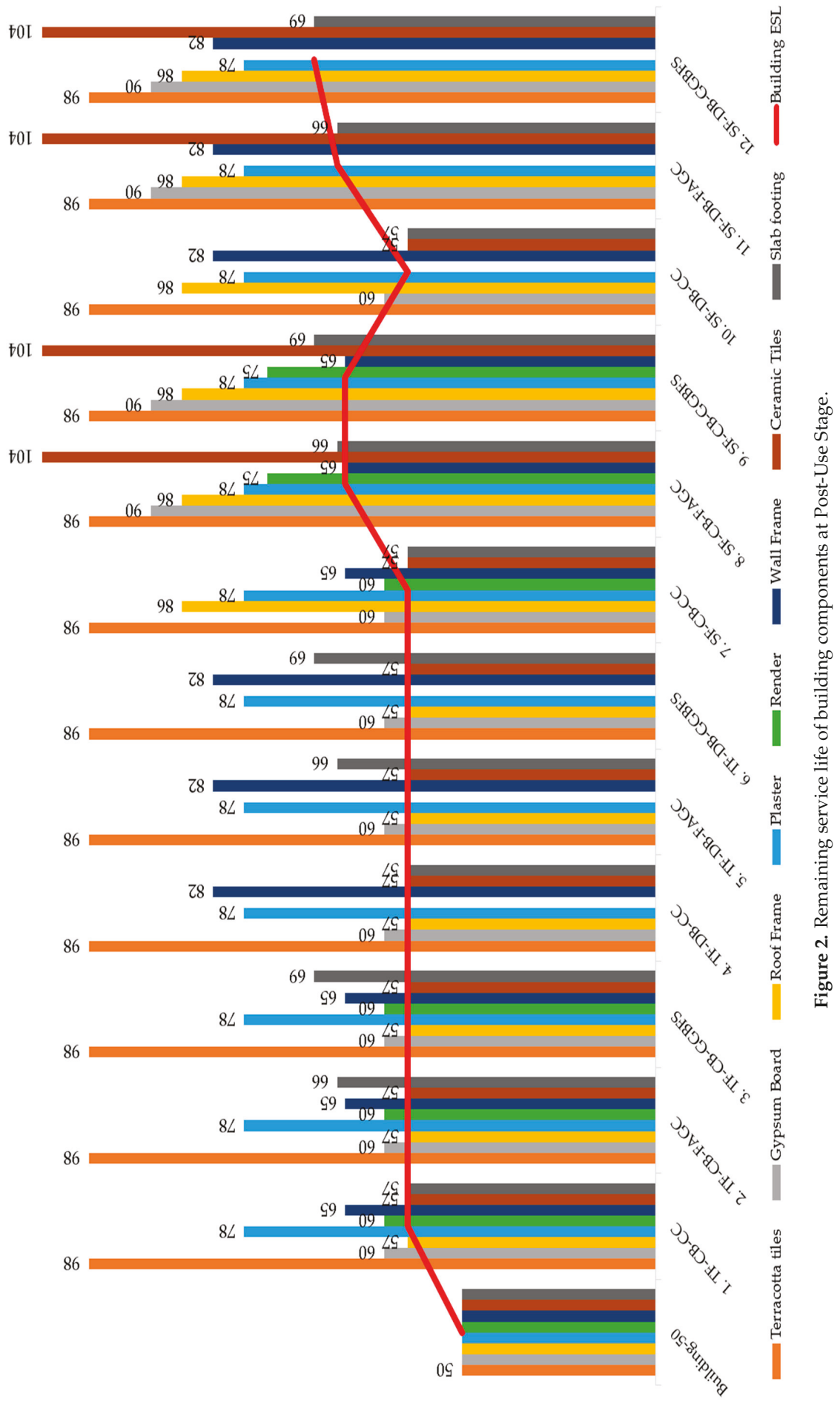




\subsection{Cumulative Energy Demand}

The cumulative energy demand (CED) is calculated on an annual basis to study the impact of service life on the environmental performance of buildings. The CED ranges from 97.799 to 101.813 GJ/year for 12 buildings. The CED is the highest in use stage with a value of $82.634 \mathrm{GJ} /$ year and uniform in each case as no CPS is applied to buildings. The pre-use CED values are highest after the use stage due to energy consumed in extraction of raw materials, manufacturing of materials, transportation to site and construction activities. The replacement stage is the third main contributor to the CED of buildings (range from 2.02 to $3.73 \mathrm{GJ} /$ year for 12 buildings), due to constant addition of embodied energy of replaced building components, at regular intervals (Table A6) during building service life. The post-use CED is negligible, as demolition and disposal of demolition waste to landfill ranges from 0.98 to $1.27 \mathrm{GJ} /$ year for 12 buildings (1\% of total energy demand) [4,67].

Figure 3 shows that CED is the lowest for building 8 (SF-CB-FAGC) with an ESL of 65 years i.e., $4.23 \%$ lower than the conventional Building-50 (TF-DB-CC) due to its longer ESL and the use of green concrete (OPC replaced by 30\% FA). Similarly, the CED of building 9 (SF-CB-GGBFS) is $4.08 \%$ lower than Building-50, also mainly due to longer ESL. Buildings 4 (TF-DB-CC), 5 (TF-DB-FAGC), 6 (TF-DB-GGBFS) and building 10 (SF-DB-CC) have almost the same CED as Building-50 (102.118 GJ/year) with negligible differences between $0.37 \%$ and $0.63 \%$ owing to relatively shorter ESL than buildings 8-9, 11-12, and also because of the use of energy intensive structural material (e.g., double brick wall).

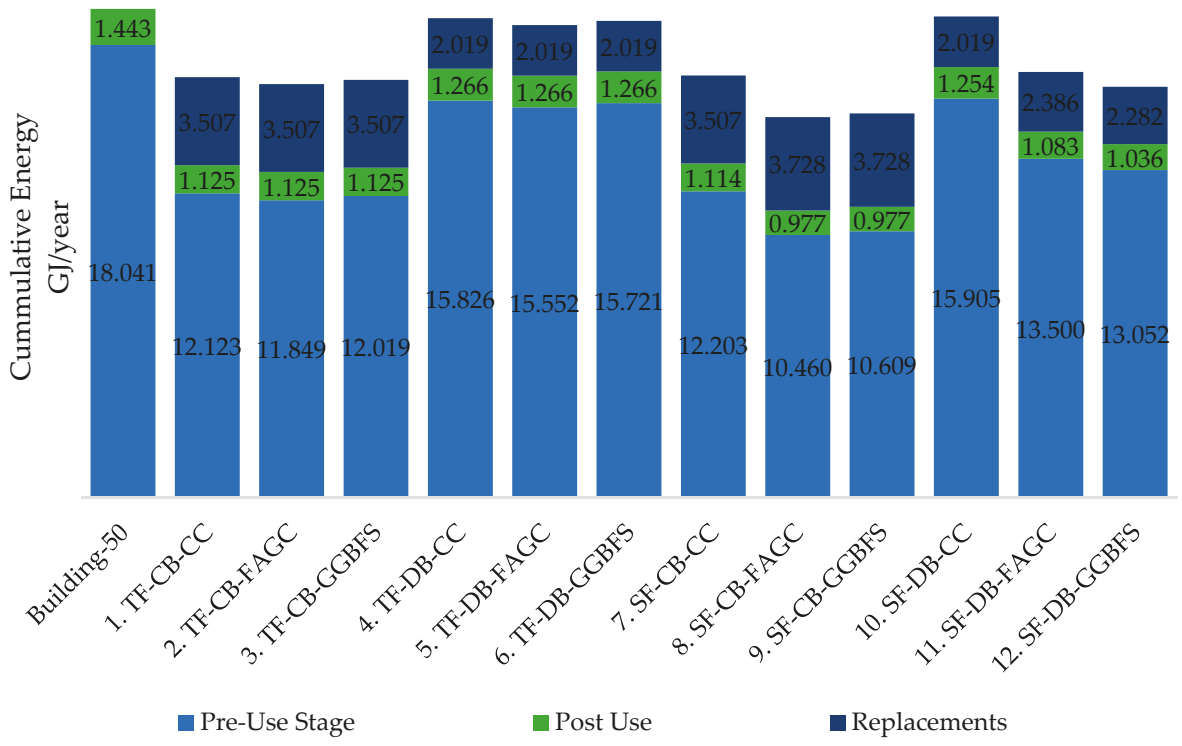

Figure 3. Cumulative Energy Demand per year per building, for 12 buildings and Building-50. (Use stage is omitted in the graph as the use-stage CED value $82.634 \mathrm{GJ} /$ year is uniform in all cases and if plotted on same scale, other stages due to low values cannot be presented properly).

The longer ESL of building 12 (SF-DB-FAGC) and 11 (SF-DB-GGBFS) with ESL of 69 and 66 years, has reduced the share of pre-use energy consumption in comparison to buildings 4-6 and 10 that are composed of energy intensive brick walls and have an ESL of 57 years. Building 9 has the lowest energy demand in pre-use and post-use stage due to having low energy intensive concrete block wall and ESL of 65 years reducing per year share of CED of the building. 
In the replacement stage, buildings with concrete block wall $(1-3,7-9)$ have high replacement embodied energy due to frequent replacements of energy intensive rendering and plastering. In buildings 8-9, the replacement embodied energies are highest due to ceramic tiles replacement in addition to rendering and plastering (Figure 2). Similarly, buildings 4-6, 10 with double brick walls have low replacement embodied energy as only interior plastering is replaced at a regular interval of 26 years (Table A6). Buildings 11 and 12, with longer ESL, have slightly higher replacement stage embodied energy due to replacement of ceramic tiles.

Although replacement embodied energy is higher in some buildings, the longer ESL of buildings reduces the impact of replacement embodied energy, as in buildings 8-9. In some cases, the use of energy intensive structural building components in fact reduced the overall CED of buildings. The steel frame roof is an energy intensive material, but its use had indirectly reduced the annual CED by increasing ESL of building combinations 8-9 and 11-12.

The results of this study were compared with similar studies in WA. Lawania and Biswas [68], estimated the annual CED for residential buildings across Western Australia showed slightly higher CED (138 GJ/year), which this value varies between 97.8 and $101.81 \mathrm{GJ} /$ year under this current study. This variation happened due to the fact that Lawania and Biswas had used 18 different climatic locations and also one service life of 50 years was considered. In other studies of residential buildings that considered the embodied energy of building components replaced during ESL, embodied energy was found to increase by $20 \%$ to $40 \%$ due to increase of service life from 50 to 100 years $[4,69,70]$. Similar results were found for some buildings (buildings 8-9,11-12) in the current study, where longer ESL had in fact increased the CED by $17 \%$ to $33 \%$ due to replacement of building components during ESL.

\subsection{GHG Emissions}

The GHG emissions in 12 buildings vary from 11.383 to $11.49 \mathrm{t} \mathrm{CO}_{2}$ eq. The GHG emissions are highest in use stage with a value of $9.918 \mathrm{t} \mathrm{CO}_{2} \mathrm{eq} /$ year and uniform for all buildings like CED assessment due to use of electricity that is predominantly generated from fossil fuels ( $49 \%$ black coal and 36\% gas) in WA [71]. The pre-use GHG emissions are highest after the use stage due to fossil fuel consumptions in extraction and manufacturing of materials, transportation of materials to site and construction equipment. The replacement stage is the third main contributor to the GHG emissions of buildings, due to the addition of the materials to building during ESL. The post-use CED is negligible as the demolition and disposal of demolition waste to landfill consumes only $1 \%$ of the total energy $[4,67]$.

Building-50 (reference building) with a 50-year ESL, has annual GHG emissions of $11.455 \mathrm{t} \mathrm{CO}_{2}$ eq/year, despite the absence of the replacement stage. Annual GHG emissions for building 2 (TF-CB-FAGC) with an ESL of 57-years, are the lowest among all the building combinations (i.e., $0.626 \%$ less than Building-50) due to use of low carbon intensive materials (timber, concrete blocks), less replacements of non-structural components (rendering, plastering) and most importantly due to having a similar ESL of building components as the whole building. These design specifications result in lower wastage of material or embodied energy at the post-use stage. Building 10 (SF-DB-CC) with an ESL of 57 years has the highest GHG emissions per year of $11.49 \mathrm{t} \mathrm{CO}_{2}$ eq/year (i.e., $0.308 \%$ higher than Building 50) due to shorter ESL and use of energy intensive structural components (double brick wall, steel frame roof) with ESL longer than building ESL. It is worth mentioning that the building components with longer ESL than the whole building remains unused after the end of life demolition and disposal stage and are being considered as wastes.

Figure 4 shows that the double brick buildings 4 (TF-DB-CC), 5 (TF-DB-FAGC), 6 (TF-DB-GGBFS), and 10 (SF-DB-CC) have high pre-use stage annual GHG emissions of 1.265, 1.218, 1.230, and $1.279 \mathrm{t} \mathrm{CO}_{2}$ eq/year, than Building-50, with $1.443 \mathrm{t} \mathrm{CO}_{2}$ eq/year annual GHG emissions due to relatively longer ESL of 57 years and also due to use of energy intensive structural components i.e., brick walls (buildings 4-6,10) and steel frame roof (building 10) with longer ESL (Figure 2) that is wasted to landfill at the post-use stage. 


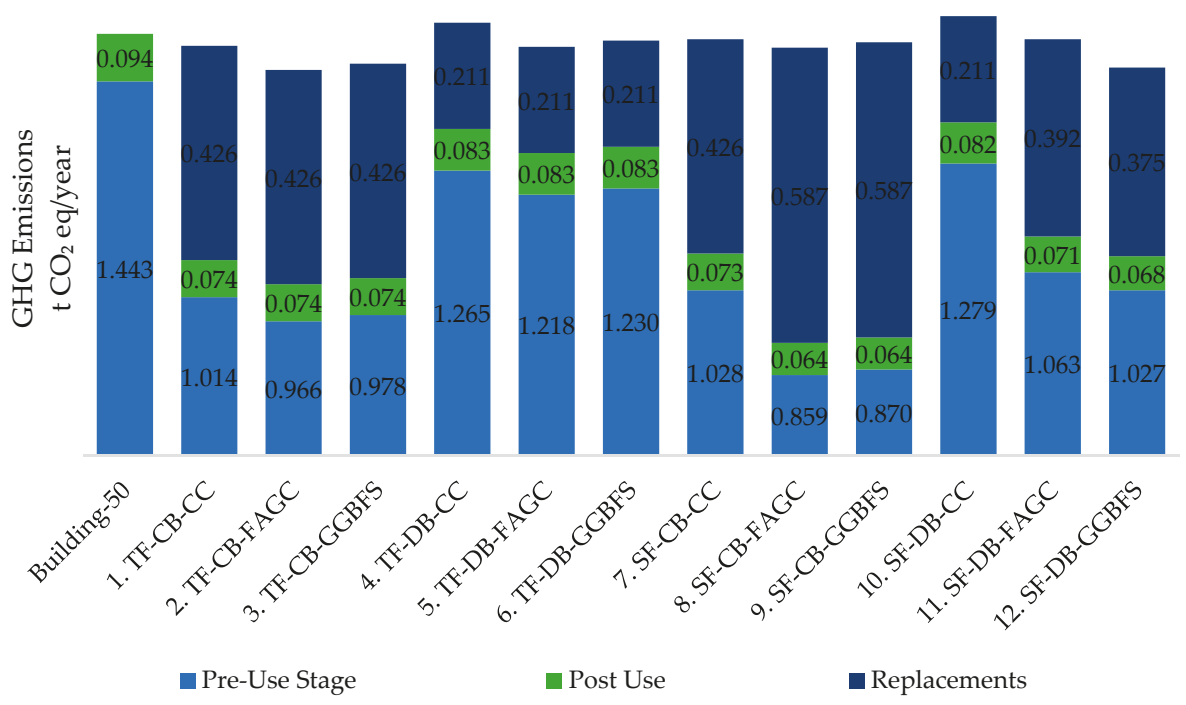

Figure 4. Life cycle greenhouse gas (GHG) emissions per year per building for 12 buildings and Building-50. (Use stage is omitted in the graph as the use-stage GHG value 9.918 t $\mathrm{CO}_{2}$ eq/year is uniform in all cases and if plotted on same scale, other stages due to low values cannot be presented properly).

The GHG emissions associated with the replacement of components during the active service life are highest for building 8 (SF-CB-FAGC) and 9 (SF-CB-GGBFS) with a value of $0.587 \mathrm{t} \mathrm{CO}_{2}$ eq/year. The reason for high replacement GHG emissions in these buildings is the use of carbon intensive ceramic tiles (13.07 $\mathrm{t} \mathrm{CO}_{2} \mathrm{eq}$ ) and rendering processes (10.56 t CO 2 eq). Additionally, the replaced ceramic tiles were not fully utilized as the ESL of buildings 8 and 9 expired at the $33 \%$ ESL of ceramic tile and therefore this valuable material was disposed along with other building materials into the landfill. The recovery of this carbon intensive material thus needs to be considered for use in similar applications during its remaining life (i.e., $67 \%$ of ESL). In addition, the rendering used large amounts of carbon intensive OPC (Ordinary Portland Cement). Nonetheless, due to the porous nature of concrete blocks, rendering or an alternative process is required to provide coverage to concrete blocks, which in fact increased the overall energy consumption as well as the GHG emissions.

Annual GHG emissions for case study buildings in the current study vary between 10.957 and $11.49 \mathrm{tCO}_{2}$ eq/year and is slightly higher than Lawania and Biswas [68,72] $\left(9.4 \mathrm{t} \mathrm{CO}_{2} \mathrm{eq} /\right.$ year$)$. This is mainly due to differences in parameters like service life and climatic conditions affecting use stage GHG emissions. In a study by Carre A. [11] for Australian houses with a 50-year service life, pre-use GHG emissions ( 0.908 t CO 2 eq/year) are similar to current study ( 0.859 to $1.279 \mathrm{t} \mathrm{CO}_{2}$ eq/year).

\subsection{Land Use}

Land use impact is the highest in the use stage (1.353 Ha_a/year) as standard energy input is used for all buildings without considering any greener choices such as wind mills, solar panels etc. The land use in the pre-use stage is the highest after the use stage as it is the summation of all land utilized during the extraction of raw materials, manufacturing of materials, transportation to site and construction equipment, followed by the replacement stage. The post-use stage land utilization is negligible as only energy consumption for the demolition and disposal of demolition waste to landfill is assessed for the study.

Figure 5 shows that the building 4 (TF-DB-CC) has the highest land use impact of 1.583 Ha_a (actual hectare) per year due to the timber frame roof (material acquired by plants) and shorter ESL. 
Building 12 (SF-DB-GGBFS) has the lowest impact with a value of $1.558 \mathrm{Ha} \_$a/year. The longer ESL of building 12 and use of industrial by-products like GGBFS [11] has contributed to the lower land use impact.

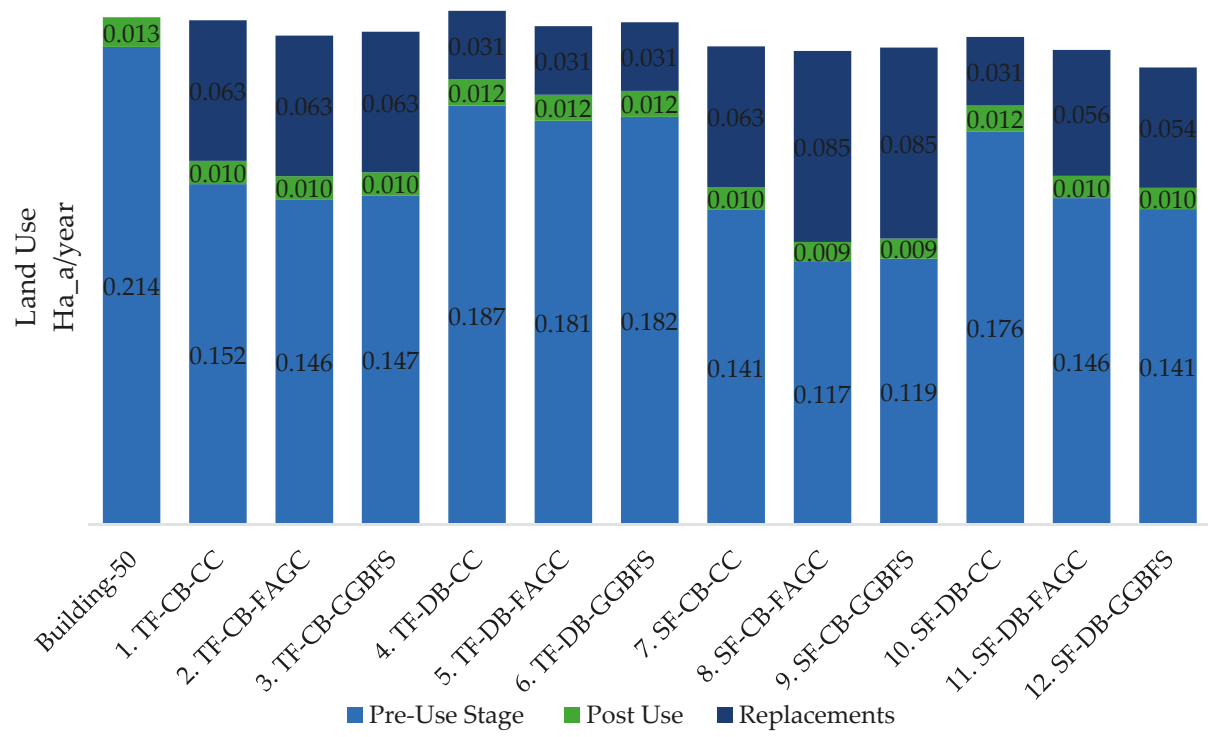

Figure 5. Life cycle land use per year per building for 12 buildings and Building-50. (Use stage is omitted in the graph as the use-stage Land use value $1.353 \mathrm{Ha}$ _a/year is uniform in all cases and if plotted on same scale, other stages due to low values cannot be presented properly).

Building 4 (TF-DB-CC), 5 (TF-DB-FAGC), and 6 (TF-DB-GGBFS) have the highest land use in the pre-use and post-use stages among 12 buildings, due to the increased amount of land requirement associated with the production of a timber frame roof, and also because these materials have short ESL meaning that more land is required to make these materials to meet the demand for replacement. The land use impact for replacement stage is higher for buildings 8 and 9 with 65-year ESL, as more energy and carbon intensive materials (e.g., ceramic tiles, rendering, plastering) requiring more space for mining, processing and manufacturing are replaced during this long ESL (Figure 2). Replaced building components in buildings 8 and 9 have about $33 \%$ to $60 \%$ of the remaining life at the end of the building service life (Figure 2).

The building with components with similar ESLs to the whole building ESL generate less waste which means the diversion of waste from landfill or residue area, thus conserving land or reducing the land footprint. From the ecological footprint point of view, the buildings with a timber roof and double brick wall frame have higher impacts than building with building components of industrial material on an annual basis, which is consistent with the existing study of Allacker et al. [73]. In the post-use stage, ceramic tiles and rendering have the highest impacts as these materials are disposed of before their ESL was finished.

\subsection{Water Consumption}

Life time water consumption by case study buildings is calculated in terms of damage to resources. The resource depletion is the minimum time step to assess the water resource depletion in areas like Western Australia with fixed annual precipitation cycle [60].

Resource depletion is the highest in the use stage due to high water consumption in electricity generation [74]. The resource depletion in the pre-use stage is the second highest in buildings due 
to water consumption mainly in the extraction of materials and manufacturing processes. In the pre-use stage, onsite water consumption (construction works) is negligible $(0.1 \%)$ as compared to upstream processing of materials. The replacement stage is contributing as the third major stage due to building component replacements. Like CED, GHG emissions and land use, the post-use stage has the least water footprint due to consideration of only demolition of buildings and transportation energy consumption to dispose of these wastes to landfill.

Figure 6 shows that the annual resource depletion is the highest for building 8 (SF-CB-GGBFS) due to use of industrial materials (steel frame, concrete block, rendering and interior plaster). The resource depletion is lowest for Building-50 as no replacement is considered for Building-50 and it has a brick wall and timber frame roof that are less water consuming materials. In the case study buildings, building 5 (TF-DB-FAGC) has slightly higher water demand as compared to the reference building (Building-50) mainly because of replacements and an ESL of 57 years.

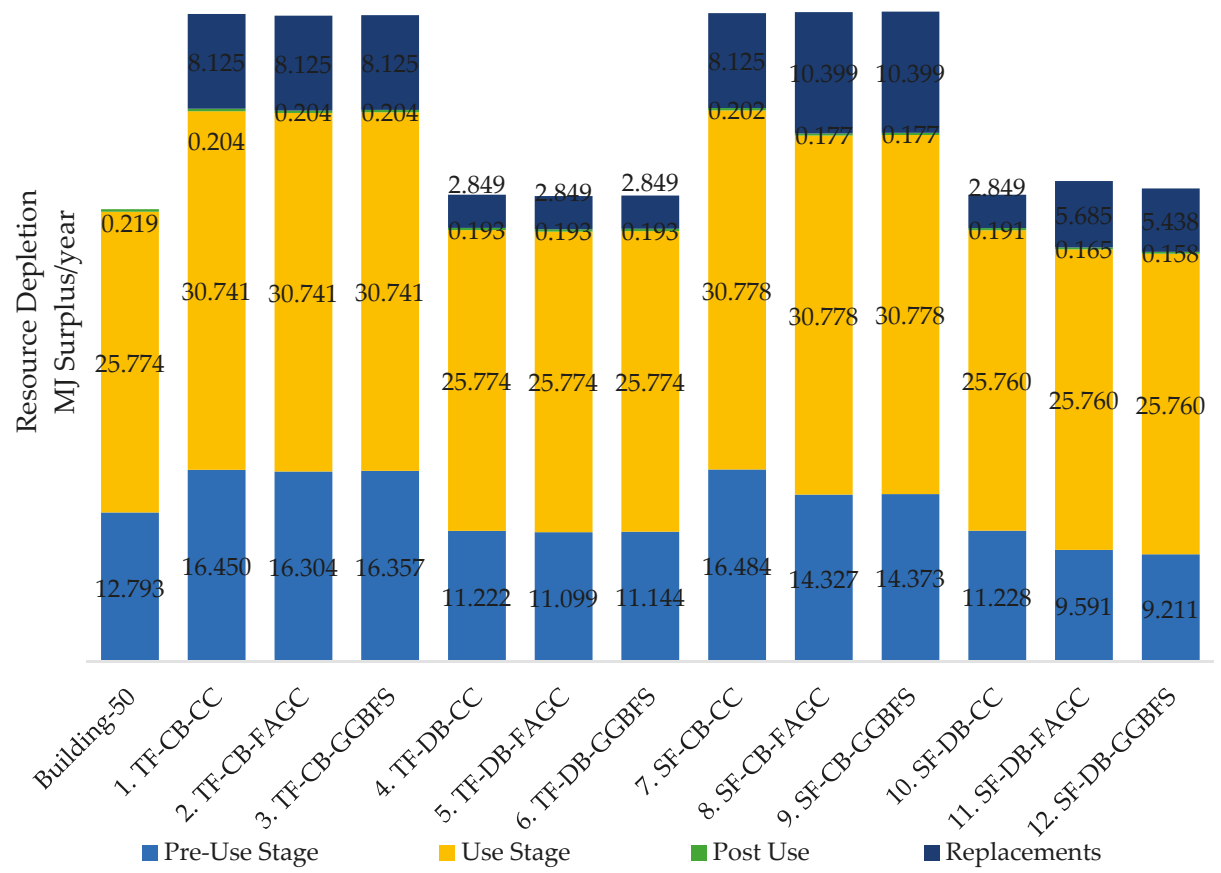

Figure 6. Life cycle resource depletion per year per building for 12 buildings and Building-50.

For pre-use stages, building 7 has the highest water footprint of $16.484 \mathrm{MJ}$ surplus/year due to a shorter ESL and use of building components of industrial materials. The lowest water footprint in pre-use stage is for building 12 (SF-DB-GGBFS) with longer ESL and structural components like brick, green concrete, that have lower water demand and decreased overall water consumption by building $[75,76]$. In concrete block wall buildings (building 1 (TF-CB-CC), 2 (TF-CB-FAGC), 3 (TF-CB-GGBFS)), water consumption in concrete block and plaster production, as well as the rendering process and their shorter ESL, are the main contributing factors for water footprint [75]. In the replacement stage, the concrete block wall and steel frame roof in buildings 8 (SF-CB-FAGC) and 9 (SF-CB-GGBFS) with 65-year ESL have the highest mineral resource depletion due to frequent replacements of rendering, interior plaster and water intensive ceramic tiles. 


\section{Conclusions}

This study used the life cycle assessment procedure (ISO 14040-44) [38] and factor method (ISO 15686-2) [31,37], to determine the impact of service life on the environmental performance of buildings. The service life of a building and building components have a direct relationship with environmental performance of building. Estimation of replacements intervals is important in the environmental life cycle assessment of buildings, as these are the third main contributing stage to environmental impacts, after use and pre-use stage. The cumulative energy demand for building 8 (SF-CB-FAGC) is 97.779 GJ/year, $4.23 \%$ lower than the reference building, due to the ESL of 65 years. The GHG emissions for building 2 (TF-CB-FAGC) is $11.383 \mathrm{t} \mathrm{CO}_{2} \mathrm{eq} /$ year, the lowest among the case study buildings, due to use of structural components with a comparatively similar service life as ESL of buildings. The land use for building 12 (SF-DB-GGBFS) is 1.558 Ha_a, the lowest among case study buildings $(0.96 \%$ lower than reference building), due to longer ESL and the use of industrial by-products which reduces land use for residue storage. Building 5 (TF-DB-FAGC) has the lowest water footprint (39.915 MJ Surplus/year) amongst case study buildings (2.827\% higher than the reference building), due to use of timber and brick.

This study showed that buildings 1-12 have better performance than Building-50 for CED, and buildings 1-3, 5-9 and 11-12 have lower GHG emissions than Building-50. In the land use impact category, buildings 1-3 and 5-12 have lower land use. However, the water footprint results are slightly different than CED, GHG and land use. Building-50 has the lowest water demand as compared to the 12 case study buildings.

Current research shows that building environmental performance is dependent on building component's materials and ESL, and the way these components are modeled into building. The use of industrial byproducts (concrete blocks, steel) could enhance performance for land use, while building materials like timber and brick have a better water footprint. Industrial byproducts (FA) have lower environmental impact for all indicators considered in this research. The service life of buildings and building components affect the environmental performance of buildings. The use of alternative, eco-friendly strategies in buildings like grey water, green concrete, renewable resources are effective only if these are aligned with building service life. Longevity of the service life of buildings can produce sustainable outcomes, if all of the building component's service life is nearest to the building's service life, which causes fewer replacements, as well as the GHG emissions from the transportation of waste during the post-use stage.

Author Contributions: Conceptualization and methodology, S.Y.J., P.K.S. and W.K.B.; Analysis, S.Y.J.; investigation, S.Y.J.; data curation, S.Y.J.; writing—original draft, S.Y.J.; visualization, S.Y.J.; writing一review and editing, S.Y.J., P.K.S. and W.K.B.; Supervision, S.Y.J., P.K.S. and W.K.B.

Funding: This research received no external funding.

Acknowledgments: The Authors would like to thank four reviewers for their insightful comments to improve the manuscript.

Conflicts of Interest: The authors declare no conflict of interest. 


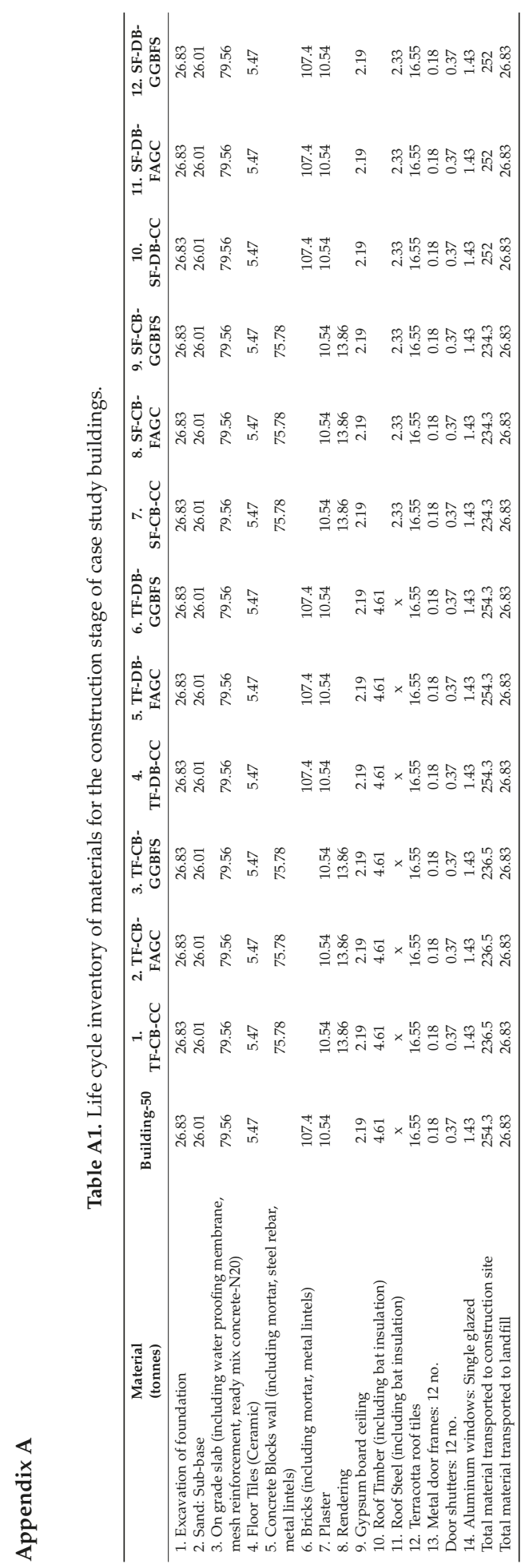


Buildings 2019, 9, 9

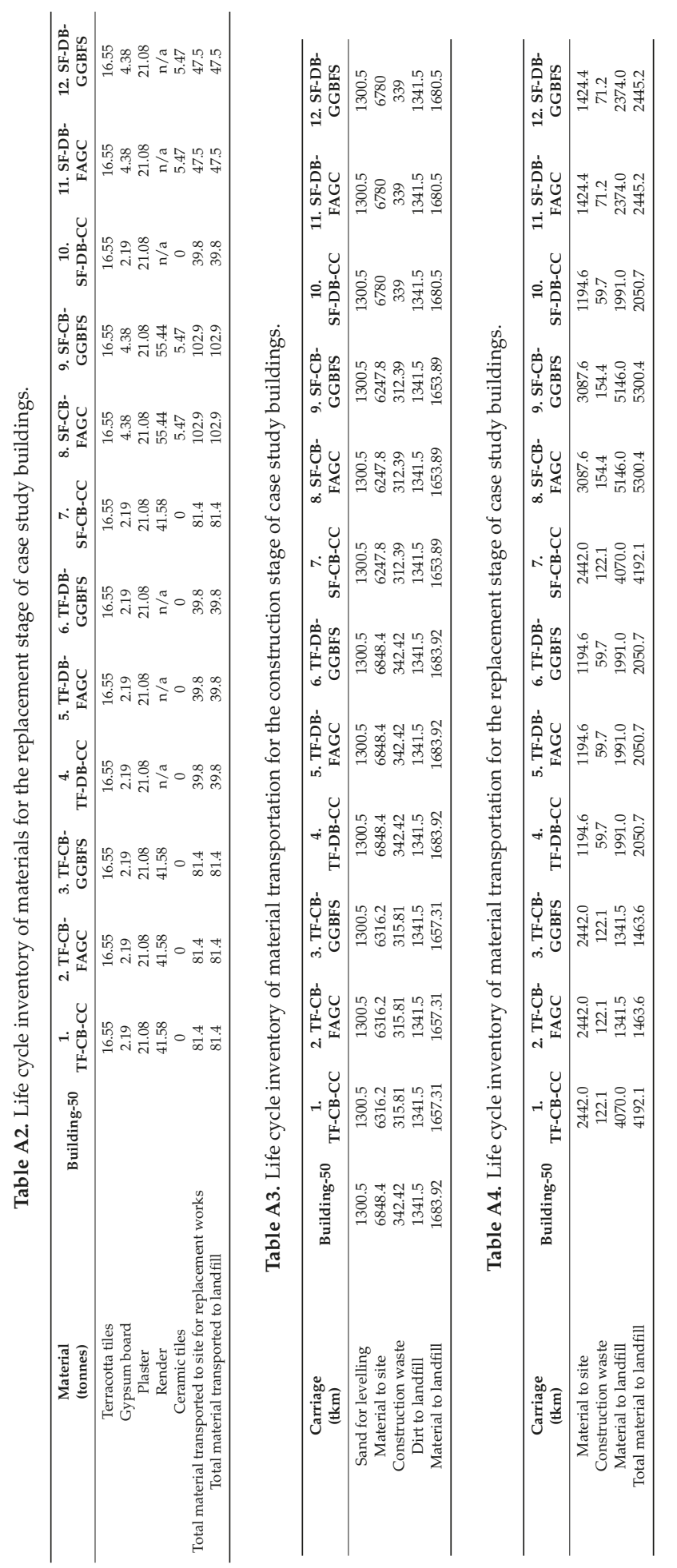




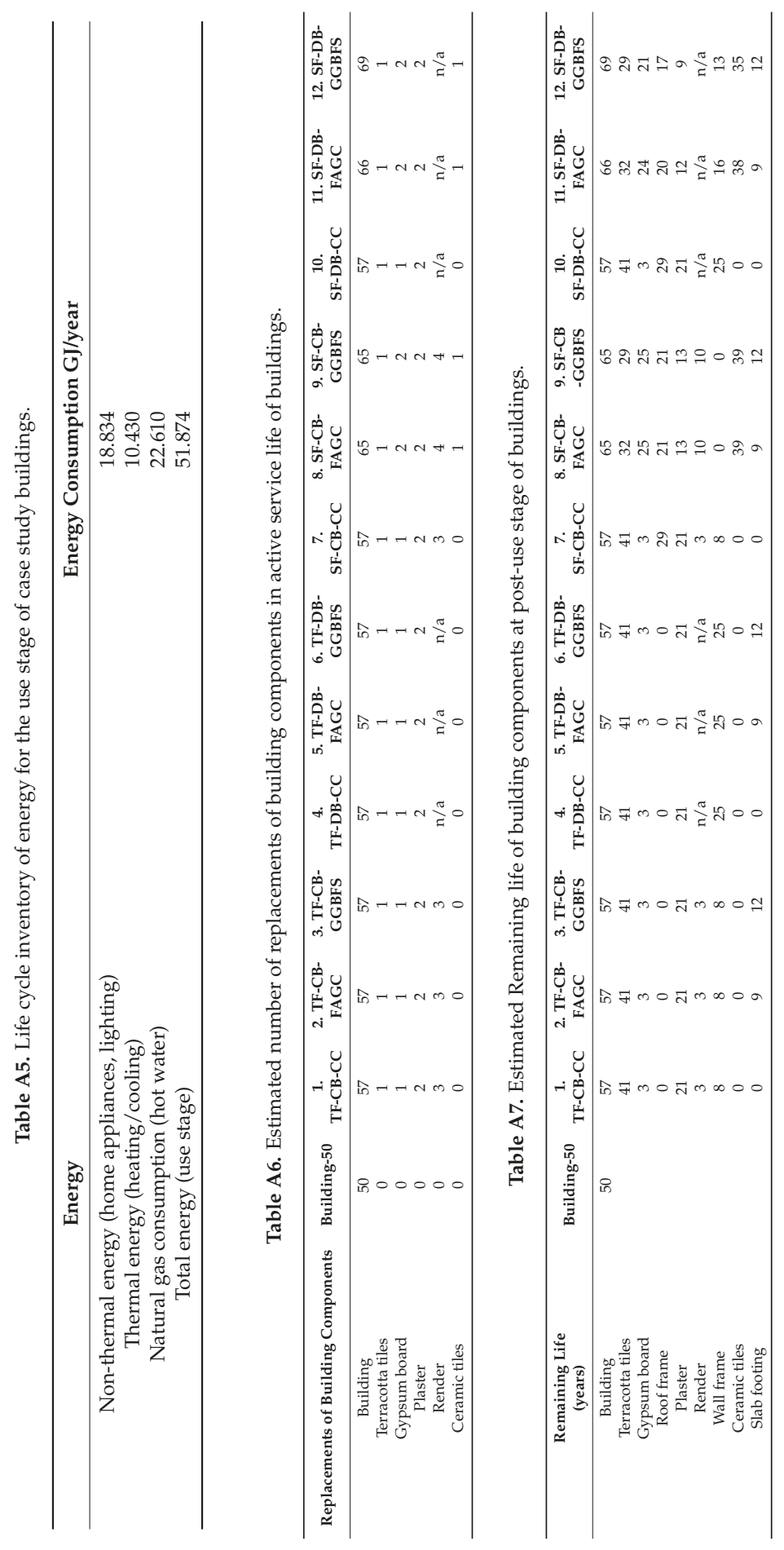




\section{References}

1. Grant, A.; Ries, R.; Kibert, C. Life cycle assessment and service life prediction: A case study of building envelope materials. J. Ind. Ecol. 2014, 18, 187-200. [CrossRef]

2. Nunen, H.V. Assessment of the Sustainability of Flexible Building: The Improved Factor Method: Service Life Prediction of Buildings in The Netherlands, Applied to Life Cycle Assessment. Ph.D. Thesis, Universiteit Eindhoven, Eindhoven, The Netherlands, 2010.

3. Leticia, O.M.; Begoña, S.L. Proposed method of estimating the service life of building envelopes. J. Constr. 2015, 14, 60-88.

4. Rauf, A.; Crawford, R.H. The relationship between material service life and the life cycle energy of contemporary residential buildings in Australia. Artich. Sci. Rev. 2013, 56, 252-261. [CrossRef]

5. Robert, H.; Crawford, R.J.F. Energy and greenhouse gas emissions implications of alternative housing types for Australia. In Proceedings of the State of Australian Cities National Conference Australian Sustainable Cities and Regions Network (ASCRN), Melbourne, VIC, Australia, 29 November-2 December 2011; pp. 1-12.

6. Robert, H.; Crawford, I.C.; Robert, J.F. A comprehensive framework for assessing the life-cycle energy of building construction assemblies. Archit. Sci. Rev. 2010, 53, 288.

7. Silvestre, J.D.; Silva, A.; de Brito, J. Uncertainty modelling of service life and environmental performance to reduce risk in building design decisions. J. Civ. Eng. Manag. 2015, 21, 308-322. [CrossRef]

8. Ramesh, T.; Prakash, R.; Shukla, K.K. Life cycle energy analysis of a residential building with different envelopes and climates in Indian context. Appl. Energy 2012, 89, 193-202. [CrossRef]

9. Allacker, K. Sustainable Building: The Developement of an Evaluation Method. Ph.D. Thesis, Katholieke Universiteit Leuven, Leuven, Belgium, 2010.

10. Audenaert, A.; de Cleyn, S.H.; Buyle, M. Lca of low energy flats using the eco-indicator 99 method: Impact of insulation materials. Energy Build. 2012, 47, 68-73. [CrossRef]

11. Carre, A. A Comparative Life Cycle Assessment of Alternative Constructions of a Typical Australian House Design; PNA147-0809; Forest \& Wood Products Australia: Melbourne, Australia, 2011.

12. Iyer-Raniga, U.; ChewWong, J.P. Evaluation of whole life cycle assessment for heritage buildings in australia. Build. Environ. 2012, 47, 138-149. [CrossRef]

13. Rouwette, R. Lca of Brick Products; Think Brick Australia: Melbourne, Australia, 2010.

14. Cuellar-Franca, R.M.; Azapagic, A. Environmental impacts of the UK residential sector: Life cycle assessment of houses. Build. Environ. 2012, 54, 86-99. [CrossRef]

15. Nemry, F.; Uihlein, A.; Colodel, C.M.; Wetzel, C.; Braune, A.; Wittstock, B.; Hasan, I.; Kreißig, J.; Gallon, N.; Niemeier, S.; et al. Options to reduce the environmental impacts of residential buildings in the european union-potential and costs. Energy Build. 2010, 42, 976-984. [CrossRef]

16. Ortiz-Rodríguez, O.; Castells, F.; Sonnemann, G. Life cycle assessment of two dwellings: One in spain, a developed country, and one in colombia, a country under development. Sci. Total Environ. 2010, 408, 2435-2443. [CrossRef] [PubMed]

17. Cabeza, L.F.; Rincón, L.; Vilariño, V.; Pérez, G.; Castell, A. Life cycle assessment (lca) and life cycle energy analysis (lcea) of buildings and the building sector: A review. Renew. Sustain. Energy Rev. 2014, 29, 394-416. [CrossRef]

18. Biswas, W.K. Carbon footprint and embodied energy assessment of a civil works program in a residential estate of western australia. Int. J. Life Cycle Assess. 2014, 19, 732-744. [CrossRef]

19. Islam, H.; Jollands, M.; Setunge, S. Life cycle assessment and life cycle cost implication of residential buildings-A review. Renew. Sustain. Energy Rev. 2015, 42, 129-140. [CrossRef]

20. Atmaca, A. Life-cycle assessment and cost analysis of residential buildings in south east of turkey: Part 2-A case study. Int. J. Life Cycle Assess. 2016, 21, 925-942. [CrossRef]

21. Lawania, K.K.; Biswas, W.K. Achieving environmentally friendly building envelope for western australia's housing sector: A life cycle assessment approach. Int. J. Sustain. Built Environ. 2016, 5, 210-224. [CrossRef]

22. Manish, K.; Dixit, J.L.F.; Lavy, S.; Charles, H.C. Need for an embodied energy measurement protocol for buildings: A review paper. Renew. Sustain. Energy Rev. 2012, 16, 3730-3743.

23. Vitale Pierluca, A.N.; Fabrizio, D.G.; Umberto, A. Life cycle assessment of the end of life phase of a residential building. Waste Manag. 2017, 60, 311-321. [CrossRef] 
24. Pierluca Vitale, U.A. An attributional life cycle assessment for an italian residential multifamily building. Environ. Technol. 2018, 39, 3033-3045. [CrossRef]

25. Balasbaneh, A.T.; Marsono, A.K.B.; Khaleghi, S.J. Sustainability choice of different hybrid timber structure for low medium cost single-story residential building: Environmental, economic and social assessment. J. Build. Eng. 2018, 20, 235-247. [CrossRef]

26. Buildings and constructed assets-Service life planning. Part-1: General Principles and Framework; ISO 15686-1; International Standards Organisation: Geneva, Switzerland, 2011.

27. Hed, G. Service life planning of building components. Durab. Build. Mater. Compnt. 1999, 8, 1543-1551.

28. Hovde, P.J.; Moser, K. Performance Based Methods for Service Life Prediction; In-House Publishing: Rotterdam, The Netherlands, 2004.

29. Masters, L.W.; Brandt, E. Prediction of service life of building materials and components. Mater. Struct. 1987, 20, 55-77. [CrossRef]

30. Building and constructed assets—Service planning. Part 1: General Principals and Framework; ISO 15686-1:2000; International Standards Organisation: Geneva, Switzerland, 2000.

31. Buildings and constructed assets-Service life planning. Part-2: Service Life Prediction Procedures; ISO 15686-2; International Standards Organisation: Geneva, Switzerland, 2012.

32. Cecconi, F. Performance lead the way to service life prediction. In Proceedings of the 9th International Conference on Durability of Building Materials and Components, Brisbane, Australia, 17-20 March 2002.

33. Ivan Cole, P.C. Predicting the service life of buildings and components. Constr. Mater. 2011, 164, 305-314. [CrossRef]

34. Chen, C.-J.; Juan, Y.-K.; Hsu, Y.-H. Developing a systematic approach to evaluate and predict building service life. J. Civ. Eng. Manag. 2017, 23, 890-901. [CrossRef]

35. Hovde, P.J. Performance Based Methods for Service Life Prediction, Part A: Factor Methods for Service Life Prediction. Available online: http://site.cibworld.nl/dl/publications/Pub294.pdf (accessed on 1 January 2019).

36. Hovde, P.J. Evaluation of the Factor Method to Estimate the Service Life of Building Components; Department of Building and Construction Engineering, The Norwegian University of Science and Technology: Trondheim, Norway, 1998.

37. Buildings and constructed assets-Service-life planning. Part 8: Reference Service Life and Service-Life Estimation; ISO 15686-8; International Standards Organisation: Geneva, Switzerland, 2008.

38. Environmental Management-Life Cycle Assessment, Principles and Framework; ISO 14040; International Standards Organization: Geneva, Switzerland, 2006.

39. Guinee, J.B.; Udo de Haes, H.A.; Huppes, G. Quantitative life cycle assessment of products: 1: Goal definition and inventory. J. Clean. Prod. 1993, 1, 3-13. [CrossRef]

40. Consoli, F.A.; Boustead, I.; Fava, J.; Franklin, W.; Jensen, A.; Oude, N.; Parrish, R.; Perriman, R.; Postlethwaite, D.; Quay, B.; et al. Guide Lines for Life-Cycle Assessment: A Code of Practice; Society of Environmental Toxicology and Chemistry: Pensacola, FL, USA, 1993.

41. Bekker, P.C.F. A life cycle approach in building. Build. Environ. 1982, 17, 3-13. [CrossRef]

42. Ortiz, O.; Castells, F.; Sonnemann, G. Sustainability in the construction industry: A review of recent developments based on lca. Constr. Build. Mater. 2009, 23, 28-39. [CrossRef]

43. Lotteau, M.; Loubet, P.; Pousse, M.; Dufrasnes, E.; Sonnemann, G. Critical review of life cycle assessment (lca) for the built environment at the neighborhood scale. Build. Environ. 2015, 93, 165-178. [CrossRef]

44. Anderson, J.E.; Wulfhorst, G.; Lang, W. Expanding the use of life-cycle assessment to capture induced impacts in the built environment. Build. Environ. 2015, 94, 403-416. [CrossRef]

45. Passer, A.; Ouellet-Plamondon, C.; Keneally, P.; John, V.; Habert, G. Impact of future scenarios on building renovation strategies towards plus energy buildings. SBE16 Zurich 2016, 124, 2.

46. Norman, J.; MacLean, H.; Kennedy, C.A. Comparing high and low residential density: Life-cycle analysis of energy use and greenhouse gas emissions. J. Urban Plan. Dev. 2006, 132, 10-21. [CrossRef]

47. Wahidul, K.; Biswasa, Y.A.; Krishna, K.L.; Prabir, K.S.; Elsarrag, E. Life cycle assessment for environmental product declaration of concrete in the gulf states. Sustain. Cities Soc. 2017, 35, 36-46.

48. Lawania, K.K.; Biswas, W.K. Cost-effective ghg mitigation strategies for western australia's housing sector: A life cycle management approach. Clean Technol. Environ. Policy 2016, 18, 2419-2428. [CrossRef] 
49. Werner, F.; Richter, K. Wooden building products in comparative lca. Int. J. Life Cycle Assess. 2007, 12, 470-479.

50. Wahidul, K.; Biswas, L.B.; Carter, D. Global warming potential of wheat production western australia: A life cycle assessment. Water Environ. J. 2008, 22, 206-216.

51. Mirabella, N.; Röck, M.; Saade, M.R.M.; Spirinckx, C.; Bosmans, M.; Allacker, K.; Passer, A. Strategies to improve the energy performance of buildings: A review of their life cycle impact. Buildings 2018, 8, 105. [CrossRef]

52. Vincenzo Franzitta, M.L.; Gennusa, G.P.; Rizzo, G.; Scaccianoce, G. Toward a european eco-label brand for residential buildings: Holistic or by-components approaches? Energy 2011, 36, 1884-1892. [CrossRef]

53. Francesco Barreca, P.P. Post-occupancy evaluation of buildings for sustainable agri-food production-A method applied to an olive oil mill. Buidings 2018, 8, 83. [CrossRef]

54. Samaratunga, M.; Ding, L.; Bishop, K.; Prasad, D.; Yee, K.W.K. Modelling and Analysis of Post-Occupancy Behaviour in Residential Buildings to Inform Basix Sustainability Assessments in Nsw. Procedia Eng. 2017, 180, 343-355. [CrossRef]

55. Aneurin Grant, R.R. Impact of building service life models on life cycle assessment. Build. Res. Inf. 2013, 41, 168-186. [CrossRef]

56. Galle, W.; de Temmerman, N.; de Meyer, R. Integrating scenarios into life cycle assessment: Understanding the value and financial feasibility of a demountable building. Buidings 2017, 7, 64. [CrossRef]

57. TCI. Australia's Emissions: What Do the Numbers Really Mean? The Climate Institute: Sydney Australia, 2015.

58. Argent, R.M. Australia State of the Environment 2016: Inland Water; Australian Government Department of the Environment and Energy: Canberra, Australia, 2017.

59. BOM. Average Anual, Seasonal and Monthly Rainfall; BOM: Melbourne, Australia, 2018.

60. Pfister, S.; Koehler, A.; Hellweg, S. Assessing the environmental impacts of freshwater consumption in lca. Environ. Sci. Technol. 2009, 43, 4098-4104. [CrossRef] [PubMed]

61. Fenton, G.G. Desalination in australia-past and future. Desalination 1981, 39, 399-411. [CrossRef]

62. Radcliffe, J.C. The water energy nexus in australia-the outcome of two crises. Water-Energy Nexus 2018, 1, 66-85. [CrossRef]

63. Joe Pickin, P.R. Australian National Waste Report 2016; Department of the Environment and Energy \& Blue Environment Pty Ltd.: Docklands, Australia, 2017.

64. PRe'-Consultants. Simapro 8.4 Lca Software; Pre' Consultants: Amersfoort, The Netherlands, 2016.

65. Shahana, Y.; Janjua, P.K.S.; Wahidul, K.B. Sustainability implication of a residential building using a lifecycle assessment approach. In Proceedings of the 4th International Conference on Low Carbon Asia and Beyond (ICLCA), Johor Bahru, Malaysia, 24-26 October 2018; Chemical Engineering Transactions: Johor Bahru, Malaysia, 2018; Volume 73, pp. 1-6.

66. AccuRate. Accurate Sustainability Tool Version 2.3.3.13 sp3; CSIRO Land \& Water Flagship and Distributed by Energy Inspection Pty Ltd.: Canberra, Austrailia, 2015.

67. Crowther, P. Design for disassembly to recover embodied energy. In Proceedings of the 16th International conference on Passive and Low Energy Architecture, Melbourne/Brisbane/Cairns, Australia, 22-24 September 1999.

68. Lawania, K.K. Improving the Sustainability Performance of Western Australian House Construction: A Life Cycle Management Approach; Curtin University: Perth, Australia, 2016.

69. Treloar, G.; Fay, R.; Love, P.E.D.; Iyer-Raniga, U. Analysing the life-cycle energy of an australian residential building and its householders. Build. Res. Inf. 2000, 28, 184-195. [CrossRef]

70. Fay, R.; Treloar, G.; Iyer-Raniga, U. Life-cycle energy analysis of buildings: A case study. Build. Res. Inf. 2000, 28, 31-41. [CrossRef]

71. Vass, N. Western Australia Energy Fact Sheet. Available online: http://www.australianpowerproject.com. au/western-australia-energy-fact-sheet/ (accessed on 19 December 2018).

72. Lawania, K.; Biswas, W.K. Application of life cycle assessment approach to deliver low carbon houses at regional level in western australia. Int. J. Life Cycle Assess. 2018, 23, 204-224. [CrossRef]

73. Allacker, K.; Maia de Souza, D.; Sala, S. Land use impact assessment in the construction sector: An analysis of lcia models and case study application. Int. J. Life Cycle Assess. 2014, 19, 1799-1809. [CrossRef]

74. Spang, E.S.; Moomaw, W.R.; Gallagher, K.S.; Kirshen, P.H.; Marks, D.H. The water consumption of energy production: An international comparison. Environ. Res. Lett. 2014, 9, 1-14. [CrossRef] 
75. Bardhan, S. Assessment of water resource consumption in building construction in India. WIT Trans. Ecol. Environ. 2011, 144, 93-101.

76. Robert, H.G.; Treloar, J.T. An assessment of the energy and water embodied in commercial building construction. In Proceedings of the 4th Australian Life Cycle Assessment Conference, Sydney, NSW, Australia, 23-25 February 2005; pp. 1-10.

(C) 2019 by the authors. Licensee MDPI, Basel, Switzerland. This article is an open access article distributed under the terms and conditions of the Creative Commons Attribution (CC BY) license (http:/ / creativecommons.org/licenses/by/4.0/). 


\title{
Article \\ Life-Cycle Asset Management in Residential Developments Building on Transport System Critical Attributes via a Data-Mining Algorithm
}

\author{
Umair Hasan ${ }^{1, *(D)}$, Andrew Whyte ${ }^{1}$ and Hamad Al Jassmi ${ }^{2}$ \\ 1 School of Civil and Mechanical Engineering, Curtin University, Perth, WA 6845, Australia; \\ andrew.whyte@curtin.edu.au \\ 2 Department of Civil and Environmental Engineering, United Arab Emirates University, Al Ain 17666, UAE; \\ h.aljasmi@uaeu.ac.ae \\ * Correspondence: umair.hasan@postgrad.curtin.edu.au; Tel.: +61-46-716-2000
}

Received: 27 November 2018; Accepted: 18 December 2018; Published: 20 December 2018

\begin{abstract}
Public transport can discourage individual car usage as a life-cycle asset management strategy towards carbon neutrality. An effective public transport system contributes greatly to the wider goal of a sustainable built environment, provided the critical transit system attributes are measured and addressed to (continue to) improve commuter uptake of public systems by residents living and working in local communities. Travel data from intra-city travellers can advise discrete policy recommendations based on a residential area or development's public transport demand. Commuter segments related to travelling frequency, satisfaction from service level, and its value for money are evaluated to extract econometric models/association rules. A data mining algorithm with minimum confidence, support, interest, syntactic constraints and meaningfulness measure as inputs is designed to exploit a large set of 31 variables collected for 1,520 respondents, generating 72 models. This methodology presents an alternative to multivariate analyses to find correlations in bigger databases of categorical variables. Results here augment literature by highlighting traveller perceptions related to frequency of buses, journey time, and capacity, as a net positive effect of frequent buses operating on rapid transit routes. Policymakers can address public transport uptake through service frequency variation during peak-hours with resultant reduced car dependence apt to reduce induced life-cycle environmental burdens of buildings by altering residents' mode choices, and a potential design change of buildings towards a public transit-based, compact, and shared space urban built environment.
\end{abstract}

Keywords: sustainable-development; life-cycle social analysis; public-engagement; modal-variability; transit-policy; work-commute; travel-satisfaction

\section{Introduction}

Municipal residential areas and new developments are often marked by economic growth and high population density, where respective higher environmental emissions affect the air quality $[1,2]$. Indeed, the high private automobile traffic in the established residential areas affects the structural integrity of buildings in such developments [3] with knock-on negative impact on the residents [4]. Similarly, sustainable development and the creation and maintenance of a built environment necessarily requires measures of construction material transportation [5,6]. For example, studies have shown that for a building element such as roofing, a sizable proportion of a built asset's life-cycle assessment (LCA) relates explicitly to transportation which has been measured to contribute $10 \%$ to a residency's new-build/building-renovation's overall carbon footprint within a LCA system boundary covering 
the entire life-cycle of building-product usage $[7,8]$. Built environment development whole-costs are similarly affected by community transportation links; locations affect life-cycle costs with congestion apt to delay resources deliveries and often result in vehicle damage across respective congested transportation routes [9].

Regional constraints notwithstanding, mass-transit system plans are generally developed by municipal and transportation agencies to reduce ever-increasing traffic congestion on road networks by affecting mode choices of building residents [10]. These plans are simultaneously targeted as being environmentally conservative for the existing municipal residential areas or any upcoming residential developments in the region. The implication of adequate public transport accessibility and reduced reliance on private automobile usage towards sustainable residential areas; e.g., compact neighbourhoods, walking habits of residents, urbanisation and shared-space designs, construction of shops and other facilities in buildings and neighbourhoods is abundant in the literature [11,12]. Jabareen [13] further include sustainable transport as one of the key design concepts of sustainable building and urban design plans. Other researchers, such as Zimring, Joseph [14] and Cervero [15] propose that sustainable residential built environments, transport systems and urban forms should be designed so as to promote sustainable modes of transport, e.g., public transport, and devise policies to discourage individual car usage, among building residents.

On the other hand, transportation researchers such as de Luca [16] and Leyden, Slevin [17] argue that planning and provision of any (public) transport system is largely "flawed" as alternatives and policies are prioritised subjectively by decision-makers alone, with very little public engagement from local building occupants or consultation at the initial stages. Often public feedback generated is neglected or only marginally used to improve the existing system, which is argued by above literature to significantly increase the risk of implementing a public transport service and an overall transportation system incoherent with public expectations. This may lead to higher private automobile dependence among the building residents of any municipal area, causing heavy traffic congestions on road networks adjacent to these residential buildings [18]. In addition to disrupting the supply-chain by delaying construction material transport for new buildings or haulage of disposal material from demolished buildings in the area, traffic congestions can result in increased cost and environmental burdens depending upon the traffic load and transport system typology. For example, in case of high traffic volume roads, around 95\% emissions are traffic-related [19], while Stephan, Crawford [20] showed that the residents' daily commute energy load for Belgian passive (i.e., energy-efficient) houses was approximately $27 \%$ of the entire life-cycle energy burdens of these passive houses. Stephan, Crawford [20] also proposed that the transport energy of these residents may be reduced by approximately $31 \%$, provided a shift in mode use occurs from private vehicle transport in favour of public transport, corresponding to a reduction of $8.4 \%$ in the houses' life-cycle energy consumption. Since environmental impact assessment rating tools for buildings, such as the United States Green Building's Leadership in Energy and Environmental Design (LEED) system, also include the residents' daily commute energy and environmental load as an integral part of the total life-cycle burden of the buildings due to the building-induced impacts (more in Section 2.2), therefore, in order to reduce the overall life-cycle impact of buildings, the mode choice redistribution in favour of public transport should be researched $[10,18]$.

In mode use redistribution or diversion research, Diana [21] and De Vos, Mokhtarian [22] suggest that traveller expectations influence commuter satisfaction, which ultimately influences the variation in their ridership preference over time (public vs. private transit), hereby referred to as modal variability. Establishing the satisfaction of an individual traveller may be difficult, aligning satisfaction with travel patterns of daily commuters is important for municipal policymakers aiming to influence mode choice and travel survey datasets are used for this purpose by building [23] and transport [24] researchers alike. However, the presence of large quantities of variables in the travel dataset complicates the pattern discovery process of deducing the potential for commuter mode choice diversion in favour of public transport [25] and optimising the consumer mode choice - satisfaction dynamics. Golob and 
Hensher [26] and Diana and Pronello [27] maintain that although the patterns in large categorical variable sets may be discovered to some extent through multiple correspondence analysis, scatter plots and cross-tabulation techniques, such methods are fairly limited when many variables are to be jointly considered. Limitations of frameworks only applying these statistical analyses to study travel survey datasets can thus be avoided by data mining $[28,29]$ through its potential to handle a large number of interrelated variables [30].

This study is part of a larger project that aims to deliver a multi-criteria decision-making framework towards the objective of sustainable cities and future green buildings served by a connected and sustainable road transportation system that meets commute demands of building residents. The proposed framework consists of: social aspect of government and user stakeholders' demands [31], life-cycle cost and environmental in/outflows [32]. In Hasan, Whyte [33], a multipartite model was developed by the authors to establish commuter satisfaction from the level of service (measured on network coverage and frequency) as the antecedent of building residents' mode choice. Moreover, market segmentation based on mode choice, satisfaction from service level and service perception as value for commuter money was also performed in Hasan, Whyte [33] to analyse the function of underlying exogenous factors in the sample residential area. The explicit objectives of the research presented in this paper are described below:

1. Examine the travel patterns in a representative intra-city (Abu Dhabi) dataset for existing residential areas or upcoming residential developments.

2. Present a systematic way of assessing critical factors eliciting mode choice in commuter market segments towards optimising the social, i.e., stakeholder demands, aspect of the overall LCA of transportation systems and in the process, reduce the user-transport life-cycle energy and environmental load of residential buildings.

3. Determine bus service desiderata for policymakers to develop an ameliorated bus service in future, which may divert more building residents to the improved bus service. This can potentially reduce the life-cycle costs and environmental (greenhouse gas emissions, smog, resource and energy use) burdens besides tacking the social parameters (stakeholders' perspectives) towards optimising overall life-cycle burdens of residential buildings as well improving future building designs, i.e., lesser parking area requirements, more shared walkable spaces, better accessibility etc.

In order to meet the study objectives, a custom travel data processing algorithm unifying association rules mining, and statistical analysis techniques is developed to identify two classes of variable combinations; statistically-significant and validated association-only. The two different groups aim to provide policymakers with the maximum information about the commute habits of local building residents in the city. Whilst statistical analysis is informative and interesting, it may fail to uncover the underlying modal variability patterns and commuter behaviour which may be visualised through association rules [34-36]. For this purpose, validation of the filtered-out association rules against an internal validation set was conducted to further generate a set of association rules $[37,38]$ followed by data reduction (similar to [36] and [39]) to remove redundant association rules.

\section{Theoretical Background}

\subsection{Multiscale Effect of Road Network Transport System on Residential Buildings}

Researchers not only propose sustainable waste disposal from building constructions sites but also advocate use of recycled construction and demolition waste for new residential developments to reduce the overall environmental impact. The presence of an adequate transportation system at regional scale is critical for facilitating the disposal and reuse, for example, Building Research Establishment (BRE) assigns a weighted contribution of $8 \%$ to building construction material transportation in the overall life-cycle of buildings $[40,41]$. Other national and international guidelines on LCA of built assets that are used for environmental impact assessment of buildings such as EN 15978 [42], CEN/TC350 [43] 
and ISO/TS 12720 [44] also recommend estimating the material transport in both construction and disposal stages for accurate calculations. At the same time, a number of government regulations, subsidies and incentives exist for promoting recycled material usage in residential buildings and housing development sectors. Decree 205/2010 in Italy mandates at least 15\% recycled material use in building construction [45] while Environmental Product Declaration on construction is now practiced in many European countries [19]. The United Kingdom Aggregates Levy for extracting quarry materials of $£ 2$ per tonne [46] has boosted recycled aggregates usage in building constructions by approximately $25 \%$ [47]. However, material supply-chain and costs due to far-off recycling sites, for e.g., accounting for $\sim 70 \%$ costs for a 350 tonne/h facility in a Portugal-based study [48] and increased travel time of material transporting trucks due to on-route traffic congestion often discourage building contractors from recycled material usage. Similarly, any excessive time spent on road networks due to congestion may reverse some of the positive environmental benefits from using recycled materials due to fuel consumption. For example, using a standard 15-tonne lorry to move 1 tonne of aggregate material over $1 \mathrm{~km}$ requires $0.014 \mathrm{~kg}$ of diesel, depending upon the local traffic conditions [40]. Thus, the question of traffic congestion mitigation should also be tackled by the policymakers aiming to promote recycled material usage in buildings (see Section 2.2).

Besides reducing traffic congestion on road networks and relieving residents' transport energy of buildings [18], public transit services also affect property prices of buildings and development projects depending upon the relative proximity to mass-transit services. Mulley, Ma [49] studied residential property market in Brisbane, Australia and found that bus rapid transit (BRT) affected housing prices at the rate of $0.14 \%$ per $100 \mathrm{~m}$ closer to the transit service routes while train service inferred a negative effect of $0.15 \%$ reduction per $100 \mathrm{~m}$ closer to the train service line. These effects were also strongly dependent upon urban form and spatial distributional densities of buildings. Their study also highlighted the importance of studying local mode use travel patterns, commuter perceptions and the key position of underlying service attributes of service frequency, on-board crowding and the journey time in determining the relative impact of BRT service on the residential property development sector.

\subsection{Interrelated Urban Form, Transport System and Buildings LCA: Public Transport Accessibility and Residents' Mode Choices}

The interrelation between urban form, transportation systems (private and public transit modes), and the overall life-cycle impacts of buildings is a complex issue which has been explored by many researchers focusing on the synergy between developing low-energy buildings and sustainable transport [10,50-52]. The lower density urban form undoubtedly puts extra load on private vehicle transport as the preferred mode choice of municipal residents, for example, accounting for $\sim 70 \%$ in European passenger transport with predominantly semi-detached houses, whereas limited parking in buildings may promote public transit usage based upon proximity to service line and accessibility [51]. One of the earliest studies of the 21st century by Steemers [51] on developing a less polluted urban built environment noted the link between the overall building energy and transport mode choice of building residents. Similarly, the "Le Plan Bâtiment Durable" (French: "The Sustainable Building Plan") launched by the Government of France in 2009 aimed at reducing the existing buildings' energy consumption by $38 \%$, also enlists the mode choice of building residents and developing strategies for promoting public transportation usage among the criteria for assessing the overall performance of buildings. Furthermore, other European Union states also highlighted the importance of understanding the interrelation between urban design, transportation system, building design, residents' mode choice pattern, "public transport connected buildings", compacted shared spaces and accessibility as environmental hotspots for future sustainable building designs [10]. Similar points on compact and shared urban form were also highlighted by Norman, MacLean [53] in their economic input-output LCA on buildings and by Cuéllar-Franca and Azapagic [54] who showed terraced house to carry $309 \mathrm{t} \mathrm{CO}_{2}$ eq. compared to the $455 \mathrm{t} \mathrm{CO}_{2}$ eq. of a semi-detached house in the UK. 
Stephan, Crawford [20] observed that the majority of so-called low-energy passive houses in Belgium are designed as suburban detached single-family dwellings compared to the public transport-connected city buildings. They further commented that any energy savings by these low-energy houses are offset by increased mode use of private vehicles compared to public transport. Earlier research by the same authors $[55,56]$ on life-cycle energy requirements of low-energy houses has shown that over the life-cycle (50-100 years) of these low-energy residential buildings, residents' transport and embodied energy are $>50 \%$ of the overall life-cycle energy load. They proposed that in order to reduce the overall energy demands of residential buildings, the transport mode choices of building residents must be tackled towards public transport uptake in addition to using recycled building components and sustainable energy measures as the mode use alone represented $27 \%$ of the built assets' life-cycle energy [20].

Two studies on buildings and environmental analysis (i.e., greenhouse gas emissions and energy use) of buildings were conducted by Anderson, et al. [23,57]. They proposed transportation systems and residents' mobility patterns (i.e., mode choice distribution) as key parameters for interlinking residential buildings and the urban environment. They emphasised the strong tie between transportation and buildings and argued that the induced environmental impacts in terms of transport habits due to the design, locality and interaction of buildings with the urban form need to be captured. They used streamlined LCA to capture this effect on urban Munich residents in Germany using detailed mode use and travel behaviour surveys [23]. They found that the overall life-cycle impact of buildings and the induced transportation environmental impact due to mobility pattern of residents is dependent upon the daily commute distance, mode choice and the location of the buildings. For example, in their study the lowest impacts were found for Munich central business district (CBD) residents due to buildings typology and short commute distance of residents, where the largest share was claimed by overall transportation impacts of CBD residents as $1160 \mathrm{~kg} \mathrm{CO}_{2} \mathrm{e} /$ capita/annum while CBD residential building emissions were $1088 \mathrm{~kg} \mathrm{CO}_{2} \mathrm{e} / \mathrm{capita} /$ annum. Both studies [23,57] concluded that although the design and material usage in buildings needs to be upgraded to be more sustainable, the real criticality still lies with improving the mode use behaviour of building residents. Similar findings were noticed by Dodd, Donatello [10] in their review on LCA of European buildings with the residents' transport energy demands claiming between a $19 \%$ share to even completely overwhelming the life-cycle energy load of some buildings.

The critical role of mobility and the mode choice of building residents induced by the interrelation between urban form, locality, transport service provision and the building design was also acknowledged by the LEED system weighting methodology by assigning a total of $\sim 15 \%$ credit weightage to transport in terms of reduced parking, bicycling and better quality public transit accessibility near buildings. Promoting sustainable mode choice among residents, proximity or connection to public transport services and bicycling and shared vehicle facilities were also included in the property/real-estate based Investment Property Databank of the triple alliance between Sustainable Building, Bureau Veritas and Barclays ( 16\% weightage); the Invesco, Allianz, AXA and AEW founded Green Rating Alliance; and, the Global Real Estate Sustainability Benchmark [10]. The extensive focus on the mobility pattern of building residents in municipal residential zones/areas proposed by these works also recommended understanding the underlying factors behind mode choice to postulate policies towards uptake of more sustainable public transport usage.

\subsection{Factors Affecting Travel Perception and Mode Choice}

Researchers studying factors affecting mode choice behaviour, such as Dell'Olio, Ibeas [58] and de Oña, de Oña [59] proposed that generally any bias possessed by commuters, as for or against a particular travel mode (referred to as travel bias, henceforth) depending upon their unique characteristics, influences their perception of the quality attributes offered by a particular mode and may translate to a subsequent mode choice. The factors behind mode choices and variation of travel behaviour were also focused in a study conducted by Schmid, Schmutz [60]. They performed a hypothetical 
study of a low carbon post-private car world and found public transport to be the most popular mode amongst survey respondents, followed by bikes and car-sharing. Stradling [61] found that the modal variability of residents in a case-study Scottish housing area is temporally constrained, with $20 \%$ of private automobile users actually acting as multimodal, i.e., using several transport modes, when the analysis period is stretched over a week. Building upon this, the present study gathered commuter behavioural responses and travel pattern data over a month to investigate the sensitivity of modal shifts in long-term mobility patterns.

Built environment around the public transit service, accessibility near commuter accommodations and offices may also influence their mode choice. An empirical study on the association between travel behaviour of urban residents in New York City and the density of the urban neighbourhoods was conducted by Chen, Gong [62]. They noted that the density and built environment affected mode choice of the survey respondents. They also proposed that government authority planners may attract more users towards public transit modes by providing better accessibility near workplaces. Similarly, Cervero [15] proposed that residential developments with lesser shared-spaces for cyclists and pedestrians may affect the mode choice, particularly an inclination towards individual car usage, more so as the building designs may also carry abundant nearby parking facilities instead of using the space for mixed-use walkable areas.

Friman and Fellesson [63] and Diana [21] found modal variability and level of commuter satisfaction from public transport as highly dependent upon the local built environment and regional characteristics of the study area. They noted that the travellers near the city centres tended to sway towards higher public transport usage compared to their urban/suburban counterparts, making the results highly sensitive to the zonal distribution (urban vs suburban) as well as number of zones covered in the study area. The current study addresses this issue by surveying commuters on the intra-city travel routes across all zones of a metropolitan city (Abu Dhabi) to capture the maximum variability of responses. The City of Abu Dhabi has witnessed an increase in population accompanied by extensive residential developments and an increasing commuter dependence on private vehicles [64], resulting in traffic congestion and as such, is a suitable case study area for the purpose of this research. Furthermore, the excessive private vehicle ridership is responsible for high greenhouse gas emissions, for example in United Arab Emirates alone, it annually exceeds 11735.6 $\mathrm{Gg} \mathrm{CO}$ equivalent [65] from road transport. The local government agencies in UAE have aimed to reduce its environmental load [66]. The research presented in this paper and its accompanying works $[19,32]$ may aid in reducing the environmental burden from road and building residents' daily transit dimensions towards an overall sustainable future city development.

\subsection{Data Mining for Analysing Travel Datasets}

Provided the competitive benefit of outlining commuter expectations, perceptions and rankings of existing service level to create pro-public transport policies, a large database of underlying variables (e.g., journey time, ride quality, transit fare, accessibility, nodes, socio-demographics of commuters etc.) are generally collected from representative population samples. A recent study by Liu, Xu [67] on improving the public mass-transit service quality in China acknowledges that an efficient data mining framework is capable of extracting useful information from transit data and representing it into clear and succinct policy-related recommendations. Liu, Xu [67] developed a data mining algorithm with data cleaning and filtration options. However, their proposed algorithm focused only on the time parameters and the pre-journey (accessibility, location, train/bus-station) and on-board (crowding, seating arrangements, fare and ride quality) parameters were not involved in the algorithm design.

Similarly, a Weka classifying algorithm-based data mining study on the occurrence of faults on tram lines, local atmospheric conditions and safety was performed by Gürbüz and Turna [36]. The study noted the ability of data mining algorithms to filter through large mobility datasets and association rules to visualise the interrelation between various variables in the collected dataset. Building upon these studies, the work presented in this current paper contends that many of the 
variables collected through travel surveys or response diaries are interdependent or associated to varying degrees. Studying them in isolation may be inadequate if environmental impact analysts aim to study the complex relationship of categorical and nonmetric variables to recommend apposite policies to promote public transport, specifically as emission-controlling measure for residential buildings, in addition to the Intergovernmental Panel on Climate Change (IPCC) [68] recommendations of using recycled materials as green construction practices [69-71]. Current literature has no such framework that can help policymakers to segregate the most desired transit service attributes from the several underlying variables affecting commuter psychometrics, thereby quantifying the stakeholder demands as part of the social aspect of LCA on any transportation system. This aspect is of particular importance for deducing marketing tactics aimed at attracting users that have somewhat of a neutral perception of either travel mode (bus or car) as well as retainment of the loyal public transport users.

Inspired by Ponte, Melo [72], who used the Gini coefficient primarily used in economics, for measuring the public bus-transit travel time heterogeneity in municipal areas and Diana [35] who used association rules for studying travel pattern, this study explores the applicability of data mining techniques used in economics and marketing research. Apriori association rules data mining is used here for achieving the objective of identifying the motivations behind commuter mode choices. Introduced by Agrawal, Imieliński [73] and Agrawal and Srikant [74] for mining frequent item-sets in transaction data without using any underlying relative and distributional assumptions, it has now developed into a robust market analysis technique. Association rules identify the frequency of different variables appearing together in an observation (data) set. An association analysis reads every single row of variables on the travel datasets to produce association rules, which are of the implication form given in Equation (1).

$$
x_{i}, x_{j}, \ldots, x_{n} \Rightarrow y
$$

where the left-hand side is the antecedent (a set of predictor variables) and the right-hand side is the consequent (and represents the response variable). Periodically used for frequent pattern mining in fields besides management sciences, e.g., health [75] and weather forecasting [76], its application in transportation research is relatively new. Nonetheless, researchers [35,77] have explored the efficacy of associations rules for handing large and complex travel and mobility datasets. A primary advantage of using Apriori over traditional multivariate statistical analyses is its ability to rapidly find an association between large sets of metric and non-metric variables. Once an association is established between the dataset variables, traffic flow patterns and the individual public transport service attributes behind commuters' observable modal variability can be extrapolated for policy recommendations in favour of low carbon and energy conserving transit among the local building residents and travellers.

Conversely, one of the main drawbacks of the Apriori algorithm is its tendency to produce a large number of association rules, rendering the technique to be an ineffective process if no other controls are provided. Pruning the rules is the next step [78] to filter out meaningless and inutile rules that may be misleading for policymakers. Association rules are constrained by the number of times a certain rule is supported by the dataset and the strength of rule (i.e., confidence) which is the fraction of dataset rows that contain both consequent and antecedent of the rule. However, confidence is an asymmetric measure which may provide erroneous results if the consequent has a large probability [79]. Moreover, if the antecedent and consequent variables are independent of each other, the generated rules may be unsuitable, irrespective of high confidence [80], for establishing inference relations for policy development. $\mathrm{Wu}$, Zhang [81] have introduced an additional measure called "interestingness" to discard unsuitable association rules (Equation (2)).

$$
\text { Interest }(X, Y)=|\operatorname{Support}(X \cup Y)-\operatorname{Support}(X) \bullet \operatorname{Support}(Y)|
$$




\section{Materials and Method}

\subsection{Survey Design and Analysis}

A questionnaire was designed to gather data on the factors that affect user perception of existing bus network and modal variability among the local building residents and travellers [33]. A total of 11 questions were developed for the survey, aimed at capturing commuter responses on the different variables according to Likert-type scales, dichotomous and multiple-choice options. Previous researchers $[21,82]$ have noted the adequacy of weekly mode choice data in modelling the mode use of surveyed commuters, the sensitivity of commuter responses to the local built environment and zonal distributions as well as the importance of zonal characteristics in defining the observed transport pattern of building residents and the calculated transport parameter in buildings' overall environmental impacts $[23,83]$. This study targets the commuters in all zonal distributions (urban and suburban) of Abu Dhabi city. The survey questionnaire used for this study and the different zonal distributions are shown in Table A1 and Figure A1, respectively. The eight arterial and medium to high traffic routes serving the daily commute demands of the residents of various types of buildings in the city were selected for data collection (Table 1) to capture an optimally representative data of the city's usual commuters and weekly data over six weeks was collected to improve the number of observations.

Table 1. Bus routes selected for the purpose of study.

\begin{tabular}{ll}
\hline \multicolumn{1}{c}{ Outer-Urban or Suburban Routes } & Route Number \\
\hline Al Mina Souq $\leftrightarrow$ Khalifa Park & 056 \\
Petroleum Institute $\leftrightarrow$ Tourist Club Municipality & 054 \\
Abu Dhabi Courts $\leftrightarrow$ Al Marina & 034 \\
\hline Downtown City and Urban Routes & Route Number \\
\hline Al Mina Fish Harbour $\leftrightarrow$ Al Marina Mall & 011 \\
Al Mina Souq $\leftrightarrow$ Al Marina Mall & 009 \\
Al Mina Road Tourist Club $\leftrightarrow$ Al Marina & 008 \\
Tourist Club Municipality $\leftrightarrow$ Al Marina & 007 \\
Al Mina ISC and Tourist Club $\leftrightarrow$ Ras Al Akhdhar & 006 \\
\hline
\end{tabular}

The completed questionnaires collected by Department of Transport survey teams [84] were then analysed. Logic checking of data consistency was performed by the authors to address data sparseness, outliers and missing data based upon the guidelines by Osborne [85]. This resulted in a useful sample of 1520 completed questionnaires (inclusive of weekdays and weekends surveys) which identified (detailed under separate cover as Hasan, Whyte [33]) ten commuter segments, namely:

1. Modal variability: distribution of generated trips for each mode (i.e., bus and car travel). Five segments as pro-sustainability (PS) passengers (i.e., regular bus travellers and non-users of cars), occasional multimodal (OMD) travellers, frequent car/taxi travellers ( $\mathrm{FrCT}$ ) and environmentally insensitive (EI) commuters (i.e., non-users of public bus service) item.

2. Perception of bus service as value for money (VfM): trade-off between quality of ride and level of fare. Three segments of good value for money, borderline value for money and bad value for money.

3. Commuter satisfaction from level of service (LoS): ranked based on perception of the current level of network coverage and frequency of buses. Three segments of good level of service, borderline level of service and bad level of service.

The statistical distribution of the collected commuter responses is shown in Table A2. The study objective is finding service desiderata critical for policymakers to deter private automobile use and increase uptake of bus usage among local building residents and travellers to promote environmental conservation by developing an improved public transit service. A data mining algorithm is thus 
proposed below which is used to analyse the above case study commuter segments to generate variable associations for explaining the daily commute behaviour of the local building residents and travellers.

\subsection{Conceptual Framework-Overall Proposed Modelling Approach}

Current research suggests a market-based analysis that unifies "statistical measurement" and "associate data mining". The combination has been used to some extent in marketing literature (e.g., Shaharanee, Hadzic [38]) for filtering out redundant rules. Work here contributes by building a multi-tier modelling approach for travel survey dataset that filters "interesting rules" to split them in two distinct categories: associated rules; and, statistically-significant models. Initially, the generated rules are filtered using an "interestingness measure" from Eq. (2). The filtered rules are then used to build ordinal regression models, followed by (only) selecting meaningful rules at the filtration stage 2. "Meaningful rules" are defined as those that provide association between the variables that have not been already construed by the other rules passing the minimum thresholds, thereby rejecting the repetitive or redundant sets of rules. The problem is further explained in Figure 1.

Definition 1: Let $V=\left\{x_{1}, x_{2}, \ldots, x_{m} ; y_{1}, y_{2}, \ldots, y_{n}\right\}$ be the set of variables, where $x_{m}$ and $y_{n}$ are respectively the antecedent and consequent variables. Apriori algorithm predicts sets of association rules $R_{1}, R_{2}, R_{3}$ as $R=\left\{R_{1}, R_{2}, R_{3}, \ldots, R_{x y}\right\}$ or $R=\left\{\left(x_{1}, x_{2} \Rightarrow y_{1}\right) ;\left(x_{1}, x_{2}, x_{3} \Rightarrow y_{2}\right) ; \ldots ;\left(x_{1}, \ldots\right.\right.$, $\left.\left.x_{m} \Rightarrow y_{n}\right)\right\}$. Note: there may be some rules in set $R$ whose variables imply the same relation or association. Towards a simplified form of the classic set cover problem to provide an approximation solution with $M$ as a set of meaningful rules, defined by the following relation:

$\mathrm{M} \subseteq \mathrm{R} \quad \exists \forall$ rule in $\mathrm{R} \in$ rules in $\mathrm{M}$

Figure 1. Definition of "meaningfulness measure" to filter repetitive set of rules.

This twofold technique proposed in this study filters out redundant rules and provides final sets of statistically-significant rules. The rejected rules are then analysed in the second phase by a validation technique using a validation set. It is argued here that this technique will remove any misleading rules while still retaining a significant number of rules for policymaking without compromising the analysis accuracy. The proposed conceptual framework is presented in Figure 2. It should be noted that there are several off-the-shelf packages available for performing the Apriori association mining [35]. However, as this paper proposes a unified framework, a tailored java script was used for data mining due to its compatibility with SPSS 23.0 regression functions, which can then be used to perform ordinal regression on the observed rules.

Initial travel dataset " $\zeta$ " was cleaned to ensure a high quality of dataset be fed into the analysis algorithm. Data cleaning is an important step in the knowledge discovery process from analysis of predictor and response variables as it removes missing or anomalous values [85]. Numerical values of household car-ownership and time to reach bus stations were also transformed into nominal variables using equally distributed classes to maintain uniformity in the data variable classes and ease the analysis procedure. The resulting dataset was then randomly split into a training dataset $\left(\zeta_{t s}\right.$, containing $\approx 70 \%$ data) and, a validation dataset $\left(\zeta_{v s}\right)$. The training dataset was then used for generating an initial set of association rules: frequency of bus travel (FBT); frequency of car/taxi travel (FCT); satisfaction with network coverage (NetCov); quality of ride (QoR); level of fare (LvlFare); and, frequency of buses (FreqBus) which were used interchangeably as response variables based upon the desired output. 


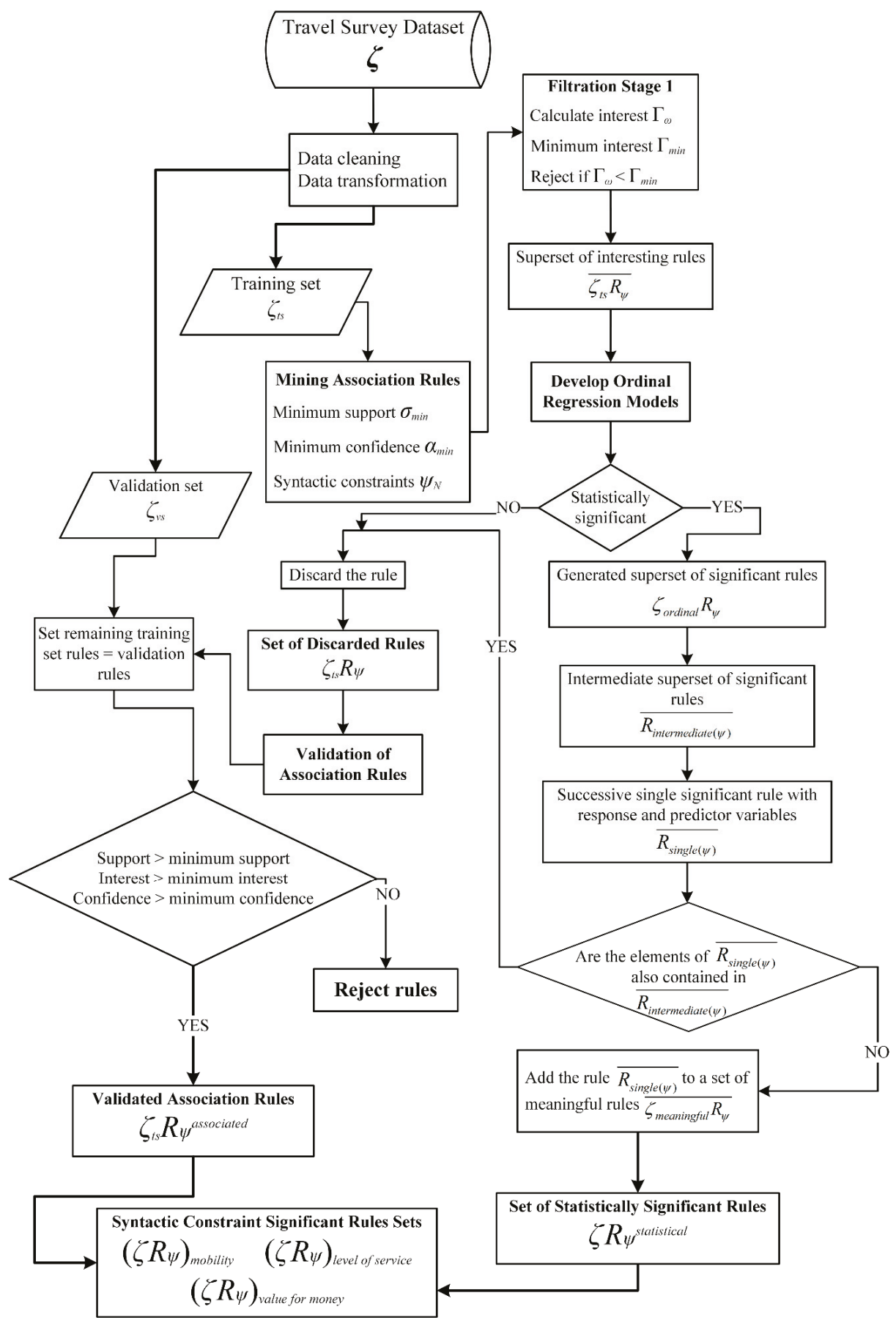

Figure 2. Conceptual framework of the proposed algorithm to mine a travel dataset. 
In order for the algorithm to generate association rules, there should be at least one tuple in the dataset for each observation. Given our target of finding transit policy-related hotspots to promote sustainable transport usage among local building residents and travellers covered within the travel dataset, syntactic constraints were put towards the consequent-side based upon the market segments. This constrained analysis is interesting for policymakers [35] as it may help to define service attributes that may be improved upon in future services that meet the public needs regarding the local bus service. According to the principles of Apriori data mining, only one response variable can be set as a consequent. Therefore, response variables were interchangeably used as a consequent for obtaining the association rules for the respective category and obtain sets of rules specific to each segment, e.g., frequent car travellers, occasional multimode travellers and commuters ranking bus service as good value for money, and so on.

Past literature has suggested that higher support and confidence relate to a better category of rules but that lower values of support and confidence are still recommended. Therefore, to capture the most "interesting" rules, minimum support and confidence were respectively set here at 0.1 and $65 \%$ [34,35]. After appropriate data transformation and setting syntactic, support and confidence constraints, a number of frequent item rules were obtained for each category. The "interestingness measure" was used in the first filtration stage by setting a minimum interest value " $\Gamma_{\min }$ ". The association rules mining through Apriori algorithm permits the analysts to set the minimum threshold for selecting useful models from a large set of created rules. Large numbers of association rules are initially generated which are then pruned by the analysts to reject falsely produced rules from the rule set that fail to qualify the established minimum threshold.

Evaluating the minimum threshold in the analysis may be guided through past experience or research literature. Therefore, in the present analysis, a minimum interest value of 0.05 was selected $[16,86]$ with any future application of the proposed algorithm able to use a higher or lower value depending upon the study objectives. The retained rules were then used for ordinal regression analysis. The ordinal regression analysis calculated $\log$ likelihood and p-values for the models (the models were based on the association rules). Models which showed considerable change in log likelihood compared to null model and $p$-values $<0.05$ were retained. The repetitive rules were then rejected using the theory defined in Figure 1 and the retained rules were used to represent the statistically-significant rules. The remaining rules were then used in phase II of the analysis to validate against the validation set while controlling for the minimum support, interest, confidence and non-repetitive criteria as discussed earlier. The algorithm proposed in this study is illustrated in Figure 3. 
Input: Travel survey dataset $\zeta$ consisting of 31 travel attributes, minimum confidence, minimum support, minimum interest and number of rules across 1,520 questionnaires.

Syntactic Constraint Parameters: FBT, FCT, NetCov, FreqBus, QoR, LvlFare (interchangeable).

Output: $\left(\zeta R_{\psi}^{\text {statistical }}\right)_{t},\left(\zeta R_{\psi}^{\text {associated }}\right)_{t}$;

as significant rules $\mid \mathrm{t} \in$ \{mode use, level of service, value for money\} .

1. Data transformation: transform numeric attributes into nominal variables.

2. Dataset partition: split the dataset into training dataset $\zeta_{t s}$ and validation dataset $\zeta_{v s}$.

3. Phase I: Generation of rules using $\zeta_{t s}$ based on syntactic constraints.

Using minimum support $\sigma_{\min }$, minimum confidence $\alpha_{\min }$ and syntactic constraints $\psi_{N}$ for

a. ; return $\overline{R_{\text {initial } \operatorname{set}(\psi)}}$ as a superset of association rules.

$\mathrm{N} \in\{$ FBT, FCT, NetCov, FreqBus, QoR, LvlFare $\}$

b. Filtration stage 1, rejecting uninteresting rules based on minimum interest $\Gamma_{\text {min }}$

For any association rule $\bar{R}_{\psi}$ contained in superset $\overline{R_{\text {initial set }(\psi)}}$ as a subset, $\overline{R_{\psi}}$ describes association between predictor variable(s) " $X$ " and response variable " $Y$ ", calculate interestingness as per Eq. (2).

If interest $\Gamma_{\omega}$ of rule $\bar{R}_{\psi}$ is less than $\Gamma_{\text {min }}$; reject rule $\bar{R}_{\psi}$ as uninteresting

Return remaining interesting rules as subsets in superset $\overline{\zeta_{t s} R_{\psi}}$.

c. Develop ordinal regression models $\overline{\ln \left(\psi_{k}\right)}$ for each response variable $\psi$ in $\overline{\zeta_{t s} R_{\psi}}$.

Compute; log likelihoods $L L$,

coefficients $\beta_{i}$ of predictor variables $x_{i}$ and $p$-values.

d. Filter rules in superset $\overline{\zeta_{t s} R_{\psi}}$ based on computed $\overline{\ln \left(\psi_{k}\right)}$ models.

For all $\overline{\ln \left(\psi_{k}\right)} \in \overline{\zeta_{t s} R_{\psi}}$

If $\beta_{i} x_{i}$ insignificant; reject the model $\overline{\ln \left(\psi_{k}\right)}$

Return retained rules passing the statistical significance test in the superset $\zeta_{\text {ordinal }} R_{\psi}$

e. Filtration stage 2 , rejecting redundant rules postulating similar results

For the superset $\zeta_{\text {ordinal }} R_{\psi}$, construct an intermediate superset $\overline{R_{\text {intermediate }(\psi)}}$ containing all rules in $\zeta_{\text {ordinal }} R_{\psi}$, while $\overline{R_{\text {single }(\psi)}}$ is any single association rule from $\zeta_{t s} R_{\psi}$ containing response and predictor variables

Select $\overline{R_{\text {single }(\psi)}} \in \zeta_{t s} R_{\psi}$ by maximising $\left|\overline{R_{\text {single }(\psi)}} \cap \overline{R_{\text {intermediate }(\psi)}}\right|$
At each stage $R_{\text {intermediate }(\psi)} \leftarrow \overline{R_{\text {intermediate }(\psi)}}-\overline{R_{\text {single }}(\psi)}$
And $\overline{\zeta_{\text {meaningful }} R_{\psi}} \leftarrow \overline{R_{\text {intermediate }(\psi)}}$, as sets of meaningful rules

f. Denote retained rules as $\zeta R_{\psi}^{\text {statistical }}$;

g. Set rejected rules from both Stages $\mathbf{d}$ and $\mathbf{e}$ as $\zeta_{t s} R_{\psi}$

4. Phase II: Validate rules $\zeta_{t s} R_{\psi}$ on $\zeta_{v s}$.

Set $\zeta_{v s} R_{\psi}=\zeta_{t s} R_{\psi}$. Compute support $\sigma$ and confidence $\alpha$ for each rule $(\mathrm{X} \Rightarrow \mathrm{Y})$ on $\zeta_{v s}$

Reject rules with $\sigma<\sigma_{\text {min }}$, and $\alpha<\alpha_{\text {min }}$

Only repeat Step 3b (Filtration Stage 1) and Step 3e (Filtration Stage 2) to further cleanout uninteresting rules as retain only non-repetitive rules.

Label retained rules as $\zeta R_{\psi}^{\text {associated }}$ for which $\exists \zeta R_{\psi}^{\text {associated }} \in \overline{\zeta_{t s} R_{\psi}} \quad$ and $\zeta R_{\psi}^{\text {associated }} \notin \zeta R_{\psi}^{\text {statistical }}$

5. Phase III: Group remaining rules into required syntactic constraint significant rules sets as

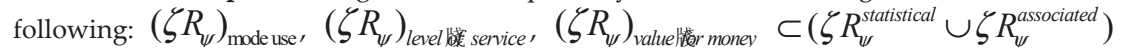

Figure 3. Proposed data mining algorithm for a travel dataset analysis of 1,520 questionnaires. 


\section{Results}

\subsection{Performance of the Proposed Algorithm}

The initial application of the proposed algorithm produced a large set ( 1559) of association rules between the collected variables in the travel dataset that passed the minimum support $\left(\sigma_{\min }=0.1\right)$ and minimum confidence $\left(\alpha_{\min }=65 \%\right)$ thresholds set in Step 3a of the algorithm proposed in this study (Figure 3). Filtration stage 1 (Step 3b) was then applied to remove uninteresting rules based on Eq. (2) with the minimum interest threshold $\left(\Gamma_{\min }=0.05\right)$. This way only 351 or $22.5 \%$ of the association rules were retained in the so-called intermediate superset as interesting rules. These $22.5 \%$ remaining association rules were then subjected to the algorithm stages in Step 3c and Step 3d and ordinal regression models were developed for each rule. All the association rules with insignificant p-values for coefficients were filtered out as a separate superset. Approximately 231 or $\sim 65.8 \%$ of the remaining association rules passed the ordinal regression performance tests and were collected in a superset of ordinal rules. Although all of these 231 association rules may be useful for developing some pro-public transit policies for local building occupants and travellers, the large number of rules may be impractical for policy analysis and may also have some redundant or reoccurring relations as also suggested in the literature (see Gürbüz and Turna [36]). The algorithm steps of feature selection and Filtration Stage 2 were thus used for data-reduction to filter out redundant rules using the superset of the 231 ordinal regression rules, as explained below.

First, an intermediate superset was created as an exact copy of ordinal rules superset and using variable selection, any smaller association rule subset (e.g., \{FBT 5 or more times a week, Weekday $\Rightarrow$ Very satisfied with level of fare\}) implying an association or interrelation already present in a larger subset association rule (e.g., \{FBT 5 or more times a week, Employed full-time, Weekday $\Rightarrow$ Very satisfied with level of fare\}) already present in the intermediate superset was removed. The steps were automatically repeated for all the remaining association rules subsets as rules describing an existing or reoccurring association were redundant since they were already contained in the larger subset in the intermediate superset. This way only 25 or $\sim 11 \%$ of the 231 ordinal regression rules were retained in the so-called intermediate superset as statistically-significant rules in Step 3f, while the filtered-out rules (total of 326 rules) from both Step $3 \mathrm{~d}$ and Step 3e were collected in a separate superset. Using the validation travel dataset, 213 rules or approximately $65 \%$ of these discarded rules were found to be validated in Phase II, where again filtration approach based on interestingness measure (Step $3 \mathrm{~b}$ ) and meaningfulness (Step 3e) resulted in retainment of $22 \%$ or 47 rules in the superset of association-only rules. Finally, both supersets were grouped to give three association rules sets for (1) mode use, (2) level of service, and (3) value for money. Figure 4 presents the results of applying various filtration techniques in the developed algorithm where Phase III results present the grouping of phase I and II association rules. The overall the algorithm application managed to filter out a total of $95 \%$ ( 1487 rules) of initially obtained association rules (total rules: $\sim 1559$ ) as redundant or insignificant to the total travel dataset, generating a total of $\sim 5 \%$ or 72 rules for policymaking purposes. 


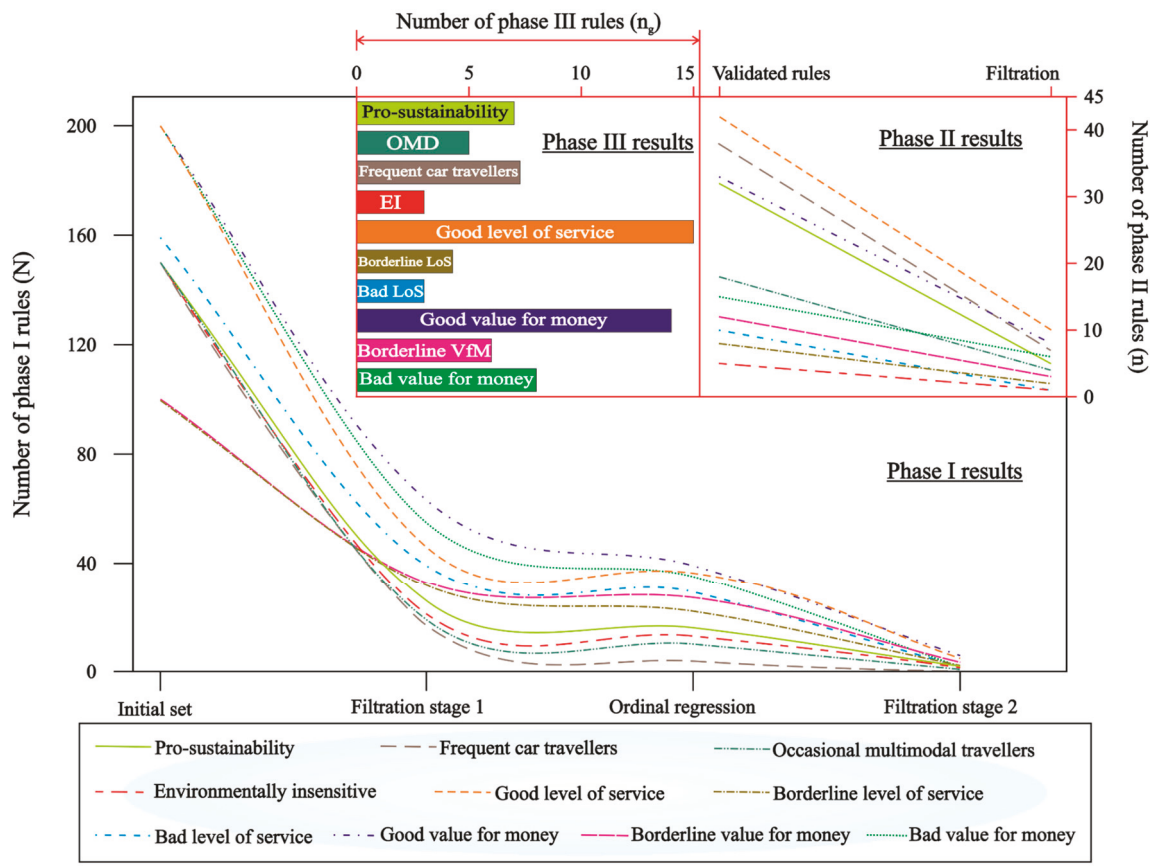

Figure 4. Filtration results of different phases in a collected travel dataset based on the developed algorithm.

The following sections present results of the proposed data mining algorithm on the selected case-study of intra-city commuters in Abu Dhabi. The results from each phase are presented separately to elucidate the respective findings. An importance index is also introduced to summarise the policy-relevant findings highlighted by public consultation regarding existing services. Policy recommendations are also given on how the transit service can be improved to promote an environmentally, resource and energy conservative transportation system by improved public (bus) transport ridership among the local residents and travellers, specifically the predominant $(\sim 55 \%)$ apartment building residents.

\subsection{Phase I Results—Public Responses From Statistically-Significant Rules}

The input and output variables were primarily categorical in nature with upper and lower bounds of each attribute explained in the previous sections. Ordinal regression showed that a majority of the commuters reported bus travel to be easy and that $36 \%$ were willing to pay more for seat. Full-time workers were more flexible towards bus use than the younger respondents. Furthermore, as the collected data was skewed towards male commuters, some of the association rules were found to be affected by the gender of the respondents. On the other hand, only a few of the quality attributes of the bus service were found to be statistically-significant. In addition, the statistically-significant models also failed to produce inference between the purpose of the commuters' journey and their mode choice, thereby requiring further analysis in phase II. The ordinal regression performance results of the meaningful association rules, retained after the second filtration stage, are presented in Table 2. Interestingly, the residential building typology (e.g., apartment building, villa-style house, etc.) had no statistically-significant influence on the mode choices of the residents, requiring further investigation to understand the association between these two factors as proposed by literature (e.g., [23,57]). 


\subsubsection{Affordability and Constrained Users}

In the first block of mode use results, the odds of a full-time employed commuter to choose public transport was 6-7 times that of their unemployed counterparts (PS rule 1: $\chi^{2}=72.68, p<0.001$ ) confirming market segmentation observations made previously by this project and identified under separate cover [33]. The commuters admitting affordability of private automobiles were $1.3(p<0.05$, $\chi^{2}=140.07$ : OMD rule 1) times more likely to be multimodal and $0.85\left(p<0.05, \chi^{2}=39.96\right.$ : EI rule 1 ) as likely to be first time travelling by bus compared to others. While as expected, the commuters with zero household car-ownership were 1.86 times $\left(p<0.05, \chi^{2}=67.18\right.$ : PS rule 2$)$ as likely to use a bus service more than twice a week. Further exploring the affordability of the bus service exhibited that the commuters with a "very satisfied" perception of level of fare, also had 6.72 times likelihood of travelling 5 or more times/week by bus transport (Good VfM rule 2). The commuter satisfaction of public transport service level exhibited a slight decline relative to passenger travel time to the nearest bus-stop (see rule 2 of borderline level of service and rule 1 of bad value for money). Similarly, modal variability was affected when analysed against the same attribute as both rule 2 of pro-sustainability and rule 2 of environmentally insensitive market segments. Moreover, the commuters reporting buses to be crowded, were also twice as likely to belong to the environmentally insensitive group, indicating its significance in defining this market segment. 
Buildings 2019, 9, 1

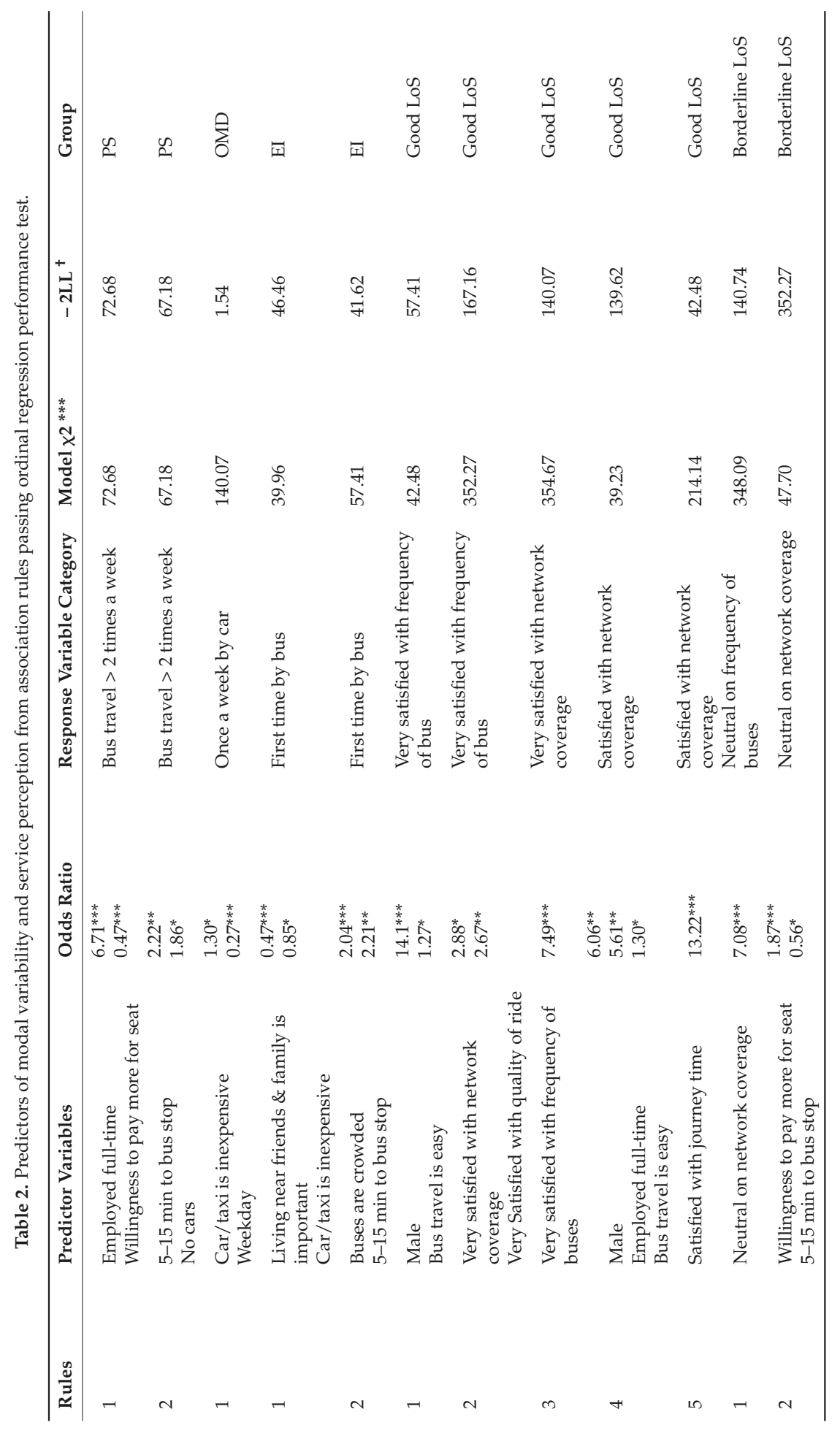




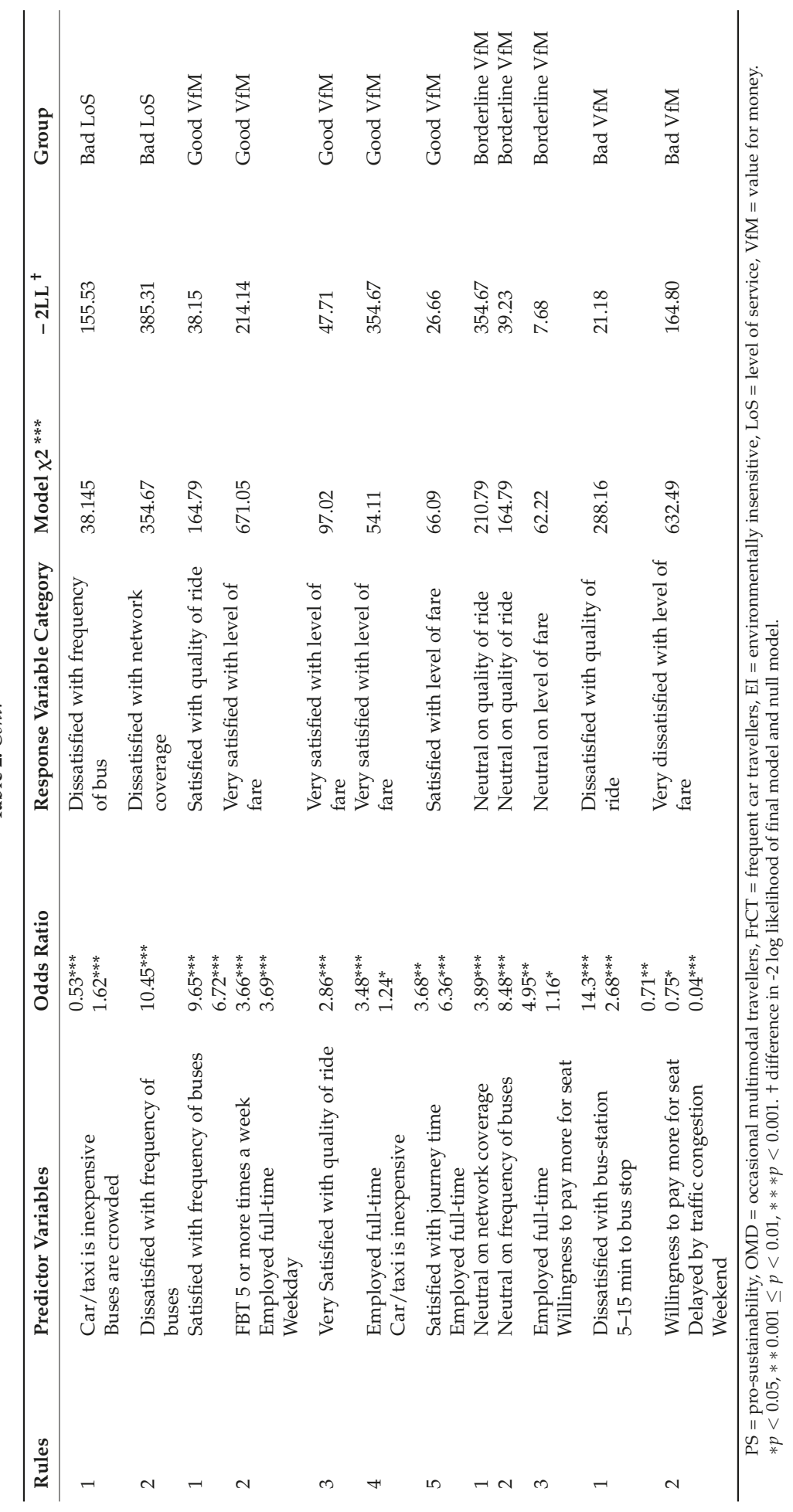




\subsubsection{Crowded Buses}

Rules pertaining to crowded buses were found in both less frequent bus users (EI rule 2) and bad service level ( $\mathrm{Bad}$ LoS rule 1) groups. The results are consistent with the previous findings by Batarce, Muñoz [24] where the disutility of public transportation in Chilean commuters was observed to be correlated with in-vehicle crowding. Comparison results of value for money groups further suggested a number of priority areas in this regard. The commuter market segment willing to pay more for a seat in the bus, were also 1.16 times more likely to hold a neutral perception of the level of fare (Borderline VfM rule 3: $\left.p<0.05, \chi^{2}=62.22\right)$ and 0.71 times more likely to be very dissatisfied $(p<0.01$, $\chi^{2}=632.49$ : Bad VfM rule 2). This implies that merely increasing the number of seats may at first persuade borderline users, but may not affect dissatisfied travellers to the same extent. Interestingly, travellers labelling buses as crowded were 1.62 times as likely to be "dissatisfied" by the frequency of buses (Bad LoS rule 2). Even though a direct relationship between the variables may have been unperceived, a deeper correlation may be present as less frequent buses on the travel routes serving the commute demands of these local building residents may impose a higher load on the existing buses. This finding indicates the presence of a potential market (of borderline and dissatisfied commuters) for policymakers by improving the public transit service based upon the public need of frequent service. The improved public transit ridership due to a corresponding reduction in private vehicle usage may then reduce the overall life-cycle environmental and energy load of the residential buildings in these studied Abu Dhabi City zones due to lesser contribution from the daily transport energy demands of their residents.

Proposing investment in size or number of units of supply (buses) to meet the local building occupants' daily commute needs can then be countered by slightly higher fares and it may optimise the financial elasticity of the publicly-owned transport agencies. A follow-up life-cycle study on the cost of running an improved public bus transport service, i.e., more frequent (shorter headways) shall also be conducted. It is reiterated by the observance of travellers "satisfied" with journey time, as 13.22 times likely to be also satisfied with the network coverage (Good LoS rule 5: $p<0.001, \chi^{2}=214.14$ ). It should also be noted that the two indicators of level of service, namely network coverage and frequency of buses were found to be highly correlated as the travellers who were "very satisfied" with the coverage were 2.88 times more likely to have the same perception of the frequency (Good LoS rule 2: $p<0.05, \chi^{2}=352.27$ ). Commuters were also around 7 times more likely (Borderline LoS rule 1: $p<0.001, \chi^{2}=348.09$ ) to hold a neutral perception of network coverage, causing a neutral opinion of the bus frequency, and 10.45 times more likely to be dissatisfied with both; thereby exhibiting a strong correlation between the two attributes.

\subsubsection{Dynamics of Bus Fare, Quality and Frequency}

Exploring the reciprocity between fare and quality added to this recommendation of a more frequent bus service supported by higher fares. The commuters unequivocally associated "levels of fare" with "quality of ride" (rule 3 of good VfM; OR =2.86, $p<0.001, \chi^{2}=97.02$ ), so the transit by bus was regarded as a value worthy of riders' money. Statistically, quality of ride was also found to be constrained by the frequency of buses as commuters satisfied with frequency of buses were 9.65 times more likely to be also satisfied by the quality of ride (rule 1 of good VfM; $p<0.001, \chi^{2}=164.79$ ) and similar trends of interdependency were observed for the neutral perception of these three variables. This current study implies that unlike findings of previous studies (see Bachman and Katzev [87], Savage [88]), and fortifying the observations by Tirachini [89] and Tirachini, Hensher [90], decreasing levels of fare may not be solely responsible for influencing the perceptions of commuters regarding existing public transport services.

A slight increase in fares may be justified by more frequent buses or a higher ride quality; even though more frequent bus travellers exhibited an unwillingness to pay more for seats, a sizeable increase in frequent bus commuters may be achieved by optimising the "fare-frequency-quality" dynamic due to modal diversion, i.e., occasional multimode (both bus and car) users and frequent 
car travellers shifting towards higher (public) bus service ridership. Transportation economists and strategists traditionally propose a balance between frequency of buses, journey time and the level of fare [88], but fall somewhat short of indicating how the balance affects commuter behaviour and perception. As the fares were recently increased by the Department of Transport-Abu Dhabi, the observations of the current study may be of significance to the policymakers to understand the straightforward implications of such decisions in the studied traveller market. A benefit of the proposed algorithm is that the endogenous variables determining the perception of these variables among the commuter market segments are analytically filtered across a broad range of travel attributes.

\subsection{Phase II Results_-Policy Insights from Validated Association Rules}

Mode choice dependency trends and bus ridership characteristics were further studied by analysing the association rules filtered out from phase I. Table 3 presents the validated association rules, grouped analogous to market segmentation analysis [33]. Some interesting econometric models about the journey purpose and backgrounds of the commuters were found; contrary to past research, this study found that statistical analyses alone may be deficient for capturing detailed characteristics of the traveller market. Inner correspondence of association rules was also partially detected by rule 1 of PS where first time car travellers at the time of the survey were found to be more frequent bus users.

\subsubsection{Targeting Work Commutes and Full-Time Workers}

Studies on building residents working full-time have found that a majority of them use private automobiles for work commutes [18,23,91], yet research targeting work-related commutes to encourage public transport use among these building residents is usually neglected. Policymakers may need to further investigate the quality improvements for attracting these consumers as this study found full-time workers commuting to/from work as predominant in both occasional multimodal (OMD rule 3) and frequent car travellers (FrCT rule 1). These findings are also consistent with the previous findings by Horner and Mefford [92] where the potential of public transit for work-related commutes was recognised. Furthermore, the need to live close to place of work and/or friends and family was one of the primary elicited reasons across all segments (e.g., PS rule 4, Good LOS rule 7, Borderline LOS rule1 and Good VfM rule 5).

\subsubsection{Impact of Residential Building Typology, Locality and Nodal (Bus-Stop) Characteristics}

The type of residential building, local urban form and location of the buildings were found to affect the daily mode choice of the residents $[23,93,94]$. However, no association was found between origin-destination areas and mode choice for the commuter segments surveyed here. Yet some influence of the commuters' residence building type (e.g., apartment, villa house, labour camps etc.) were observed (rule 3 of PS). These observations may indicate the generalisability of the conclusions drawn from the results of the current study, specifically the dominant ( $>80 \%$, as per Abu Dhabi Government [95]) expatriate population of Abu Dhabi also being the dominant group among the survey respondents as apartment building dwellers [96]. The residual effect of commuter satisfaction with the node, i.e., bus-station waiting area, on the overall quality of ride was also exposed by the results; namely that the commuters who were dissatisfied with the waiting area were also likely to be dissatisfied with the quality of ride (rule 2 of bad VfM). This represents a probable tendency of commuters to carry forward a negative perception that was developed before embarking on the public transit journey.

\subsubsection{Budgetary Constraints, Bus Service Frequency and Network Coverage}

This work found that the environmentally insensitive commuters, i.e., those who primarily use private automobiles for daily travel (rule 1 of $E I$ ), were largely satisfied with the public transport fare level. It can be inferred that the budgetary constraints and pricing of the service may be of little or no concern to such users (high social or financial background, employment status etc.) and there can be 
several underlying reasons that may motivate their mode choice shift to public buses, if at all. Frequent car travellers indicated a willingness to pay further after observing a need for seat as a major concern (rule 5 of $\mathrm{FrCT}$ ) and attributed no delays due to traffic congestion during their daily commute. Phase II results also showed that some commuters may have been compelled to use public transport due to necessity, rules 1 and 4 of PS (no driving license or car-ownership). Investigation of the rules on neutral and dissatisfied consumers of both $\operatorname{LoS}$ and $V f M$ also revealed that financially (or otherwise) obliged travellers might have settled for public transport against a more idealised mode.

Consumer satisfaction from the level of fare was also found to be dependent upon the quality of ride, thereby confirming initial perceptions that commuters perceive fare as a function of ride quality, as presented in rule 2 of VfM. This is also largely consistent with the findings of Hensher, Stopher [97] and fare resilience addressed in the literature review by Redman, Friman [98] where fare was largely associated with service quality. It is likely that the solution to motivating transit mode choice shift from private vehicles and/or improving the service perception may not be a reduction in fares but delivering consumer-expected quality for the charged price. One interesting finding of phase I and II was the tendency of a majority of commuters to purchase cash tickets instead of monthly passes regardless of the transit service perception. Marketing policies for monthly fare collection may prove to be significant in this regard. Additionally, follow up analysis attributed to rules 1 and 2 ( good LoS) and rules 1, 4, 5, 6 and 7 (good VfM) exemplifies that contrary to past research (see Redman, Friman [98]), economic restraints only partly diminish the commuters' positive cognitive assessment of the public transport. Moreover, perception of the service quality attributes, such as journey time was also found to influence the satisfaction from level of bus service and should also be carefully considered by the policymakers.

\subsubsection{Journey Time and Ride Quality}

Rule 3 of bad VfM suggests that the commuters mentioning a neutral opinion of the journey time were very dissatisfied about the quality of the ride. It implies the role of long commute time in developing stress among travellers, as past studies [99] also found commuter sensitivity to journey time. Longer journey time is also significant due to: high vehicle operating costs to local building residents [100,101]; higher fuel consumption [102,103] and high environmental burden to the buildings' overall embodied life-cycle [10]. The local government policymakers should, therefore, be mindful of the journey time detriments caused by any variations in the service route or frequency. In addition to confirming previously noticed significance of journey time on commuter satisfaction [97] and mode choice [104], phase II of the proposed algorithm was also able to pinpoint the contingent service level factors (namely frequency of buses and crowded buses). Policymakers can then predict the relative influence of changing any of the antecedent variables on commuter satisfaction from remaining variables and the subsequent mode choice. Another implication was the relative nature of quality of ride and level of service attributes of network coverage (Rule 4 of good LoS), also noticed in ordinal regression performance. 


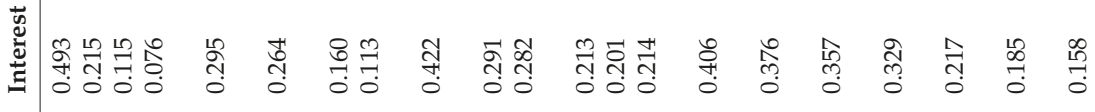

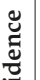

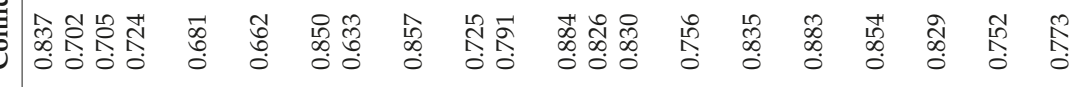

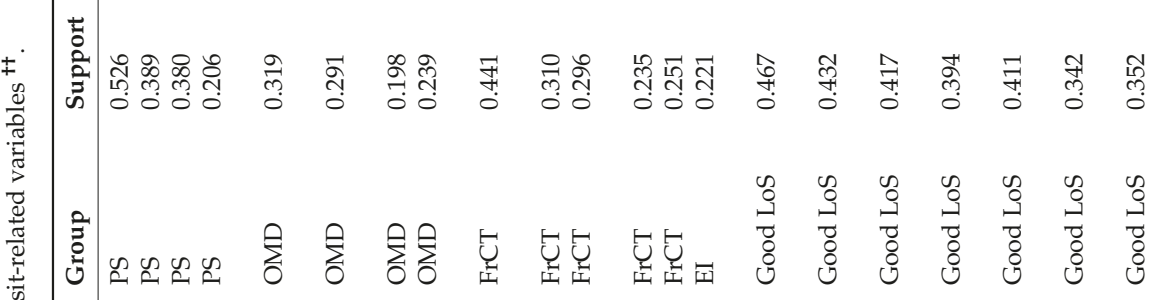

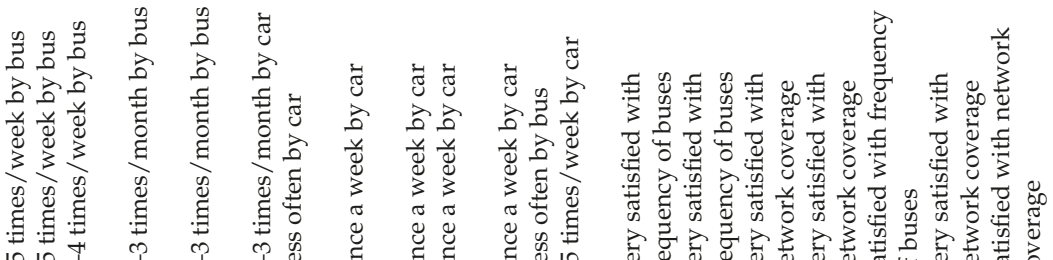

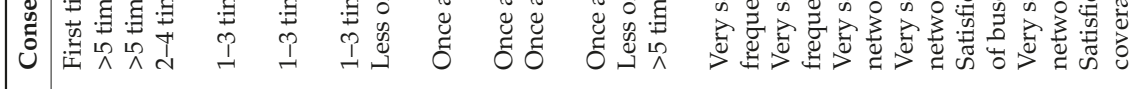

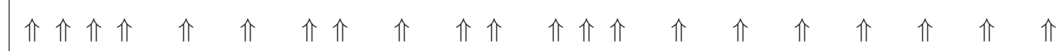

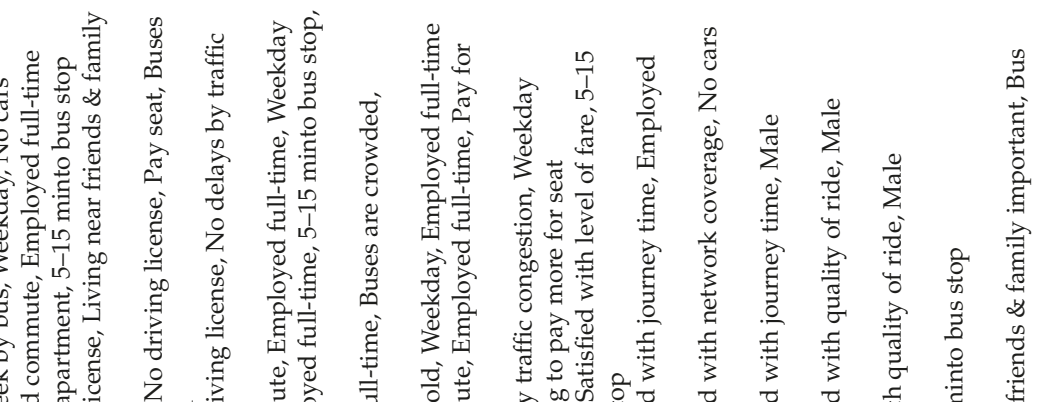

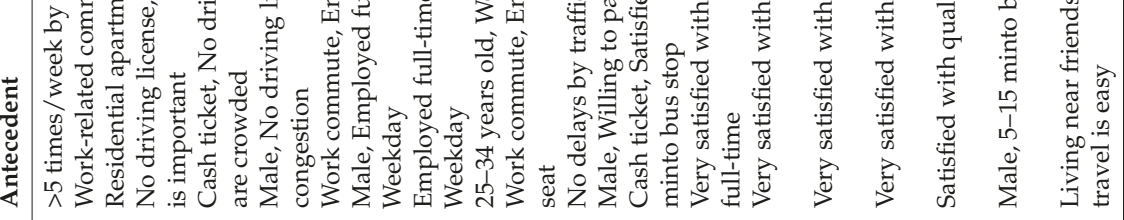




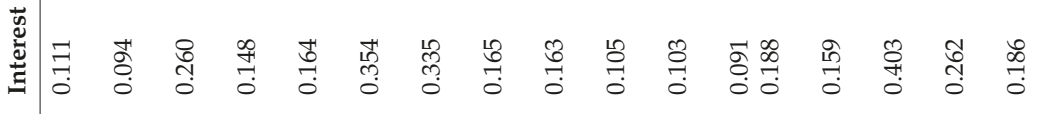
节

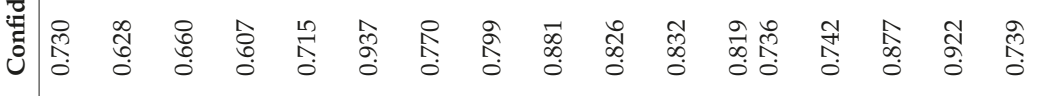

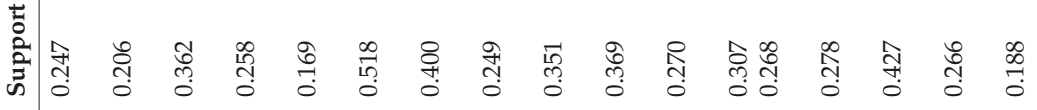

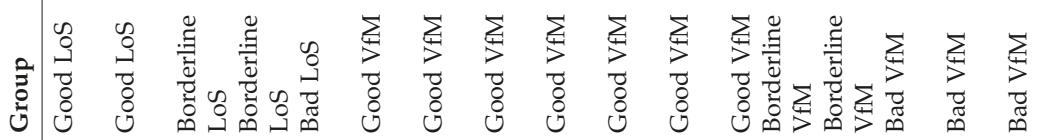




\subsection{Public-Accorded Desiderata for Value-Added Bus Service for Local Building Residents}

Public demand-based policy implications for the bus service to improve bus ridership among local building residents and travellers towards reduction in the residents' transport energy and environmental component of the local residential buildings are distributed across the generated "meaningful rules". In order to encapsulate the findings of the algorithm proposed in this study on the case study dataset, this work also sought to solve an importance index $\left(I_{i n}\right)$ to estimate the policy recommendations consistent with the public demands. For a response variable $\psi$ in the phase III results, with categorical values ranging from 1 to $N$, the importance index can be calculated for a predictor variable $x_{i}$ as shown in Equation (3). It should be worth noting, as the predictor variables are also nominal in nature, only one value $\eta$ is used at a time to determine the index $\left(I_{x}\right)$ for the specific predictor variable. The results of applying Equations (3) and (4) on the grouped association rules of phase III are illustrated in Figure 5 and have been summarised to some degree to eliminate similar findings from any particular commuter market segment. For example, the variable category Weekday was kept for only frequency of car travel despite its occurrence in the results for frequency of bus travel models:

$$
\begin{gathered}
I_{x}^{\eta}=\left[\sum_{\psi=1}^{N}\left(x_{i}\right)_{\psi}\right]_{\eta} \\
I_{\text {in }}=\frac{I_{x}^{\eta}}{\max \left(I_{x}^{\eta}\right)} \times 100 \quad \forall I_{x} \in \text { phaseIII rules }
\end{gathered}
$$

Findings here suggest that full-time workers in the 25-34 age group formed the major portion of the target market, and frequently commuted on the case study routes during weekdays. These study observations were distinct from some of the past studies that analysed only segregated student and young traveller markets [105], whereas a majority of the young users studied in this paper travelled by private automobiles. Further findings are detailed in the text below.

\subsubsection{Residential Apartment Building Designs May Need to Be Upgraded}

Residential apartments scored higher than any other dwelling types in the existing residential zones of the surveyed Abu Dhabi city $\left(I_{i n}=16.6 \%\right)$ as majority of the commuters responded as living in such buildings. This may reflect a pattern of denser land-use with an abundance of multi-storeyed buildings either on streets traversing or facing main arterial roads serviced by adequate public bus transport routes, especially since most commuters travelled short distance to reach the bus-stop (further details in Section 4.4.2), similar to the observations made by Thøgersen [106] and Hrelja [107]. Improving public transport service in these residential areas may impact the parking requirements in the residential apartment buildings [108]. Further work on building design implications may be developed from this study for upcoming residential development projects with adequate by provided local or building-connected public transport, as fewer parking floors may be needed in such buildings in the studied Abu Dhabi City area. 


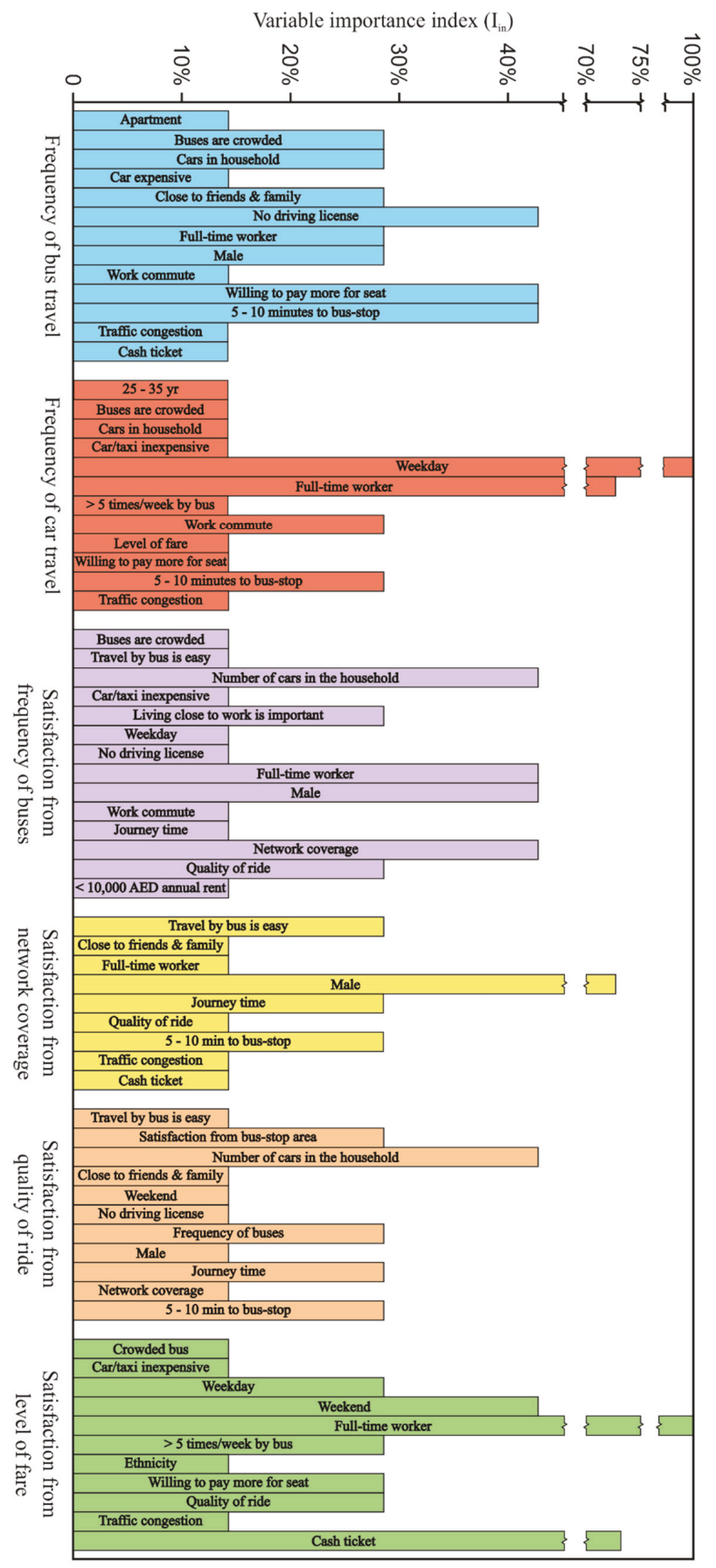

Figure 5. Importance index values for the phase III association rules of satisfaction and frequency criteria. 


\subsubsection{Existing Nodal (Bus-Stop) Distribution is Adequate}

The survey respondents generally stated travelling a short distance to reach the nodes (bus-stop) from their residential and office buildings across the studied travel routes and thus the time to reach bus-station from these buildings only had nominal effect on the modal variability of their occupants. For example, $I_{i n}=45.57 \%$ for the frequency of bus travel and $I_{i n}=28.57 \%$ for satisfaction from network coverage and ride quality. This study, therefore proposes that establishing more bus-stations or further updating the connection between these buildings and a public transit service to serve the local building residents on the studied Abu Dhabi City routes may not necessarily encourage them to shift towards bus transport. This is a policy-sensitive observation and different from some of the past studies (e.g., Chien and Qin [109]). However, as Heinen and Chatterjee [110] found in their review on the status of research in transportation literature, few of the studies extensively explored modal variability over long-term and a majority only utilised a limited set of categorical variables to study university students or employees living in near-work communities, which may have also restricted their findings in terms of application to real-world situations.

\subsubsection{Optimise Journey Time to Impact Commuter Satisfaction}

Intrinsically, importance indices from this study for network coverage and quality of ride show that the commuters assume upper and lower bounds of journey time regardless of mode choice, in line with past works [111]. Any deviation in either direction causes a positive/negative ripple in commuter predilection of the service depending upon the journey time, confirming findings from previous research (see Hensher, Stopher [97]). In general, the commuters satisfied with the journey time on public bus transit were also satisfied from its network coverage $\left(I_{i n}=28.57 \%\right)$ and ride quality $\left(I_{\text {in }}=42.86 \%\right)$. This supports the findings of previous studies $[89,112]$ where the travellers were found to associate public transport as a slow and inflexible travel mode and the importance of journey time in promoting modal diversion among local residents towards a more sustainable mode (e.g. buses) was identified. On the other hand, unlike some of the past works [113,114], results gathered by this work found that the commuters admitting affordability of private automobiles were more likely to be multimodal in their transit behavior.

\subsubsection{Bus Service Frequency, Crowded Buses and Level of Fare}

Results here argue that the public ranking of the ride quality was influenced more by the frequency of bus service $\left(I_{\text {in }}=28.57 \%\right)$ and less by the level of fare. The commuters interviewed were also found to be mainly concerned with the low capacity (crowded) buses, as both frequent bus and car travellers labelled the existing buses to be crowded. Other similar interesting correlations were also found, as the commuters who commented on over-crowded buses were also dissatisfied with the frequency of buses $\left(I_{\text {in }}=14.29 \%\right)$ and level of fare. It builds upon the deductions from the econometric ordinal models that even though the commuters satisfied with the fare level travelled the most by buses ( $\mathrm{OR}=6.72)$; neutral $(\mathrm{OR}=1.16)$ and dissatisfied respondents were more willing to pay extra for seats. Validated association rules further explained these observations by indicating that the level of fare was of little to no concern to non-users of bus services (i.e., the environmentally insensitive commuter segment), unlike past works $[114,115]$. Commuters ranking level of fare as satisfactory also indicated willingness to pay more for a seat $\left(I_{\text {in }}=28.57 \%\right)$.

Frequent car travellers were also willing to pay more for the bus service if they get a seat $\left(I_{\text {in }}=14.29 \%\right)$ and face no delays due to traffic congestion $\left(I_{\text {in }}=14.29 \%\right)$. In addition, the level of fare was mostly perceived by surveyed commuters in terms of ride quality and it is argued here that strong correlations exist between the two variables. These findings support a change in the current perspective of policymakers where agencies generally advocate a reduction in fare level [116] to encourage local building residents in the cities to choose public buses instead of private automobiles for the daily commute. This study proposes that instead of implementing a blanket reduction in the fare level, 
policymakers may be able to achieve better results in terms of user predilection towards bus service and modal use by increasing the frequency of buses, economically supported by a commensurate reasonable increase in the current level of fare. Furthermore, as journey time was of significant concern to the commuting public, travel should also be optimised by route improvements such as establishing a bus rapid transit (BRT) service to facilitate the daily commutes of the current and potential service users in Abu Dhabi. The cost and environmental implication of any improved transit system alternatives for future modifications based on public demand and the resulting journey time savings can then be compared through a detailed LCA study.

\section{Discussion}

There is a lack of research in the behavioural econometric analysis of the social aspect of commuter decision-making regarding transport mode choice, factors and attributes affecting these decisions such as biases, service quality, and frequency etc., which, according to IPCC (Intergovernmental Panel on Climate Change) [68], considerably hinders the selection of a suitable climate-conserving transport alternative for a sustainable municipal built environment. Apart from influencing daily commute pattern of local building residents in cities, inadequate transportation systems also impact the construction of sustainable buildings due to their direct impact on the material supply-chain and disposal options due to time delays caused by congestions on local road (Section 2.1). Therefore, by extension transportation systems are also argued to hinder sustainability performance of residential buildings. Stakeholders then seek to limit multiple-handling and transportation of feed-stock from building construction and demolition activities, as well as properly factor the impact of haulage and disposal distances and traffic congestion on the material choice of building developers. Furthermore, as explained in Section 2.1, the provision of an effective transportation system with less congestion and a better public transportation system may also influence the residency choices, sale and property development aspects of buildings.

In order to address these issues, the study presented here analyses a survey questionnaire of 1,520 responses gathered to capture the commuter perceptions on mode choice and predilection of an existing intra-city setting bus service towards improving the overall transportation system. Passenger responses can be used to influence their mode choice and reduce overall traffic congestion of the transport system after implementing the prospective changes in the transport service, based upon the public demand. Literature review covered in Section 2.1 explained that this reduction in traffic congestion via more uptake of public-transport contributes to an efficient distribution of building materials. While Section 2.2 explained that the reduction of embodied operational and life-cycle energy and environmental load of residential buildings is significantly influenced by the daily commute mode choices of its residents and may be reduced by relying on public transport instead of private vehicle transport.

To identify the motivations behind the public and private transport as preferred mode of building residents, this study proposed a data-mining algorithm unifying a modified version of the Apriori algorithm and ordinal regression to highlight policymaking proposals pertinent to the studied Abu Dhabi and Middle Eastern residents. Training portion of the travel dataset was subjected to the modified Apriori algorithm in order to generate the initial set of association rules that were partitioned according to the individual market segment candidates in the consequent of the rules. After initial interestingness-based filtration of rules, the results were exported to SPSS for externally executing ordinal regression analyses. Ordinal regression performance results of the obtained association rules, after passing a meaningfulness measure, were used to analyse the market segments. Throughout the ordinal regression experiments, a majority of the respondents stated travelling a short distance to reach the bus-stop from their residential and/or office buildings, and time to bus-station had nominal effect on the modal variability of commuters. This may indicate that the current connection between these buildings and the supplied public transit service is adequate. 
Mode use pattern was found to be only partly related to the socio-demographic characteristics of the surveyed local Abu Dhabi City building residents. The gender of these respondents had no statistically-significant influence on modal variability but was found to influence their perception of the service as the males generally had a more positive outlook. As such, a majority of similar variables (e.g., building typology, location, age etc.) failed to pass the ordinal regression tests and the next stage (validation of association rules) was used to capture the influence of these variables. Towards travel constraints limiting mode choice of commuters, this study found that a significant share of frequent bus travellers may have been compelled to uptake of public transport due to socio-demographics (lack of access to cars and lack of driving license). Nonetheless, the economic restraints only partly prejudiced their negative perception of the bus service and a majority of the so-called "compelled" travellers viewed public buses as good value for money and deemed the current service level to be satisfactory.

It is noted here that occasionally multimodal and frequent car travellers exhibit a substantial willingness to travel by public buses provided the capacity is increased or the buses become less crowded, even at the cost of higher fare. The results show that commuter satisfaction from the quality of ride and level of fare were highly interrelated. Frequency of the public bus service, as a measure of the passenger satisfaction from the level of service, is found to influence the mode choices of local building occupants. Given the competitive nature of private automobiles and the tendency of commuters in the studied dataset to use public transport for work-related commute dissimilar to past findings, policymakers may need to optimise quality-frequency-fare dynamics especially targeting peak work hours to reduce residents' transport-related environmental load of local buildings. One of the common strategies that is often implemented in many countries around the world for this purpose is investing in mass-transit systems. Technical and regulatory aspects of implementing the mass-transit system may include smoother traffic flow due to lesser private vehicles on the road network, reduction in cost and environmental burdens, fewer energy and fuel requirements on the power and fuel supply grids in the municipal regions, reduced overall operational and user-transport energy of residential buildings and availability of more recycled material haulage options (from far-off locations) in some areas for building construction projects. The mode use changes as a result of any improved public transit service may also affect the urban form and building designs: accessibility and shared spaces, lesser parking needs routine maintenance due to lower traffic and noise vibration damages.

\section{Conclusions}

The life-cycle energy and environmental load inventory of residential buildings includes the impact of material usage choices due to haulage requirements from virgin material suppliers vs. recycling plants, traffic congestion impact on per tonne kilometre $(\mathrm{tkm})$ energy load during the actual material transport, disposal feedback loops and the embodied building residents' daily transportation requirements. Public transport services are generally proposed for alleviating excessive private commuter traffic load on road networks and reduce the overall transport system energy and environmental burdens in the local municipal regions. Yet, the interrelations of mode choice to underlying social (i.e., stakeholder-related) attributes of journey time, location of residential and office buildings comparative to the public transit service node (bus-stop), on-board crowding and ride quality are somewhat unexplored.

To that end, the methodology proposed in this study aids the policymakers in finding the critical attributes for improving performance of any built asset by engaging the stakeholders in the life-cycle asset management process through a social component. The findings of the current study demonstrate its application to a real-world case study of Abu Dhabi City building residents and travellers. Based on results, it recommends that a bus rapid transit (BRT) service, more frequent at peak office hours, may entice significant car users towards the public bus transport service. Whilst the overall whole-cost and explicit environmental impact of meeting public demands by constructing and managing a proposed practicable BRT system can be explored through subsequent detailed LCA, the work presented here 
does find that addressing public transportation systems preferences can contribute to congestion reduction and impact positively to sustainable development.

The proposed framework used data-mining to filter through the large set of public response survey data for a transport pattern behavioural case study among local building occupants. However, future works may apply the same procedure for data-mining the stakeholder perspectives of other aspects in the residential building development: need for a recreational building facility, upgrading/modifying an existing building, façade renovations, and interior works for buildings, etc.

Author Contributions: Conceptualization, methodology, formal analysis, validation and writing —original draft, U.H.; Supervision, writing-review and editing, and validation, A.W.; Resources and data curation, H.A.J.

Funding: This research project is supported by an Australian Government Research Training Program (RTP) scholarship.

Acknowledgments: The authors thank the Integrated Planning Department at the Department of Transportation (DoT) Abu Dhabi for their support of data collection and assistance.

Conflicts of Interest: The authors declare no conflict of interest.

\section{Appendix A}

The appendix that contains details and data supplemental to the main text is provided below. 


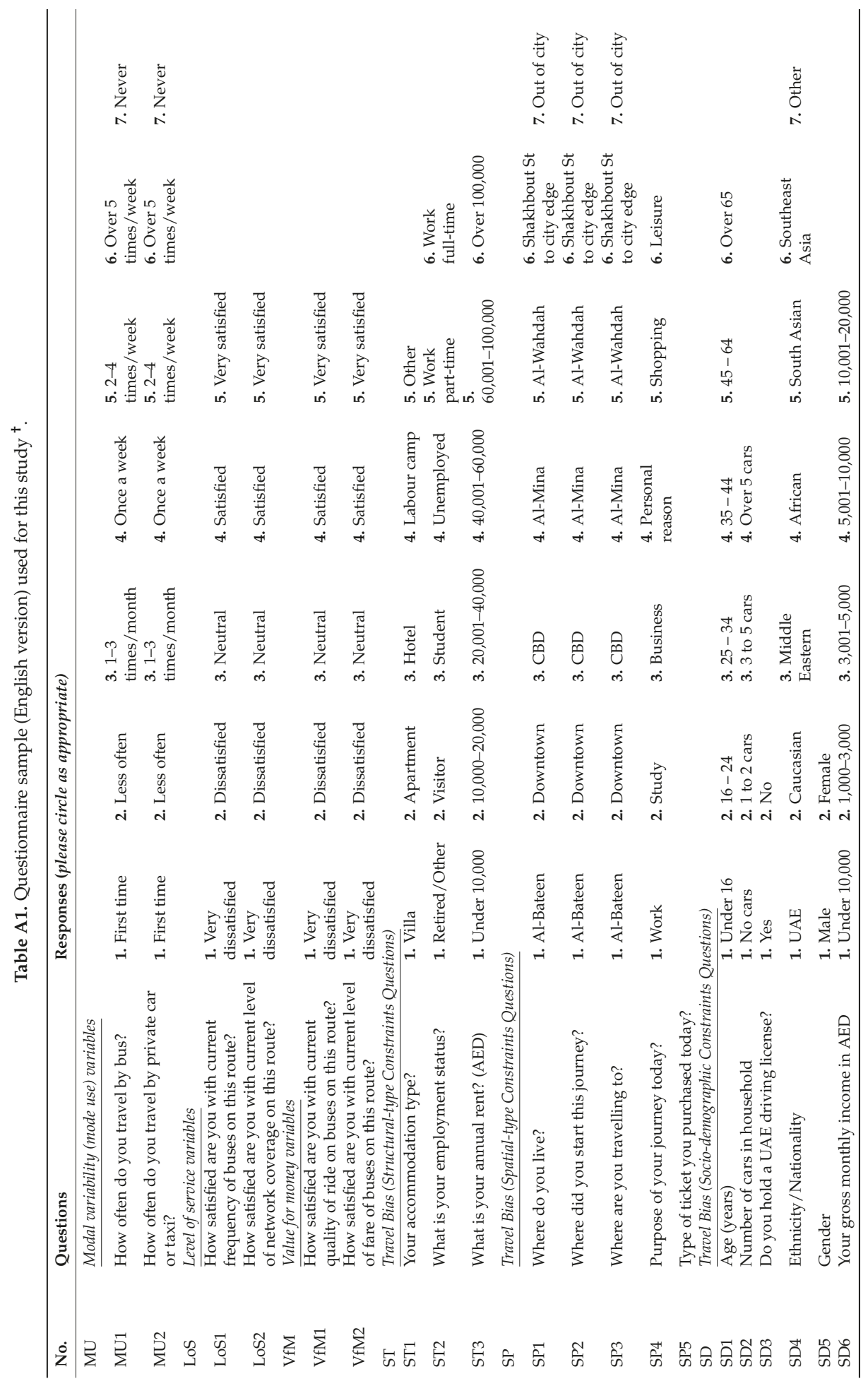


Buildings 2019, 9, 1

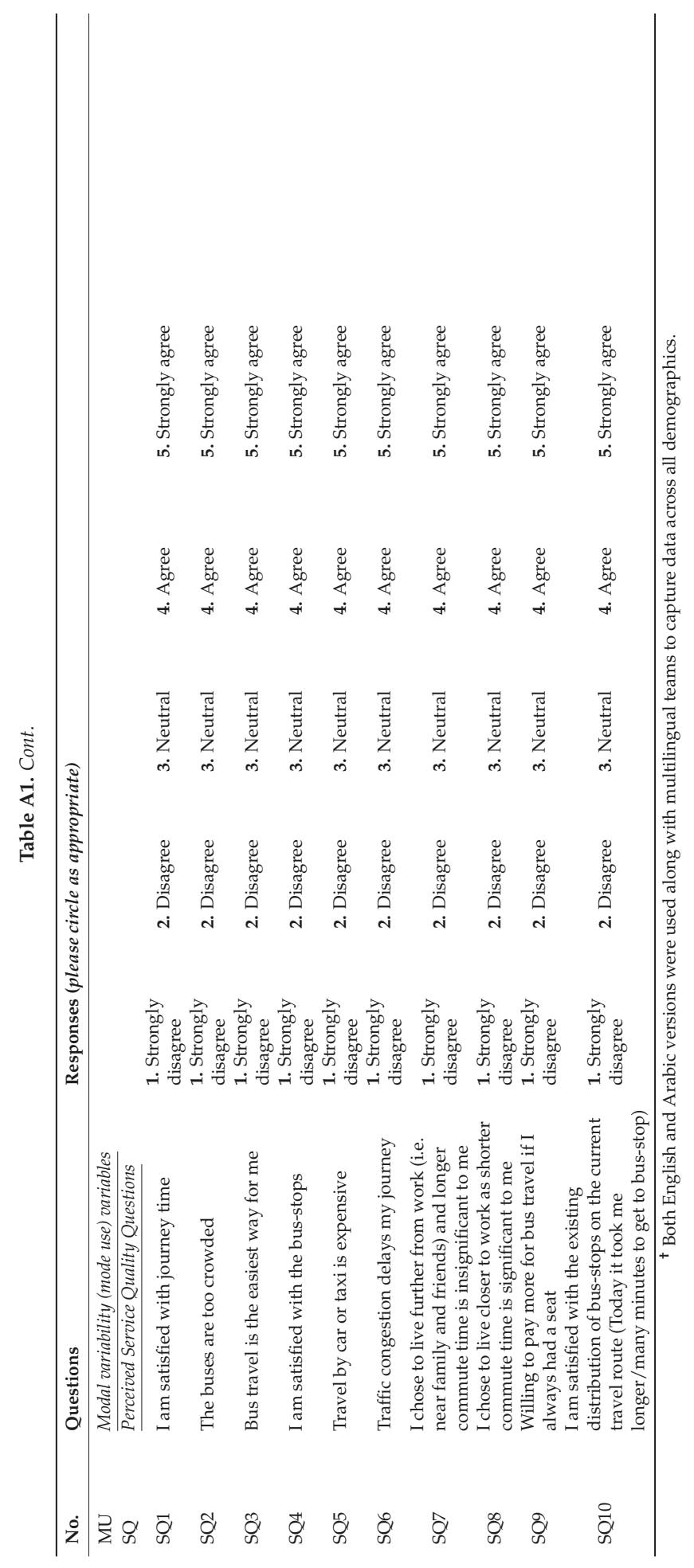




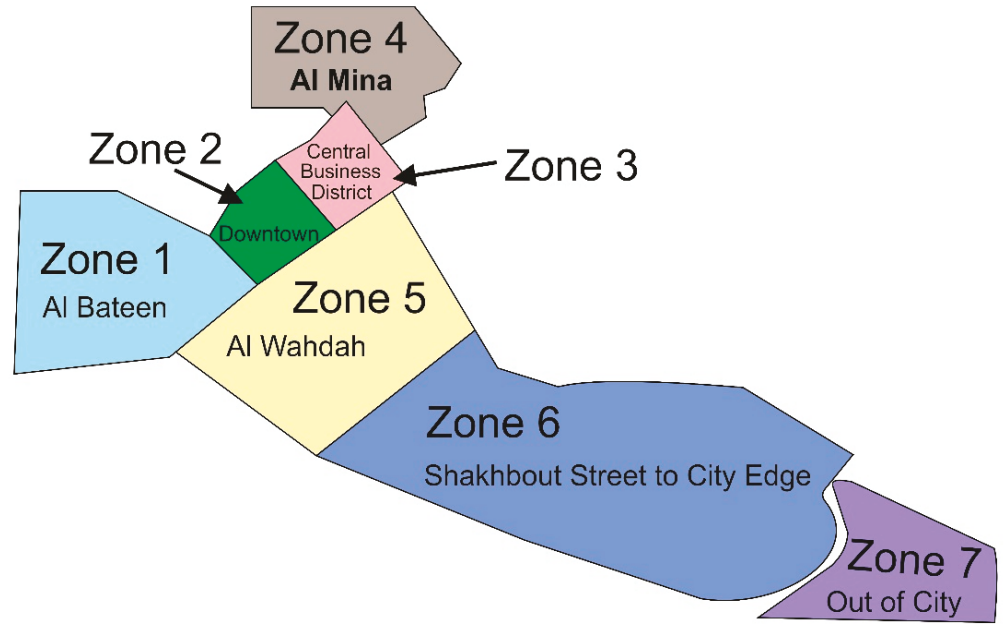

Figure A1. Zonal distribution of the Abu Dhabi City (based on AECOM (2015) [84].

Table A2. Statistical descriptive distribution of the collected variables.

\begin{tabular}{|c|c|c|c|c|}
\hline Variables & N (Valid) & Mean & Standard Deviation & Variance \\
\hline Frequency of bus travel & 1517 & 5.20 & 1.149 & 1.321 \\
\hline Frequency of car travel & 1305 & 2.94 & 1.414 & 2.000 \\
\hline Satisfaction with frequency of buses & 1512 & 3.70 & 0.899 & 0.809 \\
\hline Satisfaction with network coverage & 1494 & 3.74 & 0.890 & 0.793 \\
\hline Satisfaction with quality of ride & 1501 & 3.98 & 0.976 & 0.953 \\
\hline Satisfaction with level of fare & 1505 & 3.37 & 1.351 & 1.824 \\
\hline Your accommodation type? & 1509 & 2.52 & 1.390 & 1.933 \\
\hline What is your employment status? & 1505 & 5.55 & 1.103 & 1.216 \\
\hline What is your annual rent? (AED) & 1384 & 2.09 & 1.252 & 1.566 \\
\hline Where do you live? & 1519 & 3.76 & 1.814 & 3.291 \\
\hline Where did you start this journey? & 1518 & 3.35 & 1.845 & 3.405 \\
\hline Where are you travelling to? & 1515 & 3.38 & 1.823 & 3.323 \\
\hline Purpose of your journey today? & 1514 & 3.25 & 2.130 & 4.539 \\
\hline Type of ticket you purchased today? & 1516 & 1.32 & 0.732 & 0.536 \\
\hline Age (years) & 1507 & 3.21 & 0.923 & 0.851 \\
\hline Number of cars in household & 1440 & 0.17 & 0.392 & 0.153 \\
\hline Do you hold a UAE driving license? & 1503 & 1.79 & 0.411 & 0.169 \\
\hline Ethnicity/Nationality & 1507 & 5.02 & 1.070 & 1.145 \\
\hline Gender & 1509 & 1.13 & 0.333 & 0.111 \\
\hline Your gross monthly income in AED & 1385 & 2.47 & 1.048 & 1.099 \\
\hline I am satisfied with journey time & 1508 & 3.95 & 0.826 & 0.682 \\
\hline The buses are too crowded & 1519 & 0.60 & 0.489 & 0.240 \\
\hline Bus travel is the easiest way for me & 1519 & 0.66 & 0.475 & 0.226 \\
\hline I am satisfied with the bus-stops & 1496 & 3.38 & 1.125 & 1.265 \\
\hline Travel by car or taxi is expensive & 1519 & 0.45 & 0.497 & 0.247 \\
\hline Traffic congestion delays my journey & 1519 & 0.35 & 0.478 & 0.228 \\
\hline I chose to live further from work & 1519 & 0.66 & 0.472 & 0.223 \\
\hline I chose to live closer to work & 1319 & 4.70 & 2.70 & 7.301 \\
\hline Willing to pay more for bus seat & 1519 & 0.36 & 0.479 & 0.229 \\
\hline $\begin{array}{l}\text { Satisfied with existing bus-stop } \\
\text { distribution }\end{array}$ & 1519 & 2.10 & 0.676 & 0.457 \\
\hline
\end{tabular}




\section{References}

1. Borrego, C.; Tchepel, O.; Barros, N.; Miranda, A.I. Impact of road traffic emissions on air quality of the Lisbon region. Atmos. Environ. 2000, 34, 4683-4690. [CrossRef]

2. Gray, D.; Laing, R.; Docherty, I. Delivering lower carbon urban transport choices: European ambition meets the reality of institutional (mis)alignment. Environ. Plan. A Econ. Space 2016, 49, 226-242. [CrossRef]

3. Crispino, M.; D'Apuzzo, M. Measurement and prediction of traffic-induced vibrations in a heritage building. J. Sound Vib. 2001, 246, 319-335. [CrossRef]

4. Rychtáriková, M.; Jedovnický, M.; Vargová, A.; Glorieux, C. Synthesis of a Virtual Urban Soundscape. Buildings 2014, 4, 139-154. [CrossRef]

5. Hasan, U.; Chegenizadeh, A.; Budihardjo, M.; Nikraz, H. A review of the stabilisation techniques on expansive soils. Aust. J. Basic Appl. Sci. 2015, 9, 541-548.

6. Hasan, U. Experimental Study on bentonite Stabilisation Using Construction Waste and Slag. Ph.D. Thesis, Curtin University, Perth, Australia, 2015.

7. Le, A.B.D.; Whyte, A.; Biswas, W.K. Carbon footprint and embodied energy assessment of roof-covering materials. Clean Technol. Environ. Policy 2018. [CrossRef]

8. Mawed, M.; Al-Hajj, A.; Alshemery, A.A. The impacts of sustainable practices on UAE mosques' life cycle cost. In Proceedings of the Smart, Sustainable and Healthy Cities: 1st International Conference of the CIB Middle East and North Africa Research Network, Abu Dhabi, UAE, 14-16 December 2014; pp. 307-324.

9. Alqahtani, A.; Whyte, A. Evaluation of non-cost factors affecting the life cycle cost: An exploratory study. J. Eng. Des. Technol. 2016, 14, 818-834. [CrossRef]

10. Dodd, N.; Donatello, S.; Garbarino, E.; Gama-Caldas, M. Identifying Macro-Objectives for the Life Cycle Environmental Performance and resource Efficiency of EU Buildings; JRC EU Commission: Luxembourg, 2015; p. 117.

11. Badland, H.; Schofield, G. Transport, urban design, and physical activity: An evidence-based update. Transp. Res. Part D Transp. Environ. 2005, 10, 177-196. [CrossRef]

12. Yigitcanlar, T.; Kamruzzaman, M.; Teriman, S. Neighborhood Sustainability Assessment: Evaluating Residential Development Sustainability in a Developing Country Context. Sustainability 2015, 7, 2570-2602. [CrossRef]

13. Jabareen, Y.R. Sustainable Urban Forms: Their Typologies, Models, and Concepts. J. Plan. Educ. Res. 2006, 26, 38-52. [CrossRef]

14. Zimring, C.; Joseph, A.; Nicoll, G.L.; Tsepas, S. Influences of building design and site design on physical activity: Research and intervention opportunities. Am. J. Prev. Med. 2005, 28, 186-193. [CrossRef] [PubMed]

15. Cervero, R. Public transport and sustainable urbanism: Global lessons. In Transit Oriented Development; Routledge: London, UK, 2009; pp. 23-35.

16. De Luca, S. Public engagement in strategic transportation planning: An analytic hierarchy process based approach. Transp. Policy 2014, 33, 110-124. [CrossRef]

17. Leyden, K.M.; Slevin, A.; Grey, T.; Hynes, M.; Frisbaek, F.; Silke, R. Public and Stakeholder Engagement and the Built Environment: A Review. Curr. Environ. Health Rep. 2017, 4, 267-277. [CrossRef] [PubMed]

18. Stephan, A.; Stephan, L. Life cycle energy and cost analysis of embodied, operational and user-transport energy reduction measures for residential buildings. Appl. Energy 2016, 161, 445-464. [CrossRef]

19. Hasan, U.; Whyte, A.; Al Jassmi, H. Critical review and methodological issues in integrated life-cycle analysis on road networks. J. Clean. Prod. 2019, 206, 541-558. [CrossRef]

20. Stephan, A.; Crawford, R.H.; de Myttenaere, K. A comprehensive assessment of the life cycle energy demand of passive houses. Appl. Energy 2013, 112, 23-34. [CrossRef]

21. Diana, M. Measuring the satisfaction of multimodal travelers for local transit services in different urban contexts. Transp. Res. Part A Policy Pract. 2012, 46, 1-11. [CrossRef]

22. De Vos, J.; Mokhtarian, P.L.; Schwanen, T.; Van Acker, V.; Witlox, F. Travel mode choice and travel satisfaction: Bridging the gap between decision utility and experienced utility. Transportation 2016, 43, 771-796. [CrossRef]

23. Anderson, J.E.; Wulfhorst, G.; Lang, W. Expanding the use of life-cycle assessment to capture induced impacts in the built environment. Build. Environ. 2015, 94, 403-416. [CrossRef] 
24. Batarce, M.; Muñoz, J.C.; de Dios Ortúzar, J.; Raveau, S.; Mojica, C.; Ríos, R.A. Use of Mixed Stated and Revealed Preference Data for Crowding Valuation on Public Transport in Santiago, Chile. Transp. Res. Rec. J. Transp. Res. Board 2015, 2535, 73-78. [CrossRef]

25. Stathopoulos, A.; Cirillo, C.; Cherchi, E.; Ben-Elia, E.; Li, Y.-T.; Schmöcker, J.-D. Innovation adoption modeling in transportation: New models and data. J. Choice Model. 2017, 25, 61-68. [CrossRef]

26. Golob, T.F.; Hensher, D.A. The trip chaining activity of Sydney residents: A cross-section assessment by age group with a focus on seniors. J. Transp. Geogr. 2007, 15, 298-312. [CrossRef]

27. Diana, M.; Pronello, C. Traveler segmentation strategy with nominal variables through correspondence analysis. Transp. Policy 2010, 17, 183-190. [CrossRef]

28. Tan, P.-N.; Steinbach, M.; Kumar, V. Introduction to Data Mining, 1st ed.; Addison-Wesley Longman Publishing Co., Inc.: Boston, MA, USA, 2005.

29. Elder, J. Handbook of Statistical Analysis and Data Mining Applications, 1st ed.; Nisbet, R., Miner, G., Eds.; Academic Press: Boston, MA, USA, 2009; p. 864

30. Al-Hussaeni, K.; Fung, B.C.M.; Iqbal, F.; Dagher, G.G.; Park, E.G. SafePath: Differentially-private publishing of passenger trajectories in transportation systems. Comput. Netw. 2018, 143, 126-139. [CrossRef]

31. Laing, R.; Tait, E.; Gray, D. Public engagement and participation in sustainable transport issues. In Proceedings of the Construction, Building and Real Estate Research Conference of the Royal Institution of Chartered Surveyors, Las Vegas, NV, USA, 11-13 September 2012.

32. Hasan, U.; Whyte, A.; Al Jassmi, H. Framework for Delivering an AV-based Mass Mobility Solution: Integrating Government-Consumer Actors and Life-cycle Analysis of Transportation Systems. In Proceedings of the 46th European Transport Conference, Dublin, Ireland, 10-12 October 2018; p. 18.

33. Hasan, U.; Whyte, A.; Al Jassmi, H. Public-Transport System Management: Improving Service Satisfaction and Sustainable Uptake. 2018. submitted.

34. Chu, K.; Chapleau, R. Augmenting transit trip characterization and travel behavior comprehension. Transp. Res. Rec. J. Transp. Res. Board 2010, 2183, 29-40. [CrossRef]

35. Diana, M. Studying patterns of use of transport modes through data mining: Application to us national household travel survey data set. Transp. Res. Rec. J. Transp. Res. Board 2012, 2308, 1-9. [CrossRef]

36. Gürbüz, F.; Turna, F. Rule extraction for tram faults via data mining for safe transportation. Transp. Res. Part A Policy Pract. 2018, 116, 568-579. [CrossRef]

37. Ordonez, C. Association rule discovery with the train and test approach for heart disease prediction. IEEE Trans. Inf. Technol. Biomed. 2006, 10, 334-343. [CrossRef]

38. Shaharanee, I.N.M.; Hadzic, F.; Dillon, T.S. Interestingness measures for association rules based on statistical validity. Knowl. Based Syst. 2011, 24, 386-392. [CrossRef]

39. Lazcorreta, E.; Botella, F.; Fernández-Caballero, A. Towards personalized recommendation by two-step modified Apriori data mining algorithm. Expert Syst. Appl. 2008, 35, 1422-1429. [CrossRef]

40. Whyte, A.; Laing, R. Deconstruction and reuse of building material, with specific reference to historic structures. In Proceedings of the 1st Australasia and South East Asia Conference in Structural Engineering and Construction (ASEA-SEC-1), Perth, Australia, 28 November-2 December 2012; pp. 171-176.

41. Whyte, A. Life-Cycle Assessment of Built-Asset Waste Materials: Sustainable Disposal Options; Lambert Aademic Publishing: Saarbrucken, Germany, 2012.

42. NSAI. EN 15978:2011: Sustainability of Construction Works-Assessment of Environmental Performance of Buildings_Calculation Method; British Standard Institute: London, UK, 2011.

43. AFNOR Normalisation. CEN/TC 350 Sustainability of Construction Works. Available online: http:// portailgroupe.afnor.fr/public_espacenormalisation/CENTC350/index.html (accessed on 10 December 2018).

44. International Standards Organisation (ISO). ISO/TS 12720: Sustainability in Buildings and Civil Engineering Works_Guidelines on the Application of the General Principles in ISO 15392; ISO: Geneva, Switzerland, 2014.

45. Giorgi, S.; Lavagna, M.; Campioli, A. Guidelines for Effective and Sustainable Recycling of Construction and Demolition Waste. In Designing Sustainable Technologies, Products and Policies: From Science to Innovation; Benetto, E., Gericke, K., Guiton, M., Eds.; Springer International Publishing: Cham, Switzerland, 2018; pp. 211-221.

46. HM Government. Environmental Taxes, Reliefs and Schemes for Businesses. Available online: https: //www.gov.uk/green-taxes-and-reliefs/aggregates-levy (accessed on 12 December 2018). 
47. Bleischwitz, R. Towards a resource policy-Unleashing productivity dynamics and balancing international distortions. Miner. Econ. 2012, 24, 135-144. [CrossRef]

48. Coelho, A.; de Brito, J. Economic viability analysis of a construction and demolition waste recycling plant in Portugal-Part I: Location, materials, technology and economic analysis. J. Clean. Prod. 2013, 39, 338-352. [CrossRef]

49. Mulley, C.; Ma, L.; Clifton, G.; Yen, B.; Burke, M. Residential property value impacts of proximity to transport infrastructure: An investigation of bus rapid transit and heavy rail networks in Brisbane, Australia. J. Transp. Geogr. 2016, 54, 41-52. [CrossRef]

50. Strømann-Andersen, J.; Sattrup, P.A. The urban canyon and building energy use: Urban density versus daylight and passive solar gains. Energy Build. 2011, 43, 2011-2020. [CrossRef]

51. Steemers, K. Energy and the city: Density, buildings and transport. Energy Build. 2003, 35, 3-14. [CrossRef]

52. Tronchin, L.; Manfren, M.; Nastasi, B. Energy efficiency, demand side management and energy storage technologies-A critical analysis of possible paths of integration in the built environment. Renew. Sustain. Energy Rev. 2018, 95, 341-353. [CrossRef]

53. Norman, J.; MacLean, H.L.; Kennedy, C.A. Comparing High and Low Residential Density: Life-Cycle Analysis of Energy Use and Greenhouse Gas Emissions. J. Urban Plan. Dev. 2006, 132, 10-21. [CrossRef]

54. Cuéllar-Franca, R.M.; Azapagic, A. Environmental impacts of the UK residential sector: Life cycle assessment of houses. Build. Environ. 2012, 54, 86-99. [CrossRef]

55. Stephan, A.; Crawford, R.H.; de Myttenaere, K. Towards a comprehensive life cycle energy analysis framework for residential buildings. Energy Build. 2012, 55, 592-600. [CrossRef]

56. Stephan, A.; Crawford, R.H.; de Myttenaere, K. Towards a more holistic approach to reducing the energy demand of dwellings. Procedia Eng. 2011, 21, 1033-1041. [CrossRef]

57. Anderson, J.E.; Wulfhorst, G.; Lang, W. Energy analysis of the built environment-A review and outlook. Renew. Sustain. Energy Rev. 2015, 44, 149-158. [CrossRef]

58. Dell'Olio, L.; Ibeas, A.; Cecín, P. Modelling user perception of bus transit quality. Transp. Policy 2010, 17, 388-397. [CrossRef]

59. De Oña, J.; de Oña, R.; Calvo, F.J. A classification tree approach to identify key factors of transit service quality. Expert Syst. Appl. 2012, 39, 11164-11171. [CrossRef]

60. Schmid, B.; Schmutz, S.; Axhausen, K.W. Explaining mode choice, taste heterogeneity, and cost sensitivity in a post-car world. In Proceedings of the 95th Annual Meeting of the Transportation Research Board, Washington, DC, USA, 10-14 January 2016.

61. Stradling, S. Determinants of Car Dependence. In Threats from Car Traffic to the Quality of Urban Life; Garling, T., Steg, L., Eds.; Emerald Group Publishing Limited: New York, NY, USA, 2007; pp. 187-204.

62. Chen, C.; Gong, H.; Paaswell, R. Role of the built environment on mode choice decisions: Additional evidence on the impact of density. Transportation 2008, 35, 285-299. [CrossRef]

63. Friman, M.; Fellesson, M. Service supply and customer satisfaction in public transportation: The quality paradox. J. Public Transp. 2009, 12, 57-69. [CrossRef]

64. Menichetti, D.; Vuren, T.V. Modelling a low-carbon city. Proc. Inst. Civ. Eng. Transp. 2011, 164, 141-151. [CrossRef]

65. Environment Agency (Abu Dhabi). Greenhouse Gas Inventory for Abu Dhabi Emirate-Inventory Results Executive Summary; Environment Agency (Abu Dhabi): Abu Dhabi, UAE, 2012; p. 25.

66. Al Tayer, S.M. UAE is committed to reducing carbon footprint. In Khaleej Times; Galadari Printing and Publishing LLC: Dubai, UAE, 2018.

67. Liu, F.; Xu, R.; Fan, W.; Jiang, Z. Data analytics approach for train timetable performance measures using automatic train supervision data. IET Intell. Transp. Syst. 2018, 12, 568-577. [CrossRef]

68. IPCC. Climate Change 2007: The Physical Science Basis. Contribution of Working Group I, II and III to the Fourth Assessment Report of the IPCC; Pachauri, R.K., Reisinger, A., Core Writing Team, Eds.; Intergovernmental Panel on Climate Change: Geneva, Switzerland, 2008; p. 104.

69. Hasan, U.; Chegenizadeh, A.; Budihardjo, M.A.; Nikraz, H. Experimental Evaluation of Construction Waste and Ground Granulated Blast Furnace Slag as Alternative Soil Stabilisers. Geotech. Geol. Eng. 2016, 34, 1707-1722. [CrossRef]

70. Hasan, U.; Chegenizadeh, A.; Budihardjo, M.A.; Nikraz, H. Shear Strength Evaluation Of Bentonite Stabilised With Recycled Materials. J. GeoEng. 2016, 11, 59-73. 
71. Hasan, U.; Chegenizadeh, A.; Nikraz, H. Nanotechnology Future and Present in Construction Industry: Applications in Geotechnical Engineering. In Advanced Research on Nanotechnology for Civil Engineering Applications; IGI Global: Hershey, PA, USA, 2016; pp. 141-179.

72. Ponte, C.; Melo, H.P.M.; Caminha, C.; Andrade, J.S., Jr.; Furtado, V. Traveling heterogeneity in public transportation. EPJ Data Sci. 2018, 7, 42. [CrossRef]

73. Agrawal, R.; Imieliński, T.; Swami, A. Mining association rules between sets of items in large databases. In Proceedings of the ACM SIGMOD International Conference on Management of Data, Washington, DC, USA, 25-28 March 1993; pp. 207-216.

74. Agrawal, R.; Srikant, R. Fast algorithms for mining association rules. In Proceedings of the 20th Very Large Data Bases (VLDB) Conference, Santiago de Chile, Chile, 12-15 September 1994; Bocca, J.B., Jarke, M., Zaniolo, C., Eds.; Morgan Kaufmann Publishers Inc.: San Francisco, CA, USA, 1994; pp. 487-499.

75. Nahar, J.; Imam, T.; Tickle, K.S.; Chen, Y.-P.P. Association rule mining to detect factors which contribute to heart disease in males and females. Expert Syst. Appl. 2013, 40, 1086-1093. [CrossRef]

76. Hu, L.; Zhuo, G.; Qiu, Y. Application of Apriori Algorithm to the Data Mining of the Wildfire. In Proceedings of the 2009 Sixth International Conference on Fuzzy Systems and Knowledge Discovery, Tianjin, China, 14-16 August 2009; pp. 426-429.

77. Pande, A.; Abdel-Aty, M. Discovering indirect associations in crash data through probe attributes. Transp. Res. Rec. J. Transp. Res. Board 2008, 2083, 170-179. [CrossRef]

78. Tan, P.-N.; Kumar, V.; Srivastava, J. Selecting the right objective measure for association analysis. Inf. Syst. 2004, 29, 293-313. [CrossRef]

79. Nosratabadi, H.E.; Pourdarab, S.; Nadali, A.; Khalilinezhad, M. Evaluating discovered rules from association rules mining based on interestingness measures using fuzzy expert system. In Proceedings of the Fourth International Conference on the Applications of Digital Information and Web Technologies (ICADIWT 2011), Stevens Point, WI, USA, 4-6 August 2011; pp. 112-117.

80. Ma, W.-M.; Wang, K.; Liu, Z.-P. Mining potentially more interesting association rules with fuzzy interest measure. Soft Comput. 2011, 15, 1173-1182. [CrossRef]

81. Wu, X.; Zhang, C.; Zhang, S. Efficient mining of both positive and negative association rules. ACM Trans. Inf. Syst. 2004, 22, 381-405. [CrossRef]

82. Cherchi, E.; Cirillo, C.; de Dios Ortúzar, J. Modelling correlation patterns in mode choice models estimated on multiday travel data. Transp. Res. Part A Policy Pract. 2017, 96, 146-153. [CrossRef]

83. Arbabi, H.; Mayfield, M. Urban and Rural-Population and Energy Consumption Dynamics in Local Authorities within England and Wales. Buildings 2016, 6, 34. [CrossRef]

84. AECOM. Working Paper No. 1: Task 3 Review and Recommendations on the Proposed Travel Surveys; Abu Dhabi Department of Transport: Abu Dhabi, UAE, 2015; p. 94.

85. Osborne, J.W. Conceptual and Practical Introduction to Testing Assumptions and Cleaning Data for Logistic Regression. In Best Practices in Logistic Regression; SAGE Publications: Thousand Oaks, CA, USA, 2014; p. 488.

86. Shaheen, M.; Shahbaz, M. An Algorithm of Association Rule Mining for Microbial Energy Prospection. Sci. Rep. 2017, 7, 46108. [CrossRef]

87. Bachman, W.; Katzev, R. The effects of non-contingent free bus tickets and personal commitment on urban bus ridership. Transp. Res. Part A Gen. 1982, 16, 103-108. [CrossRef]

88. Savage, I. The dynamics of fare and frequency choice in urban transit. Transp. Res. Part A Policy Pract. 2010, 44, 815-829. [CrossRef]

89. Tirachini, A. Estimation of travel time and the benefits of upgrading the fare payment technology in urban bus services. Transp. Res. Part C Emerg. Technol. 2013, 30, 239-256. [CrossRef]

90. Tirachini, A.; Hensher, D.A.; Rose, J.M. Multimodal pricing and optimal design of urban public transport: The interplay between traffic congestion and bus crowding. Transp. Res. Part B Methodol. 2014, 61, 33-54. [CrossRef]

91. Wang, T.; Chen, C. Attitudes, mode switching behavior, and the built environment: A longitudinal study in the Puget Sound Region. Transp. Res. Part A Policy Pract. 2012, 46, 1594-1607. [CrossRef]

92. Horner, M.W.; Mefford, J.N. Examining the Spatial and Social Variation in Employment Accessibility: A Case Study of Bus Transit in Austin, Texas. In Access to Destinations; Emerald Group Publishing Limited: New York, NY, USA, 2005; pp. 193-214. 
93. Currie, G.; De Gruyter, C. Exploring links between the sustainability performance of urban public transport and land use in international cities. J. Transp. Land Use 2018, 11, 325-342. [CrossRef]

94. Kennedy, C.; Miller, E.; Shalaby, A.; Maclean, H.; Coleman, J. The Four Pillars of Sustainable Urban Transportation. Transp. Rev. 2005, 25, 393-414. [CrossRef]

95. Abu Dhabi Government. Abu Dhabi Emirate: Facts and Figures. Available online: https://www.abudhabi. ae/portal/public/en/abu-dhabi-emirate/abu-dhabi-emirate-facts-and-figures;jsessionid=zKnROF_ msRJQoP3Lu22DJzCLFXxFVXf5ED6y_2KpOCR0wIG8-4k7!496354345!-733067616!1541108424678 (accessed on 2 November 2018).

96. Flint, S. Living in: Abu Dhabi. Available online: http://www.bbc.com/travel/story/20131203-living-inabu-dhabi (accessed on 2 November 2018).

97. Hensher, D.A.; Stopher, P.; Bullock, P. Service quality-Developing a service quality index in the provision of commercial bus contracts. Transp. Res. Part A Policy Pract. 2003, 37, 499-517. [CrossRef]

98. Redman, L.; Friman, M.; Gärling, T.; Hartig, T. Quality attributes of public transport that attract car users: A research review. Transp. Policy 2013, 25, 119-127. [CrossRef]

99. Sottile, E.; Cherchi, E.; Meloni, I. Measuring Soft Measures Within a Stated Preference Survey: The Effect of Pollution and Traffic Stress on Mode Choice. Transp. Res. Procedia 2015, 11, 434-451. [CrossRef]

100. Santos, G.; Bhakar, J. The impact of the London congestion charging scheme on the generalised cost of car commuters to the city of London from a value of travel time savings perspective. Transp. Policy 2006, 13, 22-33. [CrossRef]

101. Trigaux, D.; Wijnants, L.; De Troyer, F.; Allacker, K. Life cycle assessment and life cycle costing of road infrastructure in residential neighbourhoods. Int. J. Life Cycle Assess. 2017, 22, 938-951. [CrossRef]

102. Kuo, Y. Using simulated annealing to minimize fuel consumption for the time-dependent vehicle routing problem. Comput. Ind. Eng. 2010, 59, 157-165. [CrossRef]

103. Biswas, W.K.; Thompson, B.C.; Islam, M.N. Environmental life cycle feasibility assessment of hydrogen as an automotive fuel in Western Australia. Int. J. Hydrogen Energy 2013, 38, 246-254. [CrossRef]

104. Nguyen-Phuoc, D.Q.; Currie, G.; De Gruyter, C.; Young, W. How do public transport users adjust their travel behaviour if public transport ceases? A qualitative study. Transp. Res. Part F Traffic Psychol. Behav. 2018, 54, 1-14. [CrossRef]

105. Nobis, C. Multimodality: Facets and Causes of Sustainable Mobility Behavior. Transp. Res. Rec. J. Transp. Res. Board 2007, 2010, 35-44. [CrossRef]

106. Thøgersen, J. Promoting public transport as a subscription service: Effects of a free month travel card. Transp. Policy 2009, 16, 335-343. [CrossRef]

107. Hrelja, R. Integrating transport and land-use planning? How steering cultures in local authorities affect implementation of integrated public transport and land-use planning. Transp. Res. Part A Policy Pract. 2015, 74, 1-13. [CrossRef]

108. Rowe, D.H.; Christine Bae, C.H.; Shen, Q. Evaluating the Impact of Transit Service on Parking Demand and Requirements. Transp. Res. Rec. 2011, 2245, 56-62. [CrossRef]

109. Chien, S.I.; Qin, Z. Optimization of bus stop locations for improving transit accessibility. Transp. Plan. Technol. 2004, 27, 211-227. [CrossRef]

110. Heinen, E.; Chatterjee, K. The same mode again? An exploration of mode choice variability in Great Britain using the National Travel Survey. Transp. Res. Part A Policy Pract. 2015, 78, 266-282. [CrossRef]

111. Milakis, D.; Cervero, R.; Van Wee, B. Stay local or go regional? Urban form effects on vehicle use at different spatial scales: A theoretical concept and its application to the San Francisco Bay Area. J. Transp. Land Use 2015, 8, 59-86. [CrossRef]

112. Yao, B.; Hu, P.; Lu, X.; Gao, J.; Zhang, M. Transit network design based on travel time reliability. Transp. Res. Part C Emerg. Technol. 2014, 43, 233-248. [CrossRef]

113. Kingham, S.; Dickinson, J.; Copsey, S. Travelling to work: Will people move out of their cars. Transp. Policy 2001, 8, 151-160. [CrossRef]

114. Eriksson, L.; Friman, M.; Gärling, T. Stated reasons for reducing work-commute by car. Transp. Res. Part F Traffic Psychol. Behav. 2008, 11, 427-433. [CrossRef] 
115. Thøgersen, J.; Møller, B. Breaking car use habits: The effectiveness of a free one-month travelcard. Transportation 2008, 35, 329-345. [CrossRef]

116. Trépanier, M.; Habib, K.M.N.; Morency, C. Are transit users loyal? Revelations from a hazard model based on smart card data. Can. J. Civ. Eng. 2012, 39, 610-618. [CrossRef]

(C) (

(C) 2018 by the authors. Licensee MDPI, Basel, Switzerland. This article is an open access article distributed under the terms and conditions of the Creative Commons Attribution (CC BY) license (http:/ / creativecommons.org/licenses/by/4.0/). 

MDPI

St. Alban-Anlage 66

4052 Basel

Switzerland

Tel. +41616837734

Fax +41 613028918

www.mdpi.com

Buildings Editorial Office

E-mail: buildings@mdpi.com

www.mdpi.com/journal/buildings

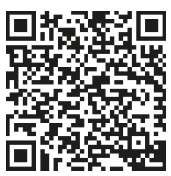



MDPI

St. Alban-Anlage 66

4052 Basel

Switzerland

Tel: +41 616837734

Fax: +41 613028918 